\title{
A systematic approach to history matching CBM production on a complex reservoir for a pilot test in Marshall County, WV, US
}

\author{
Cesar A. Silva Molero \\ West Virginia University
}

Follow this and additional works at: https://researchrepository.wvu.edu/etd

\section{Recommended Citation}

Silva Molero, Cesar A., "A systematic approach to history matching CBM production on a complex reservoir for a pilot test in Marshall County, WV, US" (2008). Graduate Theses, Dissertations, and Problem Reports. 3279.

https://researchrepository.wvu.edu/etd/3279

This Thesis is protected by copyright and/or related rights. It has been brought to you by the The Research Repository @ WVU with permission from the rights-holder(s). You are free to use this Thesis in any way that is permitted by the copyright and related rights legislation that applies to your use. For other uses you must obtain permission from the rights-holder(s) directly, unless additional rights are indicated by a Creative Commons license in the record and/ or on the work itself. This Thesis has been accepted for inclusion in WVU Graduate Theses, Dissertations, and Problem Reports collection by an authorized administrator of The Research Repository @ WVU. For more information, please contact researchrepository@mail.wvu.edu. 
A Systematic Approach to History Matching CBM Production on a Complex Reservoir for a Pilot Test in Marshall County, WV, US.

\author{
Cesar A. Silva Molero
}

Thesis submitted to the College of Engineering and Mineral Resources

at West Virginia University in partial fulfillment of the requirements

for the degree of

Master of Science

in

Petroleum and Natural Gas Engineering

Approved by

Shahab D. Mohaghegh, PhD., Chair

Khashayar Aminian, PhD.

Razi Gaskari, PhD.

Grant Bromhal, PhD.

Department of Petroleum and Natural Gas Engineering

Morgantown, West Virginia

2008

Keywords: Coalbed Methane, Unconventional Reservoirs, History Matching, Reservoir Simulation, Complex Reservoir

Copyright 2008 Cesar A. Silva Molero 


\title{
A Systematic Approach to History Matching CBM Production on a Complex Reservoir for a Pilot Test in Marshall County, WV, US.
}

\author{
Cesar A. Silva Molero
}

Effective history matching of a simulation model with real data from the field requires the resolution of three outstanding issues. First, a conflict may exist between the production data and the existing geological model built from static information. Second, during model updates, geological consistency must be maintained by honoring the prior geologic information. Third, uncertainties related to mechanical and operational issues must be taken into account.

The objective of this study is to build a realistic simulation model able to predict future behavior of a complex CBM reservoir for a $\mathrm{CO}_{2}$ sequestration pilot project in Marshall County, WV by using a systematic approach for history matching. Our study is limited to building a history matched model for the Methane production.

As a general overview, the field project covered in our work includes two known coal seams, Pittsburgh coal (upper layer) and Upper Freeport coal (lower layer). Production is from six horizontal wells, two of them completed in Pittsburgh coal and the other four completed in Upper Freeport coal. This project is part of the national plan of $\mathrm{CO}_{2}$ sequestration with the goals of improving the quality of the environment and increasing methane production from coal.

In order to accomplish the objective of this study, a systematic history matching approach was devised. In this approach, data from the field are gathered and analyzed in order to be used as input in a commercial reservoir simulator software. Then, effective strategies and key reservoir parameters are defined to realistically history match the field production. The resulted approach propose a new systematic methodology for performing history matching complex reservoirs. This approach accounts for production data inconsistency related to reservoir characteristics heterogeneity, mechanical, and operational issues within different scenarios.

The systematic approach included a detail analysis of the field production data in order to learn as much about the reservoir behavior as possible. The analysis included a normalized production comparison done based on the amount of gas produced in a per-foot of the well, in a per-foot of thickness around the well, and based on the average gas content. This information will be used extensively in the history matching process, which included sensitivity analysis of conventional parameters (permeability, porosity, relative permeability, and water-gas contact), unconventional parameters (Gas content, desorption time, and Langmuir parameters), and finally wellbore parameters (skin factor, bottom-hole pressure, and well length). Using the results of the sensitivity analysis above, an analysis table is formed to be used as a guide toward the final history matched model. 
This work is dedicated especially to my wife DAatieli BBencomo, my daughter Gabriela Pilva, my mother. Maria MDotero, and my sister Maria Qilva. They are the main source of my inspiration and the strength of my will. They patiently gave me support in every stage of my journey towards my Master's degree.

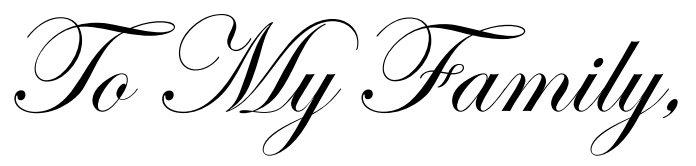


In first place it is a pleasure to express my gratitude to my Advisor Dr. Shahab D. Mohaghegh, who provided me with his knowledge and wise advice, the necessary tools to develop my criteria to solve the problems I encountered in my research and for helping me to continue developing my skills as a professional. He gave me a complement to increase my confidence and examples of professionalism on how tasks should be completed and presented.

I must also acknowledge Dr. Kashy Aminian for his willingness to assist me in my early stages of planning during my school, I really appreciate his help.

A special thanks to Dr. Razi Gaskari for his suggestions, friendship, and kindness.

Thanks goes out to Dr. Grant Bromhal for his suggestions and for agreeing to be on my thesis committee despite his extremely busy schedule.

Thanks to DOE-ZERT Program for providing the funding of this project.

Thanks to Computer Modeling Group (CMG) for providing us with the software for the realization of this study.

Thanks to CONSOL Energy for providing the data.

Thanks to Department Chair Samuel Ameri and my professors in the PNGE Department for their support and for their time to share their knowledge with me. Thanks to the administrative associate of PNGE Dpeartment, Beverly Matheny, for her kindness, friendship, and always there to help the students.

This thesis represents all my effort and hard work done through the last couple of years. By this time I have been given the opportunity of working with a team led by the hand of my Advisor and thesis director, Dr. Shahab. Special thanks to the members of my team, colleagues and friends Jalal Jalali, Domingo Mata, Daniel Gonzalez, Delal Gunaydin, Camilo Calderon, Eduardo Delgado, Jorgi Gomez, Yassaman Khassaini, Vida Golami and Massoud Kalantari whom helped me throughout discussions to clear my ideas on many issues during the years of graduate school.

A big thanks to my family for their support throughout my life and career. 


\section{Table of Contents}

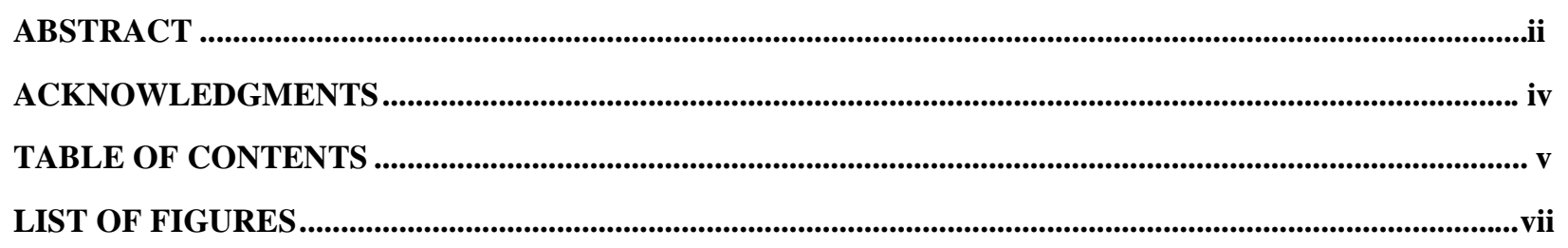

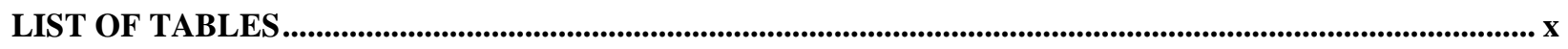

LIST OF SYMBOLS AND ABBREVIATIONS ……......................................................................................................... xi

CHAPTER 1 INTRODUCTION ...............................................................................................................................................

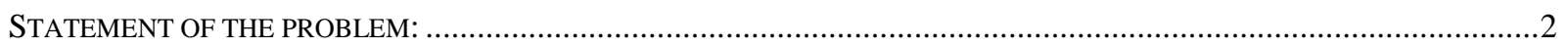

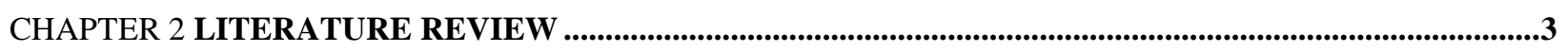

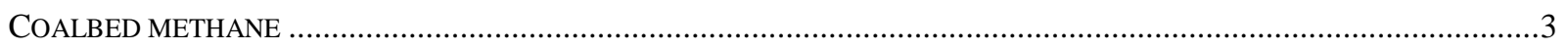

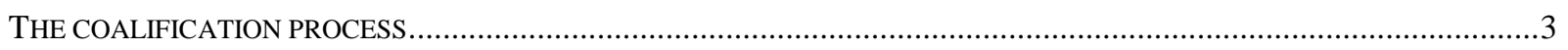

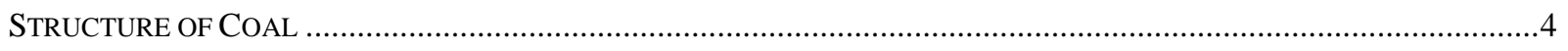

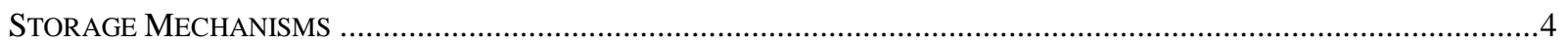

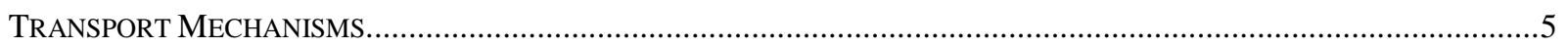

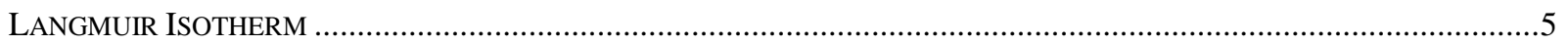

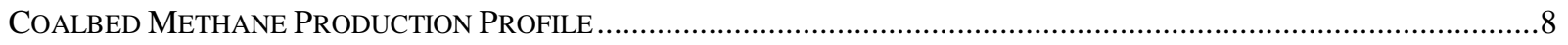

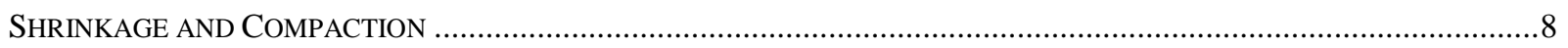

ENHANCE COALBED METHANE (ECBM) AND SEQUESTRATION ..............................................................

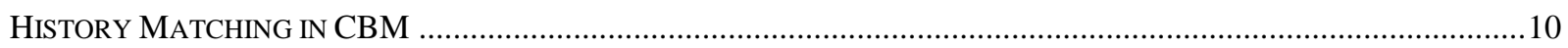

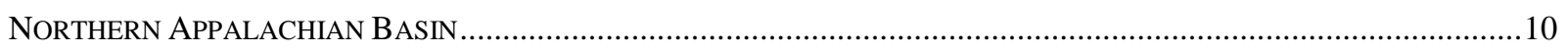

CHAPTER 3 METHODOLOGY …….............................................................................................................................................15

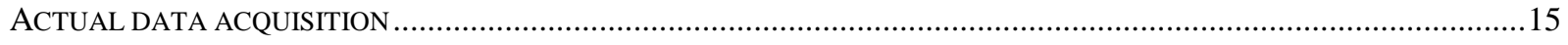

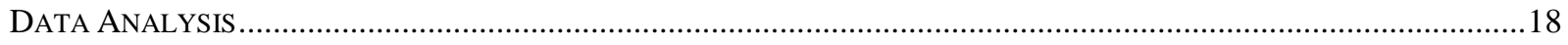

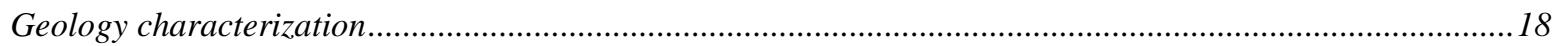

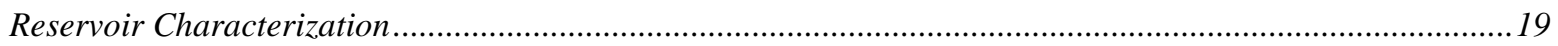

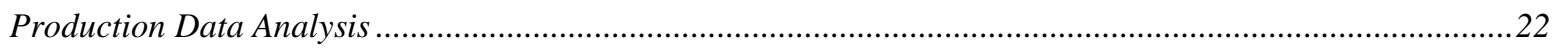

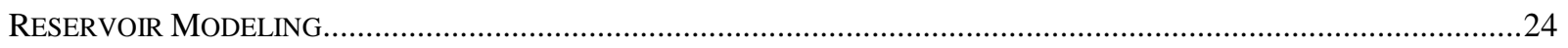

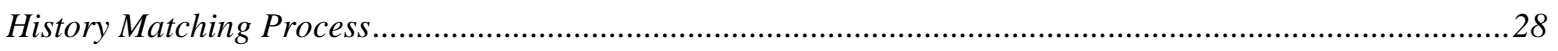

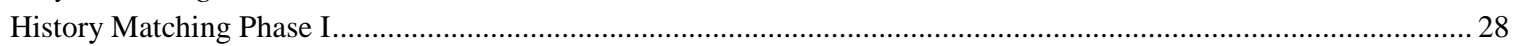

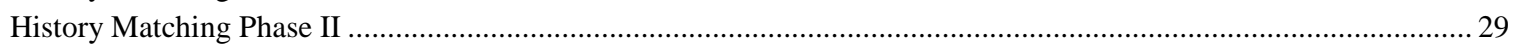

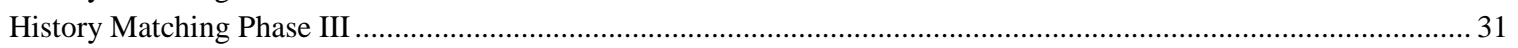

CHAPTER 4 RESULTS ......................................................................................................................................................................35

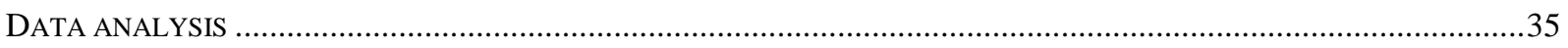

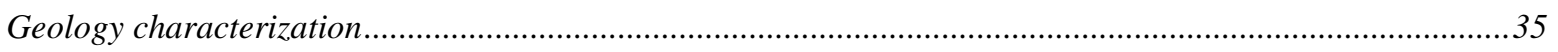

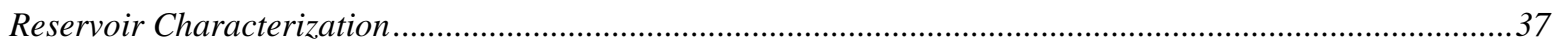

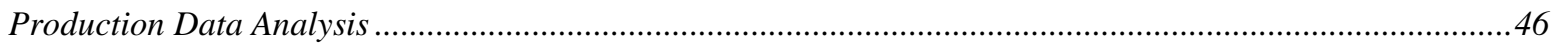

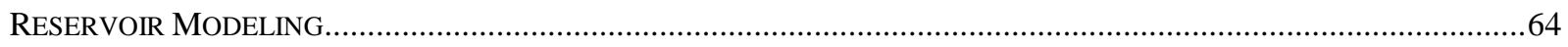

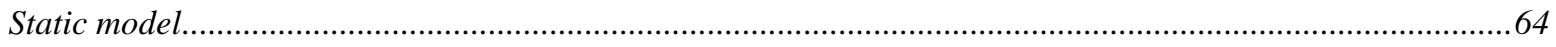

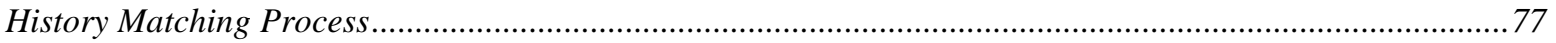


History Matching Phase I

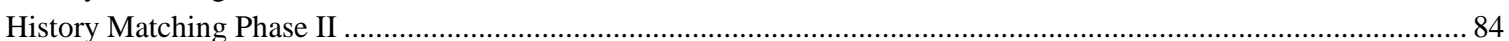

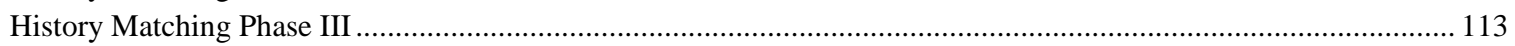

CHAPTER 5 CONCLUSIONS AND RECOMMENDATIONS....................................................................129

REFERENCES 


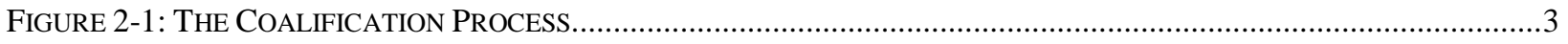

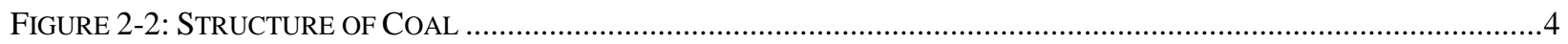

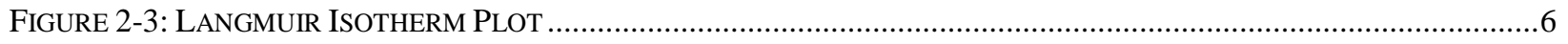

FIGURE 2-4: UNDERSATURATED COALBED METHANE RESERVOIR INITIAL CONDITIONS ...........................................

FIGURE 2-5: DEWATERING PROCESS IN AN UNDERSATURATED COALBED METHANE RESERVOIR ................................7

Figure 2-6: CoAL Bed METHANE Production PRofILE ...............................................................................

FIGURE 3-1: AERIAL VIEW OF THE PITTSBURGH AND UPPER FrEEPORT WELLS ....................................................17

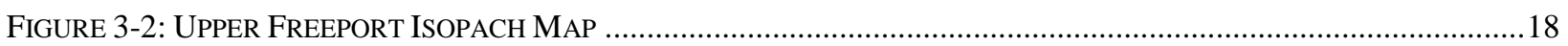

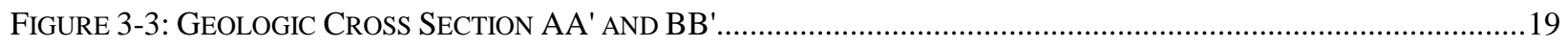

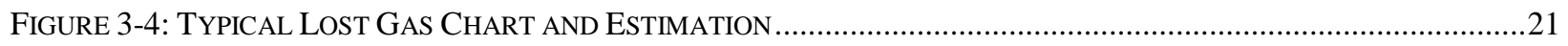

FIGURE 3-5: TYPICAL RESIDUAL GAS ESTIMATION BY REGRESSION ( 7.3SCF/TON) .........................................21

FIGURE 3-6: LOCATION AND DisTRIBUTION ZONES OF THE PROJECT ............................................................24

FIGURE 3-7: RELATIVE PERMEABILITY FOR PITTSBURGH COAL .........................................................................27

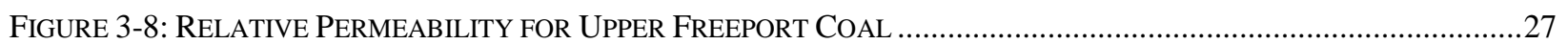

Figure 3-9: AERIAL Distribution ZONE FOR History MATCH PHASE II PITTSBURGH COAL................................29

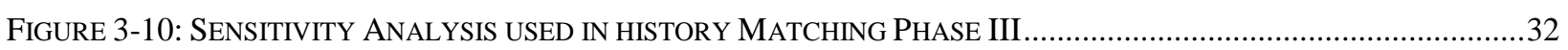

FIGURE 3-11: COMPARISON OF TREND-LINES SLOPES FOR HISTORY MATCHING PHASE III .......................................33

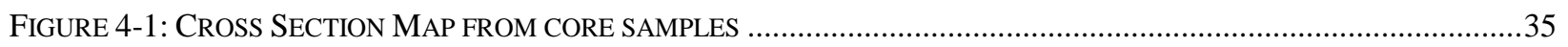

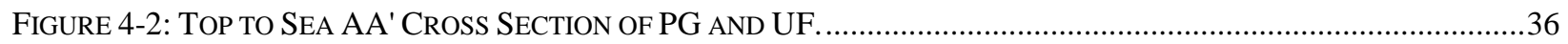

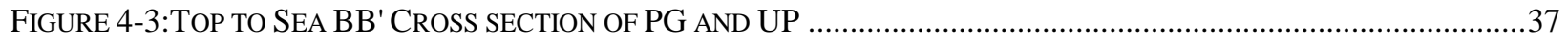

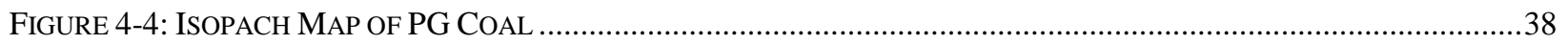

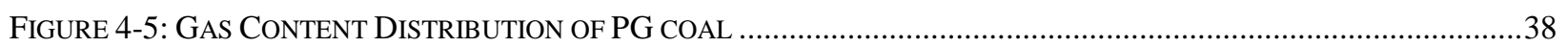

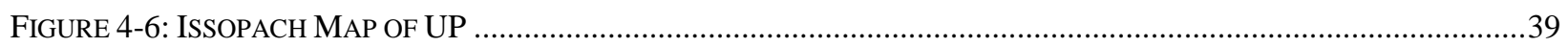

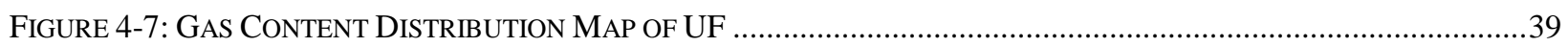

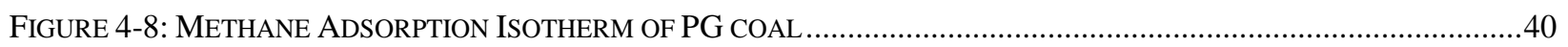

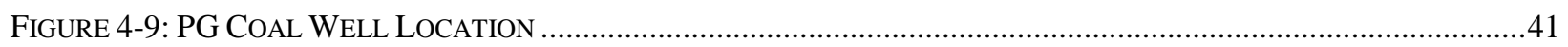

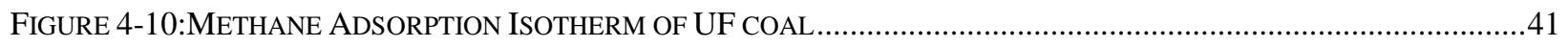

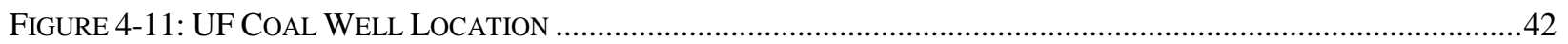

FIGURE 4-12: METHANE ADSORPTION ISOTHERM WITH PG GAS CONTENT ......................................................43

FIGURE 4-13: METHANE ADSORPTION ISOTHERM AND UF GAS CONTENT .........................................................43

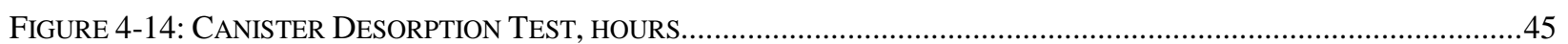

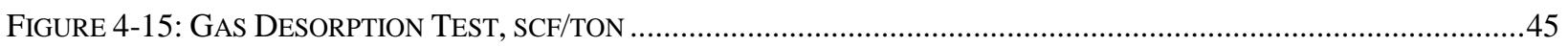

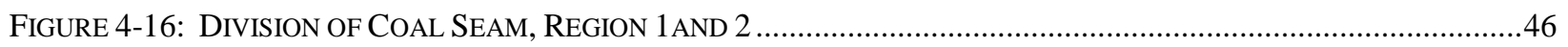

FIGURE 4-17: COMPARISON OF GAS PRODUCTION BETWEEN WELLS MH3 AND MH12 ..........................................48

FIGURE 4-18: COMPARISON OF GAS PRODUCTION AMONG WELLS MH5, MH18, MH20 AND MH11 ........................48

FIGURE 4-19: ACTUAL GAS AND WATER PRODUCTION FOR PG COAL ...............................................................49

FIGURE 4-20: ACTUAL PRODUCTION RATE AT MH12 AND MH3 FOR PG COAL ......................................................50

Figure 4-21: ACTUAL GAS RATE PRODUCTION IN UF COAL WELLS.................................................................51

Figure 4-22: ACTUAL GAS PRODUCTION RATIOS AMONG WELl MH18 AND OTHER WELLS IN PG COAL ..................51

Figure 4-23: PRODUCTION NORMALIZATION By CONTACT LENGTH AT WELLS MH12 AND MH3 FOR PG COAL.......52

FIGURE 4-24: COMPARISON OF ACTUAL RATIO AND NORMALIZED RATIO BY CONTACT LENGTH .............................53

FIGURE 4-25: UF ALL WELLS GAS NORMALIZED PRODUCTION BY CONTACT LENGTH ..............................................54

FIGURE 4-26: MH18/MH5 PRODUCTION NORMALIZED BY CONTACT LENGTH FOR UF...........................................54

FIGURE 4-27: MH18/MH20 PRODUCTION NORMALIZED BY CONTACT LENGTH FOR UF.........................................55

FIGURE 4-28: MH18/MH11 PRODUCTION NORMALIZED BY CONTACT LENGTH FOR UF ........................................55 
Figure 4-29: PRoduction NoRmaLIZATION By ThiCKNESS AT WeLlS MH12 AND MH3 FOR PG COAL ..................56

FIGURE 4-30: MH12/MH3 PRODUCTION NORMALIZED BY THICKNESS FOR PG COAL ….............................................57

FIGURE 4-31: UF ALL WELLS GAS PRODUCTION NORMALIZATION BY THICKNESS .......................................................58

FIGURE 4-32: MH18/MH5 PRODUCTION NORMALIZED BY THICKNESS FOR UF COAL …........................................58

FIGURE 4-33: MH18/MH20 PRODUCTION NORMALIZED BY THICKNESS FOR UF COAL ............................................59

FIGURE 4-34: MH18/MH11 PRODUCTION NORMALIZED BY THICKNESS FOR UF COAL ………..............................59

Figure 4-35: Production NoRMALIZATION BY GAS CONTENT AT WELlS MH12 AND MH3 FOR PG COAL ..............60

FigURE 4-36: MH12/MH3 PRODUCTION NORMALIZED By GAS CONTENT FOR PG COAL .........................................61

FIGURE 4-37: UF ALL WELLS GAS NORMALIZED PRODUCTION ...............................................................................62

FigURE 4-38: MH18/MH5 PRODUCTION NORMALIZED BY GAS CONTENT FOR UF COAL .......................................62

FIGURE 4-39: MH18/MH20 PRODUCTION NORMALIZED BY GAS CONTENT FOR UF COAL ..........................................63

FIGURE 4-40: MH18/MH11 PRODUCTION NORMALIZED BY GAS CONTENT FOR UF COAL ........................................63

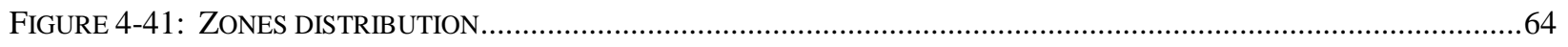

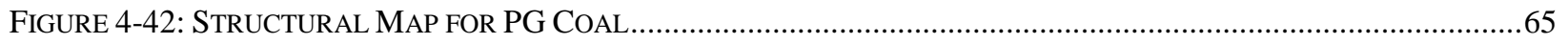

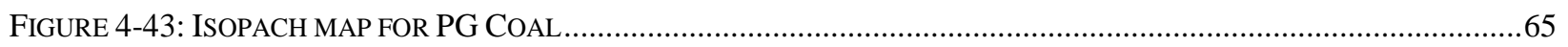

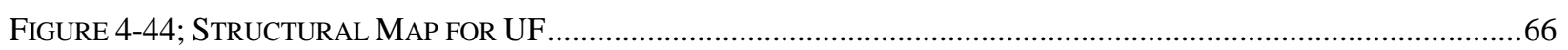

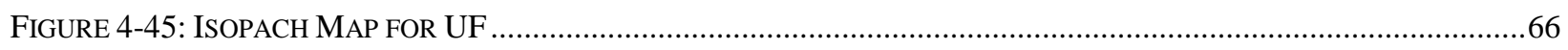

FigURE 4-46 MH12 BASE MOdEL GAS PRODUCTION ...................................................................................67

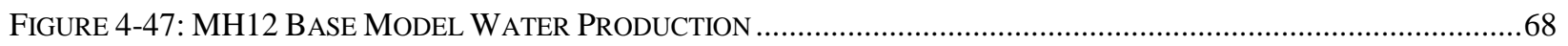

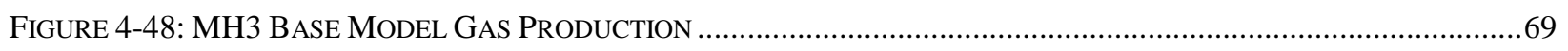

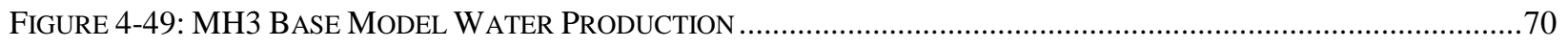

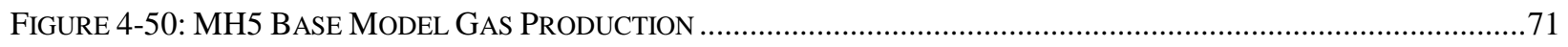

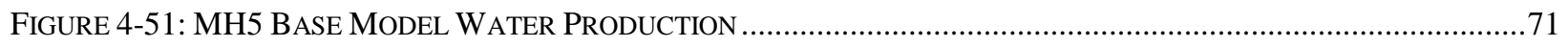

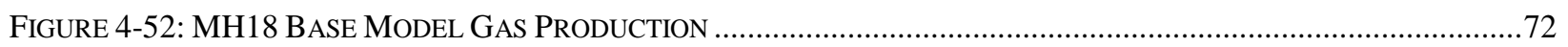

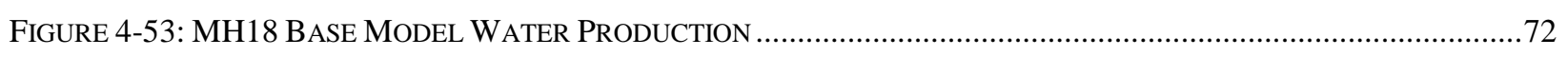

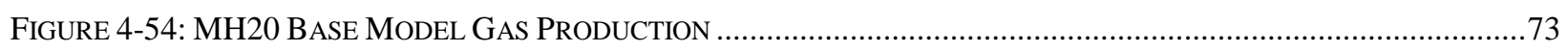

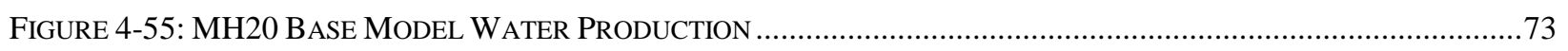

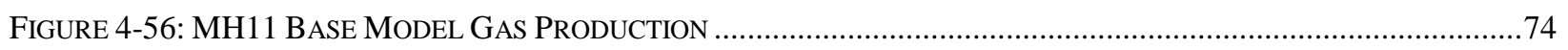

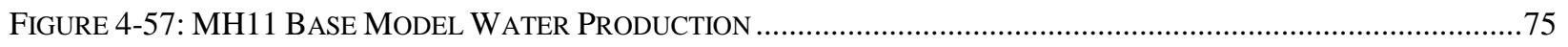

FIGURE 4-58: COMPARISON BETWEEN ACTUAL AND SIMULATED PRODUCTION FOR PG COAL WELLS .........................76

FIGURE 4-59: COMPARISON BETWEEN ACTUAL AND SIMULATED PRODUCTION FOR UF COAL WELLS ..........................77

FIGURE 4-60: GAS PRODUCTION SENSITIVITY FOR PERMEABILITY IN MH12- HMPH1-PG COAL ……..........................79

FIGURE 4-61: WATER PRODUCTION SENSITIVITY FOR PERMEABILITY IN MH12- HMPH1-PG COAL.............................79

FIGURE 4-62: GAS PRODUCTION SENSITIVITY FOR PERMEABILITY IN MH3- HMPH1-PG COAL .......................................8

FIGURE 4-63: WATER PRODUCTION SENSITIVITY FOR PERMEABILITY IN MH12- HMPH1-PG COAL .............................80

FIGURE 4-64: GAS PRODUCTION SENSITIVITY FOR POROSITY IN MH12- HMPH1-PG COAL ……………………......... 81

FIGURE 4-65: WATER PRODUCTION SENSITIVITY FOR PERMEABILITY IN MH12- HMPH1-PG COAL ...........................82

FIGURE 4-66: WATER PRODUCTION SENSITIVITY FOR POROSITY IN MH3- HMPH1-PG COAL.....................................82

FIGURE 4-67: WATER PRODUCTION SENSITIVITY FOR POROSITY IN MH3- HMPH1-PG COAL ......................................83

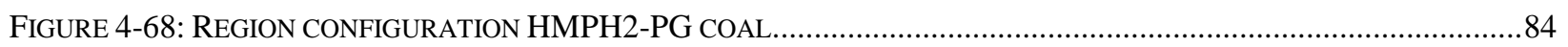

FIGURE 4-69: GAS PRODUCTION SENSITIVITY FOR PERMEABILITY IN MH12 HMPH2-PG COAL ..................................85

FIGURE 4-70: WATER PRODUCTION SENSITIVITY FOR PERMEABILITY IN MH12 HMPH2-PG COAL .............................86

FIGURE 4-71: GAS PRODUCTION SENSITIVITY FOR PERMEABILITY IN MH3 HMPH2-PG COAL ....................................87

FIGURE 4-72: GAS PRODUCTION PERMEABILITY CASE STRATEGY 1 MATCH IN MH3 HMPH2-PG COAL .......................87

FIGURE 4-73: WATER PRODUCTION SENSITIVITY FOR PERMEABILITY STRATEGY 1 IN MH3 HMPH2-PG COAL ............88

FIGURE 4-74: RELATIVE PERMEABILITY CURVE REGION 2 HMPH2-PG COAL..........................................................8

FIGURE 4-75: GAS PRODUCTION SENSITIVITY FOR RELATIVE PERMEABILITY IN MH12 HMPH2-PG COAL ..................90

FIGURE 4-76: WATER PRODUCTION SENSITIVITY FOR RELATIVE PERMEABILITY IN MH12 HMPH2-PG COAL .............90

FIGURE 4-77: GAS PRODUCTION SENSITIVITY FOR RELATIVE PERMEABILITY IN MH3 HMPH2-PG COAL .....................91 
FIGURE 4-78: GAS PRODUCTION MATCH FOR RELATIVE PERMEABILITY IN MH3 STRATEGY 2 IN HMPH2-PG COAL....91 FIGURE 4-79: WATER PRODUCTION FOR RELATIVE PERMEABILITY IN MH3 STRATEGY 2 IN HMPH2-PG COAL...........92

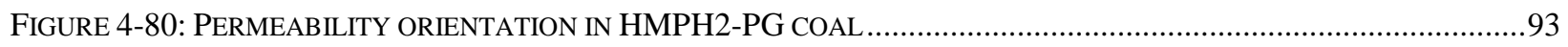
FIGURE 4-81: GAS PRODUCTION SENSITIVITY FOR ANISOTROPY RATIO IN MH12 HMPH2-PG COAL ........................94 FIGURE 4-82: WATER PRODUCTION SENSITIVITY FOR ANISOTROPY RATIO IN MH12 HMPH2-PG COAL.....................95 FIGURE 4-83: GAS PRODUCTION COMPARISON DUE TO ANISOTROPY PERMEABILITY ………..................................96 FIGURE 4-84: WATER PRODUCTION DUE TO ANISOTROPY PERMEABILITY …...............................................................97 FIGURE 4-85: GAS PRODUCTION SENSITIVITY FOR WELL LENGTH REDUCTION IN MH12 HMPH2-PG COAL ................98 FIGURE 4-86: WATER PRODUCTION SENSITIVITY FOR WELL LENGTH REDUCTION IN MH12 HMPH2-PG COAL ............99 FIGURE 4-87: GAS PRODUCTION SENSITIVITY FOR WELL LENGTH REDUCTION IN MH3 HMPH2-PG COAL ..................99 FIGURE 4-88: WATER PRODUCTION SENSITIVITY FOR WELL LENGTH REDUCTION IN MH3 HMPH2-PG COAL ........... 100 FIGURE 4-89: GAS PRODUCTION SENSITIVITY FOR PERMEABILITY IN MH18 HMPH2-UF COAL ...............................101 FIGURE 4-90: GAS PRODUCTION SENSITIVITY FOR PERMEABILITY IN MH5 HMPH2-UF COAL .................................102 FIGURE 4-91: GAS PRODUCTION SENSITIVITY FOR PERMEABILITY IN MH20 HMPH2-UF COAL ...............................103 FIGURE 4-92: GAS PRODUCTION SENSITIVITY FOR PERMEABILITY IN MH11 HMPH2-UF COAL ...............................103 FIGURE 4-93: WATER PRODUCTION SENSITIVITY FOR PERMEABILITY IN MH11 HMPH2-UF COAL............................104 FigURE 4-94: GAS PRODUCTION SENSITIVITY FOR PERMEABILITY STRATEGY 2 IN MH18 HMPH2-UF COAL ............105 FIGURE 4-95: GAS PRODUCTION SENSITIVITY FOR PERMEABILITY STRATEGY 2 IN MH5 HMPH2-UF COAL ..............106 FIGURE 4-96: GAS PRODUCTION SENSITIVITY FOR PERMEABILITY STRATEGY 2 IN MH20 HMPH2-UF COAL ............107 FIGURE 4-97: GAS PRODUCTION SENSITIVITY FOR PERMEABILITY STRATEGY 2 IN MH11 HMPH2-UF COAL ............107 FigURE 4-98: WATER PRODUCTION SENSITIVITY FOR PERMEABILITY STRATEGY 2 IN MH11 HMPH2-UF COAL .......108 FIGURE 4-99: GAS PRODUCTION SENSITIVITY FOR WELL LENGTH REDUCTION IN MH18 HMPH2-UF COAL ..............109 FIGURE 4-100: WATER PRODUCTION SENSITIVITY FOR WELL LENGTH REDUCTION IN MH18 HMPH2-UF COAL .......109 FIGURE 4-101: GAS PRODUCTION SENSITIVITY FOR WELL LENGTH REDUCTION IN MH5 HMPH2-UF COAL ..............110 FIGURE 4-102: WATER PRODUCTION SENSITIVITY FOR WELL LENGTH REDUCTION IN MH5 HMPH2-UF COAL ..........110 FIGURE 4-103: GAS PRODUCTION SENSITIVITY FOR WELL LENGTH REDUCTION IN MH20 HMPH2-UF COAL ............111 FIGURE 4-104: WATER PRODUCTION SENSITIVITY FOR WELL LENGTH REDUCTION IN MH20 HMPH2-UF COAL .......111 FIGURE 4-105: GAS PRODUCTION SENSITIVITY FOR WELL LENGTH REDUCTION IN MH11 HMPH2-UF COAL ............112 FIGURE 4-106: WATER PRODUCTION SENSITIVITY FOR WELL LENGTH REDUCTION IN MH11 HMPH2-UF COAL .......112 FIGURE 4-107: COMPARISON OF PERMEABILITY SENSIBILITY ALL WELLS HMPH3-UF ...........................................113 FIGURE 4-108: COMPARISON OF GAS CONTENT SENSITIVITY HMPH3-UF.........................................................114 FigURE 4-109: RELATIVE PERMEABILITY CURVES FOR REGION 1 IN CASE 1 HMPH3-PG ........................................117 FigURE 4-110: ReLATIVE PERMEABILITY CURVES FOR REGION 2 IN CASE 1 HMPH3-PG .......................................117 FiguRe 4-111: RELATIVE PERMEABILITY CURVES FOR REGION 1 IN CASE 2 HMPH3-PG ……............................119 FigURE 4-112: ReLATIVE PERMEABILITY CURVES FOR REGION 2 IN CASE 2 HMPH3-PG .......................................119 FiguRE 4-113: ReLATIVE PERMEABILITY CURVES FOR REGION 1 IN CASE 3 HMPH3-PG .......................................121 FIGURE 4-114: RELATIVE PERMEABILITY CURVES FOR REGION 2 IN CASE 3 HMPH3-PG ......................................121 Figure 4-115: MH12 Gas Rate Production History MatChing ReSUlts FOR ALL THE CASES HMPH3-PG.....122 FiguRE 4-116: MH12 WATER RATE PRODUCTION HistoRy MATCHING RESULTS FOR ALL THE CASES HMPH3-PG122 Figure 4-117: MH3 GAS RATE PROdUCtION History MATCHING RESUlTS FOR ALL THE CASES HMPH3-PG........123 FigURE 4-118: RELATIVE PERMEABILITY CURVES FOR ALL THE REGIONS FOR ALL THE CASES HMPH3-UF...............125 Figure 4-119: MH5 Gas Rate Production History MatChing ReSUltS FOR ALL THE CASES HMPH3-UF.......126 Figure 4-120: MH18 Water RATE PRODUCTION History MATCHING RESUltS FOR ALL THE CASES HMPH3-UF127 Figure 4-121: MH20 Gas Rate Production History MatChing ReSUlts FOR ALL THE CASES HMPH3-UF.....127

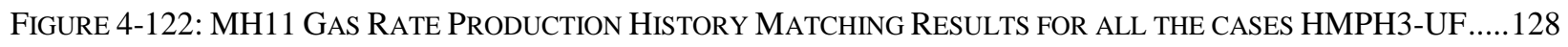




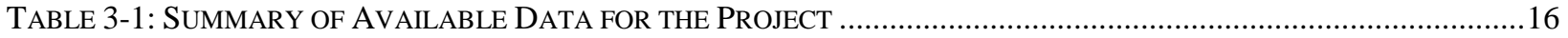

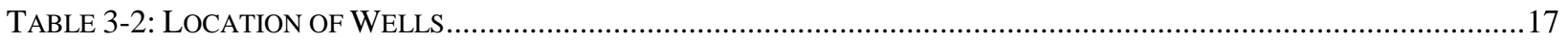

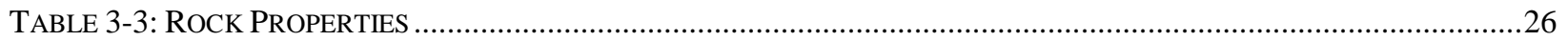

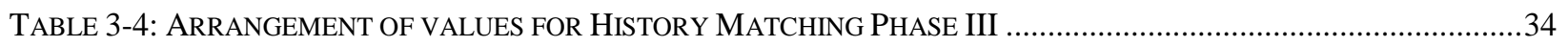

TABLE 3-5: STORED SLOPE VALUES FOR COMPARISON IN HISTORY MATCHING PHASE III..........................................34

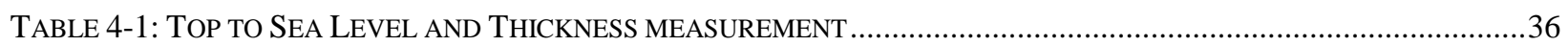

TABLE 4-2: PRESSURE GRADIENT AND INITIAL PRESSURE OF PG AND UF ........................................................42

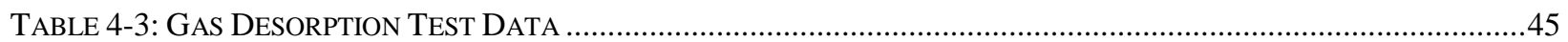

TABLE 4-4: RESULTS OF CANISTER TEST AND DESORPTION TIME FOR PG AND UF COAL .......................................46

TABLE 4-5: INITIAL COAL CONDITIONS IN REGION $1 \& 2$ FOR PG AND UF COAL......................................................47

TABLE 4-6: INITIAL GAS IN PlaCE, ACTUAL PRODUCTION AND RECOVERY FACTOR FOR PG AND UF COAL...............47

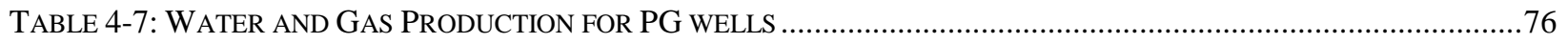

TABLE 4-8: WATER AND GAS PRODUCTION FOR UF WELLS ..............................................................................

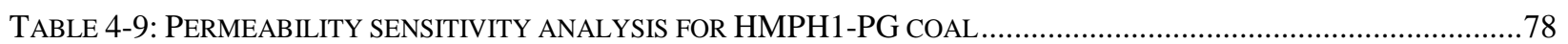

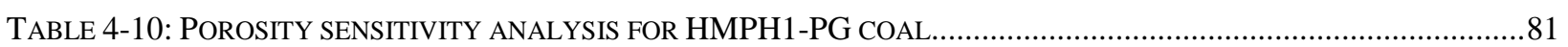

TABLE 4-11: PERMEABILITY CASE SENSITIVITY ANALYSIS FOR HMPH2-PG COAL ................................................85

TABLE 4-12: RELATIVE PERMEABILITY CASE SENSITIVITY ANALYSIS FOR HMPH2-PG COAL..................................89

TABLE 4-13: ANISOTROPY RATIO CASE SENSITIVITY ANALYSIS FOR HMPH2-PG COAL ......................................94

TABLE 4-14: WELL LENGTH REDUCTION CASE SENSITIVITY ANALYSIS FOR HMPH2-PG COAL ...............................97

TABLE 4-15: PERMEABILITY STRATEGY 1 CASE SENSITIVITY ANALYSIS FOR HMPH2-UF COAL............................101

TABLE 4-16: PERMEABILITY STRATEGY 2 CASE SENSITIVITY ANALYSIS FOR HMPH2-UF COAL.............................105

TABLE 4-17: WELL REDUCTION CASE SENSITIVITY ANALYSIS FOR HMPH2-UF COAL ............................................108

TABLE 4-18: ABSOLUTE SLOPE AND SENSITIVITY RANKING FOR PERMEABILITY CASE UF COAL .............................114

TABLE 4-19: ABSOLUTE SLOPE AND SENSITIVITY RANKING FOR GAS CONTENT CASE UF COAL ............................115

TABLE 4-20: PARAMETERS RANKING BASED ON THE YARDSTICK OF 5MSCFD FOR PG WELLS ..............................115

TABLE 4-21: PARAMETER VALUES FOR HMPH3 CASE 1 IN PG COAL .................................................................116

TABLE 4-22: PARAMETER VALUES FOR HMPH3 CASE 2 IN PG COAL ...........................................................118

TABLE 4-23: PARAMETER VALUES FOR HMPH3 CASE 3 IN PG COAL ..............................................................120

TABLE 4-24: PARAMETERS RANKING BASED ON THE YARDSTICK OF 5MSCFD FOR UF WELLS ..............................124

TABLE 4-25: PARAMETER VALUES FOR HMPH3 CASE 1 IN PG COAL ...............................................................124

TABLE 4-26: PARAMETER VALUES FOR HMPH3 CASE 3 IN UF COAL ............................................................125

TABLE 4-27: PARAMETER VALUES FOR HMPH3 CASE 3 IN PG COAL ............................................................. 126 


\section{List of Symbols and Abbreviations}

PG: Pittsburg coal

UF: Upper Freeport coal

R1: Region 1

R2: Region 2

$\mathrm{h}$ : thickness

K: Permeability

$\mathrm{Kx}$ : Permeability in $\mathrm{x}$-direction, md

Ky: Permeability in y-direction, md

md: millidarcy

Kr: Relative permeability,\% or fraction

$\phi$ : Porosity

$\tau$ : Desorption time, days

Gc: Gas content, scf/ton

PL: Langmuir Pressure, psi

VL: Langmuir Volume, scf/ton

Pi: Initial pressure

Pg: Pressure gradient, psi/ft

ft: feet

S: Skin factor

Pwf: Bottom-hole pressure

$\mathrm{T}$ : Temperature

HMPH1: History matching phase 1

HMPH2: History matching phase 2

HMPH3: History matching phase 3

S1: Strategy 1

S2: Strategy 2 


\section{Chapter 1 Introduction}

The primary component of natural gas is methane $\left(\mathrm{CH}_{4}\right)$. The presence of this gas is well known from its occurrence in underground coal mining, where it presents a serious safety risk. Coal bed methane (CBM) is the methane found in coal seams. It is produced by non-traditional means, and therefore, it is sold and used as traditional natural gas. Coal bed methane has become an important source of energy in United States, Canada, and other countries. In the United States, 1.7 trillion cubic feet (Tcf) of CBM were produced in 2006, representing about $9 \%$ of the 18.4 Tcf of U.S. dry gas productions. There were 19.6 Tcf of CBM reserves in 2006, representing about $9 \%$ of the 211 Tcf of dry gas proved reserves ${ }^{(1)}$. Undeveloped resources of CBM have been estimated at $158 \operatorname{Tcf}^{(2)}$.

$\mathrm{CBM}$ is generated from a biological process as a result of the coalification process. Often coal seams are saturated with water, and methane is held into the coal by hydrostatic pressure. Coal bed methane reservoirs are distinct from conventional reservoirs because the methane is stored within the matrix of the coal by a process called adsorption. CBM reservoirs are naturally fractured; the open fractures in the coal known also as the cleats can also contain free gas or can be saturated with water. Unlike much natural gas from conventional reservoirs, coal bed methane contains very little heavier hydrocarbons and it often contains some percentage of carbon dioxide. CBM production is attractive due to several geological factors. Coal beds can store six or seven times as much gas as a conventional natural gas reservoir of equal rock volume due to the large internal surface area of coal. The adsorption capacity depends on the rank and quality of the coal. The range is usually between 100 and $800 \mathrm{SCF} /$ ton for most coal seams found in the US. Most of the gas in coal beds is in the adsorbed form. In the case of under-saturated coals, when the reservoir is put into production, water in the fracture is produced first. This leads to a reduction of the partial pressure until it reaches the critical point. Then, gas starts desorbing from the matrix. Large amounts of water, sometimes saline, are produced from coal bed methane wells, especially in the early stages of production. While economic quantities of methane can be produced, water disposal options that are environmentally acceptable and yet economically feasible are a concern. Water may be discharged on the surface if it is relatively fresh, but often it is injected into rock at a depth where the quality of the injected water is less than that of the host 
rock. In recent years, several studies have been conducted to evaluate the feasibility of injecting greenhouse gases like carbon dioxide into unmineable coal beds. Results have demonstrated that under certain conditions, injecting $\mathrm{CO}_{2}$ into the coal can significantly enhance coal bed methane production due to the $\mathrm{CO}_{2}$ molecules' affinity to attach to the surface of the coal more than methane molecules, and at the same time using the coal as storage for greenhouse gases.

This study intends to build a realistic simulation model that can be used to forecast coal bed methane production for a pilot test located in West Virginia, and eventually in future studies able to simulate $\mathrm{CO}_{2}$ injection to enhance coal bed methane and sequesters of $\mathrm{CO}_{2}$.

\section{Statement of the problem:}

The purpose of this study is to build a realistic simulation model able to predict future behavior of a reservoir for a Pilot-Test project located in Marshall County, WV, US by using a systematic approach for history matching. 


\section{Chapter 2 LITERATURE REVIEW}

\section{Coalbed methane}

Coalbed methane $(\mathrm{CBM})$ is a form of natural gas extracted from coal beds ${ }^{(3)}$. Methane is produced during the natural coalification process, when organic matter such as trees or vegetation is quickly buried and then heated (4). As a reservoir, coal is considered unconventional, characterized by a dual porosity system acting as both the source rock and the storage reservoir. Coalbed Methane has become an important source of energy in United States accounting for about $10 \%$ of total natural gas production in the United States.

\section{The coalification process}

During the coalification process, large amounts of water are created along with the coalgas. Because of this, most coalbeds are saturated with water. Coalification proceeds through four stages and classifications: lignite, sub-bituminous, bituminous, and anthracite. Coals are ranked according to these different stages, and are also identified via the levels of certain indicators within the coal. Coal rank generally increases in direct correlation to temperature, burial depth. This time-temperature relationship determines the level of maturity of the coal, which amongst other factors, controls the volume of methane generated and stored.

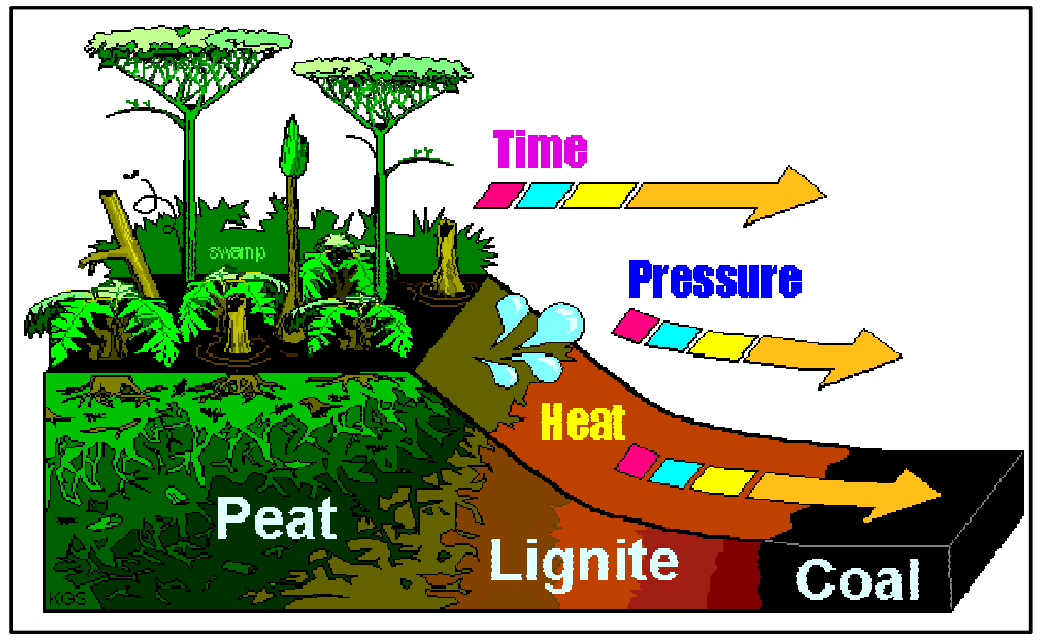

Figure 2-1: The Coalification Process 


\section{Structure of Coal}

Coals are naturally fractured. A closely-spaced fracture system (called cleats) forms in coals in response to coalification, local structure features, and other variables. The dominant (more continuous) cleat is commonly called the face cleat, and the cleat oriented roughly perpendicular to the face cleat is called the butt cleat ${ }^{(5)}$.
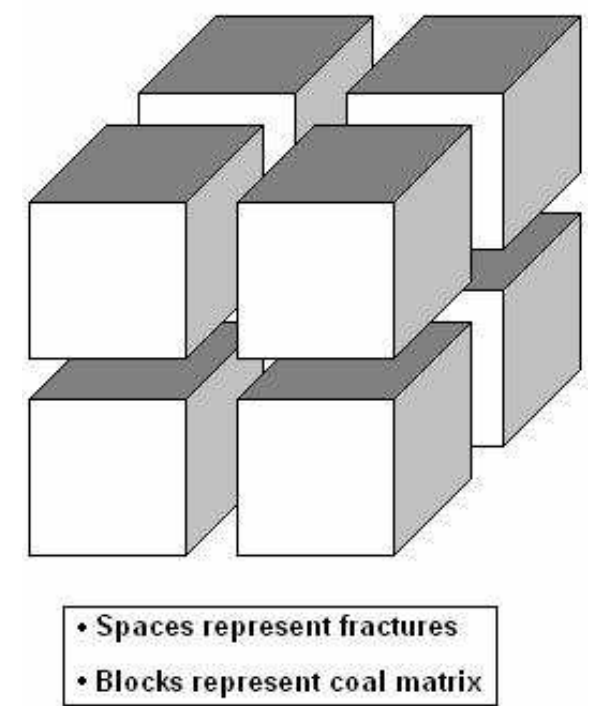

Figure 2-2: Structure of Coal

\section{Storage Mechanisms}

Gas can exist in a coal seam in two ways. It can be present as free gas within the mineral porosity of the coal (joints and fractures), and it can be present as an adsorbed gas on the internal surfaces of the coal (matrix) ${ }^{(6)}$.

Because the bulk porosity of the coal cleat system is small and the initial gas saturation in the coal cleats is typically low, most of the gas-in-place in coals is adsorbed in the coal matrix.

Water is stored in coals in two ways: as bound water in the coal matrix and as free water in the coal cleat system. 


\section{Transport Mechanisms}

Most of the gas present in coal seams is physically adsorbed on the internal surface of the coal "matrix" Gas production from coals occurs by a three-stage process in which gas; 1) flows from natural fractures, 2) desorbs from the cleat surface (natural fractures), 3) diffuses through the coal matrix to the cleats.

\section{Desorption:}

Is the process by which methane molecules detach from the micro pores surfaces of the coal matrix and enter the cleat system where they exist as free gas. The desorption isotherm defines the relationship between the adsorbed gas concentration in the coal matrix and the free gas pressure in the coal cleat system ${ }^{(7)}$.

\section{Diffusion:}

Is a process in which flow occurs via random molecular motion from an area of high concentration to an area of lower concentration ${ }^{(8)}$.

\section{Darcy Flow:}

Flow in the cleat system of coals can be described by Darcy's Law. In a general sense, Darcy's Law relates the flow rate in a reservoir to the pressure drop across the reservoir using proportionality constant.

\section{Langmuir Isotherm}

The Langmuir isotherm was developed by Irving Langmuir in 1916 to describe the dependence of the surface coverage of an adsorbed gas on the pressure of the gas above the surface at a fixed temperature ${ }^{(9)}$. 
The following equation shows the typical formulation of Langmuir Isotherm:

$V(P)=\frac{V_{L} P}{P_{L}+P}$

Where;

$\mathrm{P}=$ pressure $(\mathrm{psia})$

$\mathrm{V}(\mathrm{P})=$ amount of gas at $\mathrm{P}$, also known as gas content (scf/ton)

$\mathrm{VL}=$ Langmuir volume parameter (scf/ton)

$\mathrm{PL}=$ Langmuir pressure parameter $(\mathrm{psia})$

The Langmuir isotherm equation has 2 parameters:

Langmuir Volume $\left(\mathrm{V}_{\mathrm{L}}\right)$ : Langmuir Volume is the maximum amount of gas that can be adsorbed on a piece of coal at infinite pressure.

Langmuir Pressure $\left(\mathrm{P}_{\mathrm{L}}\right)$ : Langmuir Pressure is the pressure at which storage capacity equals one half of the maximum storage capacity $\left(\mathrm{V}_{\mathrm{L}}\right)$

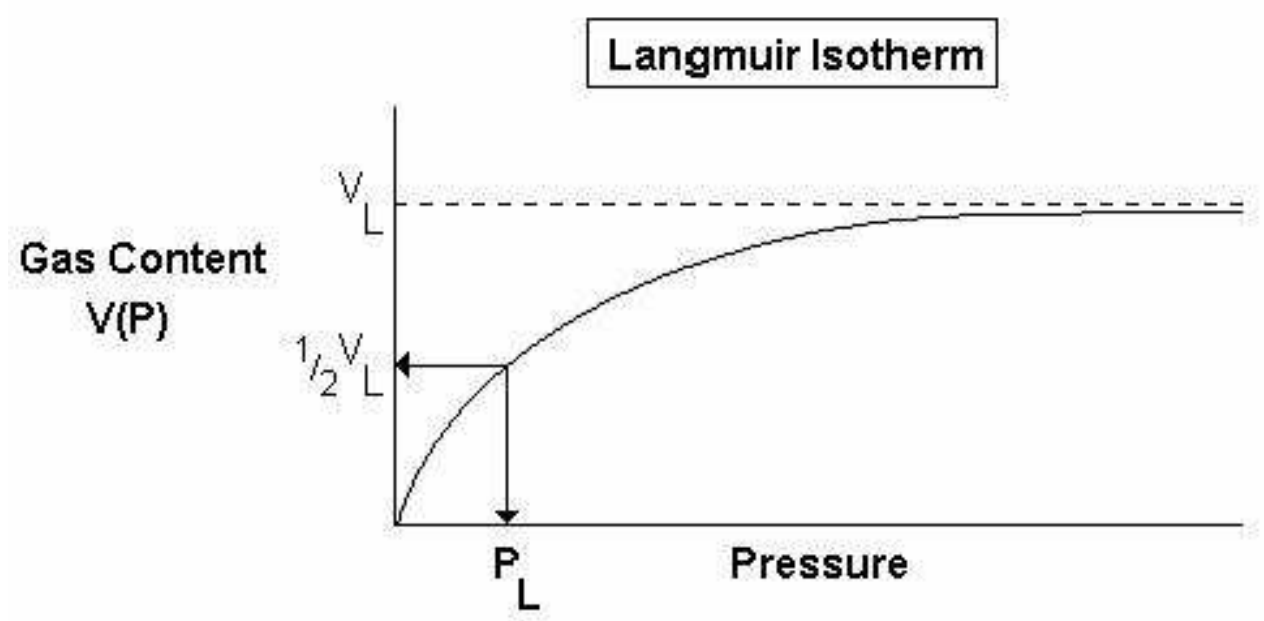

Figure 2-3: Langmuir Isotherm Plot 
Coalbed Methane reservoirs are usually undersaturated where coalbed pore space, which is in the form of cleats or fractures, is filled with water. When a coal is undersaturated, the reservoir pressure has to be reduced in order for methane to be produced, usually by pumping out the water. Ones the reservoir reaches the critical desorption pressure; the methane desorbs from the coal surface and flows through fractures towards the well bore.

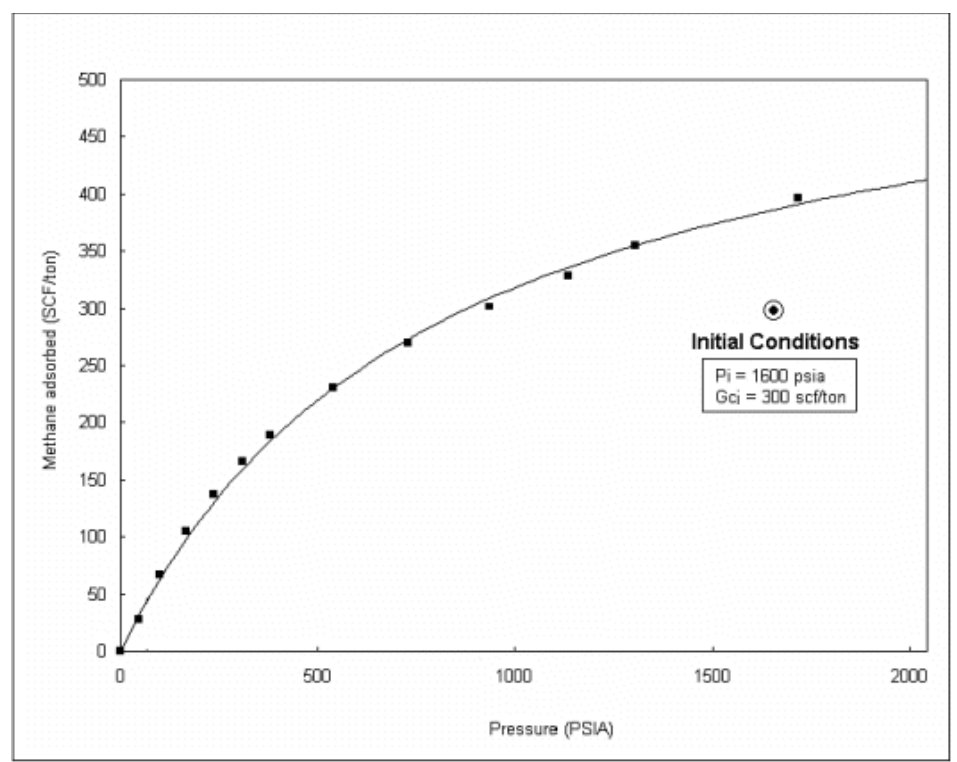

Figure 2-4: Undersaturated Coalbed Methane Reservoir initial conditions

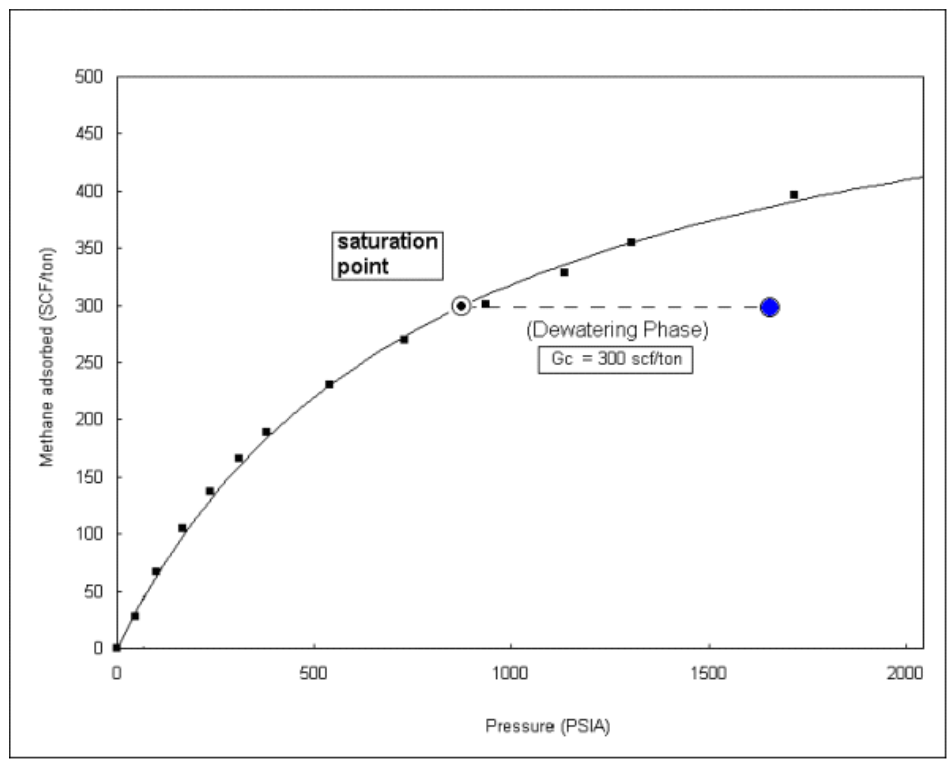

Figure 2-5: Dewatering process in an Undersaturated Coalbed Methane Reservoir 


\section{Coalbed Methane Production Profile}

In an undersaturated coal water dominates early production. As water is produced and the reservoir pressure declines, gas production starts increasing until it reaches a peak to eventually start declining. In a saturated coal, there is none or little water production. The reservoir starts producing gas at the highest rate decreasing over time.

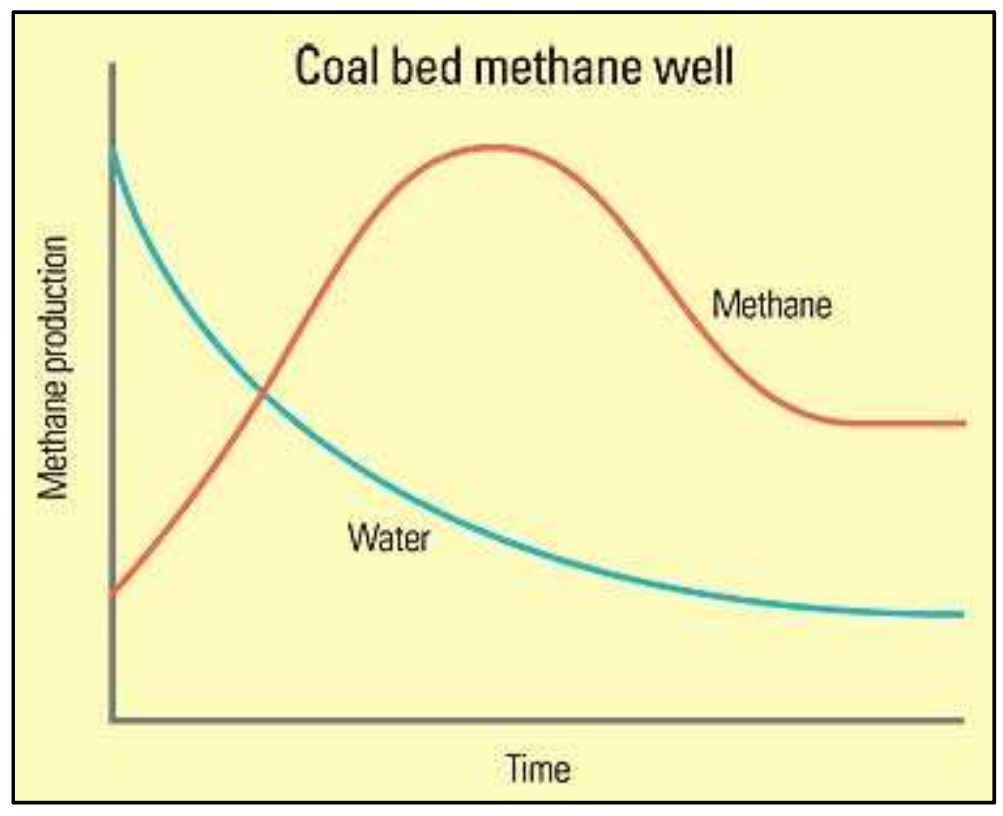

Figure 2-6: Coal Bed Methane Production Profile

\section{Shrinkage and Compaction}

One of the unique characteristics of coal bed methane is the phenomenon of pressure dependent permeability ${ }^{(10)}$. As the reservoir is produced, two distinct phenomena occur. First, as the reservoir pressure declines it causes the pressure in the fractures to also decline which led an increase in the effective stress within the cleats causing the cleats to be more compactable decreasing the permeability. At the same time the gas that has been desorbed is coming out of the matrix which causes the matrix to shrinks and the cleats to open-up increasing the permeability. Compressibility dominates in early time and shrinkage dominates in late time. 


\section{Enhance coalbed methane (ECBM) and sequestration}

Enhanced coalbed methane (ECBM) recovery is the process of injecting a gas into a coal reservoir to enhance the desorption and recovery of in-situ coalbed methane (CBM). Depending upon whether the injected gas exhibits a greater or lesser sorption capacity on coal than methane, the process is either dominated by displacing the CBM from sorption sites within the coal matrix blocks into the cleat system, or stripping it from the coal matrix with a low partial pressure to methane in the cleat system ${ }^{(11)}$. Coal bed methane recovery can primarily improve by nitrogen injection and carbon dioxide injection. Although both of these constituents can improve the recovery, their behavior is quite different in coal bed methane.

Nitrogen injection is primarily implemented to improve the recovery of coal bed methane. As seen in the figure below, nitrogen has a significantly lower affinity to coal than methane and carbon dioxide. Physically, nitrogen reduces the partial pressure of methane which allows methane to diffuse from the matrix of the coal with greater ease, hence improving the recovery of coal bed methane at a faster rate.

The injection of $\mathrm{CO}_{2}$ into coal beds has several advantages: 1) reduces production time of coal bed methane; 2) increases reserves by improving the recovery of CBM; and, 3) sequesters $\mathrm{CO}_{2}$

1. Carbon dioxide has unique characteristics that allow it to be such a great candidate for ECBM. $\mathrm{CO}_{2}$ is more adsorptive to coal than methane. In concept, the process of $\mathrm{CO}_{2}-\mathrm{ECBM}$ is simple. As $\mathrm{CO}_{2}$ is injected into a coal reservoir, it is preferentially adsorbed into the coal matrix, displacing the methane that exists in that area. The displaced methane then diffuses into the cleat system, and migrates to the production wells through Darcy flow. As discussed earlier, as the reservoir pressure decreases, the matrix tends to shrink, increasing the permeability over time. However, with injection of $\mathrm{CO}_{2}$ the matrix begins to swell which reduces the pathway of flow, decreasing the permeability. In order to determine if a potential for $\mathrm{CO}_{2}$ sequestration exists, it is imperative that the reservoir reaches an appropriate pressure where it can sustain the swelling of the matrix caused by $\mathrm{CO}_{2}$ injection. An assessment of $\mathrm{CO}_{2}$-ECBM/sequestration potential in the 
U.S. suggests a potential resource of $150 \mathrm{Tcf}$ of gas and a sequestration capacity of $90 \mathrm{Gt}$ of $\mathrm{CO}_{2}$ exists.

A technical/economic sensitivity has shed light on the most favorable coal conditions for $\mathrm{CO}_{2}$ sequestration in CBM reservoirs. These include deep, high-rank coals with low permeability and that have not been previously developed for conventional coalbed methane production. However, this assumes technology is developed to overcome reduced injectivity due to matrix swelling.

\section{History Matching in CBM}

Reservoir simulation and history matching provides many asset teams with a tool to understand the reservoir and predict future performance. The history matching process itself can be very time consuming and frustrating. This is due to the uncertainty about the reservoir, and the fact that a history match can usually be achieved through various parameters' configurations ${ }^{(12)}$. Relative permeability curves generated from the history match process tend to be steeper than core derived curves. Though core derived permeability curves can be used as a starting point, curves generated through history matching may provide a truer representation of the reservoir.

\section{Northern Appalachian Basin}

Cleats in Appalachian coals

Natural fractures in coal (cleats) are the principal conduits for the transfer of methane from coal reservoirs (Diamond et al., 1988; Close, 1993; Law, 1993; Rice et al., 1993; Rogers, 1994). Face and butt cleats are the primary and secondary cleat systems in coal, respectively, and these are a function of regional structure, coal rank, coal lithotype, bed thickness, and other factors. Diamond et al. (1988) suggested that closer fracture spacing results in higher permeability of coal beds for CBM. Conversely, Law (1993) reported that the spacing of face and butt cleats are similar and, therefore, the well-known permeability anisotropy of these cleat systems is due to connectivity and not cleat spacing (see also Jones et al., 1984). The permeability of face and butt cleats in the San Juan basin are generally different (Young, 1992), 
averaging about 12-20 md and 4-5 md, respectively. The greater permeability of face cleats is supported by stimulation experiments using fluorescent paint (Diamond, 1987).

In the central and northern Appalachian basin, face and butt cleats are perpendicular and parallel, respectively, to fold axes (McCulloch et al., 1974). Kelafant and Boyer (1988) reported two dominant cleat trends in the central Appalachian basin--a northeast-southwest set and a north-south set (see also Colton et al, 1981). For the Pocahontas No. 3 coal bed in Buchanan County, Virginia, the face and butt cleats strike N 18o W and N67o E, respectively. In Wise County, Virginia, Law (1993) reported similar cleat spacings of 1.02-1.32 cm for face and butt cleats.

In the northern Appalachian basin, the face cleat of the Pittsburgh coal bed rotates from $\mathrm{N}$ 80o $\mathrm{W}$ in northwestern West Virginia to $\mathrm{N} 57 \mathrm{o} \mathrm{W}$ in southwestern Pennsylvania, following a shift in the axial trend (McCulloch et al., 1974). This set of face cleats corresponds to the regional system of N70-800W face cleats mapped by Kulander et al. (1980). Cleat spacings of 0.5-9.7 cm were reported by Law (1993) in the northern Appalachian basin. McCulloch et al.(1974) and Kulander et al. (1980) reported that horizontal drill holes perpendicular to the face cleats yielded much higher gas yields (up to ten times) as compared with drill holes perpendicular to butt cleats, thus suggesting that face cleats are the primary conduit for CBM. In the Anthracite region of eastern Pennsylvania, Law (1993) reported that cleat systems are poorly developed and mineral-filled, and this will undoubtedly be a major factor in preventing CBM development in that region.

\section{CBM composition and desorption data}

In 1985, The Lower Kittanning, Lower Freeport, Upper Freeport, and Pittsburgh coal beds of West Virginia and Pennsylvania were among the 10 highest methane liberating coal beds from coal mines in the United States (Grau, 1987). In general, desorption and total gas values for the northern Appalachian basin are lower than those for the central Appalachian basin. These data probably reflect higher ranks and greater depths for coal beds of the central Appalachian basin. According to Rice (1995), coals in the northern Appalachian basin have much longer 
desorption times (as much as 600 days); in contrast, CBM in southwestern Virginia in the central Appalachian basin desorbs in a few days probably due to lower hydrostatic pressure.

Hunt and Steele (1991a) postulated CBM values of 100-150 cf/ton for the Pittsburgh coal in the northern Appalachian basin. A low gas value of less than $50 \mathrm{cf} /$ ton at a depth of $520 \mathrm{ft}$ was reported for the Pittsburgh coal (WVGES and PTGS, 1993). An average gas content of 140 cf/ton for the Pittsburgh coal bed, as compared with $192 \mathrm{cf} /$ ton and $252 \mathrm{cf} /$ ton for the Freeport and Kittanning coal beds, respectively, was reported (WVGES and PTGS, 1993; Bruner et al., 1995). These values reflect increased CBM with depth. Markowski (1993) reported 95-216 $\mathrm{cf} /$ ton for seven Monongahela samples in this part of the basin, which is in general agreement with previous reports. Adams et al. (1984) reported $100 \mathrm{cf} /$ ton for the western part of the northern Appalachian basin and 150-200 cf/ton for the eastern part. In Ohio County in the panhandle of West Virginia, Hunt and Steele (1991a) reported $112 \mathrm{cf} /$ ton for the Pittsburgh coal bed at $722 \mathrm{ft}$, which may have been affected by some CBM depletion from nearby coal mining; Hunt and Steele (1991c) reported a reservoir pressure of only 75 psi in this well, which is now shut in. In Greene County, Pennsylvania, three CBM coal tests were staked (Petroleum Information Corporation, 1991). Twenty-one coal core samples for desorption measurements were taken from six drill holes in Beaver, Lawrence, Somerset, and Washington Counties, Pennsylvania, but the results were not reported (Markowski, 1995). In Ohio, there are a limited amount of desorption data (Couchot et al., 1980; Diamond et al., 1986). For 23 core samples of the Brookville, Middle Kittanning, Lower and Upper Freeport, and Pittsburgh coal beds of Belmont, Guernsey, Monroe, Noble, and Washington Counties, Ohio, the desorption values ranged from 11 to175 cf/ton) at depths as much as $786 \mathrm{ft}$. The highest value (175 cf/ton) was for the Upper Freeport was from a depth of $667 \mathrm{ft}$. Diamond et al. (1986) reported similar low desorption values ranging from 9.5 to $95.4 \mathrm{cf} /$ ton for the Upper Freeport and Kittanning coal beds of Harrison County, Ohio.

There is a lack of information on methane emissions from Maryland coal mines. However, Maryland coal beds are not known to be gassy (R.H. Grau and W.P. Diamond, Bruceton Research Center, Department of Energy, Pittsburgh, personal commun., March, 1996). This information is consistent with mine-safety information from bottled gas samples taken quarterly at fans in the Mittiki A, B, C, and D mines (all mining Upper Freeport coal bed) in the 
southern part of the Upper Potomac coal field, the largest mines in Maryland; the Mittiki mines show generally low CBM emissions (less than 100,000 cf/day, March 1, 1996; Barry Ryan, Mine Safety and Health (Department of Labor), mining inspector, Oakland, Maryland, personal commun., March,1996). However, from the Mittiki C Mine (circa 1989) there were a few quarters that year when the $\mathrm{C}$ mine, which is now sealed, in the southernmost part of the Upper Potomac coal field had high emissions in the range of 250,000-300,000 cf/day and was put on a 15-day spot check (Barry Ryan, personal commun., March, 1996). Another deep mine in Garrett County near Steyer and owned by the Patriot Mining Company (Permit DM-90-109), which mines the Bakerstown coal bed, also has low methane emissions (Barry Ryan, personal commun., March, 1996). These data do not represent mined coal beds with the greatest amount of overburden, so they are probably misleading with respect to the CBM potential of deeply buried beds in the Maryland coal fields.

In the Anthracite region of eastern Pennsylvania there are limited known gas-content data (Diamond and Levine, 1981; Diamond et al., 1986). However, the data available from these two sources suggest very high amounts of CBM in some parts of the Anthracite region. For the Peach Mountain coal bed (Llewellyn Formation) in Schuylkill County in the Southern Anthracite field, at a depth of $685 \mathrm{ft}$, the total gas content was measured at 598 to $687 \mathrm{cf} /$ ton, the second highest total gas content known as Appalachian basin coal beds. For the Tunnel coal bed at depths of 604-608 ft in Schuylkill County, the total gas content of three samples ranged from 445 to 582 $\mathrm{cf} / \mathrm{ton}$. These gas contents can be contrasted with very low total gas contents of 6 to $29 \mathrm{cf} /$ ton for the Orchard coal bed and $13 \mathrm{cf} /$ ton for the Mammoth coal bed in Schuylkill County (Diamond et al., 1985). Similar low total gas contents of 16 to $70 \mathrm{cf} /$ ton were reported for the New County coal bed in Lackawanna County (Diamond et al., 1986) in the Northern Anthracite field These extreme differences in total gas contents may represent structural and permeability problems due to the absence of cleats or mineral-filled cleats (Law, 1993) and other local factors. These will be an important consideration that may prevent development in some areas. Nevertheless, the very high total gas contents of some coal beds in the Anthracite region indicate that CBM exploration should be carried out in this region. Northern Appalachian and San Juan Basin coals can be characterized as slow desorbers ${ }^{(13)}$. 
Appalachian CBM production data

CBM production from coal reservoirs is affected by gas content, sorption rate, saturation, pressure, permeability, and other factors. Hunt and Steele (1991b) suggested the following hypothetical minimum values for economic development from multiple seams in CBM reservoirs:

1. Gas content $125-150 \mathrm{scf} / \mathrm{ton}$

2. Permeability $0.1-0.5 \mathrm{md}$

3. Pressure 125-175 psi 


\section{Chapter 3 METHODOLOGY}

The completion of this study was accomplished through different stages. Data collection, data analysis, and reservoir modeling. The data is collected from different sources; CONSOL (Project operator), Department of Energy (DOE), The National Energy Technology Laboratory (NETL), West Virginia Geological and Economical Survey (WVGES), and other web information systems. All the data is introduced to the study as it becomes available and is then processed and analyzed. Once this step is completed, a commercial reservoir simulator software is used in order to build a model of the field. All the available data is incorporated into the model in order to history match the past behavior of the reservoir and be able to perform production forecasting. The reservoir simulation software used in this study is GEM developed by the Computer Modeling Group (CMG).

\section{Actual data acquisition}

In this step, all the collected information is gathered and organized in a database. The Table 3-1 shows a summary of the data that is available for this project. Key information is then extracted from the database to be filtered and analyzed. 
Table 3-1: Summary of Available Data for the Project

\begin{tabular}{|c|c|c|c|}
\hline \multicolumn{4}{|l|}{ DATA } \\
\hline \multirow{3}{*}{ MAPS } & \multicolumn{3}{|l|}{ Project map area } \\
\hline & \multicolumn{3}{|c|}{ Project cross sections (AA' and BB') } \\
\hline & \multicolumn{3}{|c|}{ Upper Freeport Isopach } \\
\hline WELL INFORMATION & \multicolumn{3}{|c|}{ Project and other wells location } \\
\hline \multirow{10}{*}{ LOGS } & \multirow{6}{*}{ Geologist } & \multicolumn{2}{|l|}{ Core-hole MC01-17 } \\
\hline & & \multicolumn{2}{|l|}{ Core-hole MC01-19 } \\
\hline & & \multicolumn{2}{|l|}{ Core-hole MC01-20 } \\
\hline & & \multicolumn{2}{|l|}{ Core-hole MC7922 } \\
\hline & & \multicolumn{2}{|l|}{ Core-hole MC7924B } \\
\hline & & \multicolumn{2}{|l|}{ Core-hole CNG8009 } \\
\hline & Gamma Ray (GR) & \multicolumn{2}{|l|}{ Leg \#1 MH19 to MH18 } \\
\hline & \multirow{3}{*}{ Cement Bond (CBL) } & \multicolumn{2}{|l|}{ MH18 } \\
\hline & & \multicolumn{2}{|l|}{ MH20 } \\
\hline & & \multicolumn{2}{|l|}{ MH26 } \\
\hline \multirow{6}{*}{ PRODUCTION } & \multirow{2}{*}{ Pittsburgh Coal } & \multicolumn{2}{|c|}{ MH12 Gas and Water production } \\
\hline & & \multicolumn{2}{|c|}{ MH3 Gas production } \\
\hline & \multirow{4}{*}{ Upper Freeport Coal } & \multicolumn{2}{|l|}{ MH5 Gas production } \\
\hline & & \multicolumn{2}{|l|}{ MH18 Gas Production } \\
\hline & & \multicolumn{2}{|l|}{ MH20 Gas production } \\
\hline & & \multicolumn{2}{|c|}{ MH11 Gas and some water } \\
\hline \multirow{15}{*}{$\begin{array}{l}\text { RESERVOIR } \\
\text { CHARACTERIZATION }\end{array}$} & & Core-hole MC-04-12 & $\mathrm{CO}_{2}$ Isotherm \\
\hline & & & Macerals study \\
\hline & & & $\mathrm{CH}_{4}$ Isotherm \\
\hline & & & Proximity analysis \\
\hline & & Core-hole MC-05-01 & $\mathrm{CH}_{4}$ Isotherm \\
\hline & Pittshuroh Coal & Core-hole SH-04-01 & $\mathrm{CH}_{4}$ Isotherm \\
\hline & Pittsburgn Coal & Core-hole: Well MH25 & $\begin{array}{l}\text { Desorption canister test } \\
18-3\end{array}$ \\
\hline & & & $\begin{array}{l}\text { Desorption canister test } \\
18-4\end{array}$ \\
\hline & & & $\begin{array}{l}\text { Desorption canister test } \\
40-6\end{array}$ \\
\hline & & Core-hole MC-05-01 & $\mathrm{CH}_{4}$ Isotherm \\
\hline & & Core-hole: Well MH26 & $\begin{array}{l}\text { Desorption canister test } \\
40-4\end{array}$ \\
\hline & Upper Freeport Coal & & $\begin{array}{l}\text { Desorption canister test } \\
40-5\end{array}$ \\
\hline & & & $\begin{array}{l}\text { Desorption canister test } \\
40-7\end{array}$ \\
\hline & Gas Content Data & $\begin{array}{l}27 \text { data points from we } \\
\text { coal }\end{array}$ & completed in Pittsburgh \\
\hline & $\begin{array}{l}\text { from } 34 \text { wells around } \\
\text { the area }\end{array}$ & $\begin{array}{l}7 \text { data points from } \mathrm{w} \\
\text { Freeport coal }\end{array}$ & ls completed in Upper \\
\hline
\end{tabular}


Figure 3-1 shows an aerial view of the field and how the horizontal wells are configured. The black lines represent the horizontal wells completed in Pittsburgh coal (PG), and the green lines represent the horizontal wells completed in Upper Freeport coal (UF). The red borderline around the field represents the area of study. Table 3-2 shows the wells in the project, their reference location, and directionality.

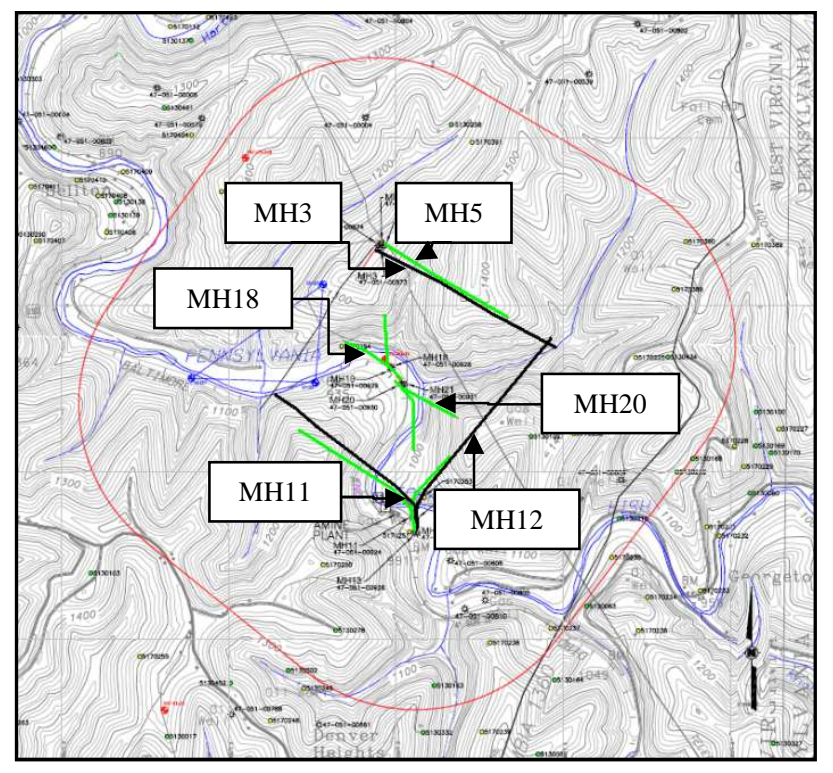

Figure 3-1: Aerial View of the Pittsburgh and Upper Freeport Wells

Table 3-2: Location of Wells

\begin{tabular}{|l|l|l|l|}
\hline Well Number & Formation & Location & Direction \\
\hline MH3 (single lateral) & Pittsburgh & North site & North-East \\
\hline MH12 (bi-lateral) & Pittsburgh & South site & South-East, South-West \\
\hline MH5 ( single lateral) & Upper Freeport & North site & North-East \\
\hline MH11 (bi-lateral) & Upper Freeport & South site & South-East, South-West \\
\hline MH18 (bi-lateral) & Upper Freeport & Center site & Center-NW, Center-N \\
\hline MH20 (bi-lateral) & Upper Freeport & Center site & Center-SE, Center-S \\
\hline
\end{tabular}


Figure 3-2 shows the provided isopach map from Upper Freeport coal where coal pinches out in the southeastern part of the study area.

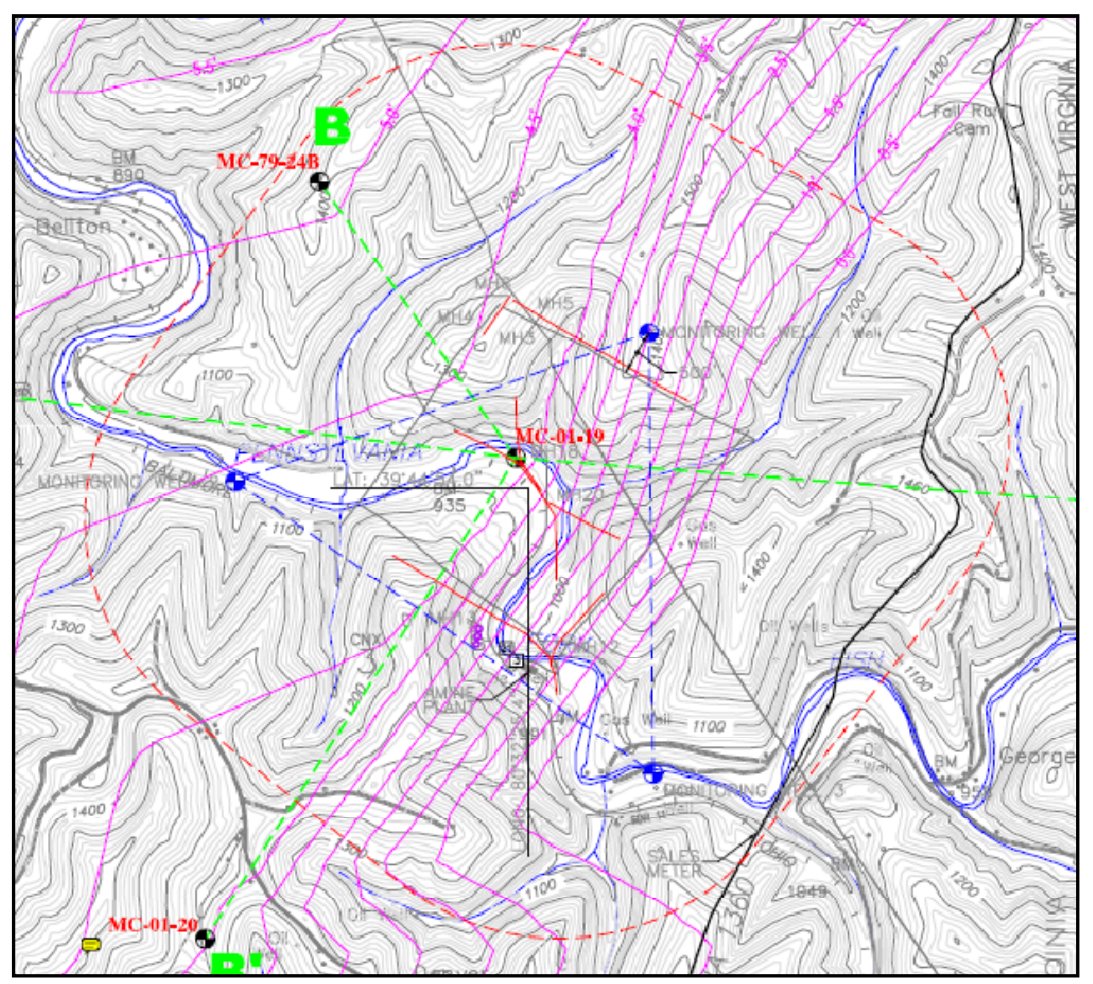

Figure 3-2: Upper Freeport Isopach Map

\section{Data Analysis}

Once all the available data has been collected and organized, the data analysis process is started. The data analysis process is subdivided into three stages: Geology characterization, reservoir characterization, and production data analysis.

\section{Geology characterization}

This stage involves extracting true vertical depth (TVD), elevation, and thickness values from the geologist logs in order to characterize the geology. Using this information, lateral cross section graphs of sections $\mathrm{AA}^{\prime}$ and $\mathrm{BB}$ ' are built in order to better understand the structure of the coal. Figure 3-3 shows AA' and BB' cross sections. 


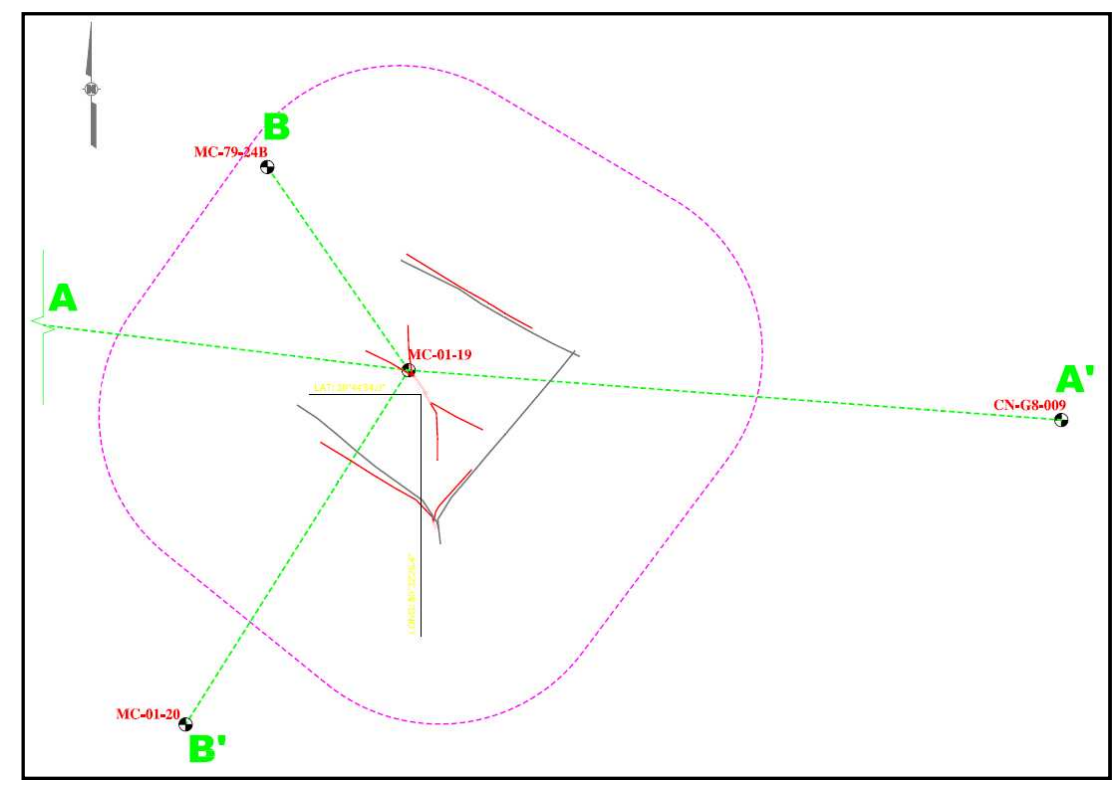

Figure 3-3: Geologic Cross Section $\mathrm{AA}^{\prime}$ and $\mathrm{BB}^{\prime}$

\section{Reservoir Characterization}

Once the structure of the formation has been analyzed, the reservoir characterization process is started. In this stage, the goal is to understand how the different reservoir characteristics are distributed along the formations and to characterize the coals in order to know whether they are saturated or under-saturated. This information will be used later for the reservoir model initialization.

First, using the thickness values from cross sections, an isopach map for Pittsburgh coal is generated by kriging the data using a software map generator called "3D Field". Also, gas content distribution maps for Pittsburgh and Upper Freeport coals are generated using the same approach.

A Methane Langmuir Isotherm comparison is performed in both coals using the data from core samples located in the surroundings of the test area. The purpose of this task is to compare the available isotherm profiles from different locations in each formation in order to evaluate the differences in the capacity for coal to release methane. Once this is done, a study of the CH4 Langmuir Isotherms is conducted in order to determine whether the coals are saturated or under-saturated. All four $\mathrm{CH} 4$ Langmuir Isotherms plots filed on the database (two from 
Pittsburgh coal and two from Upper Freeport coal) are used to perform this study. Since initial reservoir pressure data is not available, pressure gradients of $0.3 \mathrm{psi} / \mathrm{ft}, 0.35 \mathrm{psi} / \mathrm{ft}$, and $0.45 \mathrm{psi} / \mathrm{ft}$ are used to estimate initial reservoir pressure based on average formation depth. Those values are entered in the isotherms plots and extrapolated to the Isotherm profile in order to estimate initial gas content (Gci). CONSOL has provided Initial gas content values for both coals. If the calculated Gci is equal to the Gci provided, it would be an indication the coal is saturated. If the calculated Gci is greater than Gci provided, it would be an indication that the coal is undersaturated, and that water needs to be produced in order for gas to start desorbing from the matrix of the coal. This information will be used to understand the reservoir behavior and in the model initialization process. Equation 1 is used to calculate the initial reservoir pressure based on the pressure gradient.

$$
P i=P g . D \ldots \ldots \ldots \text { Equation } 1
$$

Where;

$P i=$ Calculated initial reservoir pressure, psi

$P g=$ Pressure gradient

$D=$ Average formation depth, $\mathrm{ft}$

\section{Canister Desorption Test Analysis}

Data from four canisters desorption tests, two from Pittsburgh and two from Upper Freeport coals are analyzed in order to calculate desorption time values. By definition, desorption time is the time coal releases $63.2 \%$ of its initial gas content. In order to accomplish this, lost gas and residual gas are estimated. Lost gas is the volume of gas desorbed during sample retrieval and examination, prior to sealing in a desorption canister (estimated). Residual gas is the volume of gas retained in the sample when testing is terminated (measured or estimated). To estimate lost gas, the USBM method is used. This method is the most widely used and considered the most accurate. Cumulative desorbed gas volume is plotted against the square root of desorption time, and regression analysis is applied to the steepest linear part of the curve. The regression line is projected back to "time zero" (when gas began to desorbs from the sample) to provide an estimate of gas volume lost before the canister was sealed. Figure 3-4 shows a 
typical lost gas chart \& estimation by USBM direct method where the estimated lost gas is 42 scf/ton.

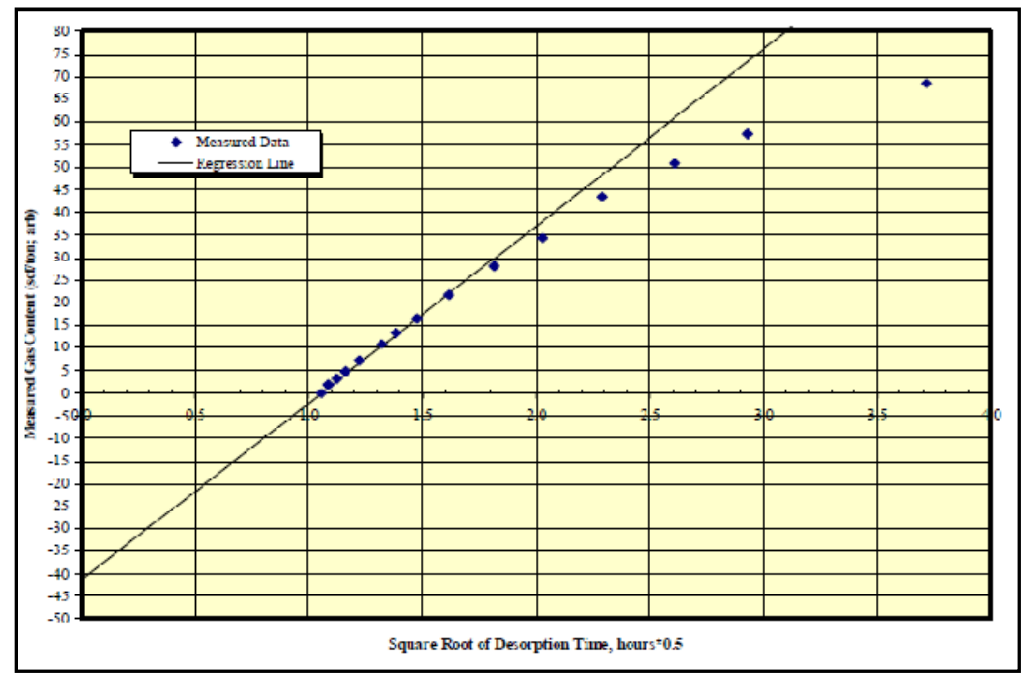

Figure 3-4: Typical Lost Gas Chart and Estimation

The next step is to estimate residual gas graphically. A plot of cumulative desorbed gas volume versus the reciprocal of desorption time will typically display a linear relationship near the end of the desorption period. Projection of this linear portion to intersect the cumulative gas axis will provide an estimate of the residual gas volume. Figure 3-5 shows a typical residual gas estimation by regression where the estimated lost gas is $7.3 \mathrm{scf} /$ ton.

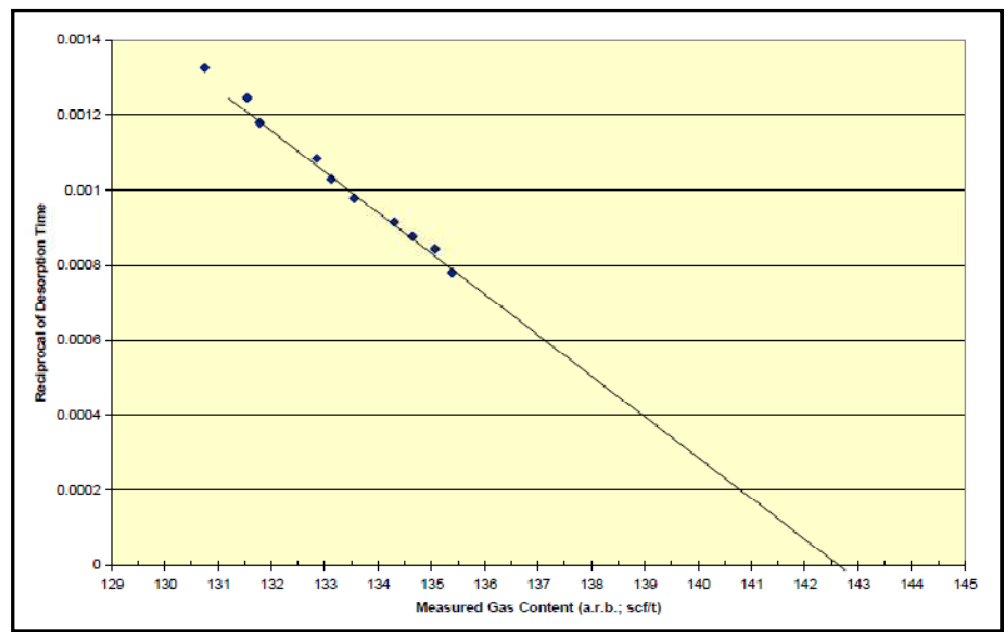

Figure 3-5: Typical Residual Gas Estimation by Regression ( 7.3scf/ton) 
Next, initial gas content is estimated by using Equation 2 .

$$
G c i=\text { Lost Gas }+ \text { Desorbed Gas + Residual Gas ........ Equation } 2
$$

Then, desorption time will be estimated by calculating the time the sample has desorbed $63.2 \%$ of its initial gas content.

\section{Production Data Analysis}

During this stage, volumetric calculations are performed in order to estimate the reserves in each coal. Equation 3 is used to estimate Original Gas-In-Place (OGIP) in a per coal basis.

$$
O G I P=21.78(G c . h . A . \rho c) \ldots . . . \text { Equation } 3
$$

Where;

$\mathrm{Gc}=$ average gas content, $\mathrm{scf} / \mathrm{ton}$

$\mathrm{H}=$ average thickness, $\mathrm{ft}$

$\mathrm{A}=$ area, acre

$\rho_{\mathrm{c}}=$ average density of coal, $\mathrm{lb} / \mathrm{ft}^{3}$

$21.78=$ conversion factor (acre to $\mathrm{ft}^{2}$ and $\mathrm{lb}$ to tons)

Then, a bubble map of total gas production for each coal is done in order to see how the total production varies from one well to another. The production rates from the wells in each coal are compared in order to evaluate their behavior and flow performance similarities. To have a better understanding of the flow performance of each well, all the available production data is compiled and normalized based on the following criteria:

- Case 1: Contact Length

- Case 2: Thickness

- Case 3: Gas Content 
Case 1: The normalization of the production data for Pittsburgh and Upper Freeport is done based on how much the well is in contact with coal (for this case it is assumed that the well is in contact with the coal at all times). Using this approach, the total amount of gas produced from a particular well is divided by its total length, resulting in the amount of gas produced by each foot of well length (scf/ft).

Case 2: The normalization of the production data for Pittsburgh and Upper Freeport is done based on the thickness. The average thickness around each well or leg is estimated first, then the total amount of gas produced from each particular well is divided by the average thickness around the well, resulting in the amount of gas produced by each foot of thickness $(\mathrm{scf} / \mathrm{ft})$

Case 3: Based on the gas content distribution and isopach maps generated in the reservoir characteristics stage, each coal is divided in two zones (see figure 3-6) Average gas content values, average coal density, and area for each zone is estimated. as well as the average thickness around each well. Using equation 4, the amount of coal in tons is estimated for each zone. Next, using equation 5, each daily rate is treated as a daily cumulative and divided by the total tons, resulting in the amount of produced gas per ton of coal(scf/ton). Then these values are divided by the average gas content for each zone.

$$
\begin{aligned}
& W=0.0005\left(h . \rho_{c} . A\right) \ldots \ldots \ldots \ldots \ldots \ldots . . \text { Equation } 4 \\
& G c^{\prime}=\frac{q^{\prime}}{W} \ldots \ldots \ldots \ldots \ldots \ldots \ldots \ldots \ldots \ldots \ldots \text { Equation } 5 \\
& \text { Normalized Production }=\frac{G c^{\prime}}{\overline{G c}} \ldots \ldots \ldots \text { Equation } 6
\end{aligned}
$$

Where;

$h=$ Average thickness around each well, $\mathrm{ft}$

$\rho_{c}=$ Average density of the coal in each zone, $\mathrm{lb} / \mathrm{ft}^{3}$

$A=$ Area for each zone, $\mathrm{ft}^{2}$

$W=$ amount of coal in each zone, tons

$q^{\prime}=$ cumulative gas production for each day, scf

$G c^{\prime}=$ produced gas per ton of coal, scf/ton

$\overline{G c}=$ Average gas content for each zone, scf/ton (based on gas content distribution)

Normalized Production $=$ fraction 


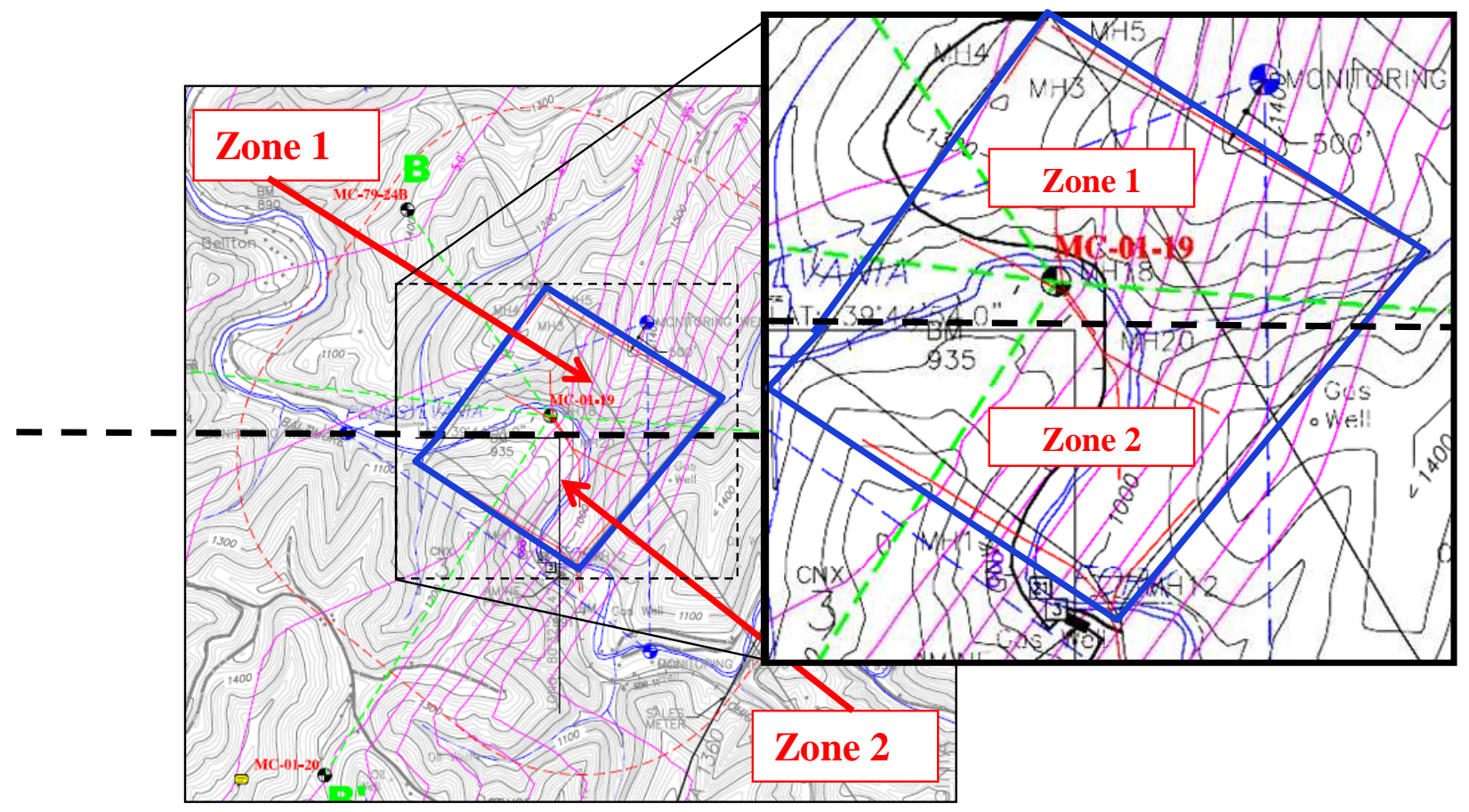

Figure 3-6: Location and Distribution Zones of the Project

\section{Reservoir Modeling}

This section is divided into two stages; building the model and history matching process. In order to build the model, two different software are used (FLOGRID-ECLIPSE and BUILDER-CMG). FLOGRID is an ECLIPSE suite software developed by Schlumberger and is used for building static models and dynamic conditions for reservoir models. FLOGRID is used to develop the geological (static) model for both coals by using the information from geologist logs and cross sections. Table 3-3 shows the data used to build the static model. A grid system for each formation is then imposed over the static model. Once the geological model is built, it is imported into BUILDER-CMG, which is software that helps the user prepare input data to be simulated in GEM and other reservoir simulators. BUILDER-CMG presents an easy-to-use visual interfaces as well as support for direct editing of the data set information. The next step is the initialization of the model. To initialize the reservoir model, all reservoir parameters from actual data provided by CONSOL and other sources are incorporated into the model. Since communication between the two coal seams and the producing wells do not exist, each coal 
model is built separately in order to reduce computation time for the simulator. The reservoir input data for the simulator is displayed in Table 3-3. Also Figures 3-7 and 3-8 show the relative permeability curves used for Pittsburgh and Upper Freeport coals respectively. After all the necessary parameters are put into the simulator, the base case models are run using GEM-CMG, which is a multi-component, multi-phase reservoir simulator used to model coal bed methane reservoirs. It incorporates dual porosity, diffusion time, adsorption and desorption of gas, and coal matrix shrinkage and swelling effects. The base case model predictions are compared to the actual production data from the field to eventually start the history matching process. 
Table 3-3: Rock Properties

\begin{tabular}{|c|c|c|c|}
\hline \multicolumn{4}{|c|}{ BASE CASE MODEL PARAMETERS } \\
\hline Group Parameters & Input Parameter & Pittsburgh & Upper Freeport \\
\hline \multirow{12}{*}{ Grid System and Properties } & Cartesian Grid Sytem & $100 \times 100$ cells & $100 \times 100$ cells \\
\hline & Grid's Size & $81 \times 81 \mathrm{ft}$ & $81 \times 81 \mathrm{ft}$ \\
\hline & Reservoir Area & 1520 acres & 1520 acres \\
\hline & Grid Top & Static Model & Static Model \\
\hline & Grid Thickness & Static Model & Static Model \\
\hline & Matrix Porosity & $1 \%$ & $1 \%$ \\
\hline & Fracture Porosity & $1 \%$ & $1 \%$ \\
\hline & Matrix Permeability kx=ky & $1 \mathrm{md}$ & $1 \mathrm{md}$ \\
\hline & Matrix Permeability kz=0.1kx & $0.1 \mathrm{md}$ & $0.1 \mathrm{md}$ \\
\hline & Fracture Permeability kx=ky & $10 \mathrm{md}$ & $10 \mathrm{md}$ \\
\hline & Fracture Permeability $\mathrm{kz}=0.1 \mathrm{kx}$ & $1 \mathrm{md}$ & $1 \mathrm{md}$ \\
\hline & Fracture Spacing & $0.2 \mathrm{ft}$ & $0.2 \mathrm{ft}$ \\
\hline \multirow{5}{*}{ Rock - Palmer \& Mansoori Parameters } & Rock Compressibility & $1 e-51 / p s i$ & $1 e-51 / p s i$ \\
\hline & Coal Density & $89 \mathrm{lb} / \mathrm{ft}^{\wedge} 3$ & $86 \mathrm{lb} / \mathrm{ft}^{\wedge} 3$ \\
\hline & Poisson Ratio & 0.35 & 0.35 \\
\hline & Young's Modulus & 250,000 & 250,000 \\
\hline & Strain at Infinite pressure & 0.0045 & 0.0045 \\
\hline \multirow{2}{*}{ Components } & Methane & $\mathrm{CH} 4$ & $\mathrm{CH} 4$ \\
\hline & Carbon Dioxide & $\mathrm{CO} 2$ & $\mathrm{CO} 2$ \\
\hline \multirow{4}{*}{ Initial Conditions } & Pressure gradient for Initial Reservoir Pressure & $0.41 \mathrm{psi} / \mathrm{ft}$ & $0.41 \mathrm{psi} / \mathrm{ft}$ \\
\hline & Reservoir Temperature & $68 \mathrm{~F}$ & $68 \mathrm{~F}$ \\
\hline & Water-Gas Contact & $726 \mathrm{ft}$ & $1317 \mathrm{ft}$ \\
\hline & Water Saturation below Water-Gas contact & $100 \%$ & $30 \%$ \\
\hline \multirow{9}{*}{ Unconventional Reservoir Parameters } & CH4 Global Composition & $100 \%$ & $100 \%$ \\
\hline & CO2 Global Composition & $0 \%$ & $0 \%$ \\
\hline & $\mathrm{CH} 4$ Langmuir Volume & $544.6 \mathrm{scf} / \mathrm{ton}$ & 554.7 scf/ton \\
\hline & $\mathrm{CH} 4$ Langmuir Pressure & 452 psi & $350.85 \mathrm{psi}$ \\
\hline & $\mathrm{CH} 4$ Initial Gas Content & 136 scf/ton & 176 scf/ton \\
\hline & CO2 Langmuir Volume & $987.3 \mathrm{scf} / \mathrm{ton}$ & 987.3 scf/ton \\
\hline & CO2 Langmuir Pressure & $239.9 \mathrm{psi}$ & $239.9 \mathrm{psi}$ \\
\hline & CO2 Initial Gas Content & unknown & unknown \\
\hline & Sorption Time & 100 days & 3 days \\
\hline Constrains & Minimum Bottom-hole Pressure & $28 \mathrm{psi}$ & $28 \mathrm{psi}$ \\
\hline
\end{tabular}




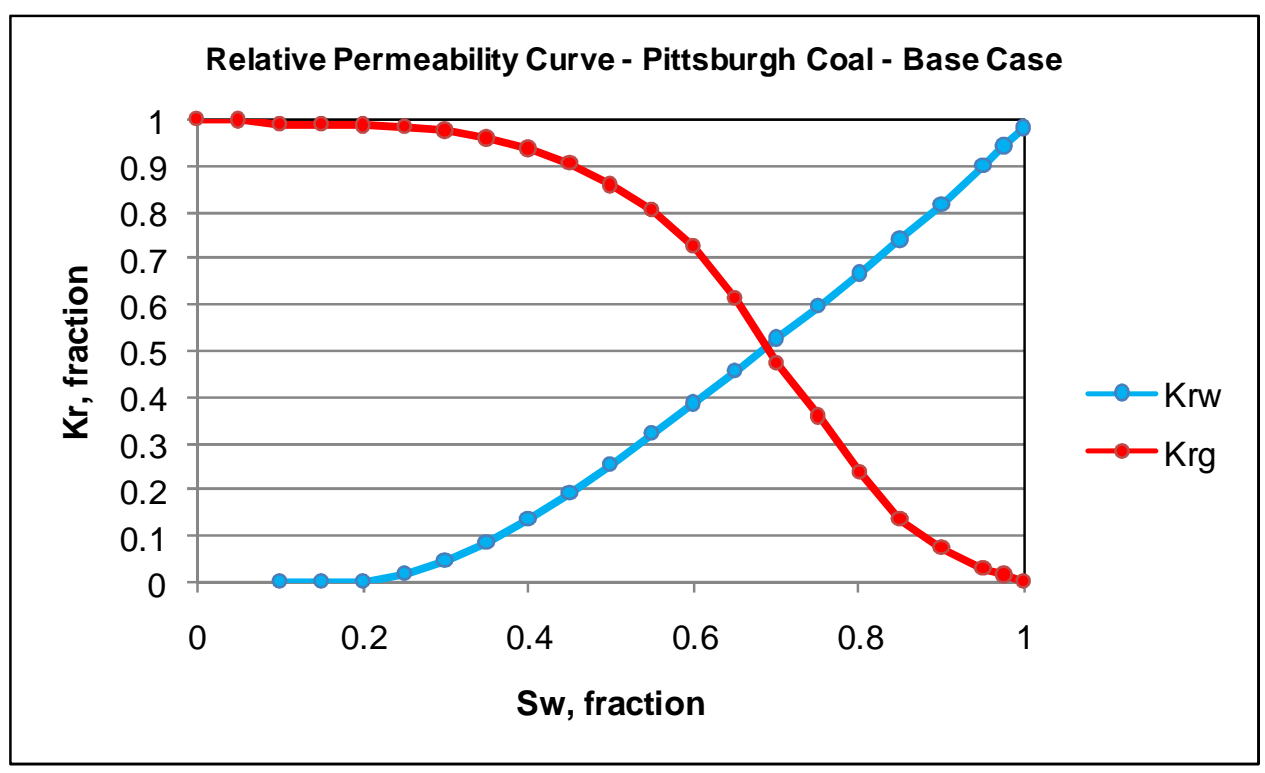

Figure 3-7: Relative Permeability for Pittsburgh Coal

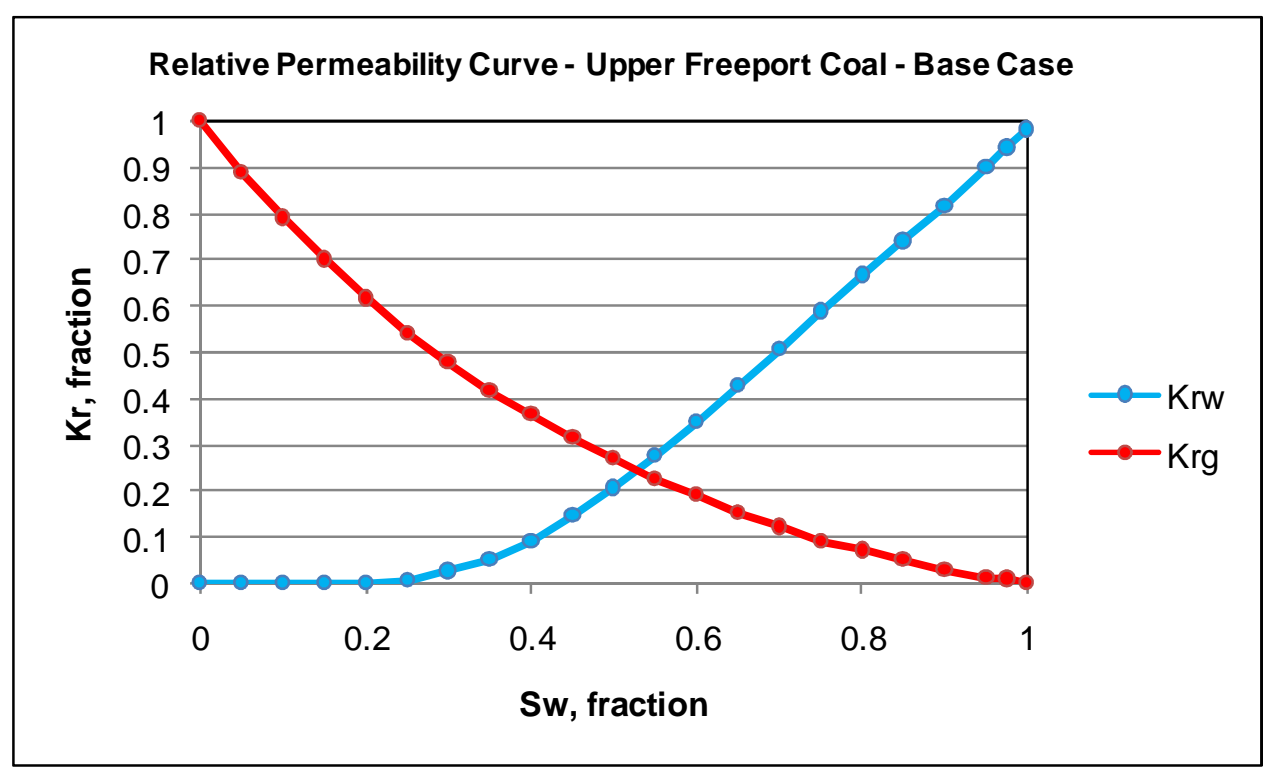

Figure 3-8: Relative Permeability for Upper Freeport Coal 


\section{History Matching Process}

The history matching process has been subdivided into three phases: history matching phase one, phase two and phase three.

\section{History Matching Phase I}

The goal of this phase is to understand the effects of each parameter on the reservoir behavior and production and to history match the production of the field in a homogenous system. In order to achieve this objective, sensitivity analyses are made for each parameter, and adjustments are made to achieve history matching in each coal.

In order to accurately history match the field, gas and water production is matched by approaching the reservoir behavior in a homogeneous system from two different perspectives. To evaluate their effect on the reservoir behavior, the reservoir parameters and settings have been divided into two groups: conventional and unconventional parameters. The conventional group contemplates reservoir parameters associated with conventional reservoirs, such as permeability $(\mathrm{k})$, porosity $(\phi)$, water-gas contact (WGC), relative permeability (kr), etc. The unconventional group associates specific parameters related to Coalbed Methane reservoir, such as gas content $(\mathrm{Gc})$, desorption time $(\tau)$, Langmuir Volume $\left(\mathrm{V}_{\mathrm{L}}\right)$ and Langmuir Pressure $\left(\mathrm{P}_{\mathrm{L}}\right)$.

Key parameters to achieve history matching are taken into consideration based on their effects on the storage and deliverability of gas and water. For conventional parameters, two key parameters needed to achieve a suitable history match for a CBM reservoir are cleat permeability and cleat porosity. Permeability is one of the most important parameters for coal bed methane production. The changes in the cleat permeability are considered to be primarily controlled by the prevailing horizontal stresses. Permeability has a direct relationship with flow rates and was the first parameter considered in order to achieve viable gas and water production matches. Since it is assumed that the cleats are initially $100 \%$ saturated with water and methane is adsorbed in the matrix of the coal, cleat porosity represents the initial water storage in the system, which is why this parameter is considered to play an important role in achieving water production matches. Also, for unconventional parameters, desorption time and gas content have been 
selected as key parameters for playing an important role in the production behavior. Desorption time represents the capacity for coal to desorb gas from the matrix and gas content represents the amount of gas on a per ton basis that is stored in the coal. Once the key parameters have been identified, a sensitivity analysis of gas and water production is performed by changing cleat permeability and cleat porosity, and by changing desorption time and gas content. Based on the results of the sensitivity analysis, gas and water production from the wells are matched (if possible). If no match is achieved for the field, the actual production data from the wells will be screened in order to continue to the next stage of the history matching process.

\section{History Matching Phase II}

The objective of this phase is to understand the effects of each parameter of the reservoir behavior and production, and to history match the production of the field by setting at least two reservoir homogeneous regions and keeping previous matches from history matching phase I. In this phase, a third type of parameter, wellbore parameter, is incorporated in order to detect possible mechanical problems generated during the drilling process and completion of the wells. The wellbore parameters used for this study are skin factor, bottom-hole pressure, and well length. In order to achieve this objective, sensitivity analyses are made for each parameter, and adjustments are made for each region in order to achieve history matching for each coal. Figure 3-9 shows an example of how the regions are set in Pittsburgh coal.

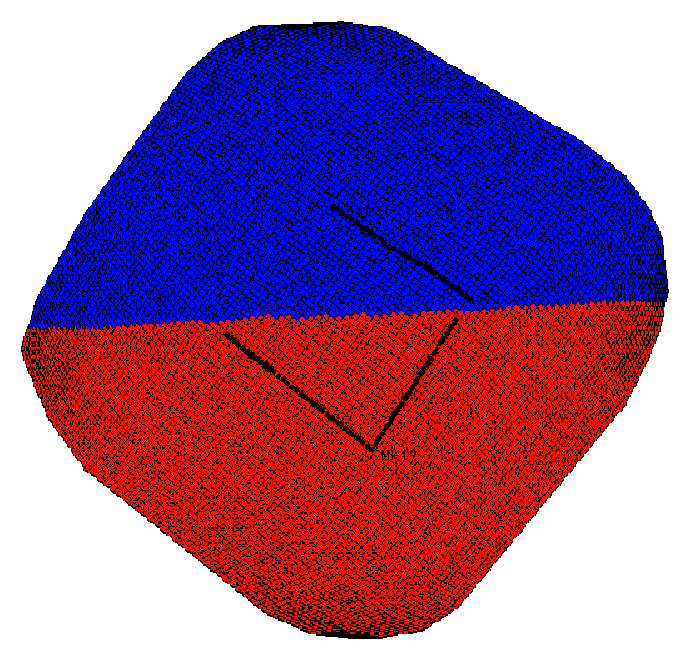

Figure 3-9: Aerial Distribution Zone for History Match Phase II Pittsburgh coal 
Conventional parameters:

Two approaches are developed in this stage. Utilizing the first approach, at least two regions are set within the formation using different permeability and porosity values while keeping previous well matches from history matching phase I. Next, a sensitivity analysis is performed and parameters in each region are adjusted until a history match is achieved for each formation. The second approach is done by setting different permeability curves and water-gas contact depth for each region in order evaluate their contribution to matches while changing permeability and porosity values.

Unconventional Parameters:

At least two regions are set within each formation with different desorption time, gas content, and Langmuir parameter values while keeping previous well matches from history matching phase I. A sensitivity analysis is performed, and parameters in each region are adjusted until a history match is achieved for each formation.

Wellbore Parameters:

At least two regions are set within each formation. Different values for skin factor and minimum bottom-hole pressure are used for the different regions, also the lengths of the wells are changed. A sensitivity analysis is performed, and parameters in each region are adjusted until a history match is achieved for each formation.

\section{Anisotropy Permeability Studies:}

CBM reservoirs have the potential for permeability anisotropy because of their naturally fractured nature, which may complicate production data analysis. To study the effects of permeability anisotropy upon production, a study is conducted assuming various permeabilityanisotropy ratios. Only large permeability ratios (>16:1) appear to have a significant effect upon single-well production characteristics. 


\section{History Matching Phase III}

The objective realistically history match the field by setting a combination of all the parameters as needed while taking into account the uncertainties associated with them. In this phase, an analysis is performed to evaluate which parameters have the most impact in the production.

In the phase II, results of the sensitivity analysis performed for each parameter are obtained. Now the goal is to compare the influence of the parameter in the production of the wells. At the end it will be given an estimation of the impact of each parameter on the production. This process is a standardization of sensitivity analysis by ranking the parameters based on their influence in the production.

The method consists of selecting three different time points $\mathrm{t} 1, \mathrm{t} 2$, and $\mathrm{t} 3$ in the sensitivity analysis of gas production vs. time for which period a well has produced. The three points are selected, one at the early ( $\mathrm{t} 1)$, one during the middle ( $\mathrm{t} 2)$, and the last one in a later time period (t3) (See Figure 3-10). Then by taking the values of gas rate production at each time, for all the parameter cases in the sensitivity analysis, those values are plotted against the parameter value, in which the production value was founded. The new graph, gas rate production (y-axis) vs. parameter values (x-axis), will have three production values for the same parameter value. The three production values corresponding to $\mathrm{t} 1, \mathrm{t} 2$, and $\mathrm{t} 3$.

Figure 3-10 describes how the points on the production plot are picked on each parameter sensitivity-production for times $\mathbf{t}_{\mathbf{1}}, \mathbf{t}_{\mathbf{2}}$ and $\mathbf{t}_{\mathbf{3}}$. The head of the arrows indicates the selected points at time $\mathrm{t} 1, \mathrm{t} 2$ and $\mathrm{t} 3$. The number of points (head of arrows) in each time $\mathbf{t}$ depends on how many parameters were tested in the sensitivity analysis cases. $\mathrm{q}_{\mathrm{j}}$ indicates Gas Rate on each parameter function. For example in this case for each $\mathbf{t}_{1}, \mathbf{t}_{\mathbf{2}}$ and $\mathbf{t}_{\mathbf{3}}$ there will be 5 different Gas Rate values because, there were 5 cases tested in the sensitivity analysis. 


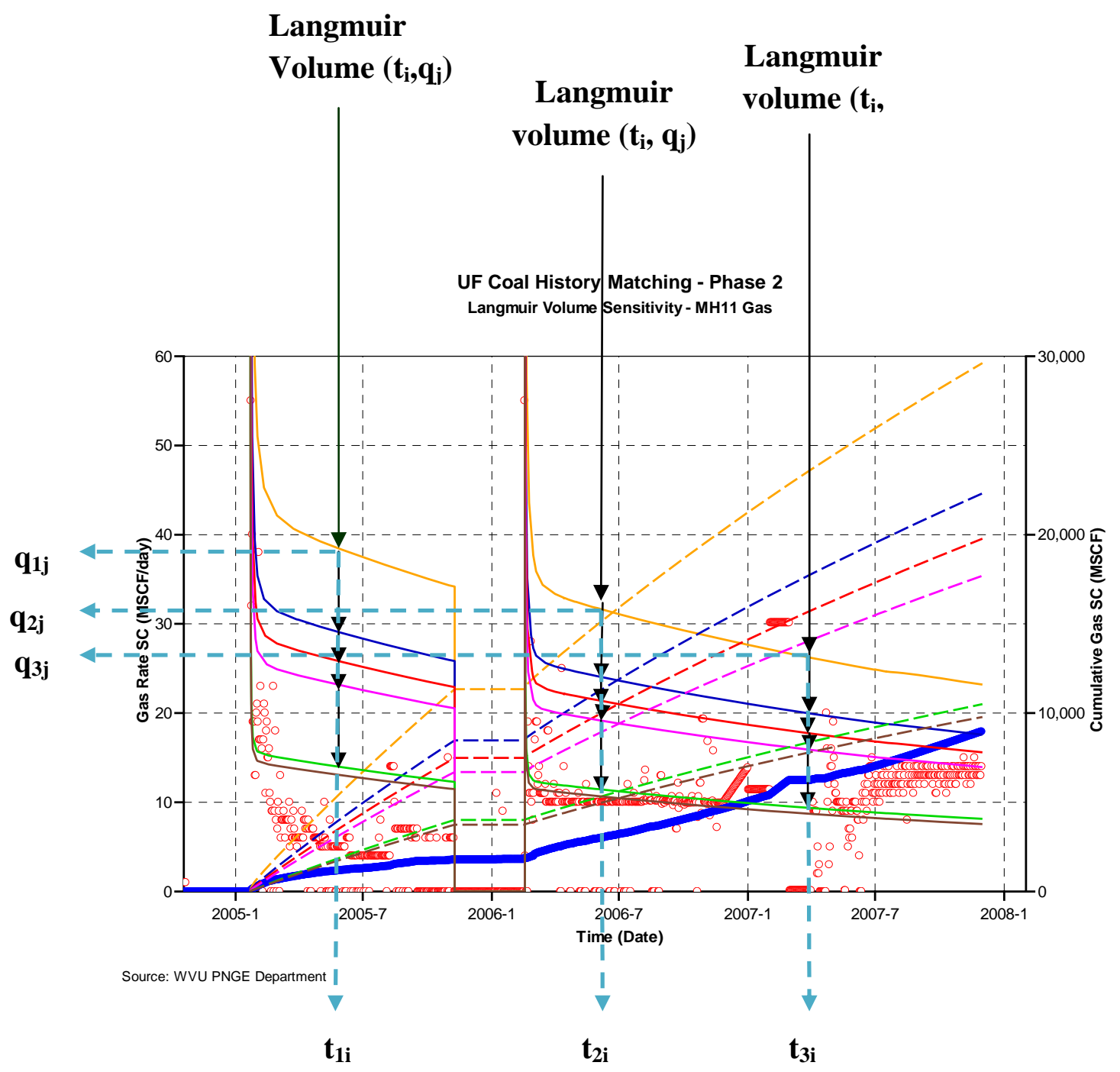

Figure 3-10: Sensitivity Analysis used in history Matching Phase III

In order to compare and establish the influence of each parameter in the production, levels of rank, high, medium or low, are assigned based on the absolute slope values calculated from trend lines for each well. The trend line is used to the get the slope or rate. Therefore the slope will tell the tendency of production indicating whether it is increasing or decreasing and also their influence in other wells. Another interpretation, going backwards is, based on the slope; it tells how the parameter should be adjusted up or down to increase or decrease production. 
Figure 3-11 shows an example of how the points previously picked are arranged to form a plot of Gas Rate MSCF/Day vs Parameter for one well. This procedure is done for all wells in which the same parameter is being evaluated.

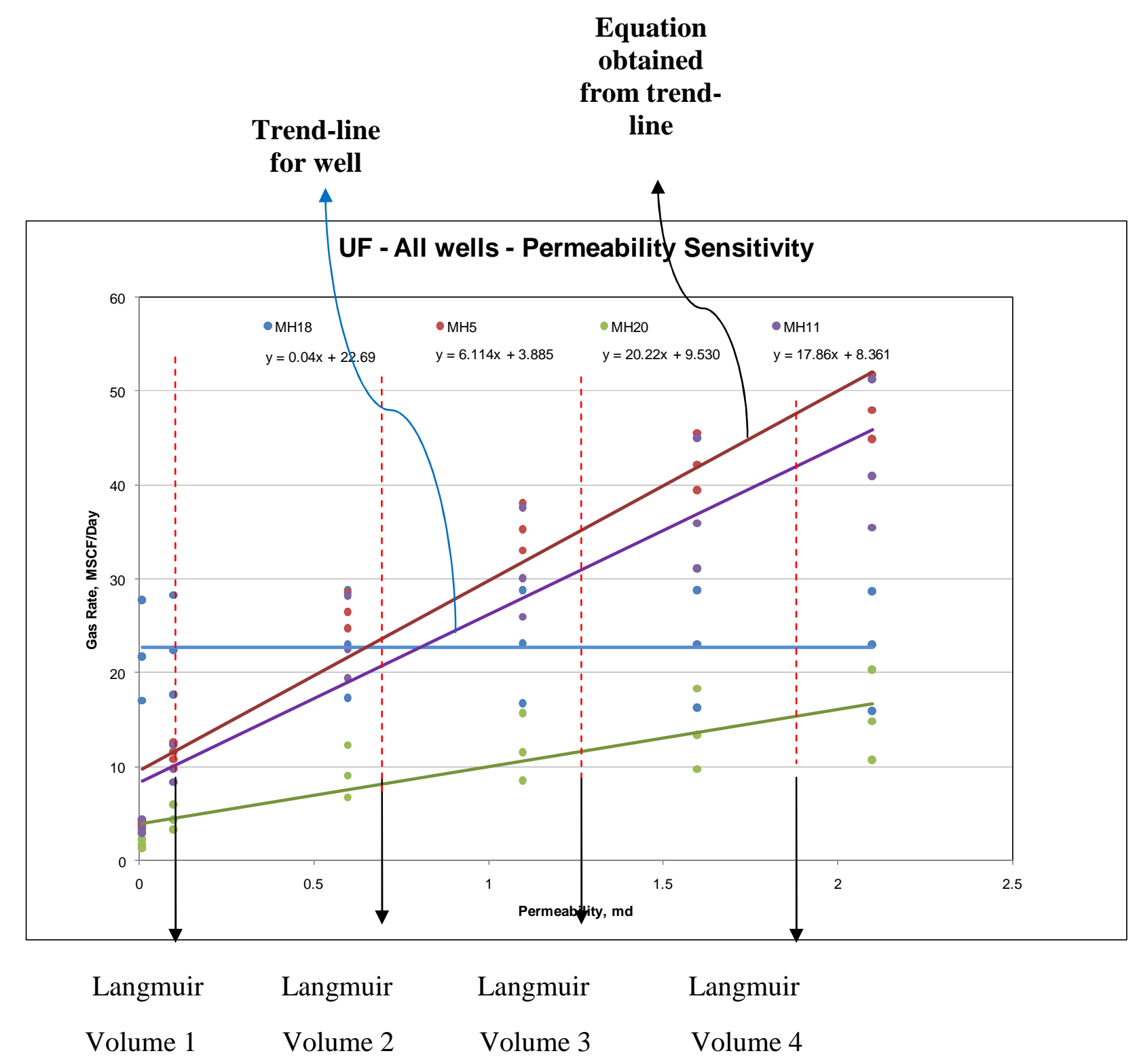

Figure 3-11: Comparison of trend-lines slopes for History Matching Phase III 
Steps to accomplish the methodology above:

1. Having the sensitivity results from HMPH2 for all the cases of the parameter were evaluated, select times $\boldsymbol{t}_{1}, \boldsymbol{t}_{2}$ and $\boldsymbol{t}_{3}$ as the beginning, middle and late time periods respectively as it is showing figure 3-10.

2. Trace a vertical line on each time $t_{n}$ so that it crosses every line of the function for the sensitivity case of the parameter.

3. Trace a Horizontal line from the point where the vertical line is crossing the sensitivity case and bring it to the axis of production $\boldsymbol{q}$. For every $\boldsymbol{t}_{\mathbf{n}}$ there will be as many $\boldsymbol{q}$ as parameter cases are in plot for sensitivity.

4. Arrange a table where data can be stored. The table should look like this:

Table 3-4: Arrangement of values for History Matching Phase III

\begin{tabular}{|c|c|c|c|c|}
\hline \multirow{2}{*}{$\begin{array}{c}\text { Parameter, } \\
\text { units }\end{array}$} & \multirow{2}{*}{$\begin{array}{c}\text { Representation } \\
\text { indicator }\end{array}$} & $\mathbf{t 1}$ & $\mathbf{t 2}$ & $\mathbf{t 3}$ \\
\cline { 3 - 5 } & Date & Date & Date \\
\hline Value & $\begin{array}{c}\text { Gas rate MSCF/day } \\
\text { or Gas Cumulative }\end{array}$ & Value of q & Value of q & Value of q \\
\hline
\end{tabular}

The table above is repeated for each well sensitivity plot.

5. Plot Gas Rate MSCF/Day vs Parameter value. For every parameter there must be $3 \boldsymbol{q}$ rate points plotted.

6. Repeat last 5 steps for every well of the same coal layer, and plot them in the same graph.

7. At each set of points of the same well, make a trend line and get the slope. Repeat this for each well individually in the same graph.

8. Set a table where number of well, absolute slope, normalized slope and sensitivity are stored. The table should look like this:

Table 3-5: Stored Slope Values for comparison in history Matching Phase III

\begin{tabular}{|c|c|c|c|}
\hline Well & $\begin{array}{c}\text { Absolute } \\
\text { Slope }\end{array}$ & $\begin{array}{c}\text { Normalized } \\
\text { Slope }\end{array}$ & Sensitivity \\
\hline \#well & Absolute Slope & $\begin{array}{c}\text { Percentage of } \\
\text { slope }\end{array}$ & $\begin{array}{c}\text { High, Medium or } \\
\text { Low }\end{array}$ \\
\hline
\end{tabular}

9. Through the previous table obtained in step 8, each parameter is evaluated at the well level. 


\section{Chapter 4 RESULTS}

\section{Data analysis}

This process is subdivided in three stages; Geology characterization, reservoir characterization, and production data analysis.

\section{Geology characterization}

Using the tops and thickness information in the geologist logs from the core samples: MC-79-22, MC-01-19, CN-G8-009, MC-79-24B, and MC-01-20; lateral cross sections graphs of the formation along the line of the cross sections AA' and BB' are built. Figure 4-1 shows how the actual cross sections are configured, Table 4-1 show the thicknesses and top elevation to each coal values from the core samples above, and Figure 4-2 shows the lateral cross sections views that describe how the coals are dipping in the different directions.

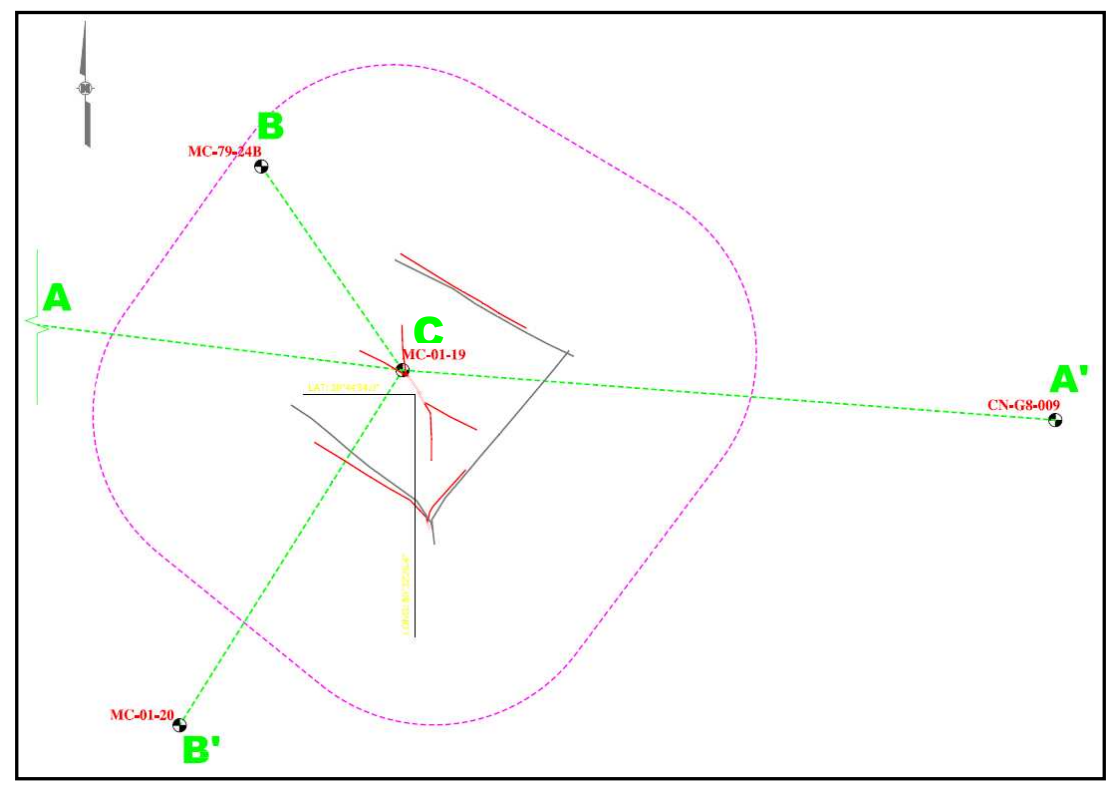

Figure 4-1: Cross Section Map from core samples 
Table 4-1: Top to Sea Level and Thickness measurement

\begin{tabular}{|c|c|c|c|}
\hline \multicolumn{4}{|c|}{ Pittsburgh Coal } \\
\hline Cross Section & Core Sample & Top to Sea Level, $\mathrm{ft}$ & Thickness, $\mathrm{ft}$ \\
\hline A $^{\prime}$ & MC-79-22 & 334.4 & 6.05 \\
C & MC-01-19 & 273.8 & 6.72 \\
A $^{\prime}$ & CN-G8-009 & 172.1 & 6.70 \\
B & MC-79-24-B & 264.8 & 6.34 \\
B' $^{\mid}$ & MC-01-20 & 245.6 & 6.15 \\
\hline \multicolumn{4}{|c|}{ Upper Freeport Coal } \\
\hline Cross Section & Core Sample & Top to Sea Level, $\mathrm{ft}$ & Thickness, $\mathrm{ft}$ \\
\hline A & MC-79-22 & -264.0 & 6.6 \\
C & MC-01-19 & -317.7 & 4.3 \\
A' & CN-G8-009 & -425.0 & 0.00 \\
B & MC-79-24-B & -327.9 & 5.1 \\
B' $^{\prime}$ & MC-01-20 & -364.2 & 3.5 \\
\hline
\end{tabular}

As it is shown in Figure 4-2, both coals are dipping down from west to east. Since Upper Freeport caol has zero thickness on the core sample CN-G8-009, the red line is shown dotted.

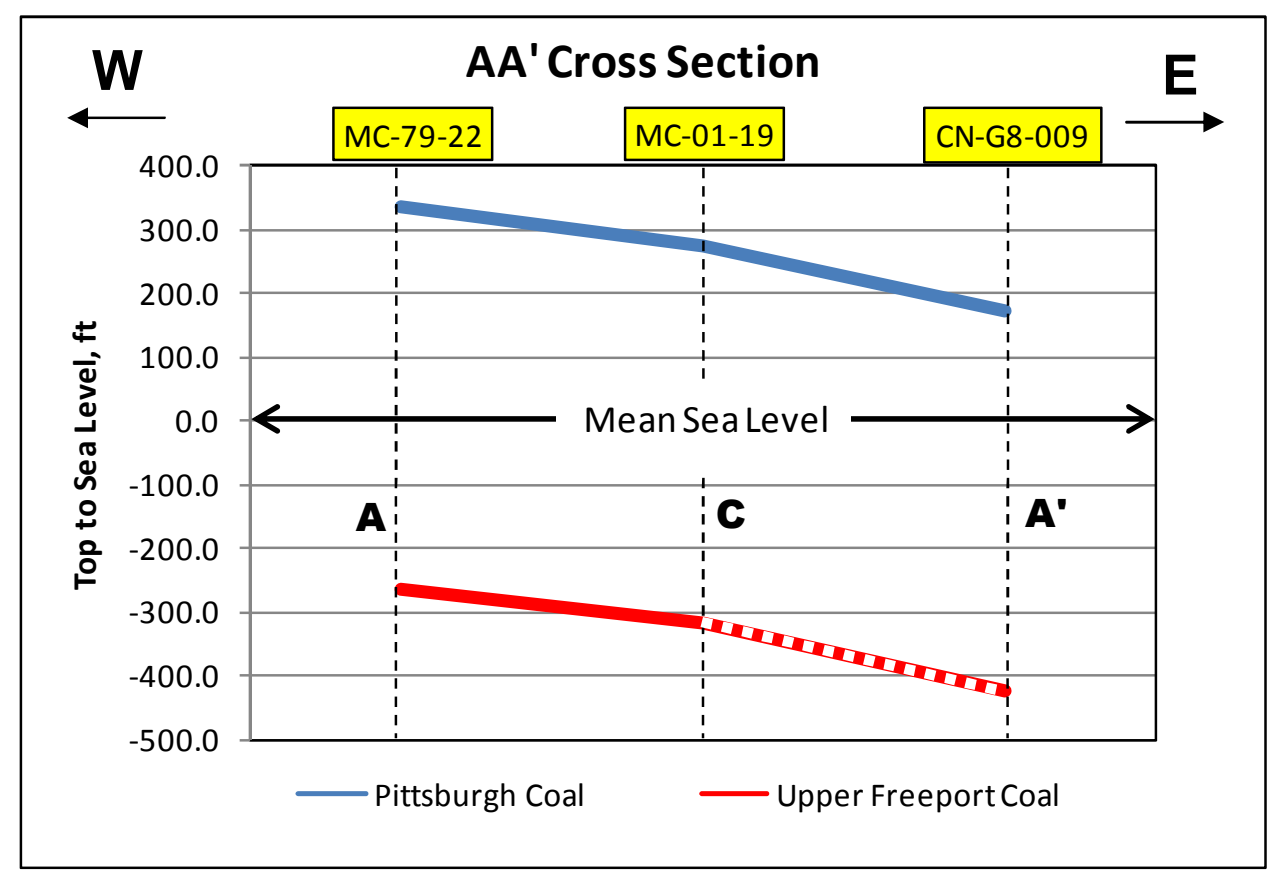

Figure 4-2: Top to Sea AA' Cross Section of PG and UF. 
Figure 4-3, shows how both coals are dipping down starting from the center of the field running south and in least proportion running north-west.

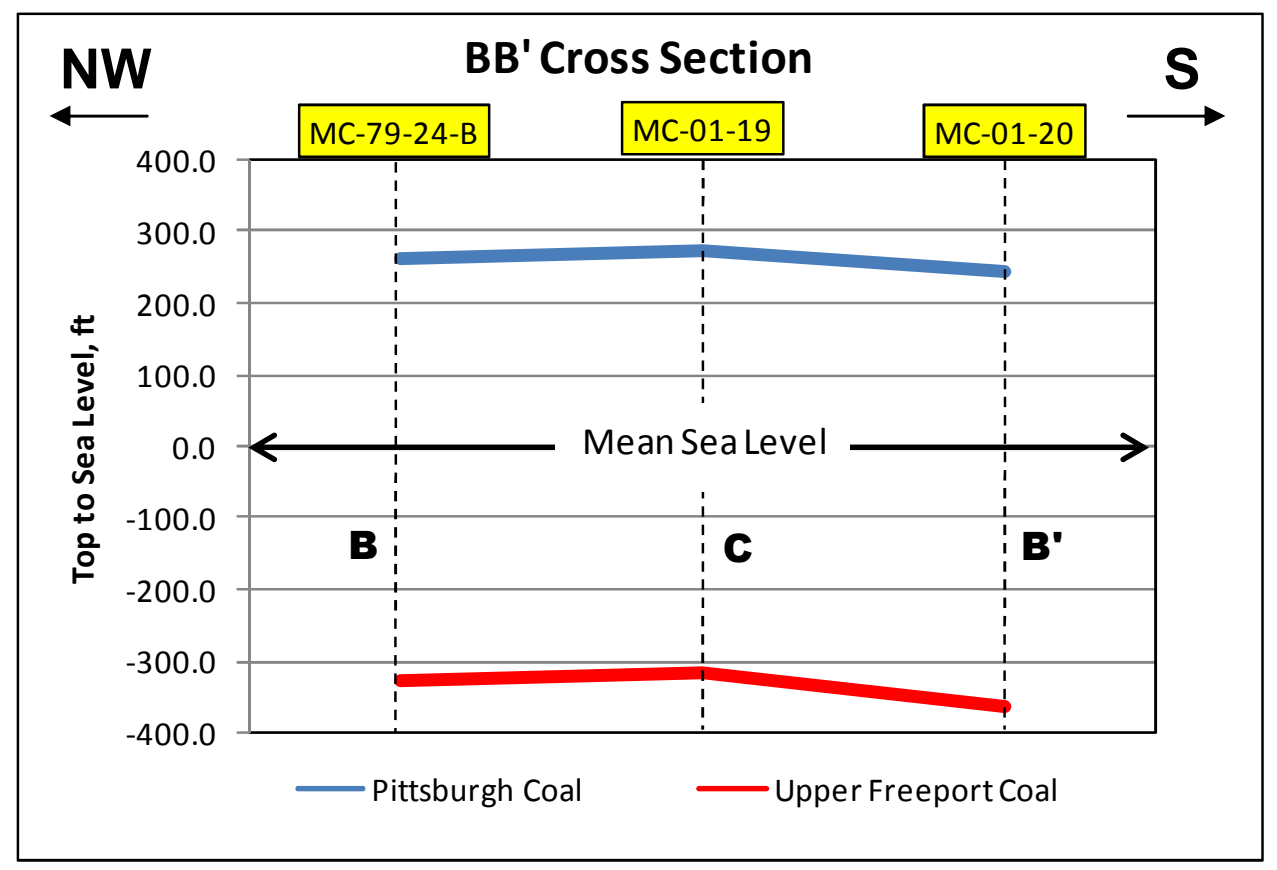

Figure 4-3:Top to Sea BB' Cross section of PG and UP

\section{Reservoir Characterization}

In order to understand how the different reservoir characteristics are distributed along the formations, isopach maps and gas content distribution for both coals are made by kriging the data using a map software generator called 3DFIELD. The data is from 27 wells in Pittsburgh coal and 7 from Upper Freeport. Figures 4-4 and 4-5 show the isopach and gas distribution maps generated for Pittsburgh coal, and Figures 4-6 and 4-7 show the isopach and gas distribution maps generated for Upper Freeport. 
As it is shown in Figures 4-5 and 4-6, the north part of the field shows thicker areas and higher gas content values.

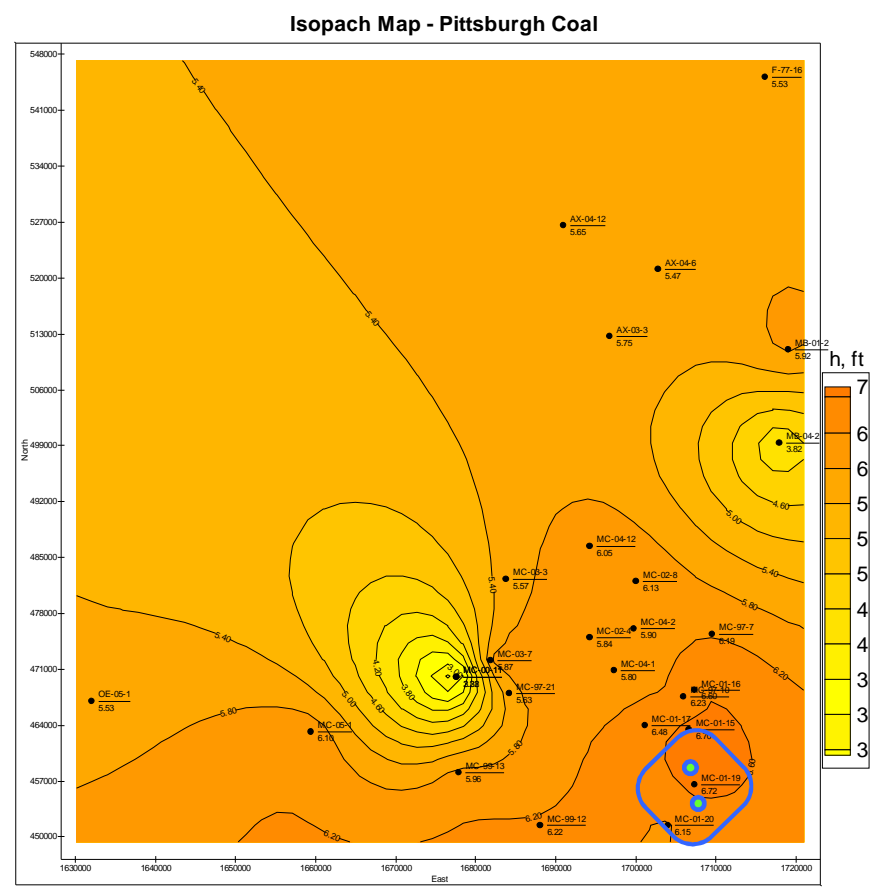

Figure 4-4: Isopach Map of PG Coal

Gas Content Distribution Map - Pittsburgh Coal

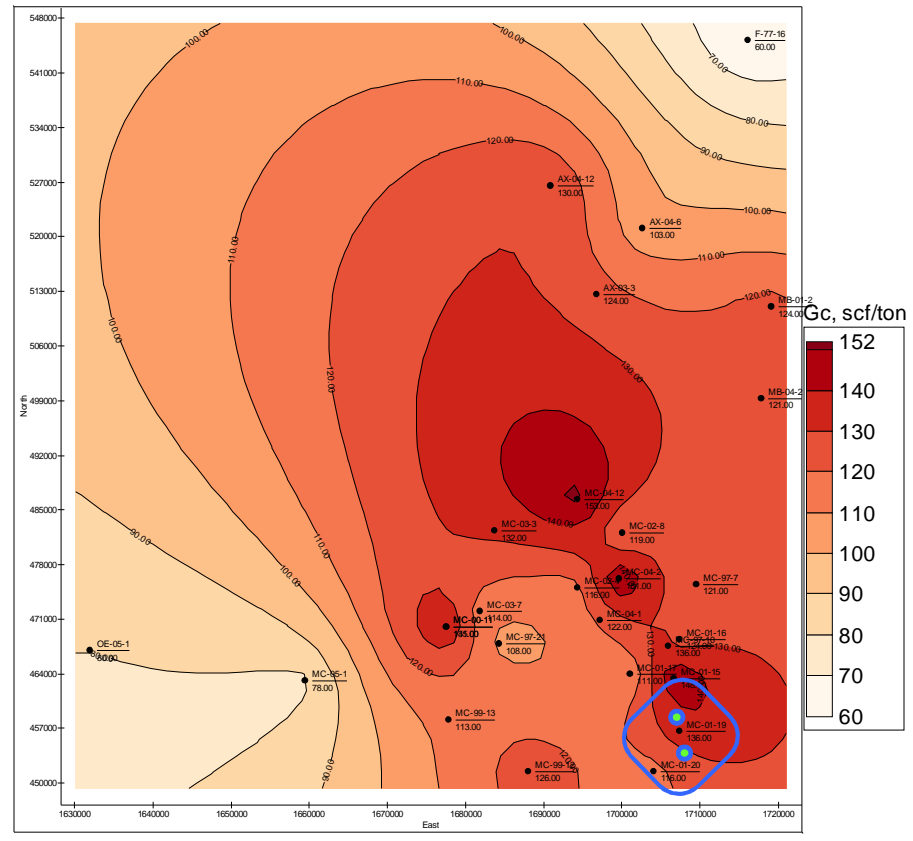

Figure 4-5: Gas Content Distribution of PG coal 
Also Figures 4-6 and 4-7, show thicker areas in the north part of the field and higher gas content values in the southern part.

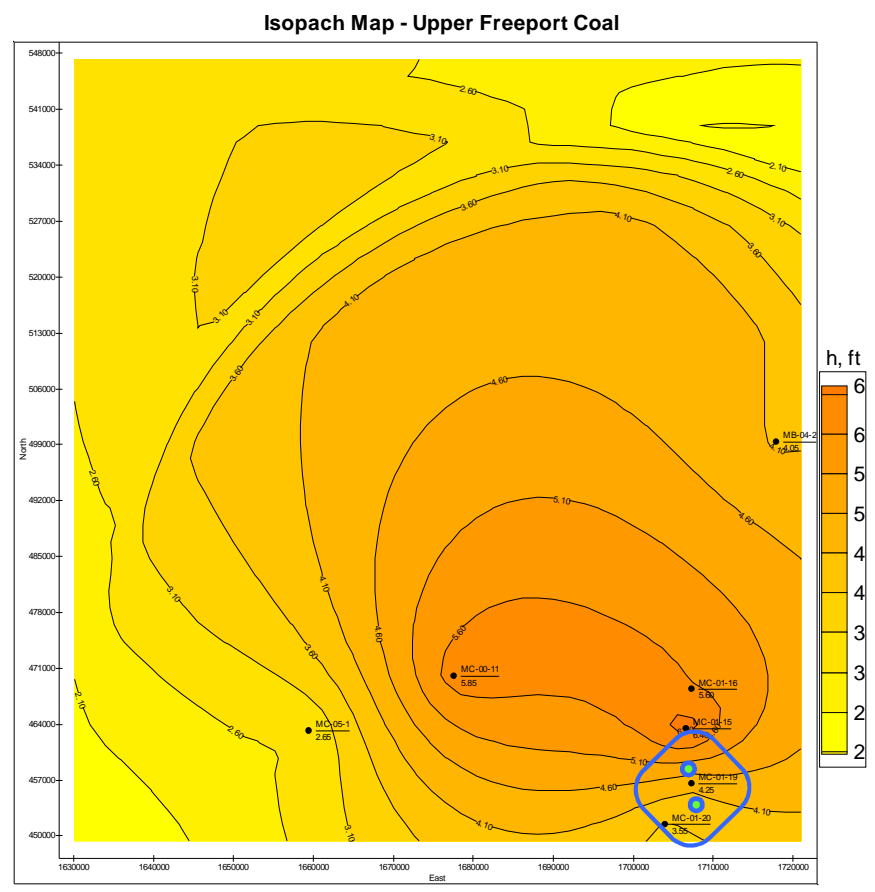

Figure 4-6: Issopach Map of UP

Gas Content Distribution Map - Upper Freeport Coal

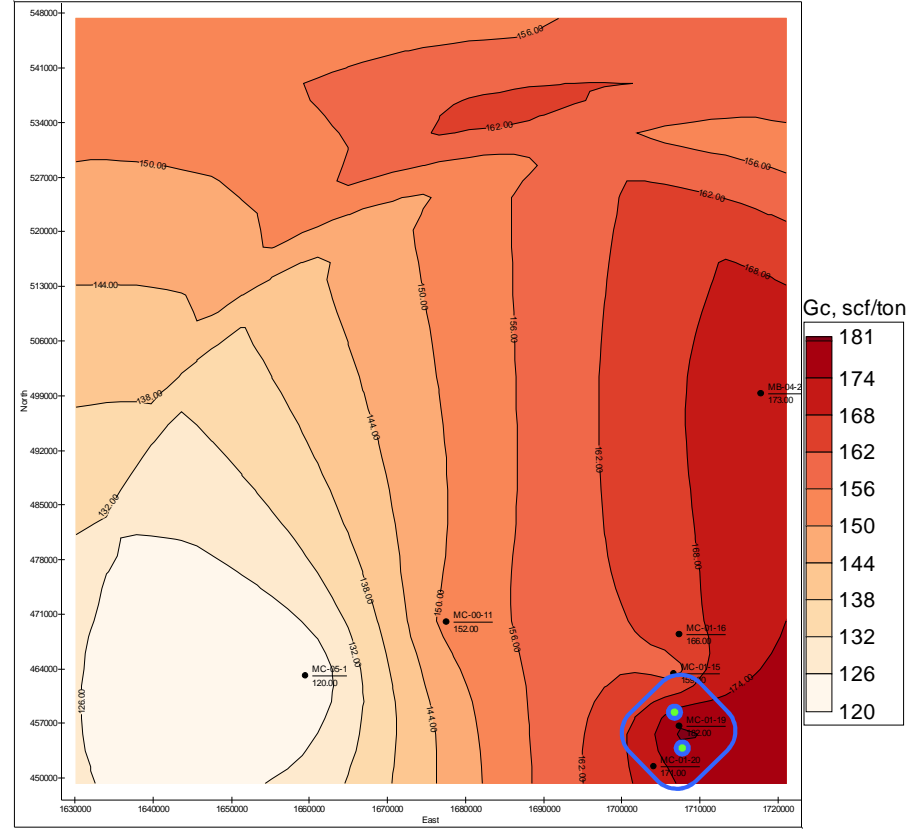

Figure 4-7: Gas Content Distribution Map of UF 
A Methane Langmuir Isotherm comparison is performed in both coals using the data from core samples located in the surroundings of the test area. The $\mathrm{CH} 4$ Langmuir isotherms used from Pittsburgh coal are MC-04-12 and MC-05-01 located about 5.6 miles and 8.4 miles respectively from the field. The ones used from Upper Freeport are SH-04-01 and MC-05-01 where the location of SH-04-01 in not available. Figure 4-8 shows the Isotherm comparison of the two samples from Pittsburgh coal. The results shows some variations between the isotherm profiles, however the maximum deviation is less than $40 \mathrm{scf} / \mathrm{ton}$ at 368 psi. Also Figure 4-10 shows the Isotherm comparison of two samples from Upper Freeport coal. The results show significant variations between the isotherm profiles. The deviation in the isotherm profiles is between $40 \mathrm{scf} /$ ton and $80 \mathrm{scf} / \mathrm{ton}$ at pressures between $150 \mathrm{psi}$ and $1700 \mathrm{psi}$.

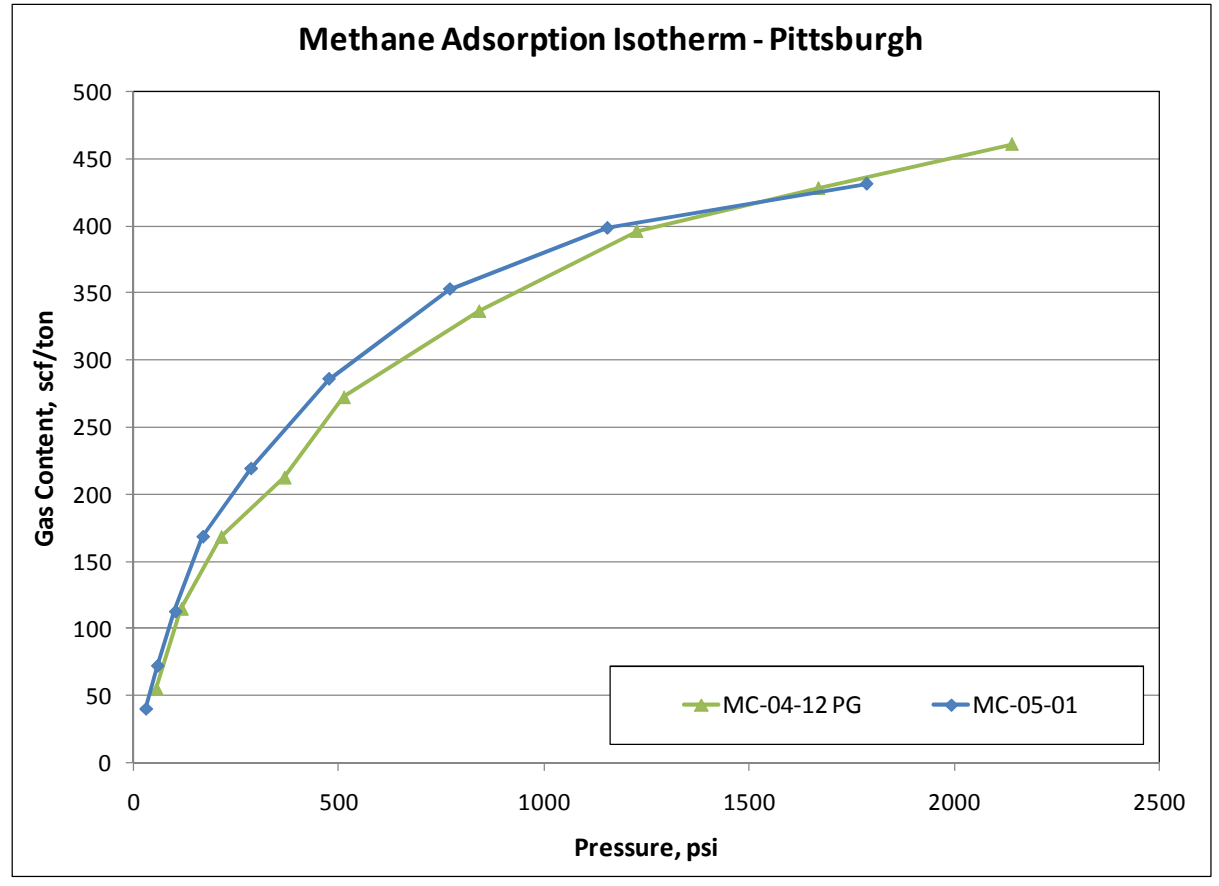

Figure 4-8: Methane Adsorption Isotherm of PG coal 


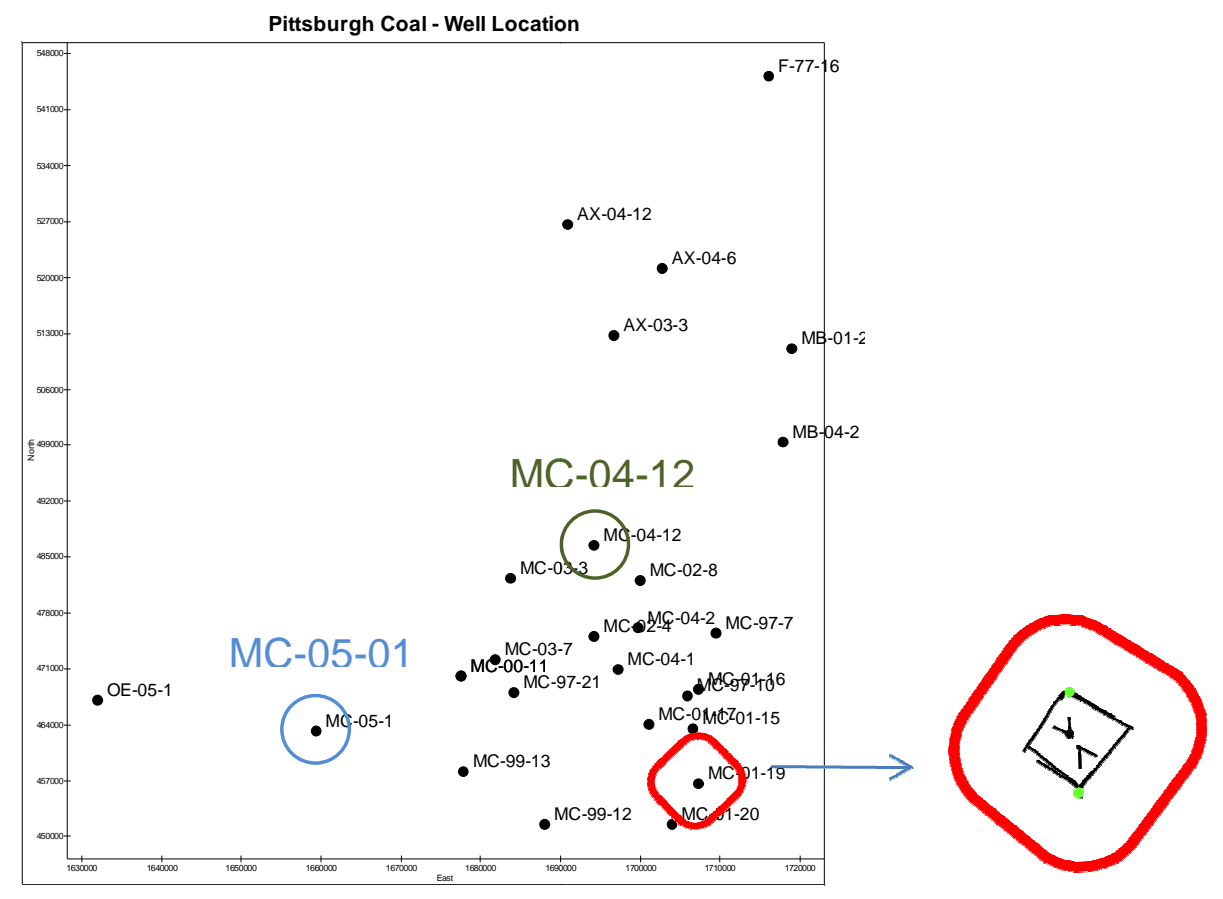

Figure 4-9: PG Coal Well Location

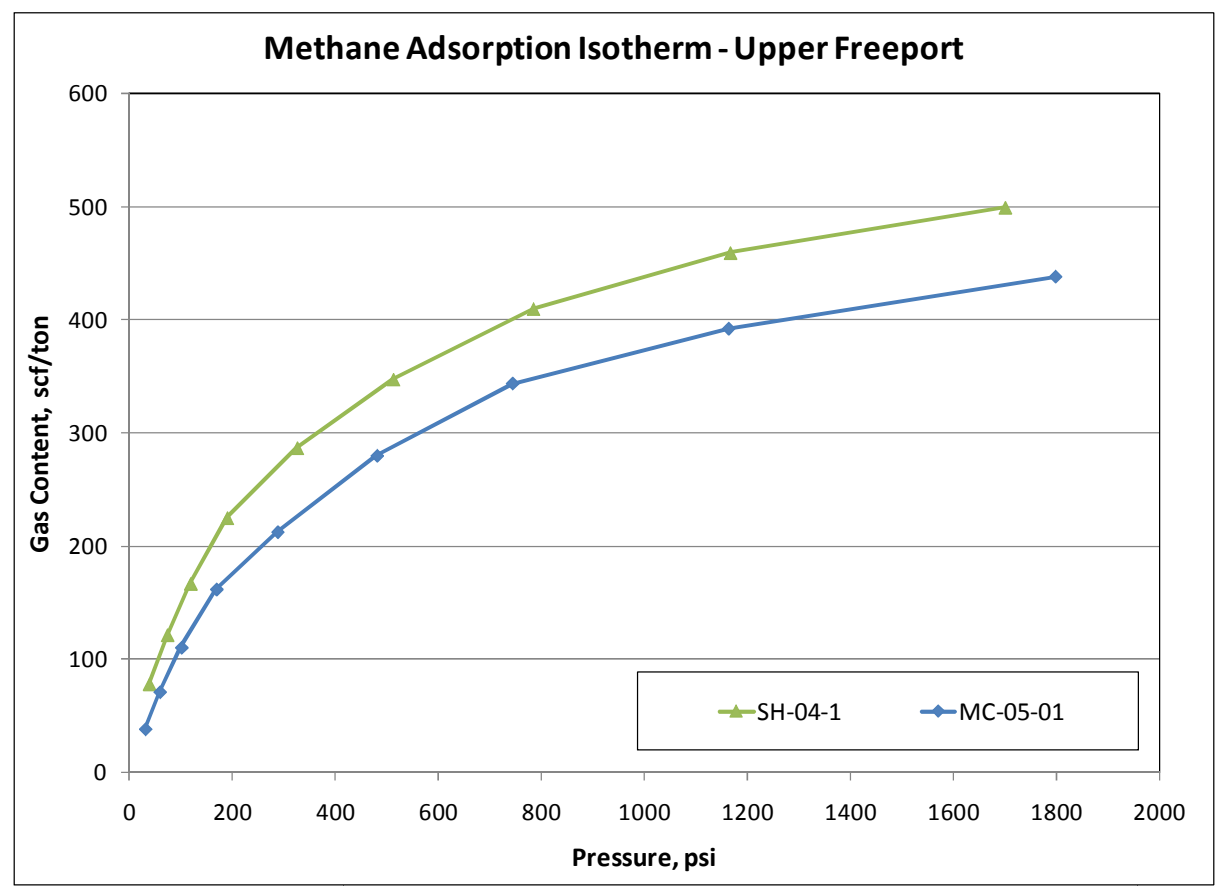

Figure 4-10:Methane Adsorption Isotherm of UF coal 


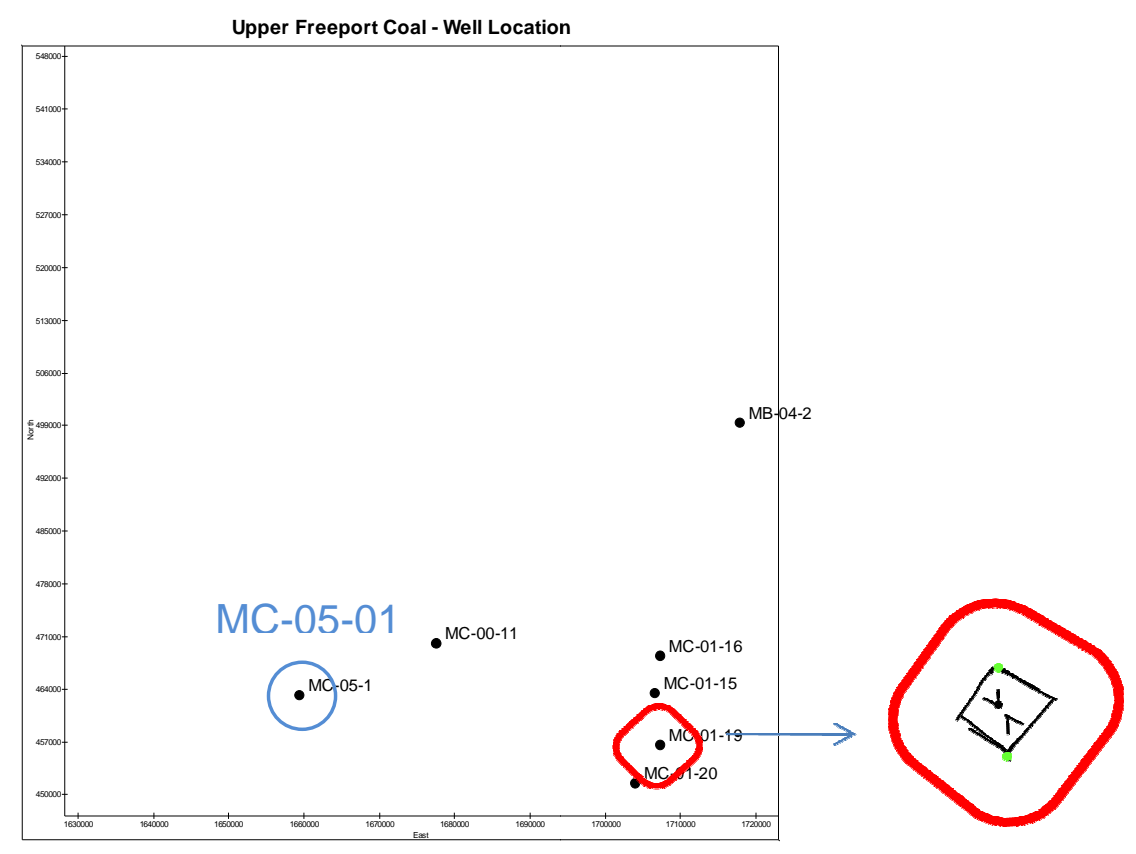

Figure 4-11: UF Coal Well Location

In order to evaluate whether the coals are under-saturated or not, a study of the $\mathrm{CH} 4$ Langmuir Isotherms is conducted. All four CH4 Langmuir Isotherms used in the previous study are used for this study. Since initial reservoir pressure data is not available, pressure gradients of $0.3 \mathrm{psi} / \mathrm{ft}, 0.35 \mathrm{psi} / \mathrm{ft}$, and $0.45 \mathrm{psi} / \mathrm{ft}$ are used to estimate initial reservoir pressure based on average formation depth. Then using measured values of initial gas content from a core samples located at the center of the field (MC-01-19), both lines, initial gas content values and calculated pressure are intercepted. If the interception of the two lines is under the isotherm profile it is presumed that the coal is under-saturated, otherwise it is saturated. Table 4-2, shows the pressure calculation and average formation depth used in the study. Figures 4-12 and 4-13 show the results of the study for Pittsburgh and Upper Freeport coals respectively.

Table 4-2: Pressure Gradient and Initial Pressure of PG and UF

\begin{tabular}{|c|c|c|}
\hline Pg, psi/ft & $\begin{array}{c}\text { Pittsburgh } \\
\text { Gci=136 scf/ton } \\
\mathrm{D}=700 \mathrm{ft}\end{array}$ & $\begin{array}{c}\text { Upper Freeport } \\
\text { Gci=182 scf/ton } \\
\mathrm{D}=1300 \mathrm{ft}\end{array}$ \\
\cline { 2 - 3 } & $\mathrm{Pi}, \mathrm{psi}$ & $\mathrm{Pi}, \mathrm{psi}$ \\
\hline 0.3 & 210 & 390 \\
\hline 0.35 & 245 & 455 \\
\hline 0.45 & 315 & 585 \\
\hline
\end{tabular}


Based on the assumed conditions and the provided data; both coals seems to be undersaturated. Now, notice that those isotherms are from core samples located between 5 and 9 miles far away from the field, and the average formation depth and measured gas content used for the study are from the field which led in uncertain conclusions, never the less in the absence of data this will be the starting point for initialization of the reservoir model during the modeling stage.

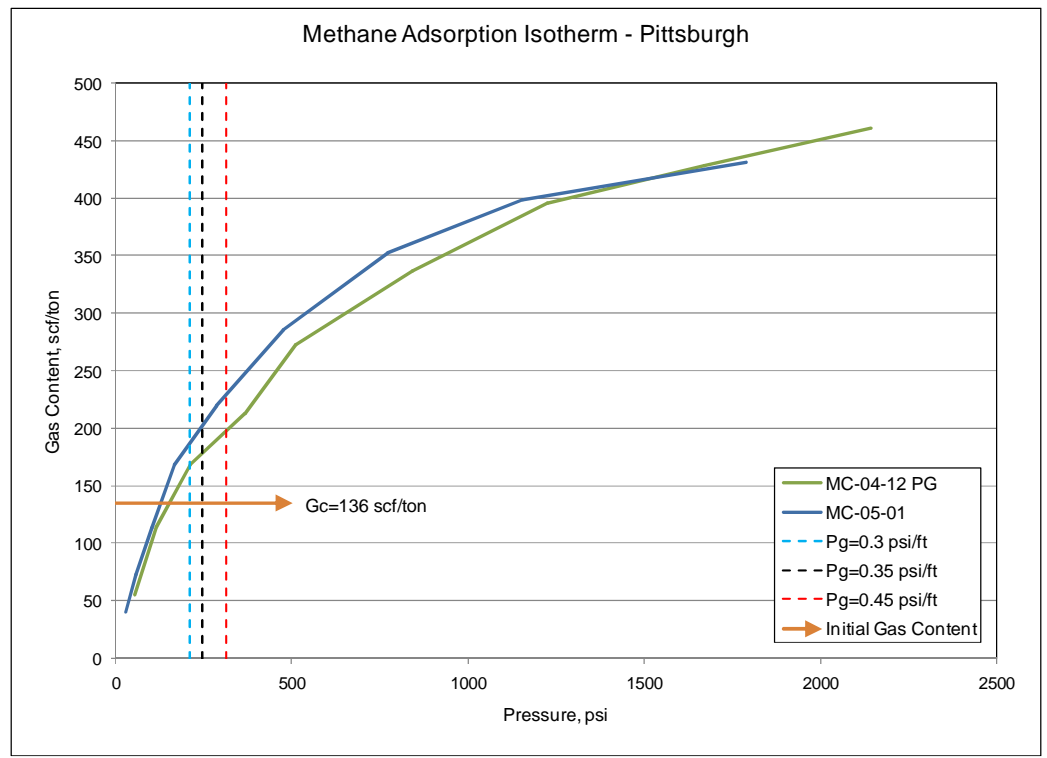

Figure 4-12: Methane Adsorption Isotherm with PG Gas Content

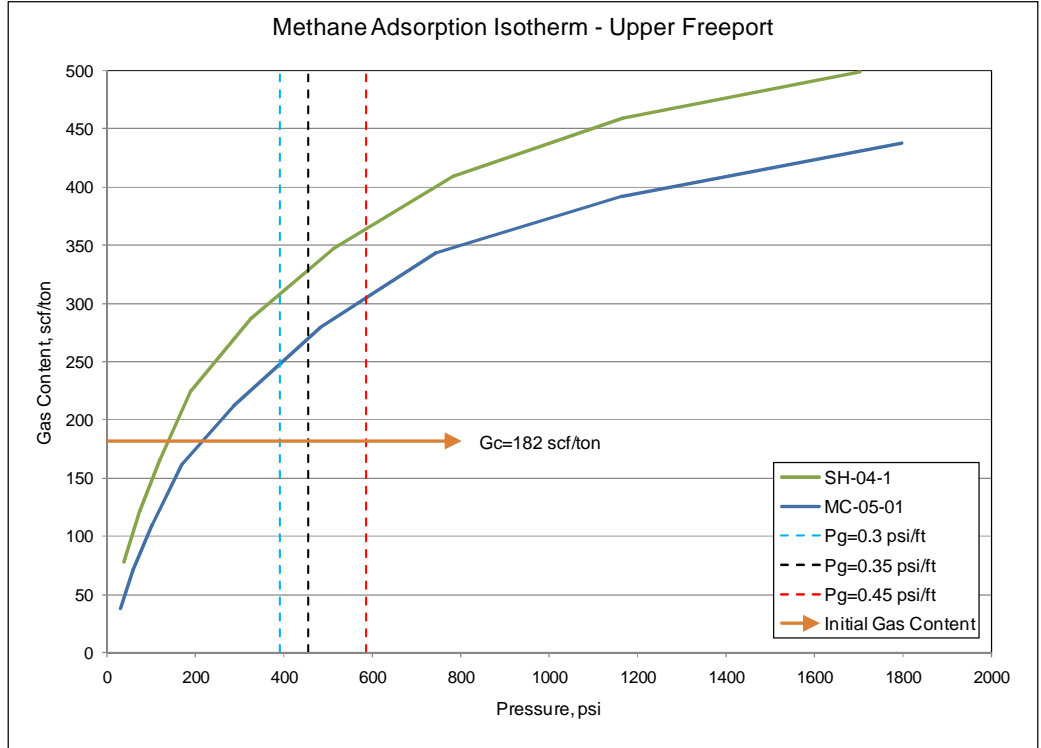

Figure 4-13: Methane Adsorption Isotherm and UF Gas Content 


\section{Canister Desorption Tests}

Data from four canister desorption tests have been received. Canister tests 18-3 and 18-4 with samples from Pittsburgh coal and canister 40-4 and 40-5 with samples from Upper Freeport. Based on the tests maximum desorbed gas are $69.7 \mathrm{scf} /$ ton and 82.9scf/ton for tests $18-3$ and 18 4 respectively, and $28.3 \mathrm{scf} /$ ton and $18.16 \mathrm{scf} /$ ton for test 40-4 and 40-5 respectively. Below is an example of desorption time calculation for the canister desorption test 18-3 from Pittsburgh coal. Table 4-3 shows the data and Figure 4-14 shows the square root of elapsed time (hrs) vs. cumulative desorbed gas (scf/ton) graph from the canister desorption test 18-3. First lost gas is estimated by tracing a straight line through the earliest data points and extrapolating it to the gas desorbed axes (Y-axes). The next step is calculating the residual gas. In order to do that a graph of reciprocal of desorption time vs. desorbed gas is plotted, Figure 4-15 shows an example of the reciprocal of desorption time vs. desorbed gas for test 18-3. By tracing a straight line through the latest data point in Figure 4-15 and extrapolating it to the desorbed gas (X-axes), residual gas is estimated. Once lost gas and residual gases are estimated it is proceeded to estimate Initial gas content using Equation 1. The next step is to calculate desorption time, below is an example of desorption time calculations made for the canister test 18-3 in Pittsburgh coal. Table 4-4 shows the calculated desorption time for all the tests.

$$
\text { Gci }=\text { Lost Gas }+ \text { Desorbed Gas }+ \text { Residual Gas ........ Equation } 1
$$


Table 4-3: Gas Desorption Test Data

$\left.\begin{array}{|l|l|}\hline \text { time, } \mathrm{h} & \begin{array}{l}\text { Desorbed } \\ \text { scf/ton }\end{array} \\ \hline 0.00 & 3.18 \\ \hline 0.87 & 3.79 \\ \hline 2.92 & 6.00 \\ \hline 314.33 & 16.18 \\ \hline 383.75 & 17.85 \\ \hline 480.75 & 20.30 \\ \hline 577.00 & 22.31 \\ \hline 721.75 & 25.44 \\ \hline 39.25 & 28.11 \\ \hline 1031.75 & 31.57 \\ \hline 1151.75 & 33.36 \\ \hline 2047.00 & 38.04 \\ \hline 2575.00 & 42.95 \\ \hline 2863.00 & 45.29 \\ \hline 3391.00 & 47.64 \\ \hline 3751.00 & 50.76 \\ \hline 3871.00 & 54.78 \\ \hline 4111.00 & 54.78 \\ \hline 4183.00 & 54.78 \\ \hline 4783.00 & 54.78 \\ \hline 5287.00 & 61.91 \\ \hline 5623.00 & 65.48 \\ \hline 6151.00 & 65.48 \\ \hline 6655.00 & 69.61 \\ \hline 6982.00 & 69.70 \\ \hline 7225.00 & 69.70 \\ \hline\end{array}\right\} \Delta G c$

$\Delta G c=G c i \times 63.2 \%$

$G c i=0+69.7+20.3=90 \mathrm{scf} / \mathrm{ton}$
Canister Desorption Test \#18-3 - Pittsburgh Coal

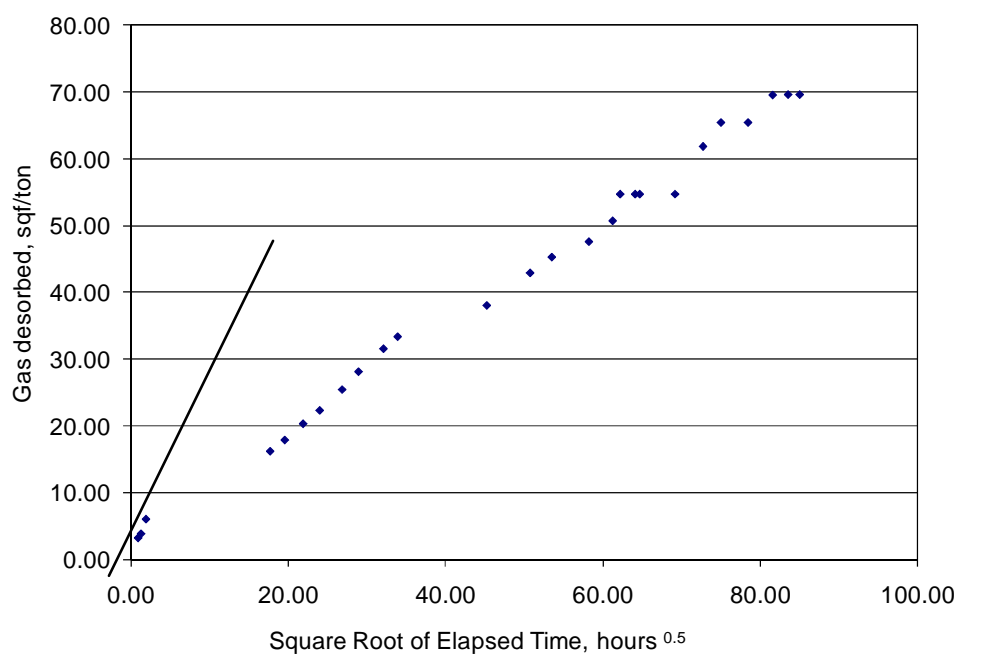

Figure 4-14: Canister Desorption Test, hours

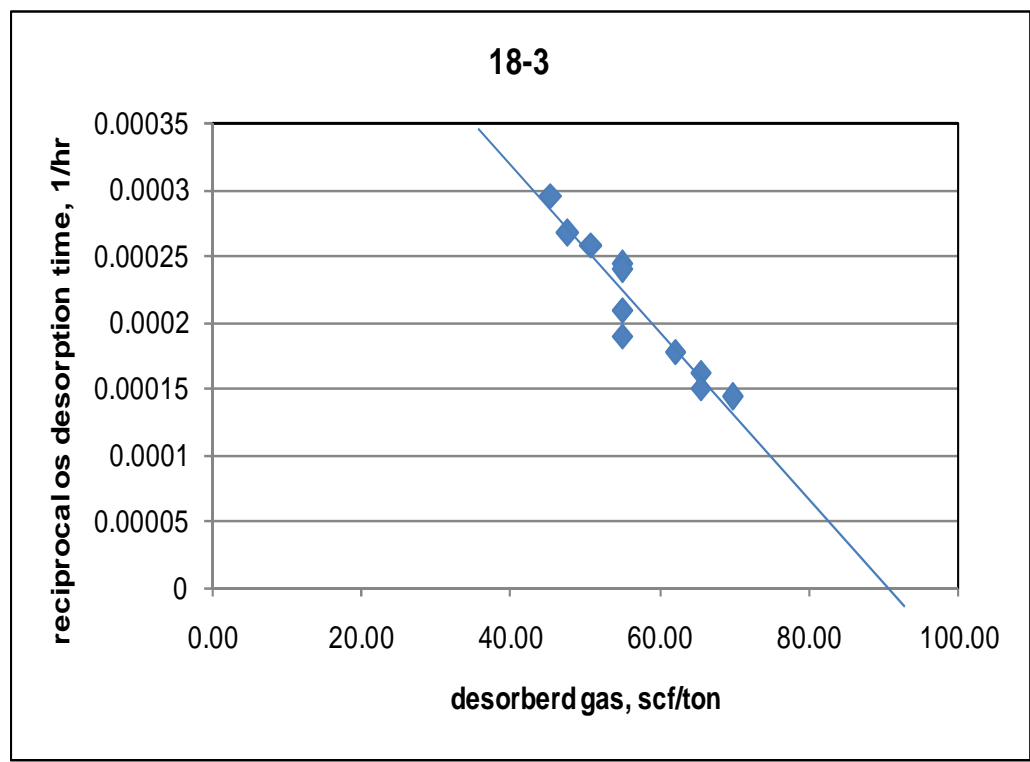

Figure 4-15: Gas Desorption Test, scf/ton

$\Delta G c=90(63.2 \%)=56.88 \mathrm{scf} /$ ton then by interpolation

$t=4931.45 \mathrm{hr}=\frac{4931.45 \mathrm{hr}}{24 \mathrm{hr} / \text { day }}=205.4$ days 
Table 4-4: Results of Canister Test and Desorption Time for PG and UF Coal

\begin{tabular}{|l|l|l|}
\hline Coal Seam & Canister Test \# & Desorption Time, days \\
\hline \multirow{2}{*}{ Pittsburgh } & $18-3$ & 205 \\
\cline { 2 - 3 } & $18-4$ & 134 \\
\hline \multirow{2}{*}{ Upper Freeport } & $40-4$ & 4.5 \\
\cline { 2 - 3 } & $40-5$ & 45 \\
\hline
\end{tabular}

\section{Production Data Analysis}

First volumetric calculations are performed for each coal in order to estimate OGIP. The isopach and gas content distribution maps generated during the reservoir characterization stage are used. The area for each coal is divided in two regions as it is shown in Figure 4-16, and then values of thickness, coal density, and gas content are averaged for each section of the coal. Table 4-5 shows the values in each region used in the calculation. As it is shown in Table 4-6 OGIP is about 2.4 BCF and 1.04 BCF in Pittsburgh and Upper Freeport coals respectively, and the recovery factor until November 2007 is $12 \%$ for Pittsburgh coal and 3.8\% for Upper Freeport.

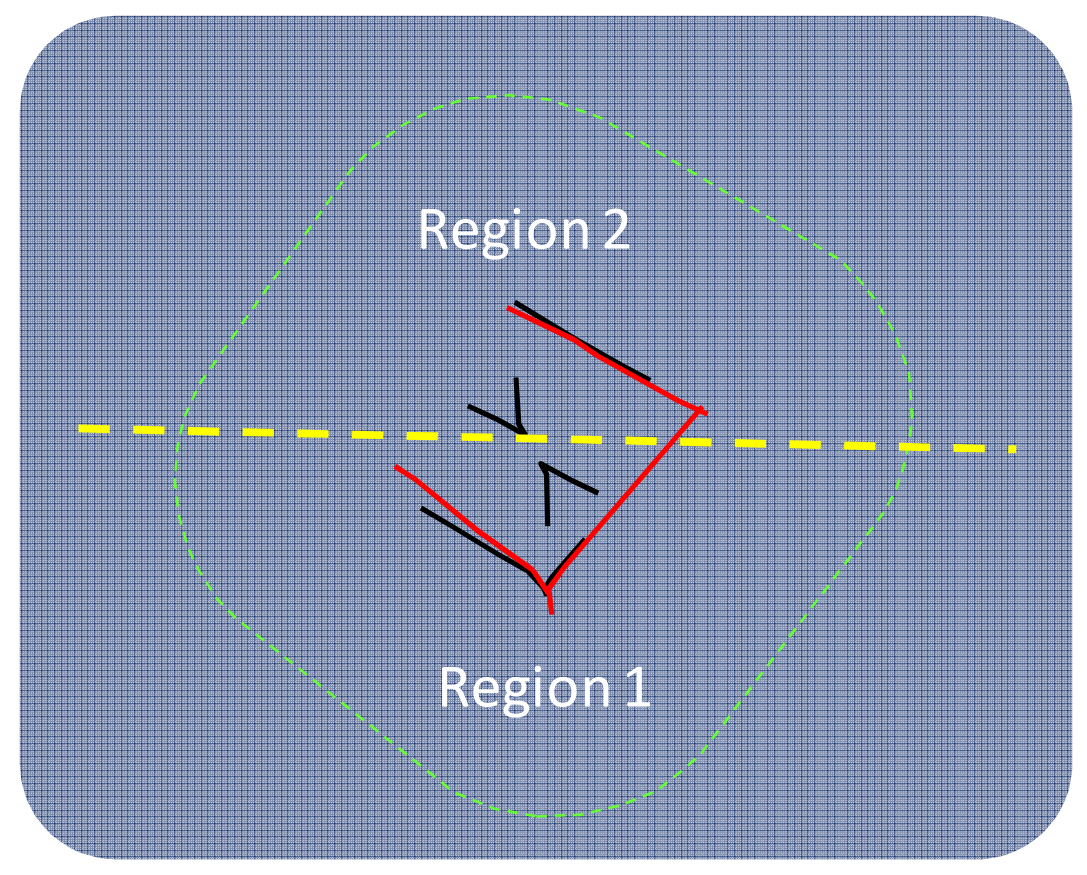

Figure 4-16: Division of Coal Seam, Region 1and 2 


\begin{tabular}{|l|l|}
\hline \multicolumn{1}{|c|}{ Pittsburgh Coal } & \multicolumn{1}{c|}{ Upper Freeport Coal } \\
\hline \multicolumn{1}{|c|}{ Region 1 } & \multicolumn{1}{c|}{ Region 1} \\
\hline $\mathrm{Gc}=128 \mathrm{scf} /$ ton & $\mathrm{Gc}=180 \mathrm{scf} /$ ton \\
\hline $\mathrm{h}=6.4 \mathrm{ft}$ & $\mathrm{h}=2.13 \mathrm{ft}$ \\
\hline Average Coal density $=86.5 \mathrm{lb} / \mathrm{ft}^{3}$ & Average Coal density $=84.9 \mathrm{lb} / \mathrm{ft}^{3}$ \\
\hline Area Zone $=760$ acres & Area Zone $2=456$ acres \\
\hline \multicolumn{1}{|c|}{ Region 2} & \multicolumn{1}{c|}{ Region 2} \\
\hline $\mathrm{Gc}=136 \mathrm{scf} / \mathrm{ton}$ & $\mathrm{Gc}=170 \mathrm{scf} /$ ton \\
\hline $\mathrm{h}=6.7 \mathrm{ft}$ & $\mathrm{h}=3.75 \mathrm{ft}$ \\
\hline Average Coal density $=86.5 \mathrm{lb} / \mathrm{ft}^{3}$ & Average Coal density $=84.9 \mathrm{lb} / \mathrm{ft}^{3}$ \\
\hline Area Zone $1=760$ acres & Area Zone $1=608$ acres \\
\hline
\end{tabular}

Table 4-6: Initial Gas in Place, Actual Production and Recovery Factor for PG and UF coal

\begin{tabular}{|l|l|}
\hline \multicolumn{1}{|c|}{ Pittsburgh } & \multicolumn{1}{|c|}{ Upper Freeport } \\
\hline OGIP $=2,477,616 \mathrm{MCF}$ & OGIP $=1,040,002 \mathrm{MCF}$ \\
\hline ACTUAL GAS PRODUCTION $=318,666 \mathrm{MCF}^{*}$ & ACTUALGAS PRODUCTION $=39,658 \mathrm{MCF}^{*}$ \\
\hline $\mathrm{RF}=12 \%\left(^{*}\right)$ & $\mathrm{RF}=3.8 \%\left(^{*}\right)$ \\
\hline
\end{tabular}

Data: Consol Figure: WVU - PNGE Department 
A bubble map of gas production for each coal is done in order to compare total production from each well. As it is shown in Figure 4-17 gas production from MH12 is much bigger than production from MH3. Also Figure 4-18 shows that MH18 is the well that has produced more gas followed by MH20, MH11, and MH5.

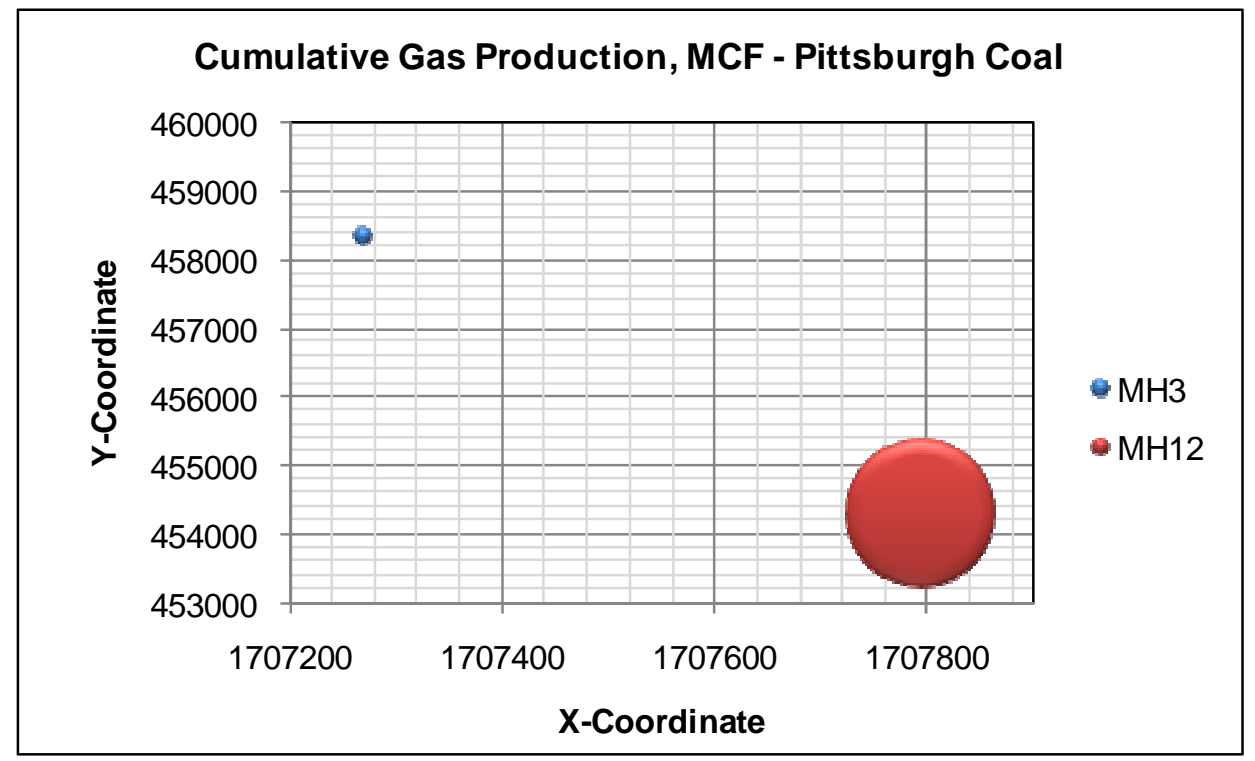

Figure 4-17: Comparison of gas production between wells MH3 and MH12

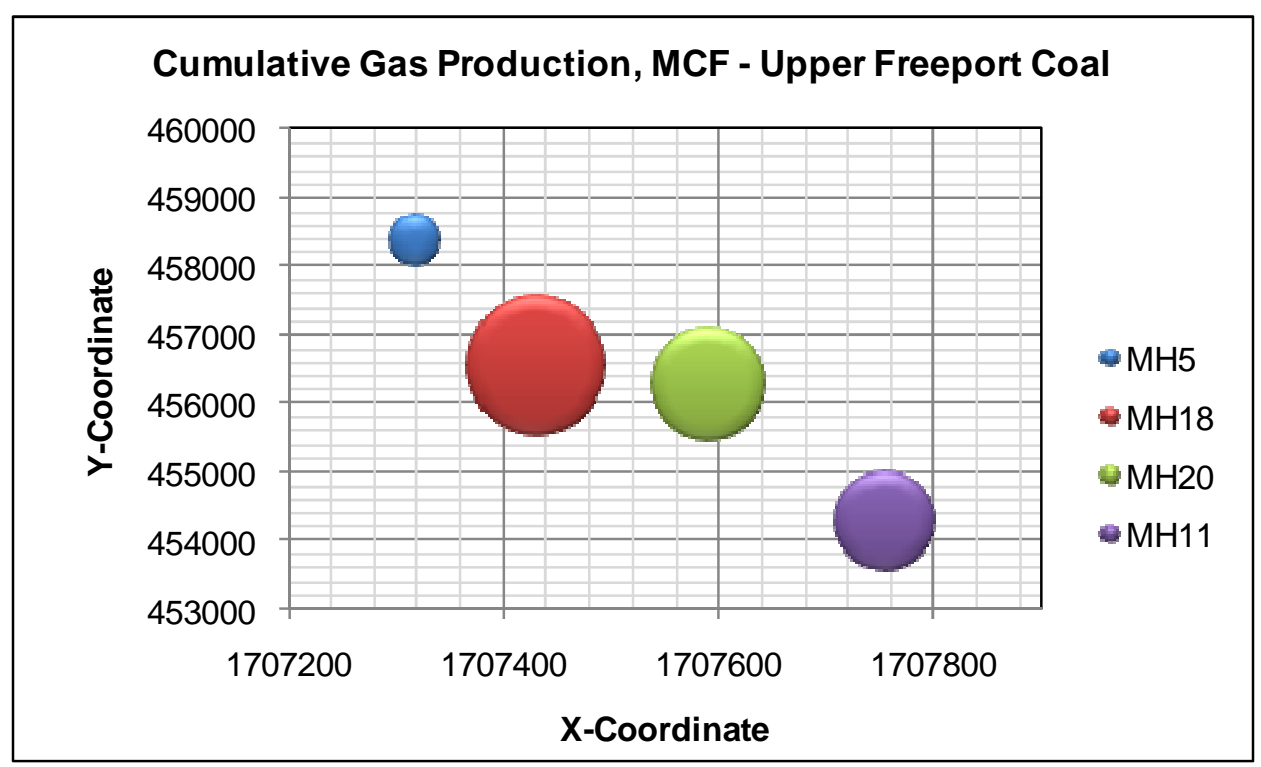

Figure 4-18: Comparison of gas production among wells MH5, MH18, MH20 and MH11 
In order to evaluate their behavior and flow performance similarities, production rates from all the wells in each coal are compared together. Figure 4-19 shows actual gas and water production from all the wells in Pittsburgh coal. There are two well completed in this coal; MH12 and MH3. MH12 gas production is from October 2004 to November 2007 and water production data is from July 2007 to November 2007, however it produced water before July 2007 and the data is not available. MH3 gas production is from April 2006 to July 2007 and it has not produced any water. Figure 4-19 from all the wells in Pittsburgh coal. Also Figure 4-20 shows that MH12 has been delivered about 50 times higher rates than MH3.

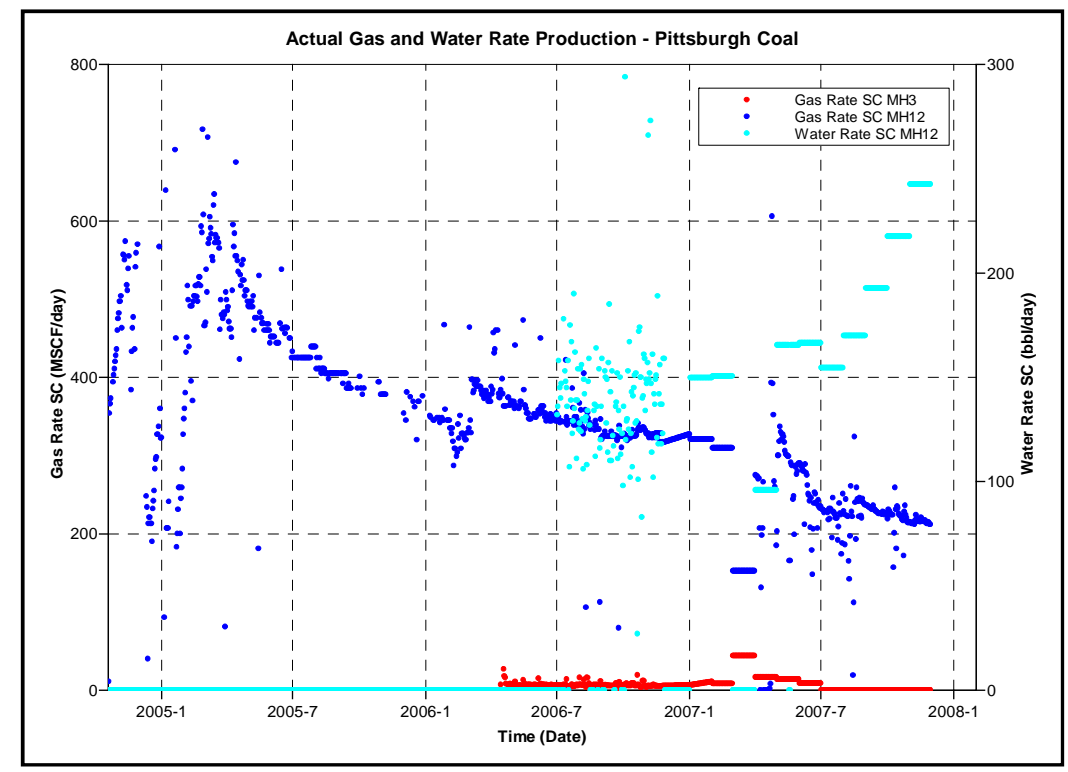

Figure 4-19: Actual Gas and Water production for PG Coal 


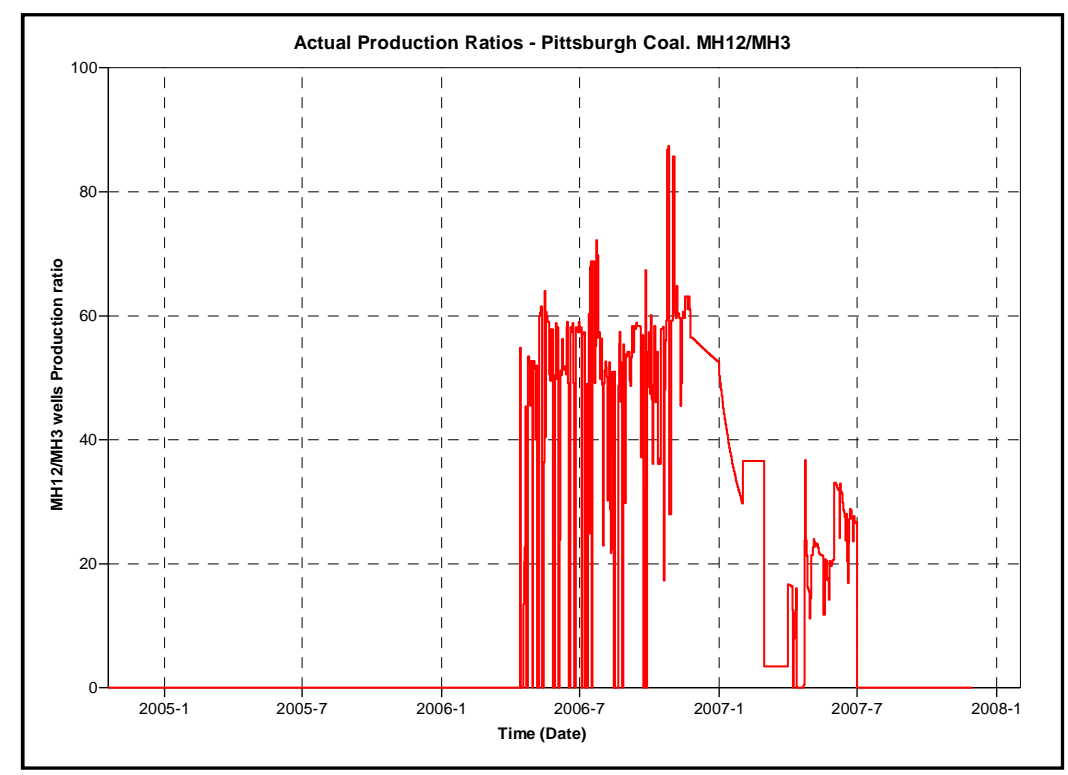

Figure 4-20: Actual production Rate at MH12 and MH3 for PG Coal

Figure 4-21 shows actual gas and water production from all the wells in Upper Freeport coal. There are four well completed in this coal; MH5, MH18, MH20, and MH11. MH5 gas production is from April 2006 to July 2007 and it has not produced any water. MH18 gas production is from October 2004 to July 2007 and it has not produced any water. MH20 gas production is from October 2004 to July 2007 and it has not produced any water. MH11 gas production is from October 2004 to November 2007 and it has produced 37 bbls of water during its life with flow rates less than 0.15 bbls/day. Also Figure 4-22 shows the production ratios between MH18 (higher producer) and the other wells. So far MH18 has delivered in average 5 times higher rates than MH5, about the same to 2 times higher than MH20 and about 3 times higher than MH11. 


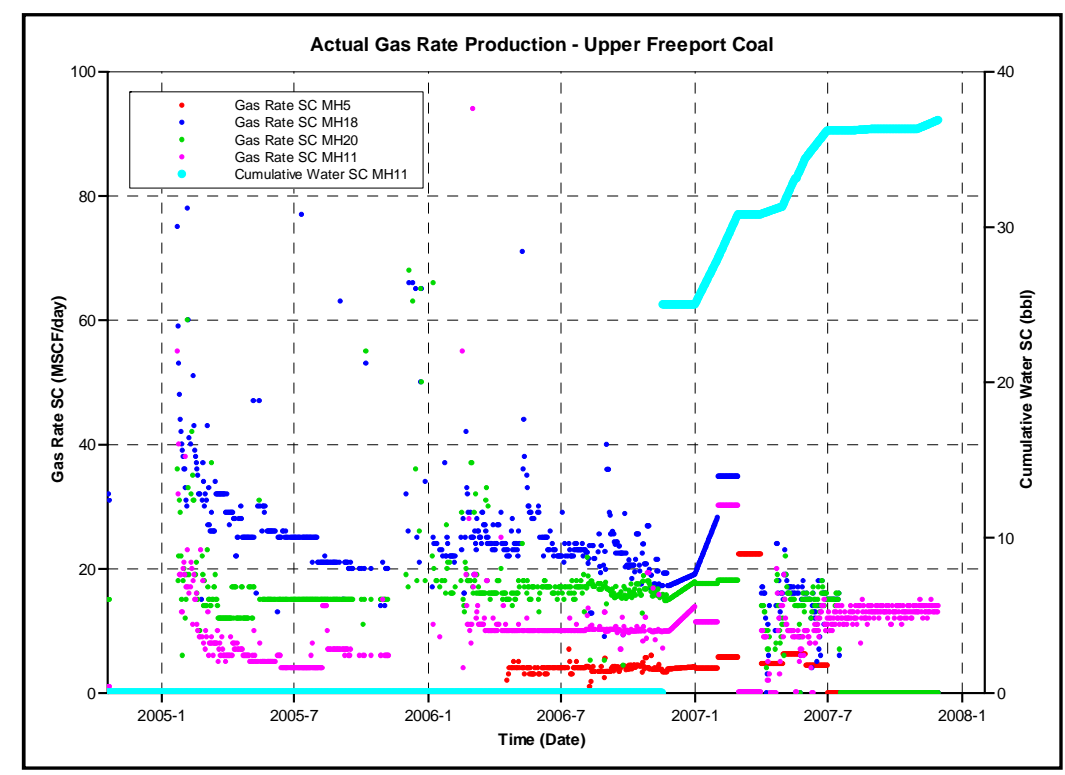

Figure 4-21: Actual Gas Rate Production in UF Coal Wells

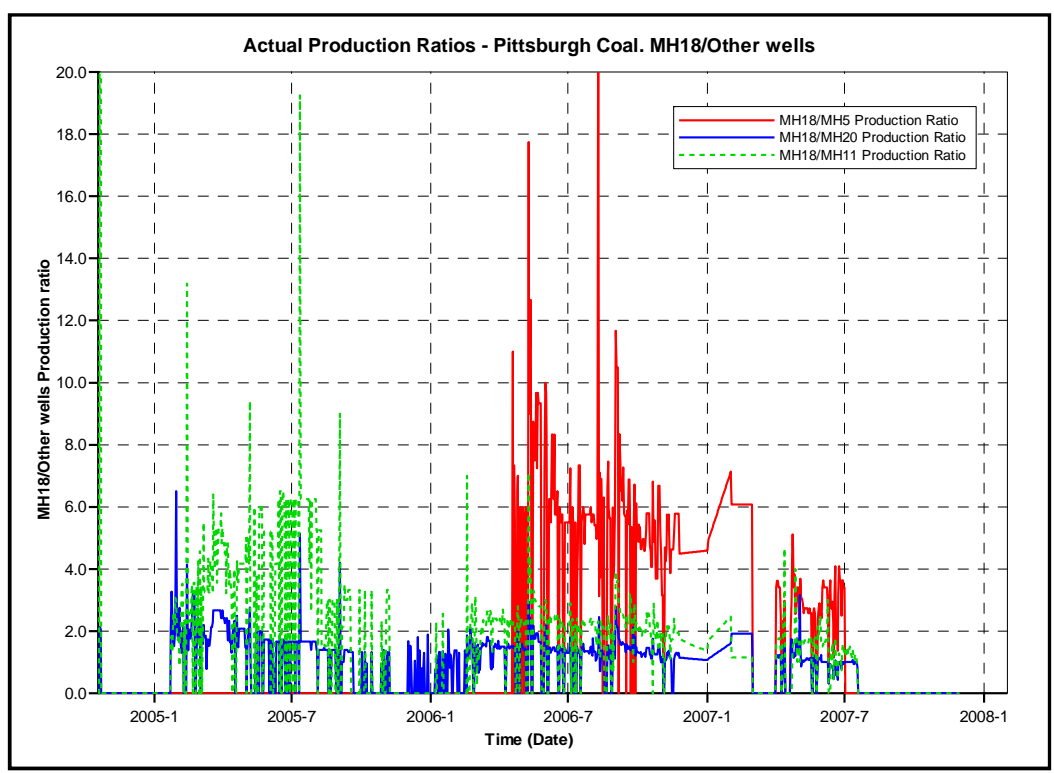

Figure 4-22: Actual Gas Production Ratios among Well MH18 and other Wells in PG Coal 
Since some wells has produced for longer periods than others and in order to have a better understanding of the flow performance for each well, all available production data is compiled and normalized based in the following criteria:

- Case 1. Contact Length Normalization:

PG Production normalization: Figure 4-23 shows the normalized production by contact length done for Pittsburgh coal. Also Figure 4-24 shows a comparison between the actual production ratio and the normalized one based on the above criteria. The green line represents the normalized ratio. As expected in the production normalization; production in a per foot basis has dropped by half since MH12 is about twice longer than MH3.

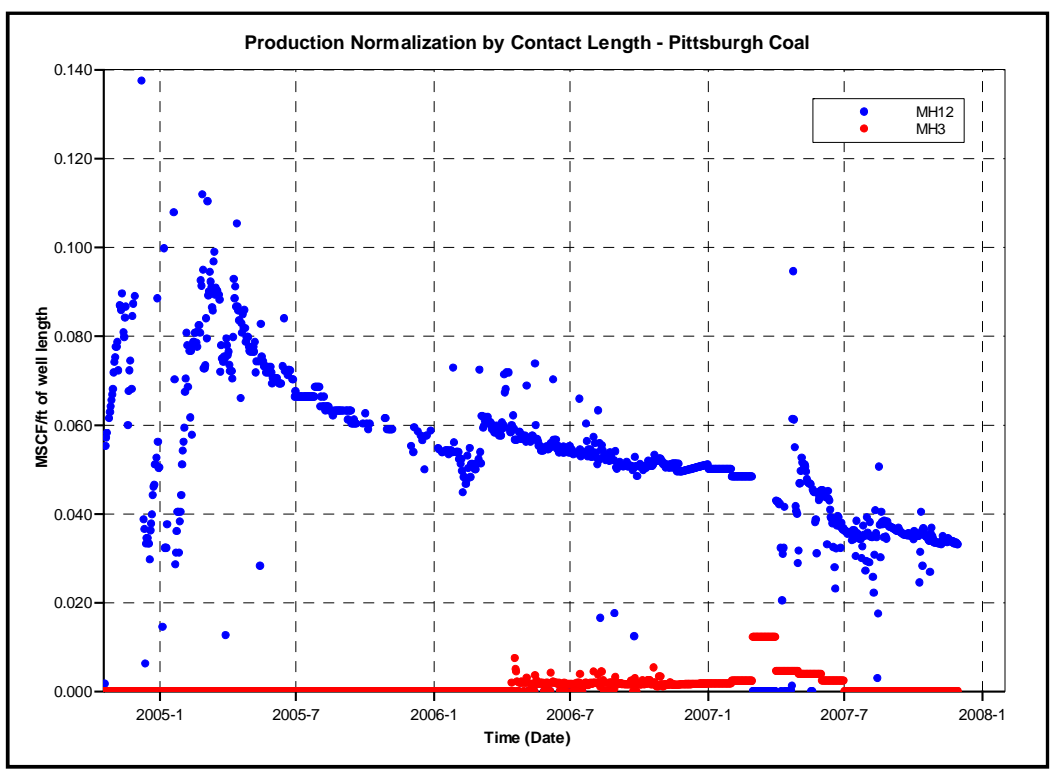

Figure 4-23: Production Normalization by Contact Length at Wells MH12 and MH3 for PG Coal 


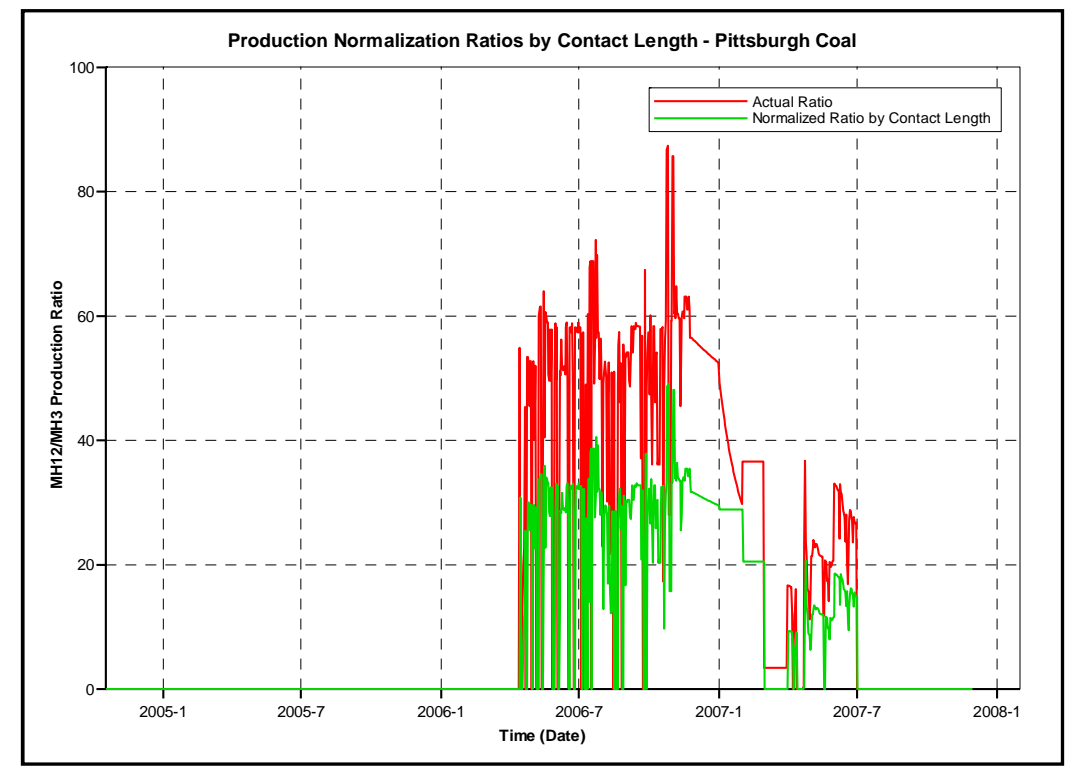

Figure 4-24: Comparison of Actual Ratio and Normalized Ratio by Contact Length

UF Production normalization: Figure 4-25 shows the normalized production by contact length done for Upper Freeport coal. A comparison between the actual production ratio and the normalized one based on the contact length criteria is done. Figure 4-26 to 4-28 show the results of the ratio comparison for MH18/MH5, MH18/MH20, and MH18/MH11 respectively. The black line represents the normalized ratios for each case. Based on the results; the production ratio in a per foot basis has remains about the same between MH18 and MH5, while MH18/MH20 and MH18/MH11 production ratios have increased even more which may be associated to mechanical problems due to drilling or completion methods. 


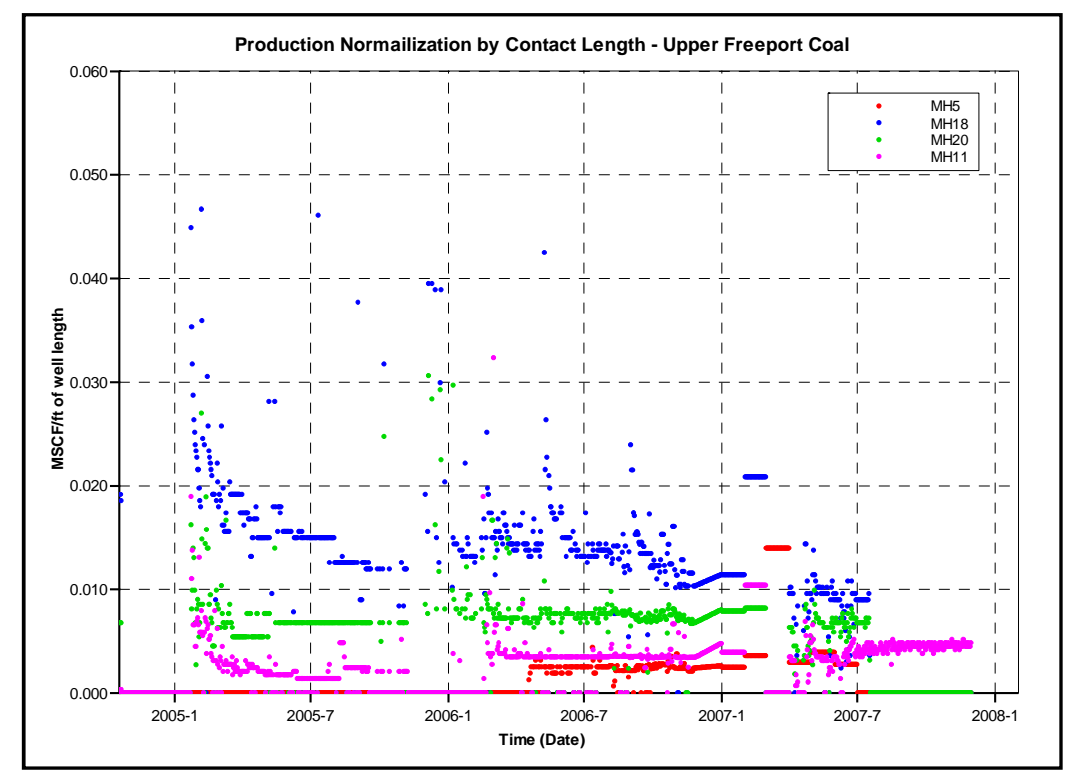

Figure 4-25: UF all wells gas normalized production by contact length

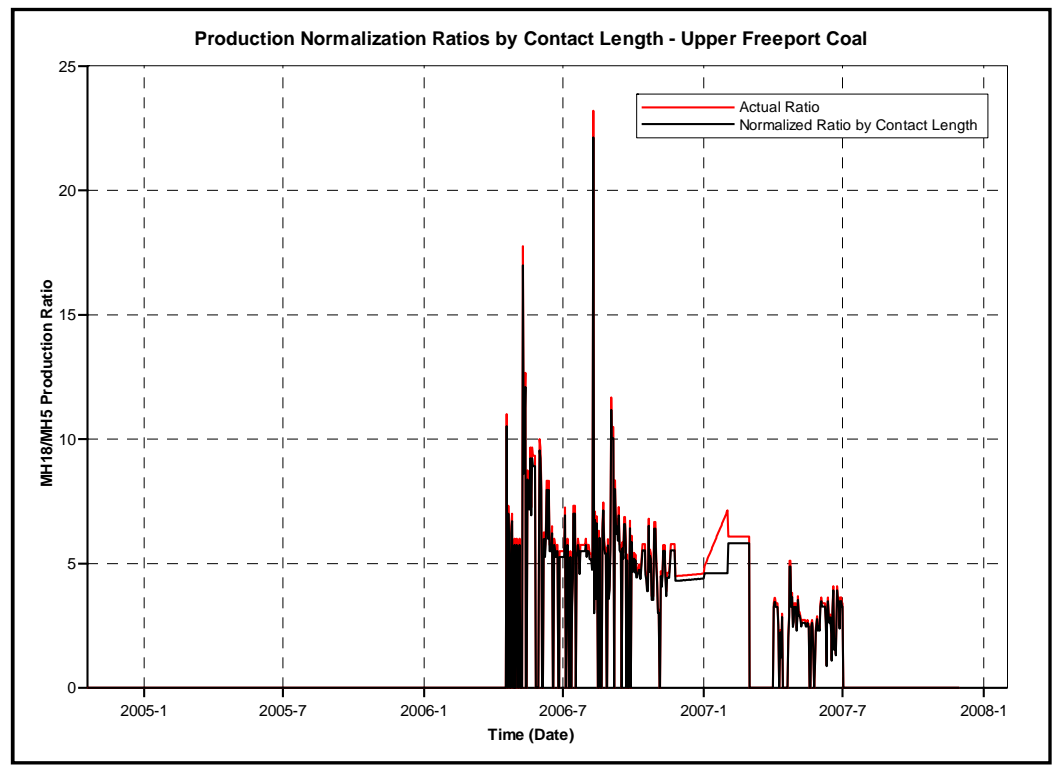

Figure 4-26: MH18/MH5 Production Normalized by Contact Length for UF 


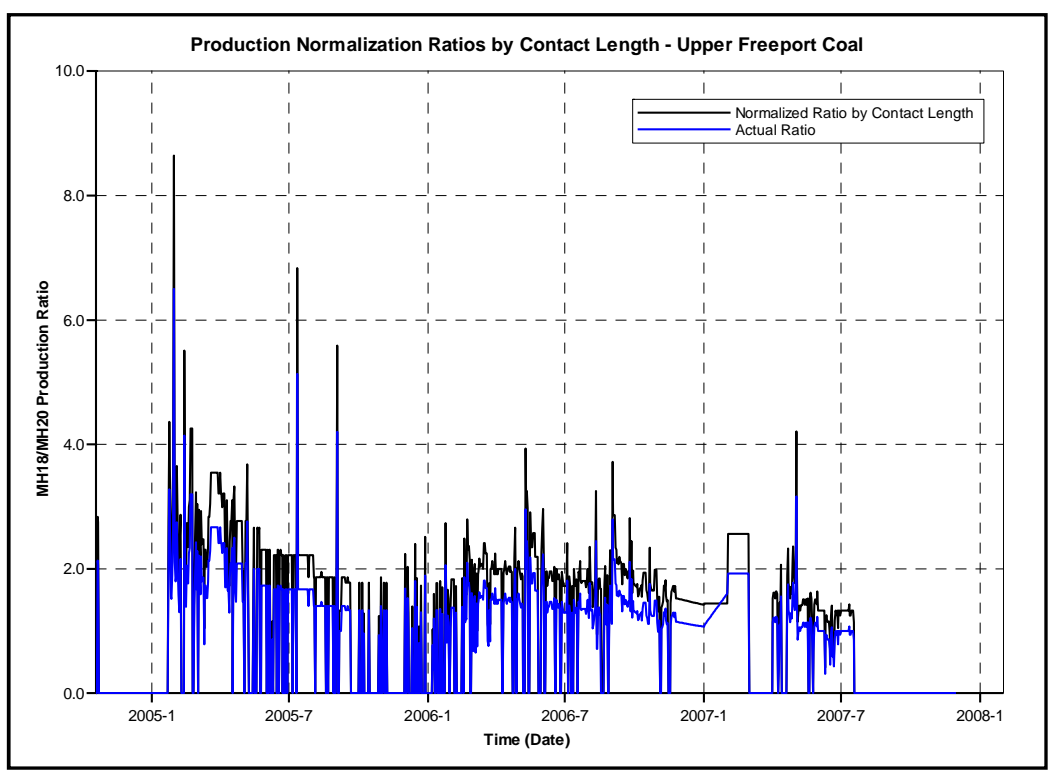

Figure 4-27: MH18/MH20 Production Normalized by Contact Length for UF

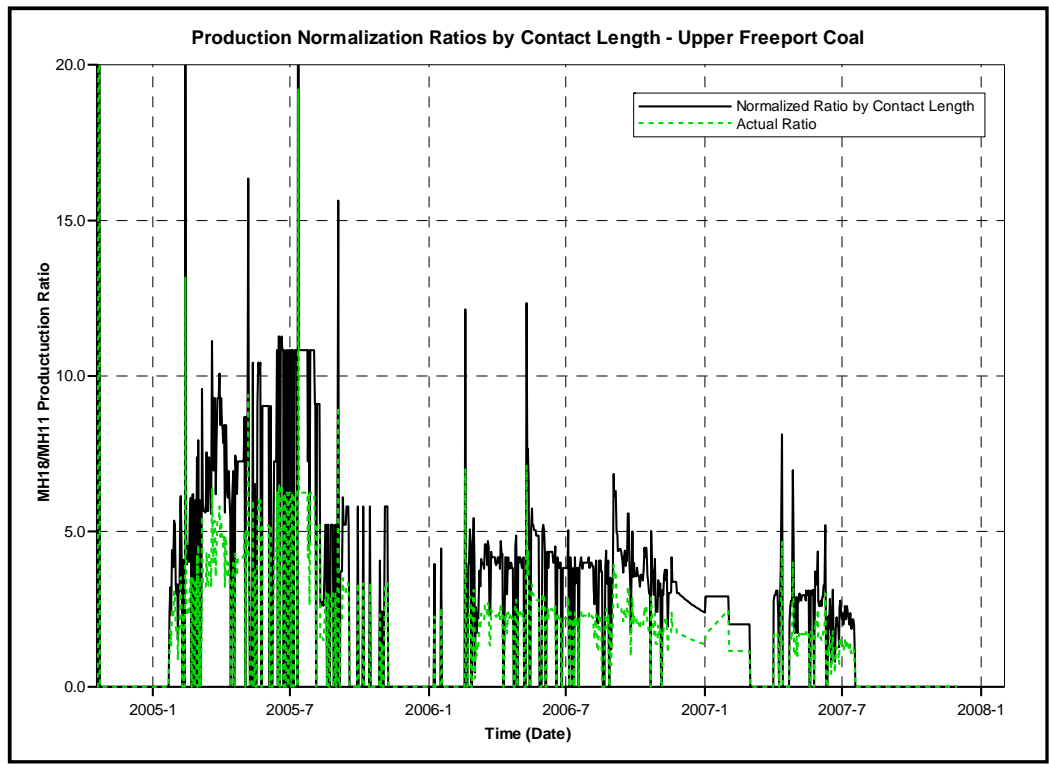

Figure 4-28: MH18/MH11 Production Normalized by Contact Length for UF 


\section{- Case 2. Thickness Normalization:}

PG Production normalization: Figure 4-29 shows the normalized production by thickness done for Pittsburgh coal. Also Figure 4-30 shows a comparison between the actual production ratio and the normalized one based on the above criteria. The green line represents the normalized ratio. Based on the thickness criteria the production ratio, between MH12 and MH3, has dropped by half.

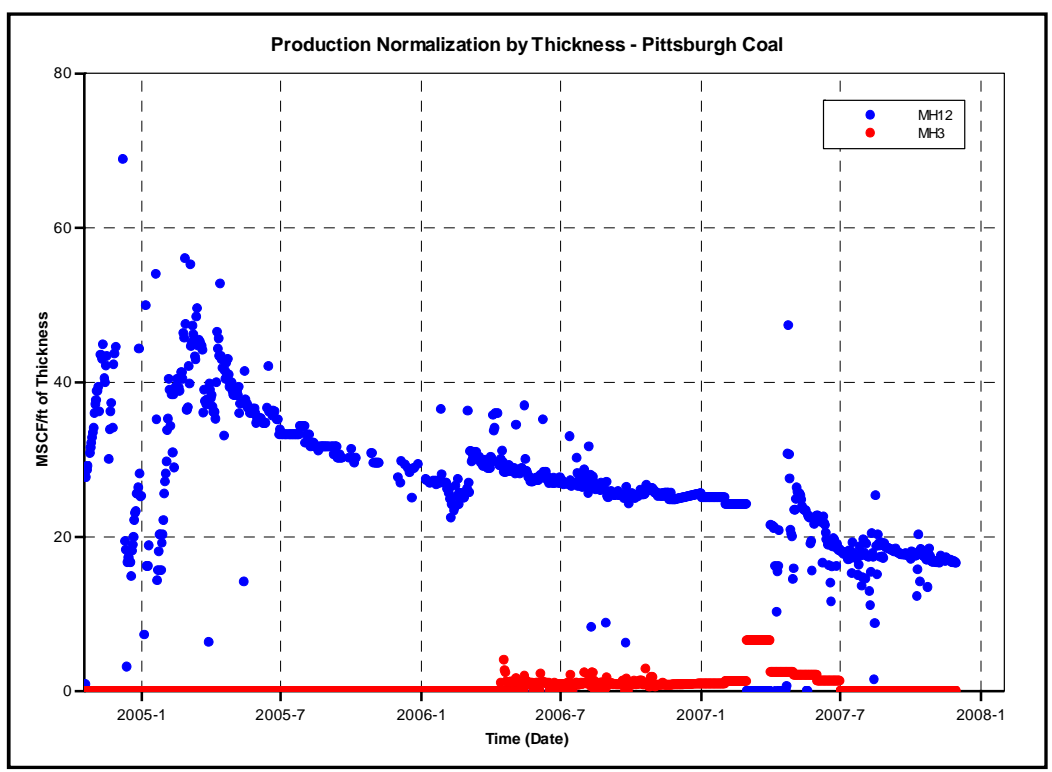

Figure 4-29: Production Normalization by Thickness at Wells MH12 and MH3 for PG Coal 


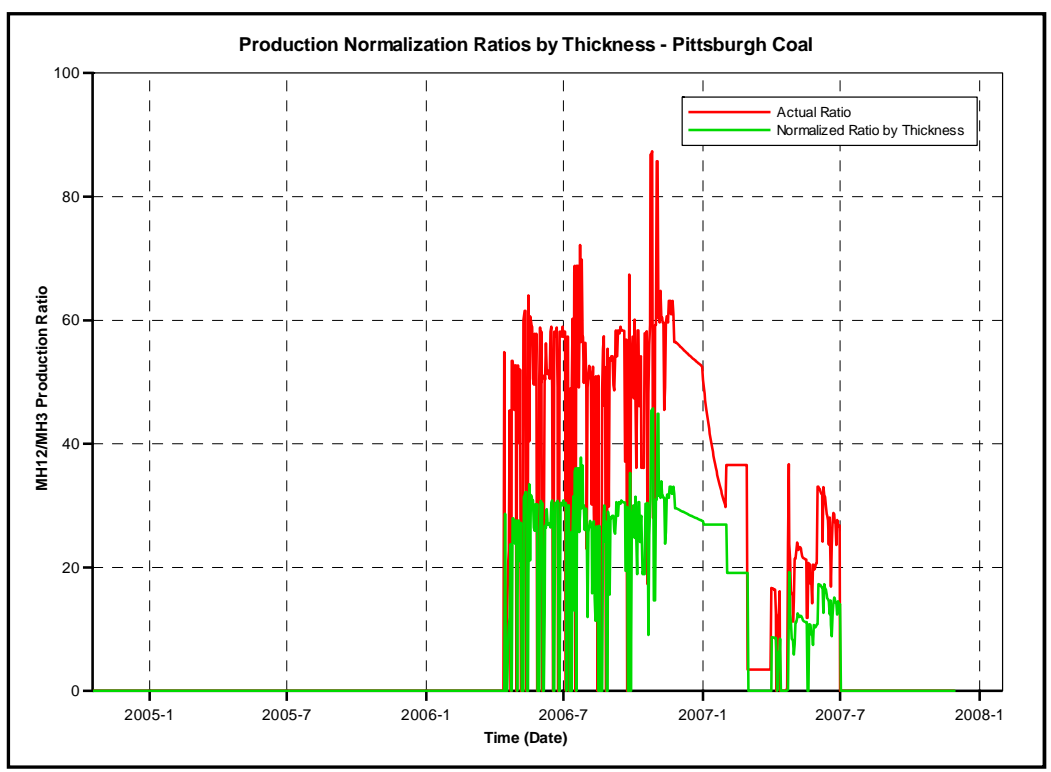

Figure 4-30: MH12/MH3 Production Normalized by Thickness for PG Coal

UF Production normalization: Figure 4-31 shows the normalized production by thickness done for Upper Freeport coal. A comparison between the actual production ratio and the normalized one based on the thickness criteria is done. Figure 4-32 to 4-34 show the results of

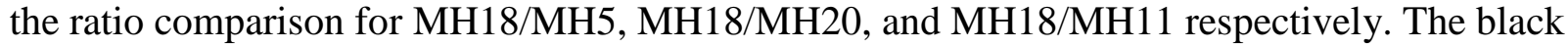
line represents the normalized ratios for each case. Based on the results; the production ratio has dropped by more than half between MH18 and MH5. Also MH18/MH20 and MH18/MH11 production ratios have dropped by half. 


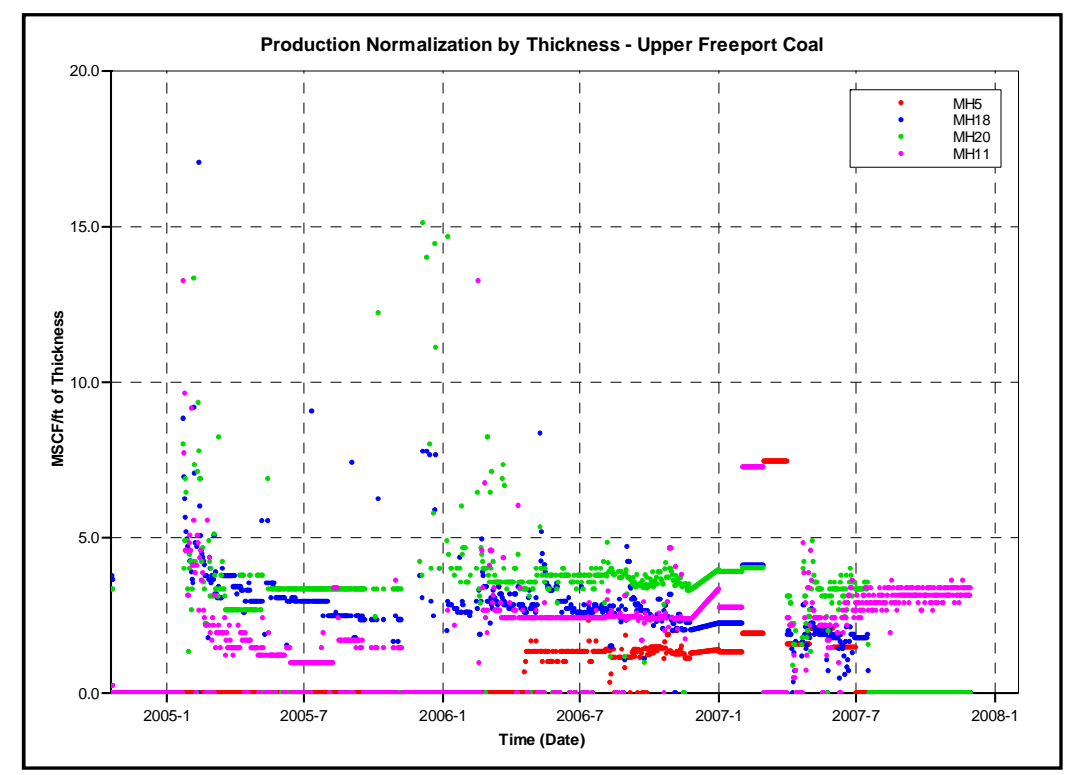

Figure 4-31: UF all wells gas production normalization by thickness

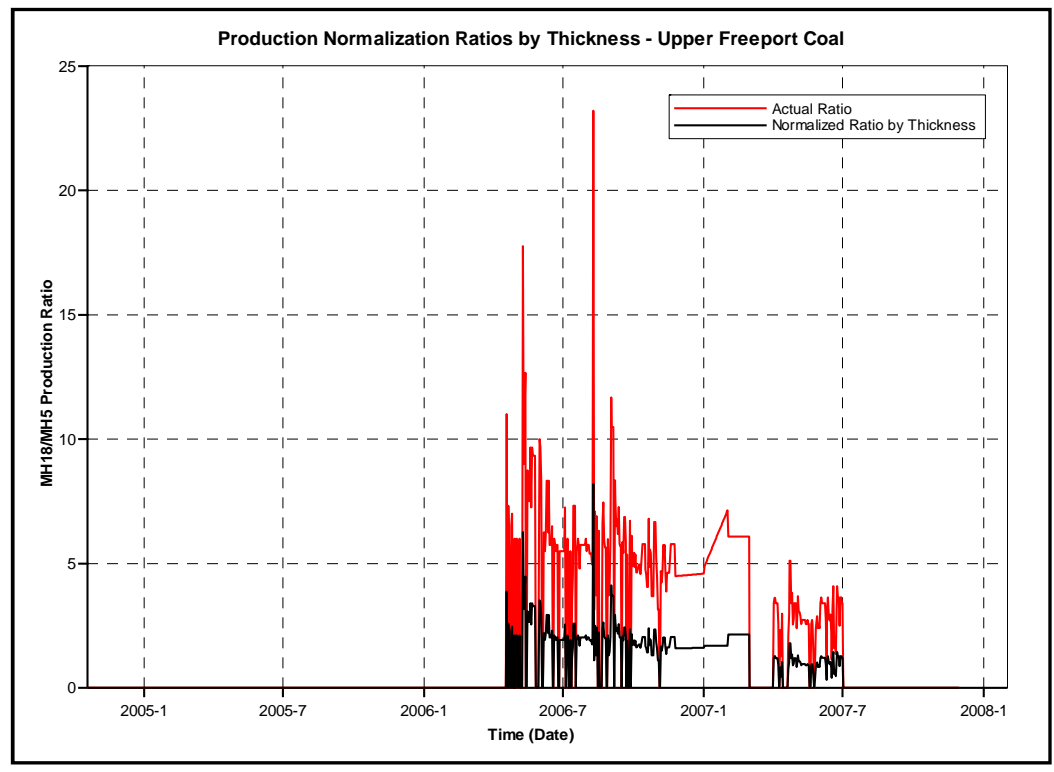

Figure 4-32: MH18/MH5 Production Normalized by Thickness for UF Coal 


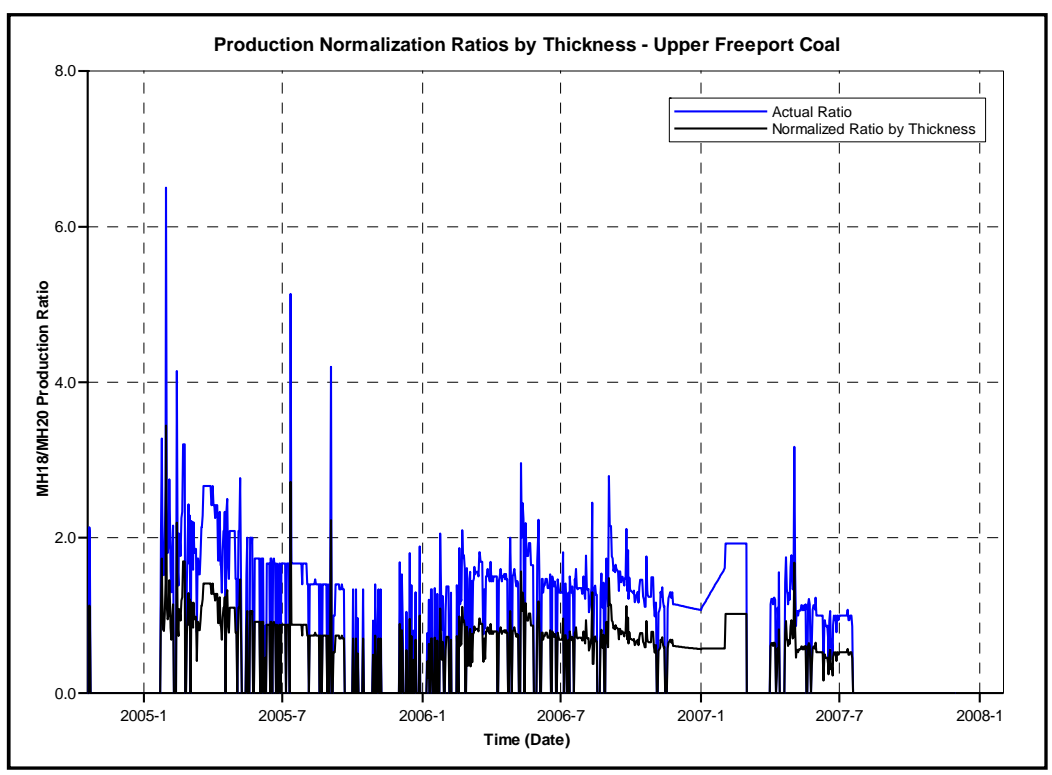

Figure 4-33: MH18/MH20 Production Normalized by Thickness for UF Coal

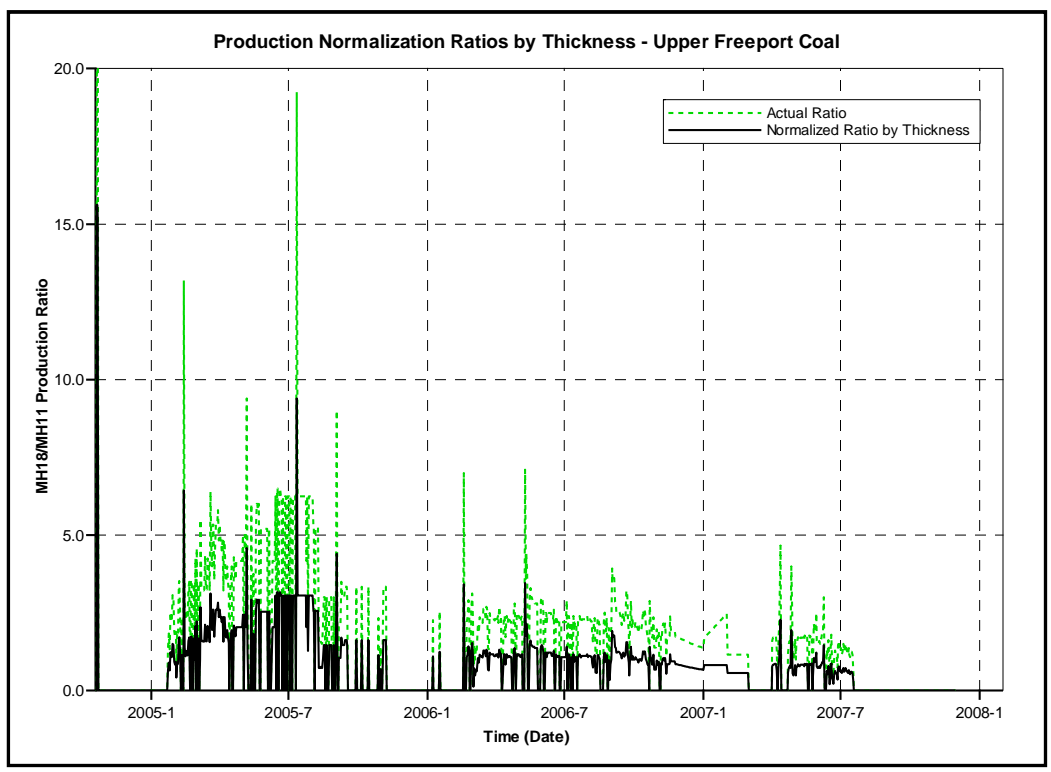

Figure 4-34: MH18/MH11 Production Normalized by Thickness for UF Coal 


\section{- Case 3. Gas Content Normalization:}

PG Production normalization: Pittsburgh coal: Figure 4-35 shows the normalized production by gas content done for Pittsburgh coal. Also Figure 4-36 shows a comparison between the actual production ratio and the normalized one based on the above criteria. The green line represents the normalized ratio. Based on the gas content criteria the production ratio, between MH12 and MH3, has remains about the same.

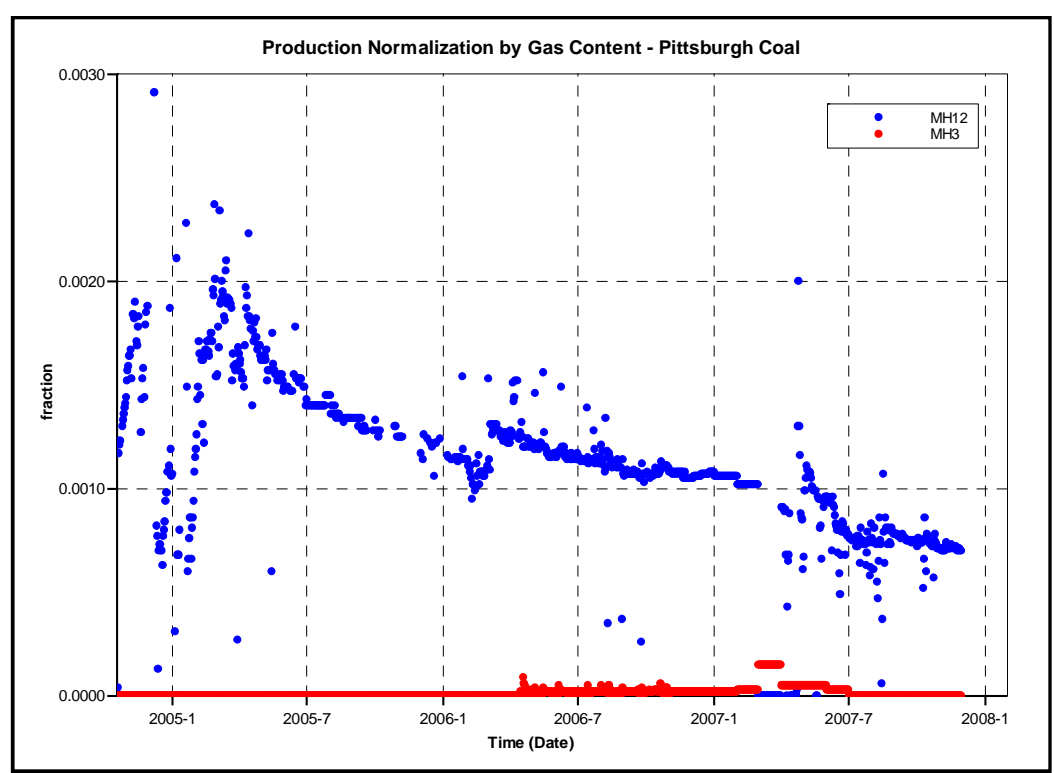

Figure 4-35: Production Normalization by Gas Content at Wells MH12 and MH3 for PG Coal 


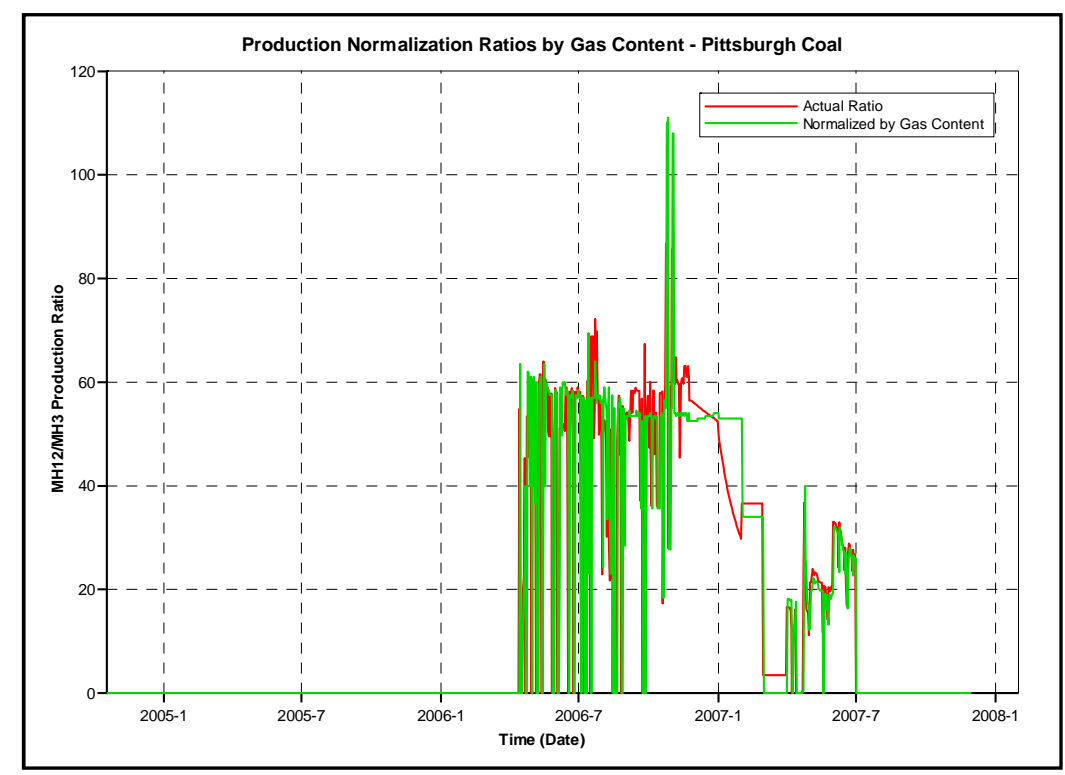

Figure 4-36: MH12/MH3 Production Normalized by Gas Content for PG Coal

UF Production normalization: Figure 4-37 shows the normalized production by gas content done for Upper Freeport coal. A comparison between the actual production ratio and the normalized one based on the gas content criteria is done. Figure 4-38 to 4-40 show the results of the ratio comparison for MH18/MH5, MH18/MH20, and MH18/MH11 respectively. The black line represents the normalized ratios for each case. Based on the results; the production ratio has dropped from 5 to 4 times between MH18 and MH5. Also production ratio between MH18 and MH11 has dropped by half, while MH18/MH20 ratio has remains about the same. 


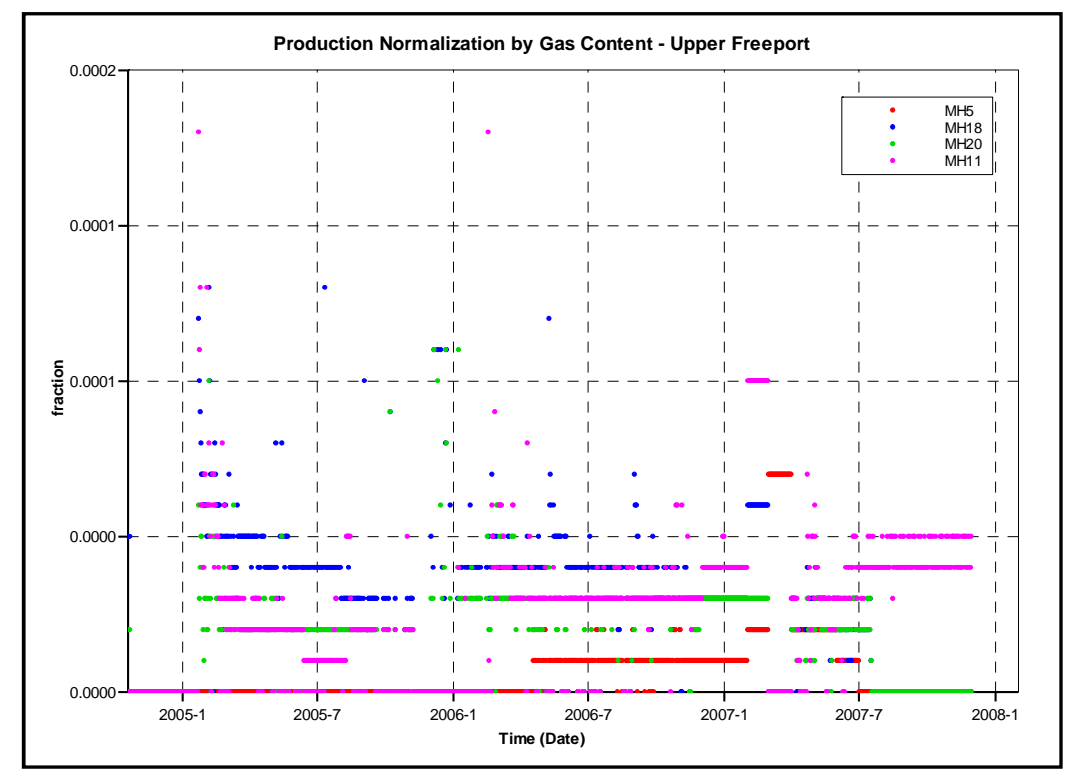

Figure 4-37: UF all wells gas normalized production

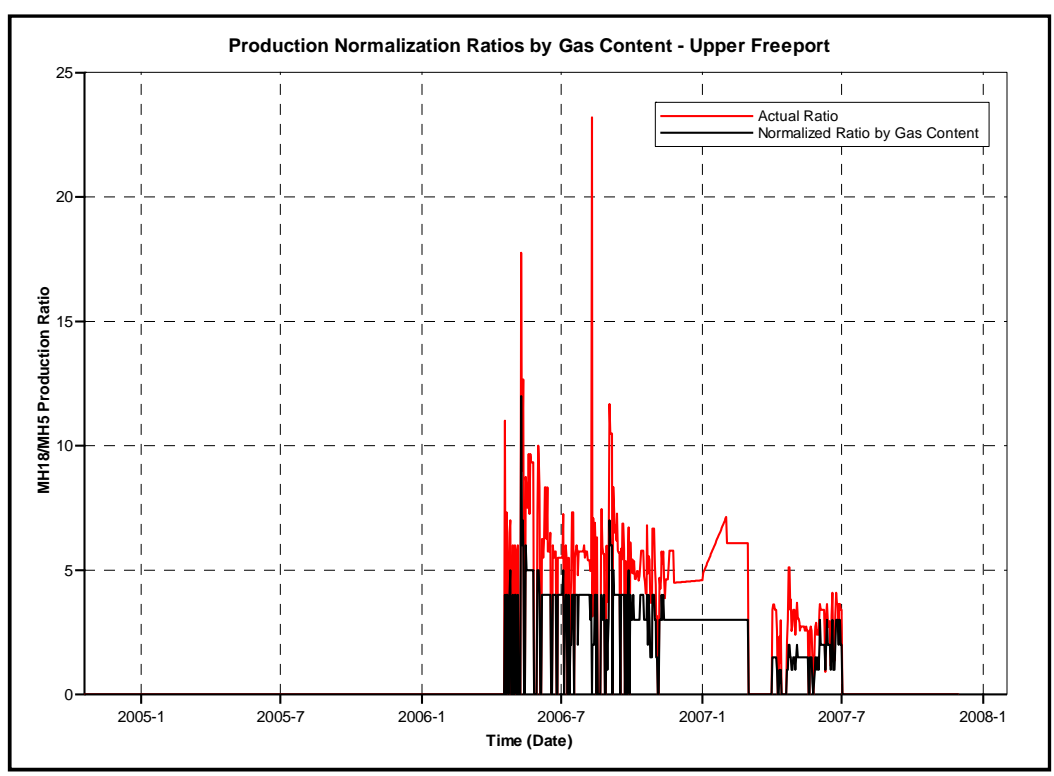

Figure 4-38: MH18/MH5 Production Normalized by Gas Content for UF Coal 


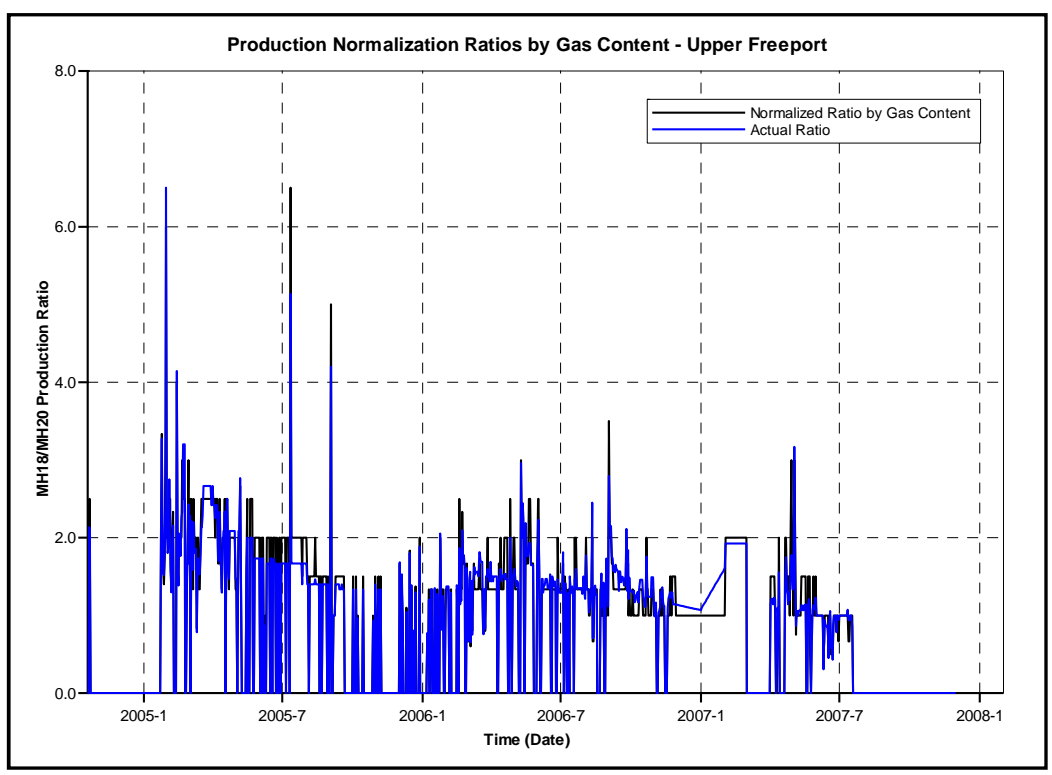

Figure 4-39: MH18/MH20 Production Normalized by Gas Content for UF Coal

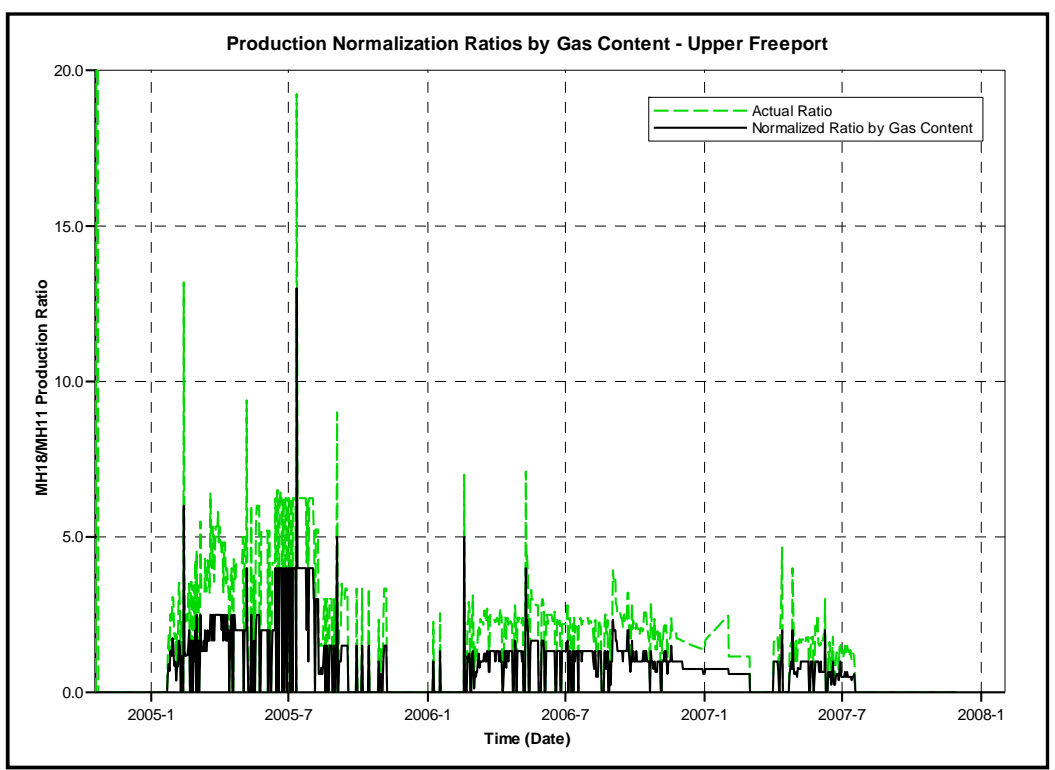

Figure 4-40: MH18/MH11 Production Normalized by Gas Content for UF Coal 


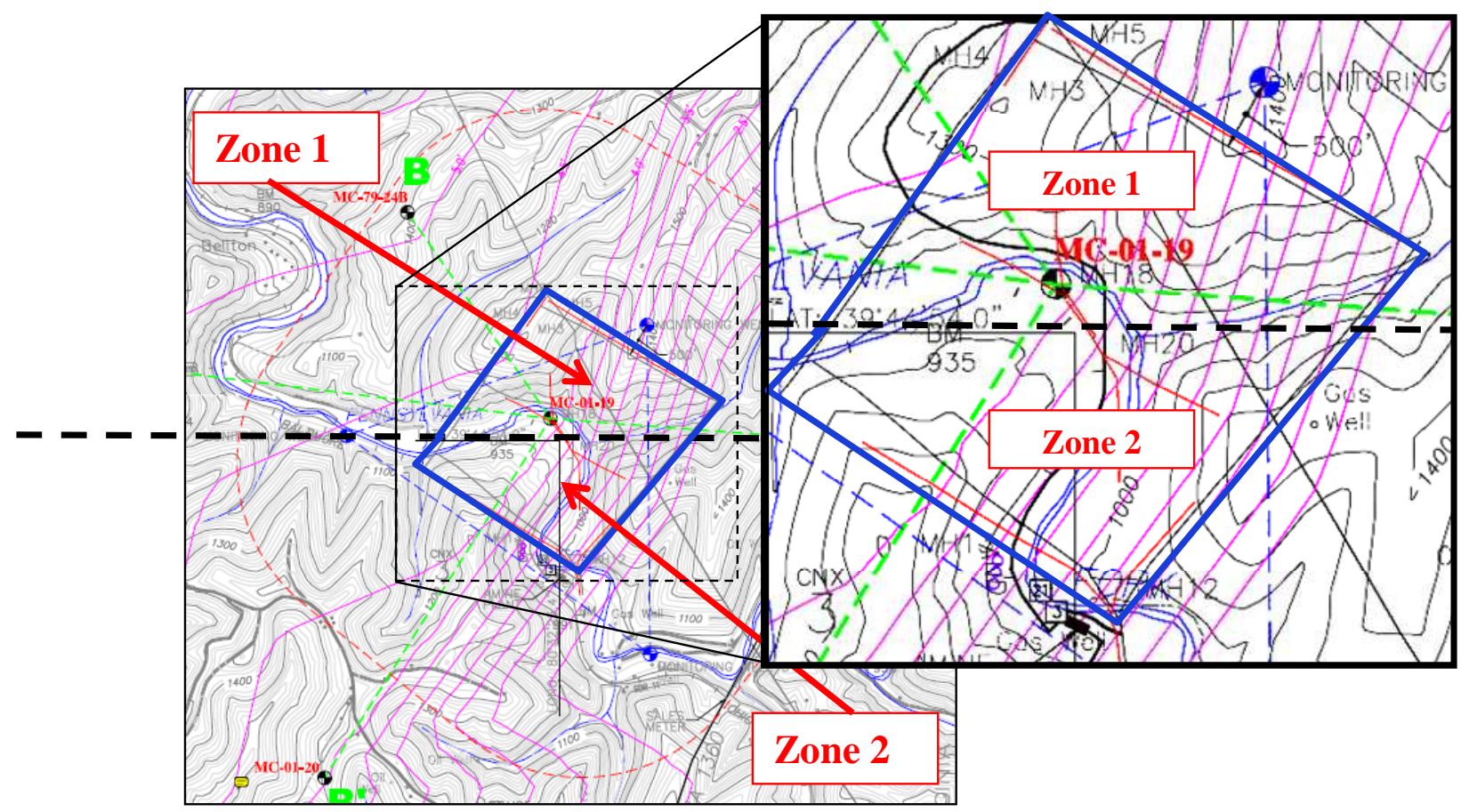

Figure 4-41: Zones distribution

\section{Reservoir Modeling}

This section is divided in three main stages; building the model and history matching process.

\section{Static model}

The static model of the field has been built using FLOGRID-ECLIPSE. The geologist logs of the five core samples taken on the extremes along the cross section AA' and BB' are used to extract the tops and thicknesses for each formation. A grid system of 100x 100 simulation cells for the 1520 acres area of study is imposed over the static model resulting for a $81 \times 81 \mathrm{ft}$ cell size, then it was imported into BUILDER-CMG. Figures 4-42 and 4-43 show the structural and isopach maps for Pittsburgh, also Figures 4-44 and 4-45 show the structural and isopach maps for Upper Freeport coals respectively. 


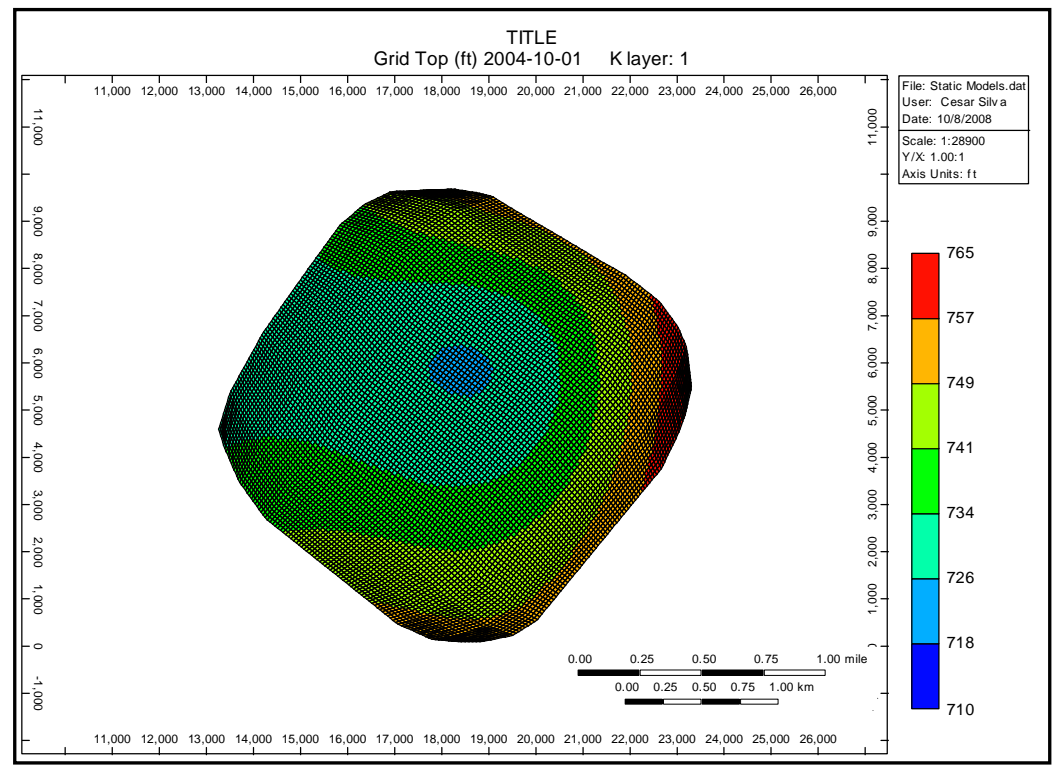

Figure 4-42: Structural Map for PG Coal

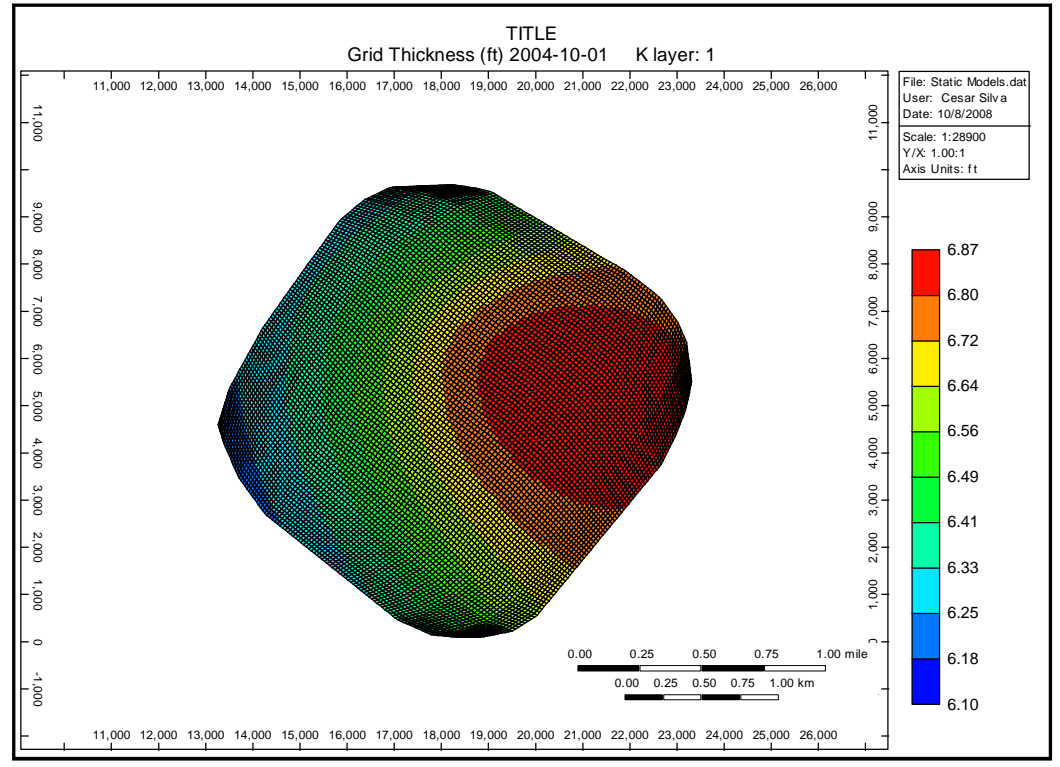

Figure 4-43: Isopach map for PG Coal 


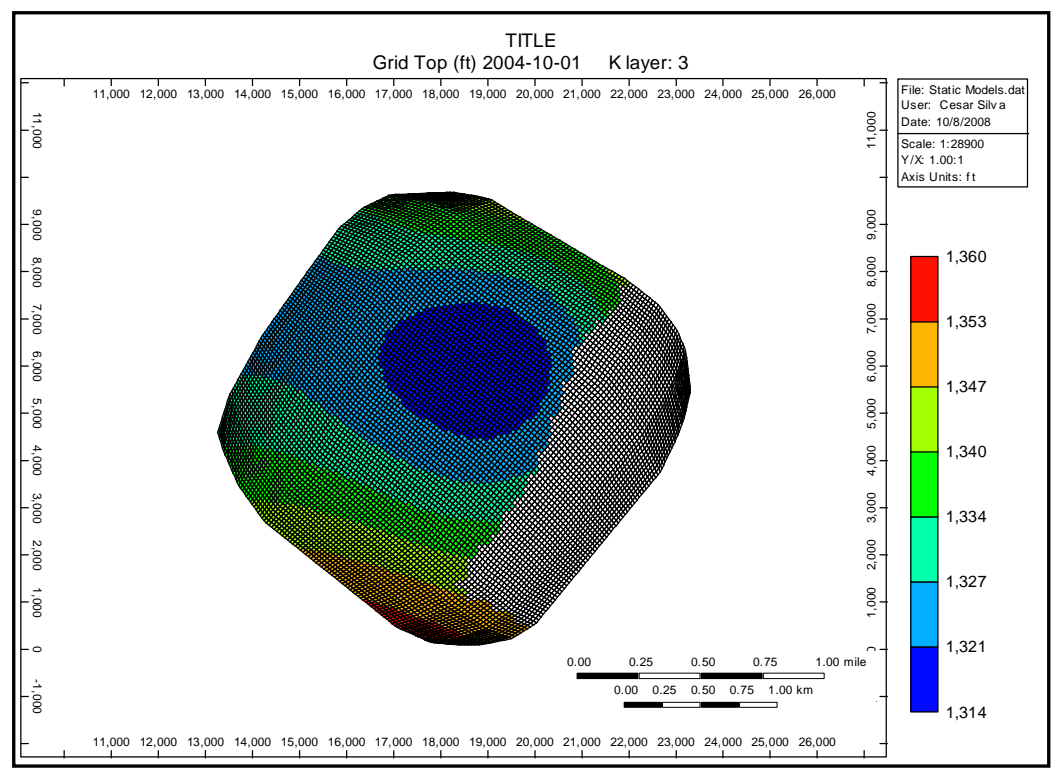

Figure 4-44; Structural Map for UF

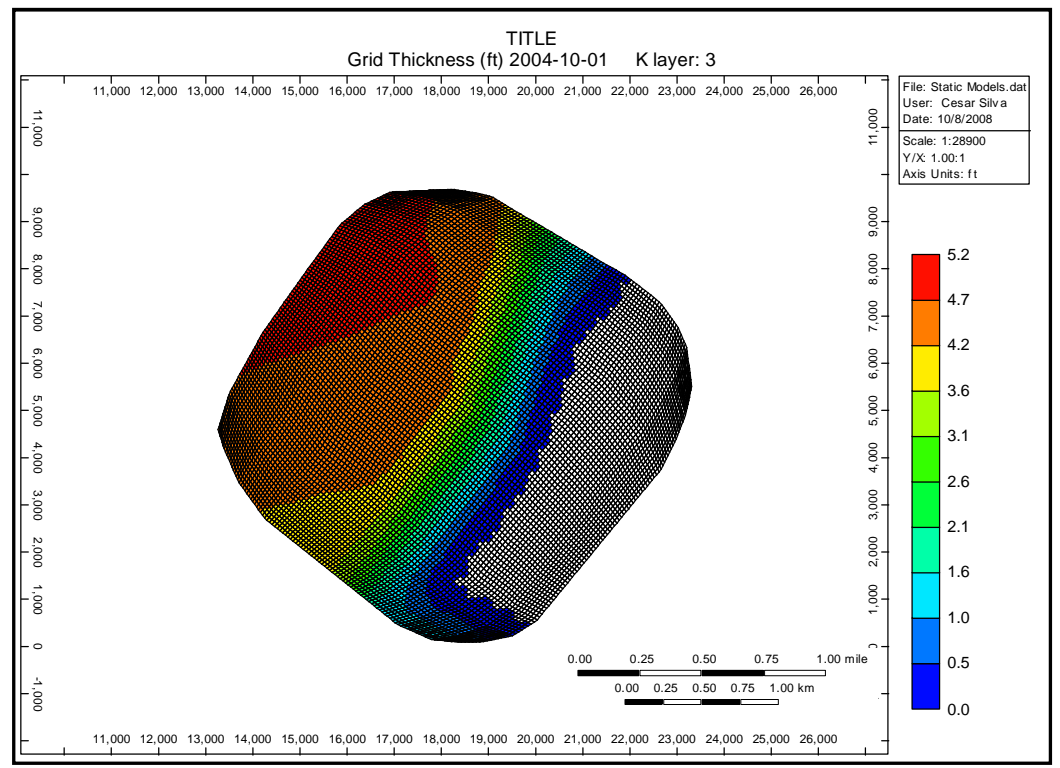

Figure 4-45: Isopach Map for UF

Model Initialization

All reservoir parameters from actual data and other sources are incorporated into the model. This 1520 acres representation is surrounded by a non- flow boundary. Both models; for Pittsburgh and Upper Freeport were initialized as undersaturated reservoirs regardless of Upper 
Freeport for not being actively a water producer. In order to account for water saturation, WaterGas contact depths have been set to $726 \mathrm{ft}$ and $1336 \mathrm{ft}$ for Pittsburgh and Upper Freeport respectively.

\section{Pittsburgh Coal Base Model}

Figure 4-46 shows a comparison between the actual gas production and the simulated one for the base case model for MH12 in Pittsburgh coal. The red and blue dots represent actual gas rate and gas cumulative respectively, and the green and dotted pink lines represent simulated gas rate and cumulative respectively. Based on the results; the model is underestimating the gas production for about 75,000 MSCF. However gas rates behaviors are very similar.

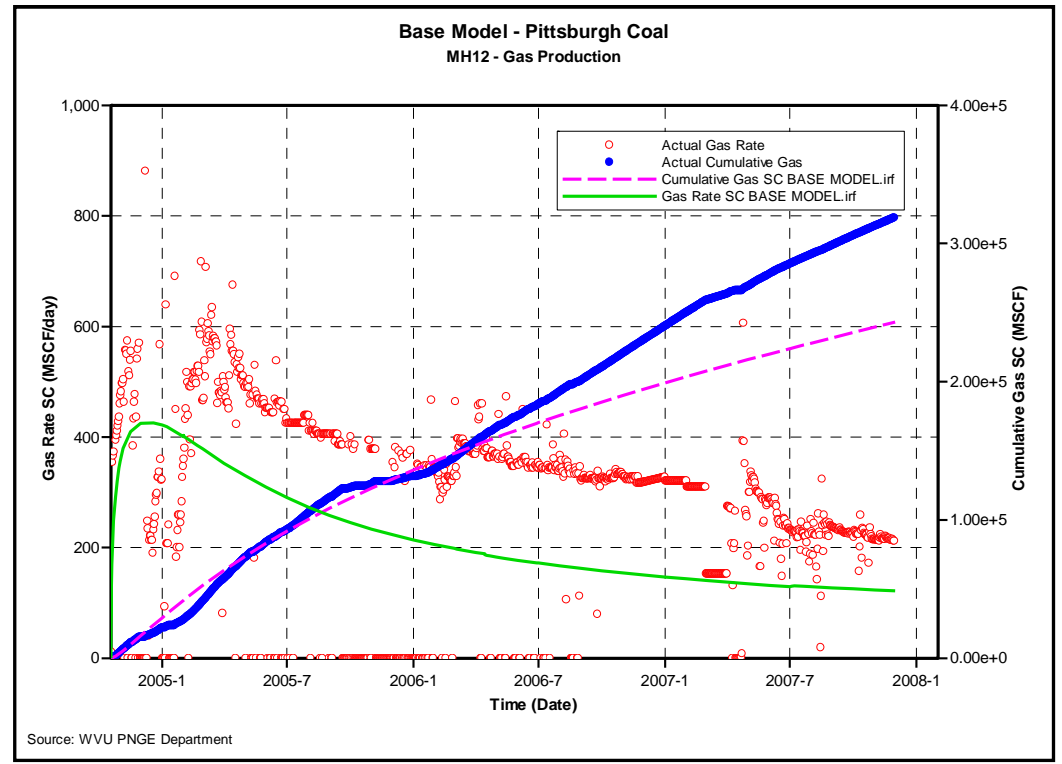

Figure 4-46 MH12 Base Model Gas Production 
Figure 4-47 shows a comparison between the actual water production and the simulated one for the base case model for MH12 in Pittsburgh coal. In this graph, the light blue and light green dots represent actual water rate and water cumulative respectively, and the dark blue and dotted dark green lines represent simulated water rate and cumulative respectively. Based on the results; the model is simulating water rates about 45 bbls while actual rates are about 145 bbls.

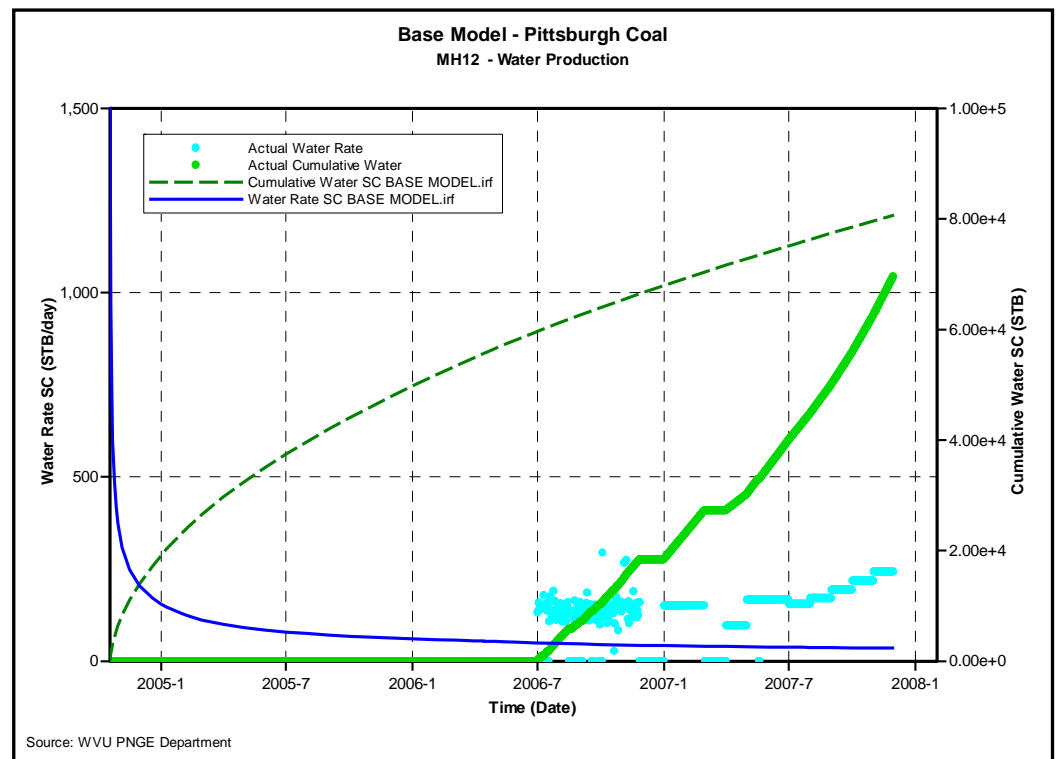

Figure 4-47: MH12 Base Model Water Production 
Figure 4-48 shows a comparison between the actual gas production and the simulated one for the base case model for MH3 in Pittsburgh coal. The red and blue dots represent actual gas rate and gas cumulative respectively, and the green and dotted pink lines represent simulated gas rate and cumulative respectively. Based on the results; the model is overestimating the gas production for about 65,000 MSCF.

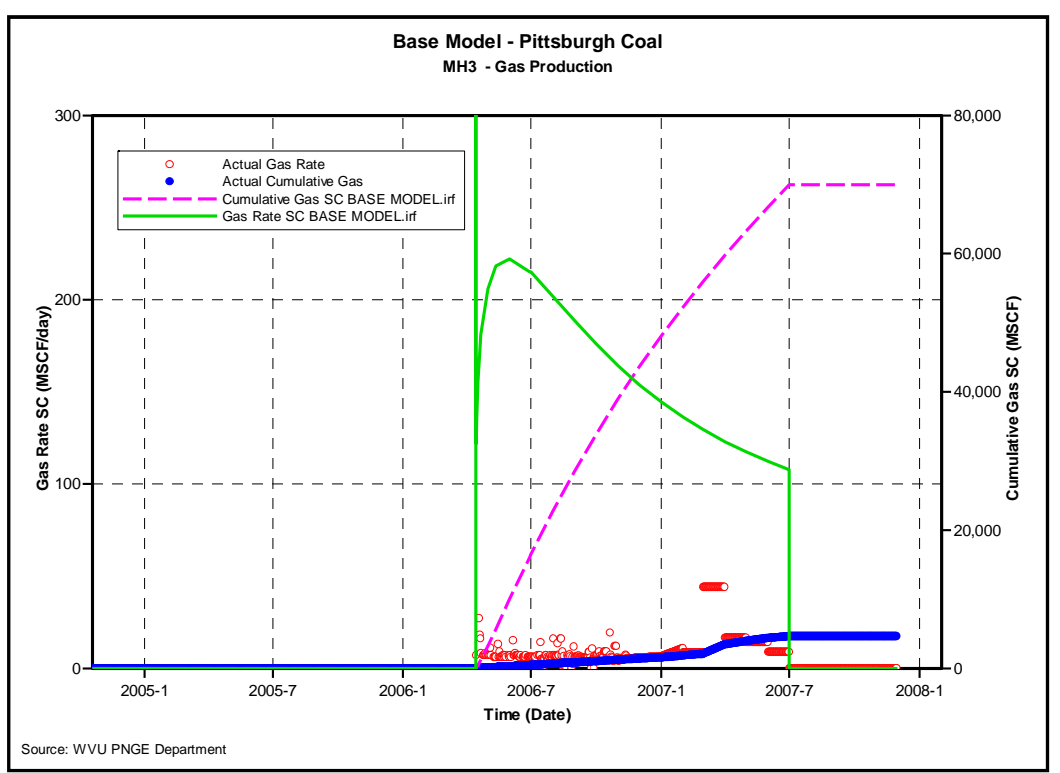

Figure 4-48: MH3 Base Model Gas Production

Figure 4-49 shows a comparison between the actual water production and the simulated one for the base case model for MH3 in Pittsburgh coal. In this graph, the dark blue and dotted dark green lines represent simulated water rate and cumulative respectively. Notice that MH3 has not produced any water during its life, however the model is simulating 21,000 bbls of cumulative water. 


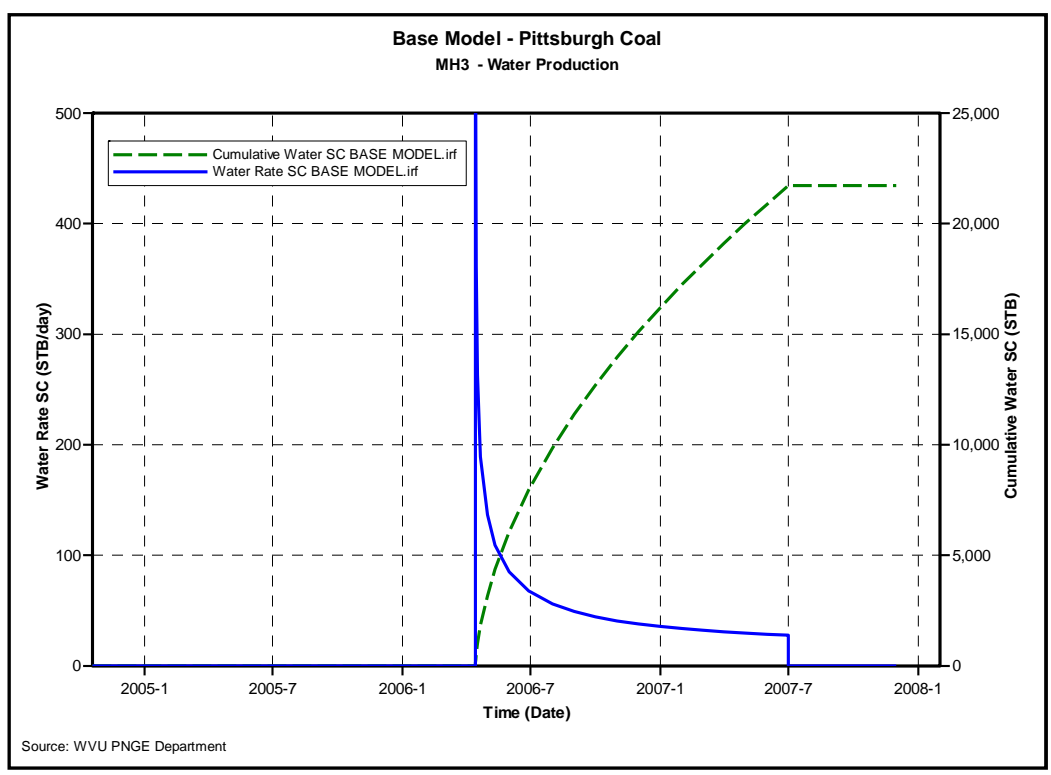

Figure 4-49: MH3 Base Model Water Production

\section{Upper Freeport Coal Base Model:}

Figure 4-50 and 4-51 show a comparison between the actual gas and water production and the simulated one for the base case model for MH5 in Upper Freeport coal respectively. The red and blue dots represent actual gas rate and gas cumulative respectively, and the green and dotted pink lines represent simulated gas rate and cumulative respectively. Based on the results; the model is overestimating the gas production for about 32,000 MSCF and for about 4.5 bbls of water. Note that there is not actual water production from MH5. 


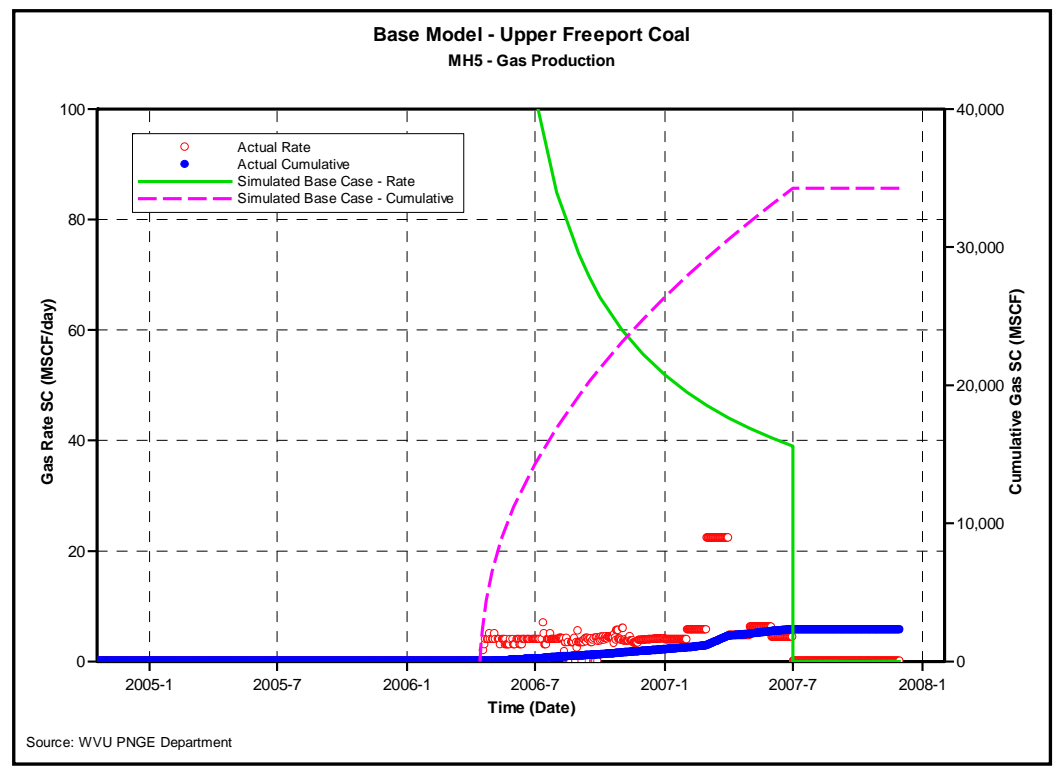

Figure 4-50: MH5 Base Model Gas Production

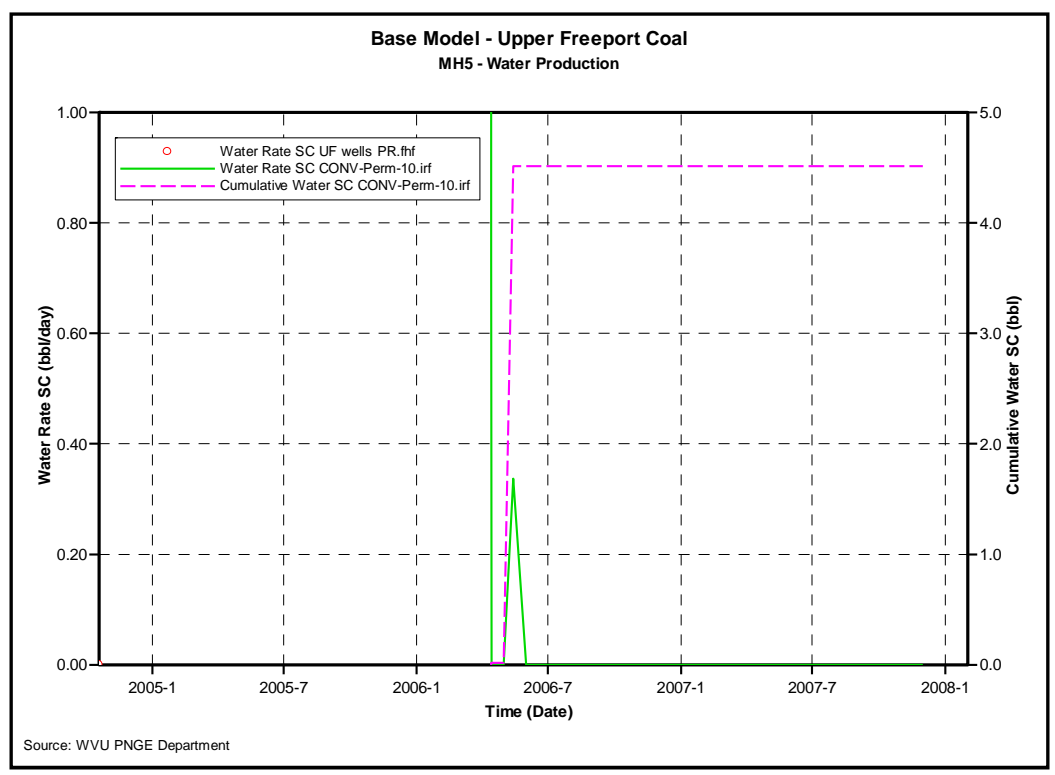

Figure 4-51: MH5 Base Model Water Production 
Figure 4-52 shows a comparison between the actual gas production and the simulated one for the base case model for MH18 in Upper Freeport coal. The red and blue dots represent actual gas rate and gas cumulative respectively, and the green and dotted pink lines represent simulated gas rate and cumulative respectively. Based on the results; the model is overestimating the gas production for about 30,240 MSCF and for about 1.6 bbls of water. Note that there is not actual water production from MH18. Figure 4-53 show water production for MH18.

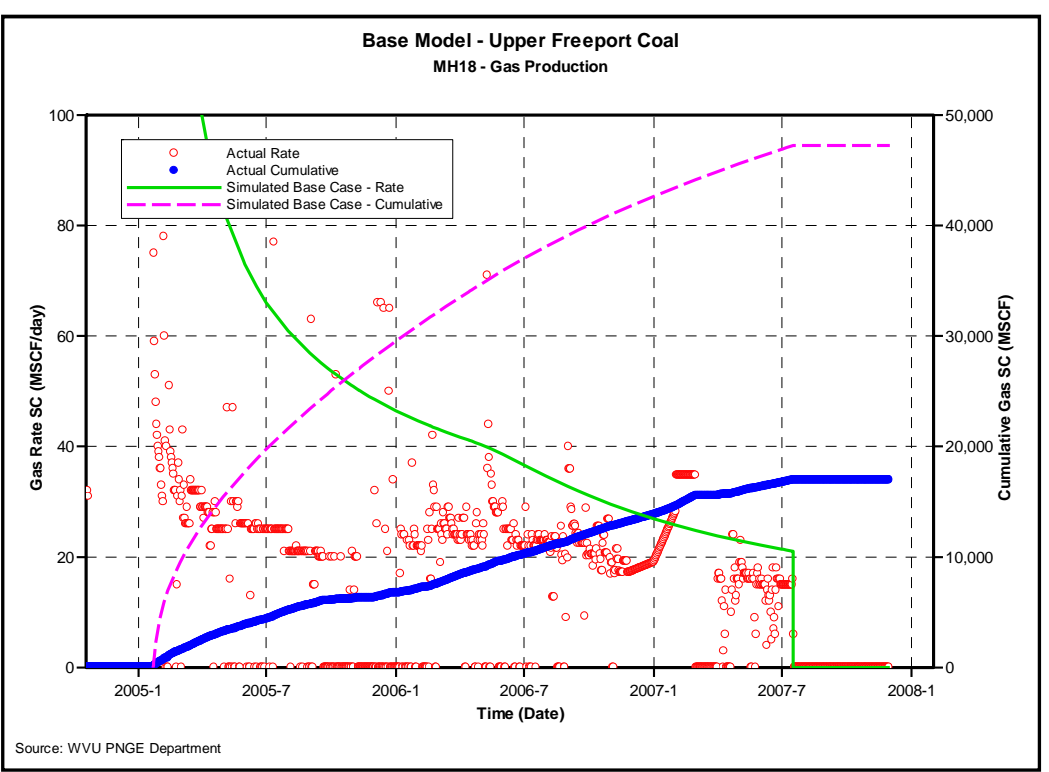

Figure 4-52: MH18 Base Model Gas Production

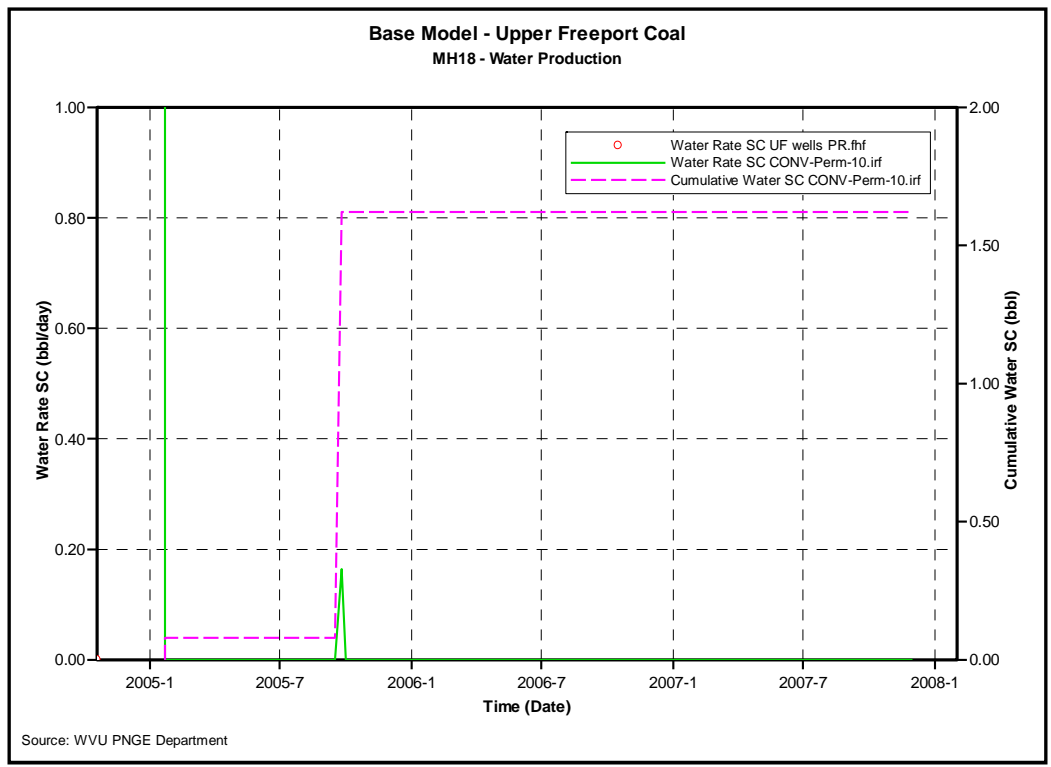

Figure 4-53: MH18 Base Model Water Production 
Figure 4-54 shows a comparison between the actual gas production and the simulated one for the base case model for MH20 in Upper Freeport coal. The red and blue dots represent actual gas rate and gas cumulative respectively, and the green and dotted pink lines represent simulated gas rate and cumulative respectively. Based on the results; the model is overestimating the gas production for about 8,432 MSCF and for about 0.27 bbls of water. Note that there is not actual water production from MH20. Figure 4-55 show water production for MH20.

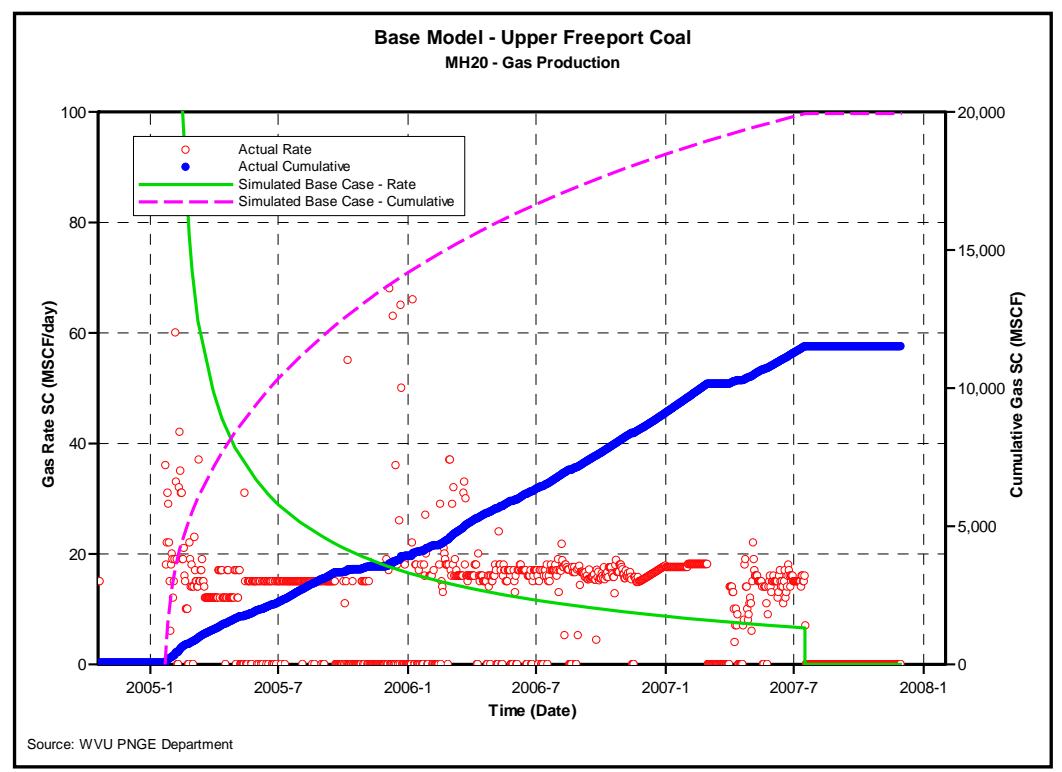

Figure 4-54: MH20 Base Model Gas Production

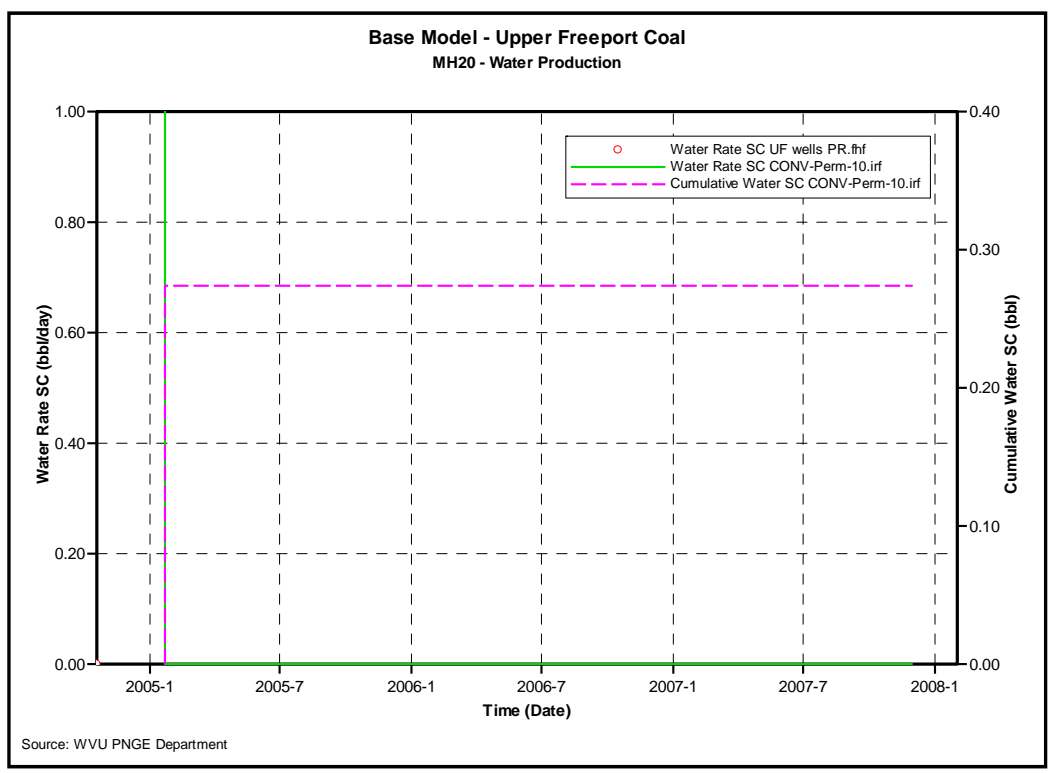

Figure 4-55: MH20 Base Model Water Production 
Figure 4-56 shows a comparison between the actual gas production and the simulated one for the base case model for MH11 in Upper Freeport coal. The red and blue dots represent actual gas rate and gas cumulative respectively, and the green and dotted pink lines represent simulated gas rate and cumulative respectively. Based on the results; the model is overestimating the gas production for about 48,100 MSCF. and underestimating the cumulative water production for about 21 bbls of water. Notice that actual cumulative water production from MH11 is less than 40 bbls during its entire life. Figure 4-57 show water production for MH11.

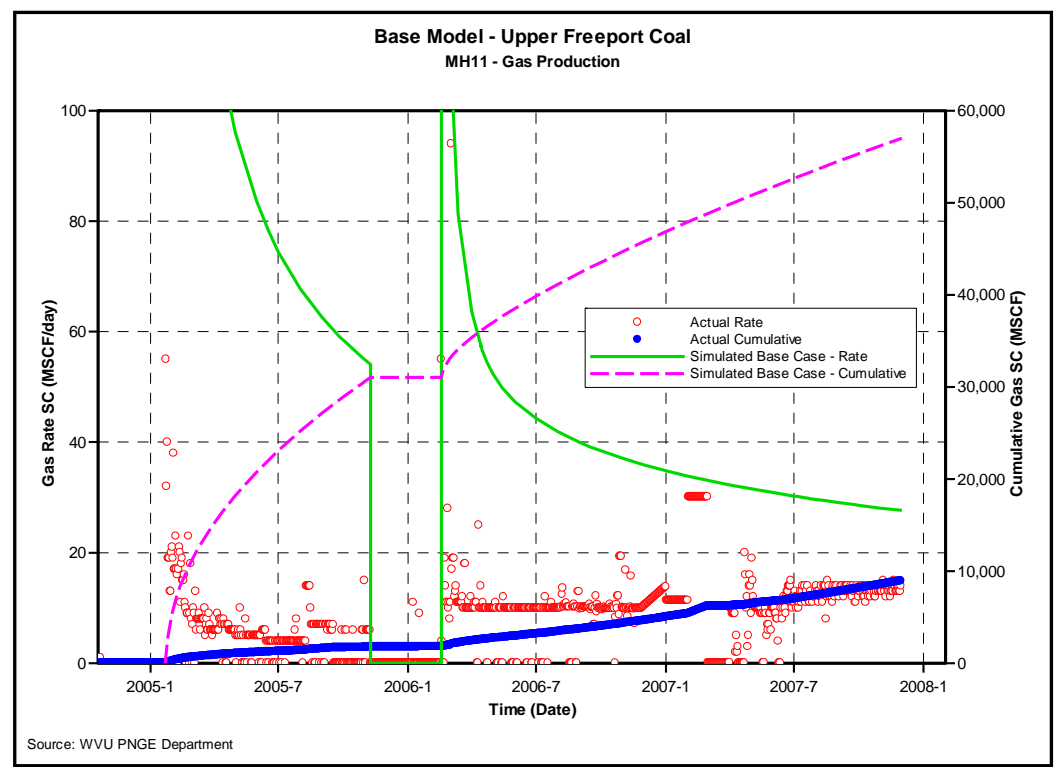

Figure 4-56: MH11 Base Model Gas Production 


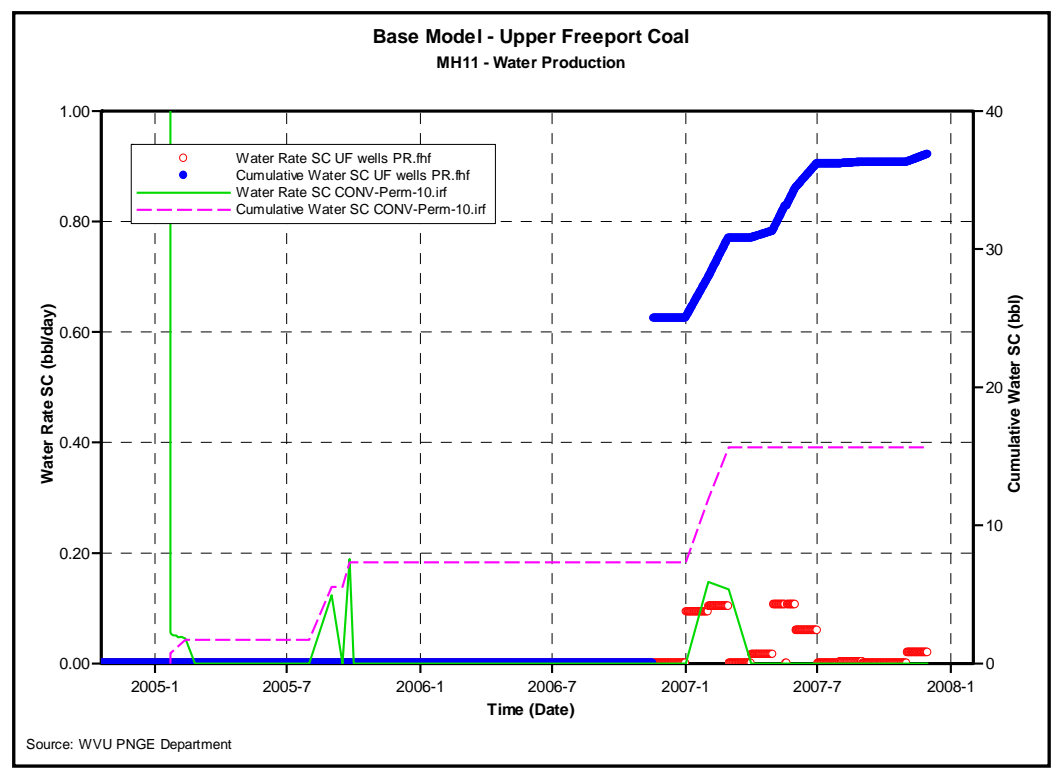

Figure 4-57: MH11 Base Model Water Production

Tables 4-7 and 4-8 show a comparison and the difference in percentage between the actual production and the simulated one for the base case for Pittsburgh and Upper Freeport coals respectively. Positive numbers in the simulated difference indicate overestimation of the production while negative numbers indicate underestimation of production of the phase. Also Figures 4-58 shows the comparison graphically in a cartesian plot for Pittsburgh coal while figure 4-59 shows the comparison graphically in a semi-log plot for Upper Freeport coal. 


\begin{tabular}{|c|c|c|c|c|}
\hline \multicolumn{5}{|c|}{ Pittsburgh Coal } \\
\hline Well & Phase & $\begin{array}{c}\text { Actual } \\
\text { Production }\end{array}$ & $\begin{array}{l}\text { Simulated } \\
\text { Production }\end{array}$ & $\begin{array}{c}\text { Simulated Diference, } \\
\%\end{array}$ \\
\hline \multirow{2}{*}{$\mathrm{MH} 12$} & Gas, MSCF & 318,437 & 243,159 & -24 \\
\hline & Water, BWPD $\left(^{*}\right)$ & 145 & 45 & -69 \\
\hline \multirow{2}{*}{$\mathrm{MH3}$} & Gas, MSCF & 4,601 & 69,999 & 1,421 \\
\hline & Water, Bbls & - & 21,713 & more than $2,171,299$ \\
\hline
\end{tabular}

Table 4-8: Water and Gas Production for UF wells

\begin{tabular}{|c|c|c|c|c|}
\hline \multicolumn{5}{|c|}{ Upper Freeport Coal } \\
\hline Well & Phase & $\begin{array}{c}\text { Actual } \\
\text { Production }\end{array}$ & $\begin{array}{l}\text { Simulated } \\
\text { Production }\end{array}$ & $\begin{array}{c}\text { Simulated Diference, } \\
\%\end{array}$ \\
\hline \multirow{2}{*}{ MH5 } & Gas, MSCF & 2,298 & 34,247 & 1,390 \\
\hline & Water, Bbls & - & 4.50 & more than 44,900 \\
\hline \multirow{2}{*}{ MH18 } & Gas, MSCF & 16,990 & 47,230 & 178 \\
\hline & Water, Bbls & - & 1.60 & more than 15,900 \\
\hline \multirow{2}{*}{ MH20 } & Gas, MSCF & 11,506 & 19,938 & 73 \\
\hline & Water, Bbls & - & 0.27 & more than 2,600 \\
\hline \multirow{2}{*}{$\mathrm{MH} 11$} & Gas, MSCF & 8,910 & 57,017 & 540 \\
\hline & Water, Bbls & 37 & 15.60 & -58 \\
\hline
\end{tabular}

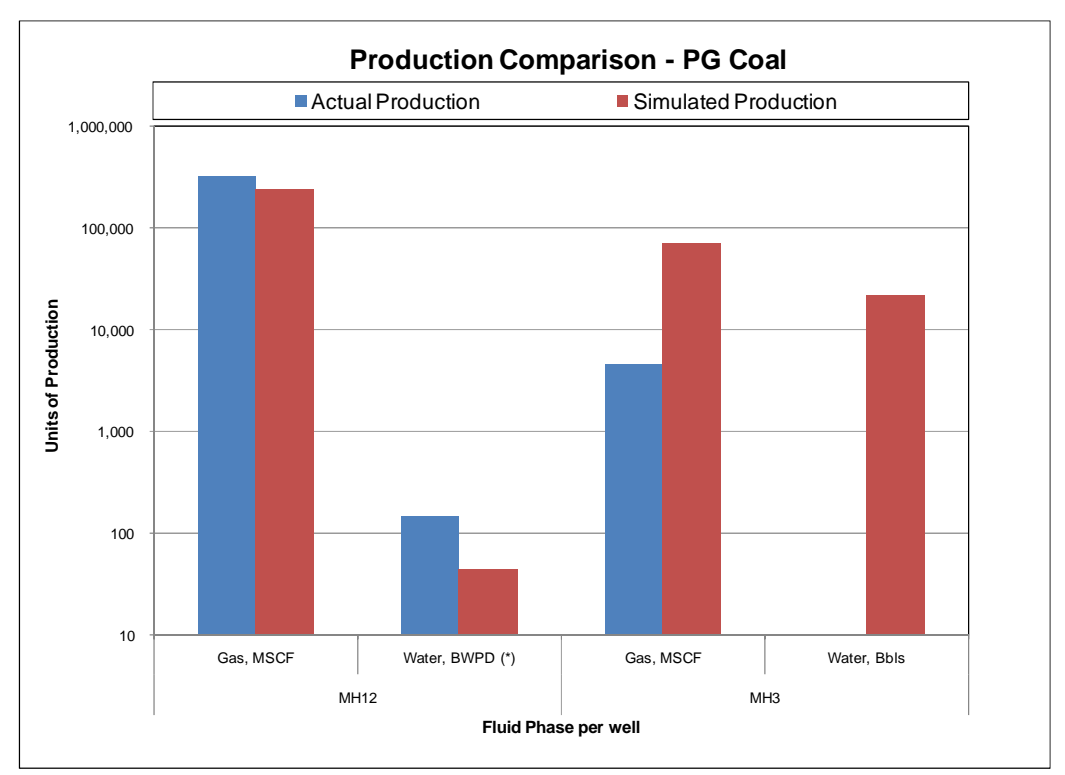

Figure 4-58: Comparison between Actual and Simulated production for PG coal wells 


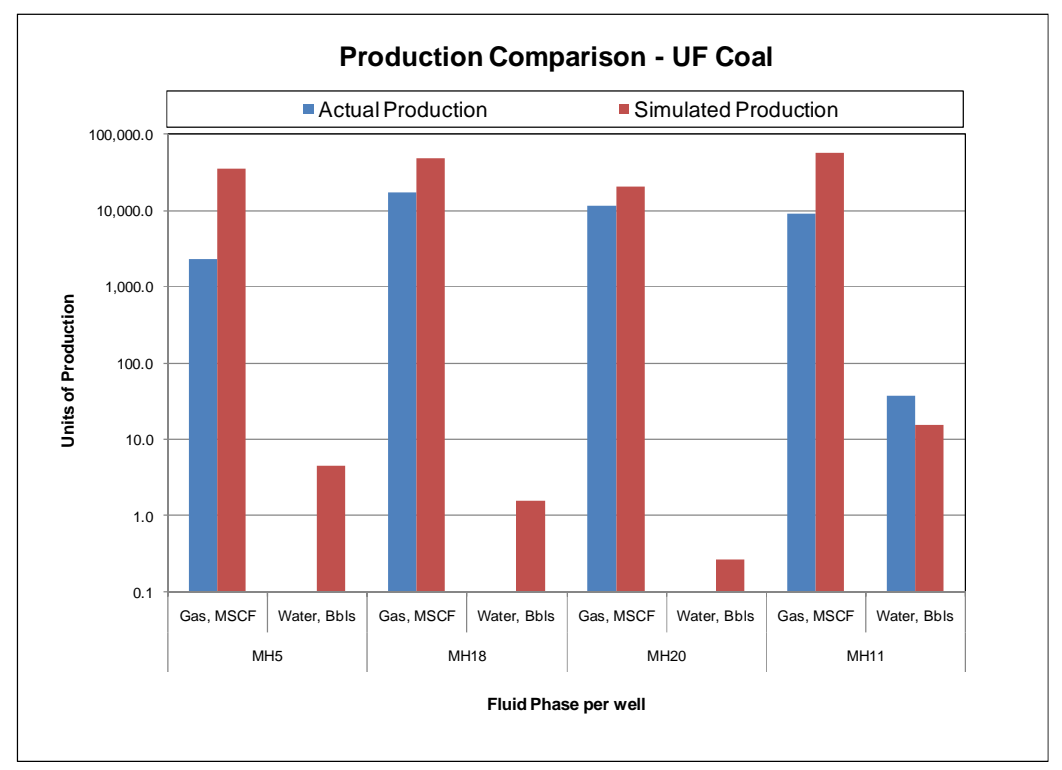

Figure 4-59: Comparison between Actual and Simulated production for UF coal wells

\section{History Matching Process}

Ones the base cases are run and analyzed; different approaches are taken to account for uncertainties in the reservoir parameters in order to achieve history matching.

\section{History Matching Phase I}

Sensitivity analyses of the conventional and unconventional parameters are done in order to evaluate their effects in the production for both coals. Then a summary of the results is presented in tables. In the table; negative or positive signs in the sensitivity column indicate that the sensitivity of the phase (gas or water) decreases or increases respectively. "AS" indicates that the sensitivity of the phase does not change as the value of the parameters does and also "N/A" indicates the sensitivity could not be evaluated. Negative or positive signs in the parameter $(\mathrm{k}, \Phi$, $\tau$, etc) column indicate that the value of the parameter decreases or increases respectively. The "From" and "To" column indicates the range of values for which the sensitivity increase or decrease. The "Match" column indicates the value at which a match is achieved or whether a match is not achieved (NM). The "Observation" column shows some notes about each particular 
case. Some tables do not contain the "Observation" column because no especial features are noticed.

Conventional Parameters: sensitivity studies by changing permeability, porosity, watergas contact, and relative permeability are performed.

As an example; sensitivity analysis of gas and water production in PG coal for permeability values of $0.01,1,5,10,15,20,25$, and $30 \mathrm{md}$, is shown below. Figures 4-60 to 463 show the sensitivity of production by changing permeability values. A summary of the results is shown in Table 4-9.

Table 4-9: Permeability sensitivity analysis for HMPH1-PG coal

\begin{tabular}{|c|c|c|c|c|c|c|c|}
\hline \multicolumn{9}{|c|}{ HMPH 1 - Sensitivity Analysis - Permeability Case } \\
\hline Well & Phase & Sensitivity & k Value & From & To & Match & Observations \\
\hline \multirow{2}{*}{ MH12 } & Gas & - & + & $5 \mathrm{md}$ & $30 \mathrm{md}$ & $25 \mathrm{md}$ & rates drop in April 2006 for k higher than 15md \\
\cline { 2 - 8 } & Water & - & + & $1 \mathrm{md}$ & $30 \mathrm{md}$ & $\mathrm{NM}$ & rates drop in April 2006 for k higher than 15md \\
\hline \multirow{2}{*}{ MH3 } & Gas & - & + & $1 \mathrm{md}$ & $30 \mathrm{md}$ & NM & \\
\cline { 2 - 8 } & Water & - & + & $1 \mathrm{md}$ & $30 \mathrm{md}$ & $\mathrm{NM}$ & \\
\hline
\end{tabular}

Table analysis: the table above shows how the sensitivity of gas or water production decreases or increases as the permeability value is increased or decreased within a range of study, it also shows if a match has been achieved for a well and the value to achieve the match, e.g. the sensitivity of gas production in MH12 increases as permeability values increases between $5 \mathrm{md}$ and $30 \mathrm{md}$ and a match is achieved in that well when permeability is set to $25 \mathrm{md}$. A decrease in gas production is observed in MH12 in April 2006 for permeability values higher than $15 \mathrm{md}$ as the effects of $\mathrm{MH} 3$ starting production. 


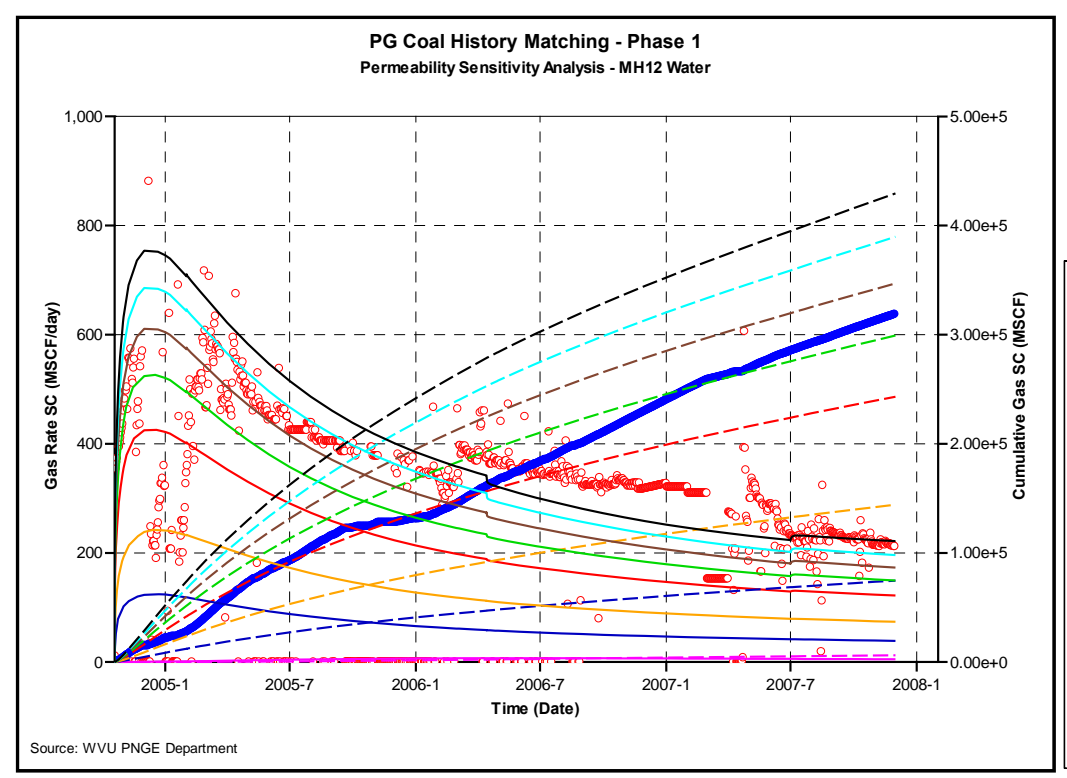

\begin{tabular}{|c|c|}
\hline$\bullet$ & $\begin{array}{l}\text { Actual Rate } \\
\text { Actual Cumulative }\end{array}$ \\
\hline----- & $\begin{array}{l}\text { - Base Case - Rate } k=10 \mathrm{md} \\
\text { - Base Case - Cumulative } \mathrm{k}=10 \mathrm{md}\end{array}$ \\
\hline$\longrightarrow$ & - Rate $\mathrm{k}=0.01 \mathrm{md}$ \\
\hline -ーーーー & $\begin{array}{l}\text { - Cumulative } \mathrm{k}=0.01 \mathrm{md} \\
\text { - Rate } \mathrm{k}=1 \mathrm{md}\end{array}$ \\
\hline----- & - Cumulative $\mathrm{k}=1 \mathrm{md}$ \\
\hline----- & - Cumulative $\mathrm{k}=5 \mathrm{md}$ \\
\hline---- & - Rate $\mathrm{k}=15 \mathrm{md}$ \\
\hline-1 & $\begin{array}{l}\text { - Cumulative } \mathrm{k}=15 \mathrm{md} \\
\text { - Rate } \mathrm{k}=20 \mathrm{md}\end{array}$ \\
\hline----- & - Cumulative $\mathrm{k}=20 \mathrm{md}$ \\
\hline & Rate $\mathrm{k}=25 \mathrm{md}$ \\
\hline & - Rate $\mathrm{k}=30 \mathrm{md}$ \\
\hline- & - Cumulative $\mathrm{k}=30 \mathrm{md}$ \\
\hline
\end{tabular}

Figure 4-60: Gas production sensitivity for permeability in MH12- HMPH1-PG coal

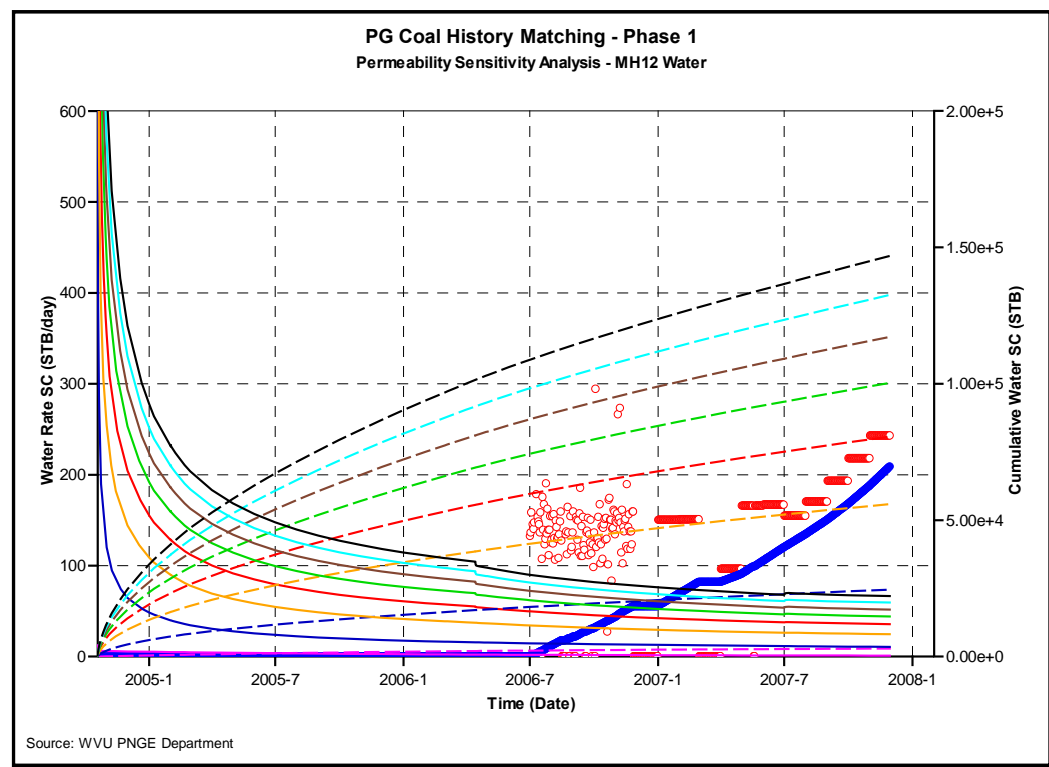

\begin{tabular}{|c|c|}
\hline$\bullet$ & $\begin{array}{l}\text { Actual Rate } \\
\text { Actual Cumulative }\end{array}$ \\
\hline$\overline{----}$ & $\begin{array}{l}\text { - Base Case - Rate } \mathrm{k}=10 \mathrm{md} \\
\text { - Base Case - Cumulative } \mathrm{k}=10 \mathrm{md}\end{array}$ \\
\hline$\overline{-----}$ & $\begin{array}{l}\text { - Rate } \mathrm{k}=0.01 \mathrm{md} \\
\text { - Cumulative } \mathrm{k}=0.01 \mathrm{md}\end{array}$ \\
\hline$--ー-ー$ & - Cumulative $\mathrm{k}=1 \mathrm{md}$ \\
\hline----- & $\begin{array}{l}\text { - Rate } \mathrm{k}=5 \mathrm{md} \\
\text { - Cumulative } \mathrm{k}=5 \mathrm{md}\end{array}$ \\
\hline & - Rate $\mathrm{k}=15 \mathrm{md}$ \\
\hline -ーーーー & $\begin{array}{l}\text { - Cumulative } k=15 \mathrm{md} \\
\text { - Rate } \mathrm{k}=20 \mathrm{md}\end{array}$ \\
\hline$-ー-ー-$ & $\begin{array}{l}\text { - Cumulative } k=20 \mathrm{md} \\
\text { - Rate } k=25 \mathrm{md}\end{array}$ \\
\hline----- & $\begin{array}{l}\text { - Cumulative } k=25 \mathrm{md} \\
\text { - Rate } \mathrm{k}=30 \mathrm{md}\end{array}$ \\
\hline$-ー-ー-~$ & - Cumulative $\mathrm{k}=30 \mathrm{md}$ \\
\hline
\end{tabular}

Figure 4-61: Water production sensitivity for permeability in MH12- HMPH1-PG coal 


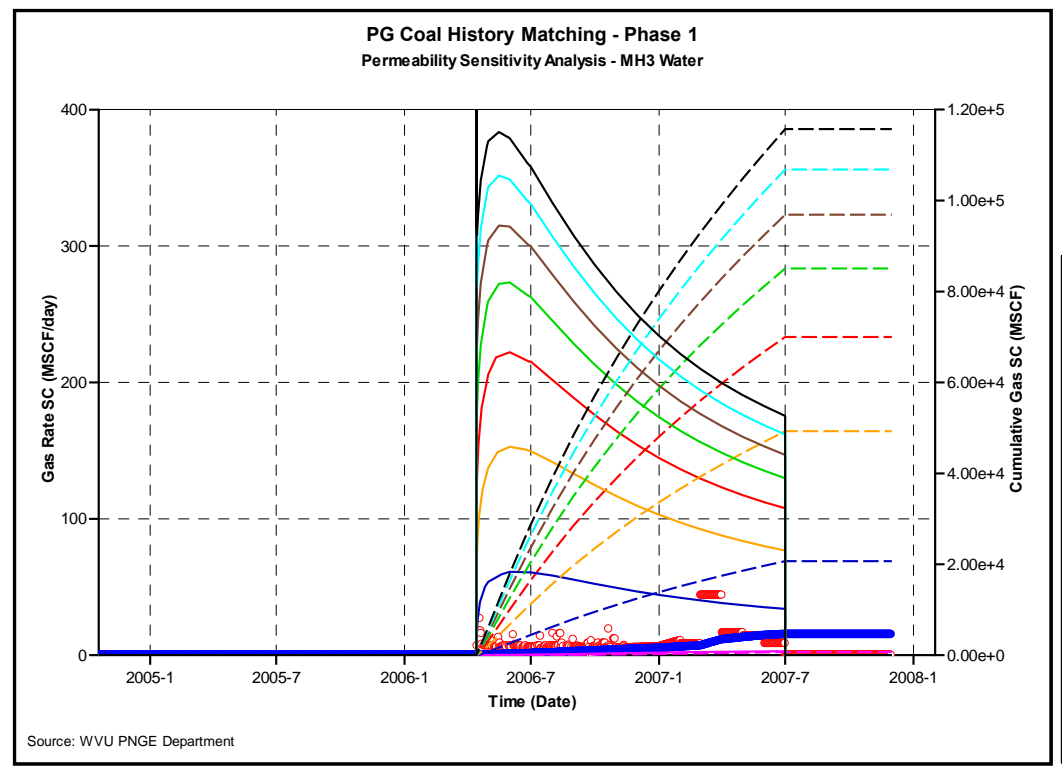

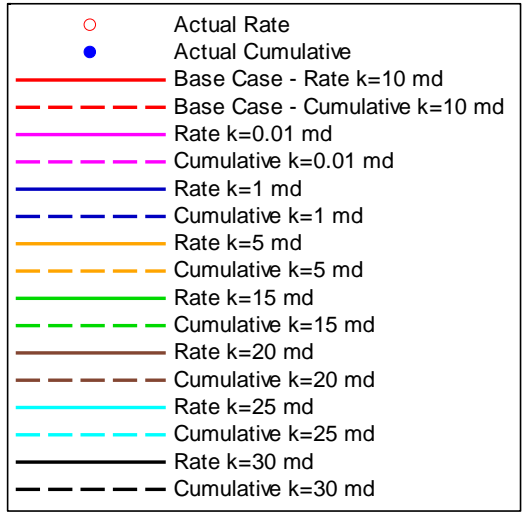

Figure 4-62: Gas production sensitivity for permeability in MH3- HMPH1-PG coal

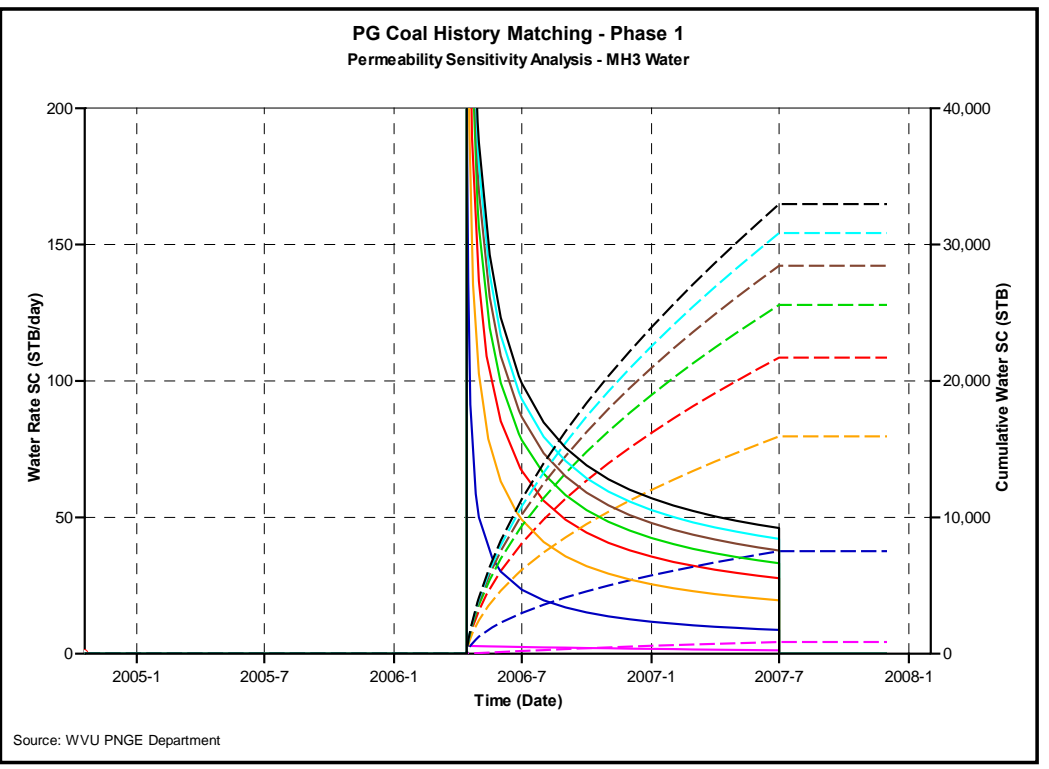

\begin{tabular}{|c|c|}
\hline$\circ$ & $\begin{array}{l}\text { Actual Rate } \\
\text { Base Case - Rate } k=10 \mathrm{md}\end{array}$ \\
\hline----- & - Base Case - Cumulative $\mathrm{k}=10 \mathrm{md}$ \\
\hline$\overline{-----}$ & $\begin{array}{l}\text { Rate } k=0.01 \mathrm{md} \\
\text { - Cumulative } \mathrm{k}=0.01 \mathrm{md}\end{array}$ \\
\hline & Rate $\mathrm{k}=1 \mathrm{md}$ \\
\hline----- & - Cumulative $\mathrm{k}=1 \mathrm{md}$ \\
\hline----- & - Cumulative $\mathrm{k}=5 \mathrm{md}$ \\
\hline-- & - Rate $k=15 \mathrm{md}$ \\
\hline & - Rate $\mathrm{k}=20 \mathrm{md}$ \\
\hline----- & - Cumulative $\mathrm{k}=20 \mathrm{md}$ \\
\hline---- & Cumulative $\mathrm{k}=25 \mathrm{md}$ \\
\hline$-ー-ー$ & $\begin{array}{l}\text { - Rate } \mathrm{k}=30 \mathrm{md} \\
\text { - Cumulative } \mathrm{k}=30 \mathrm{md}\end{array}$ \\
\hline
\end{tabular}

Figure 4-63: Water production Sensitivity for permeability in MH12- HMPH1-PG coal 
As another example; sensitivity analysis of gas and water production in PG coal for porosity values of $1,2,3,4,5$, and $6 \%$ are used for this study. Figures 4-64 to 4-67 show the sensitivity of production by changing porosity values. A summary of the results is shown in Table 4-10.

Table 4-10: Porosity sensitivity analysis for HMPH1-PG coal

\begin{tabular}{|c|c|c|c|c|c|c|}
\hline \multicolumn{7}{|c|}{ HMPH 1 - Sensitivity Analysis - Porosity Case } \\
\hline \multirow{2}{*}{ Well } & Phase & Sensitivity & $\boldsymbol{\Phi}$ Value & From & To & Match \\
\hline \multirow{2}{*}{ MH12 } & Gas & - & + & $1 \%$ & $6 \%$ & NM \\
\cline { 2 - 7 } & Water & - & + & $1 \%$ & $6 \%$ & NM \\
\hline \multirow{2}{*}{ MH3 } & Gas & - & + & $1 \%$ & $6 \%$ & NM \\
\cline { 2 - 7 } & Water & - & + & $1 \%$ & $6 \%$ & NM \\
\hline
\end{tabular}

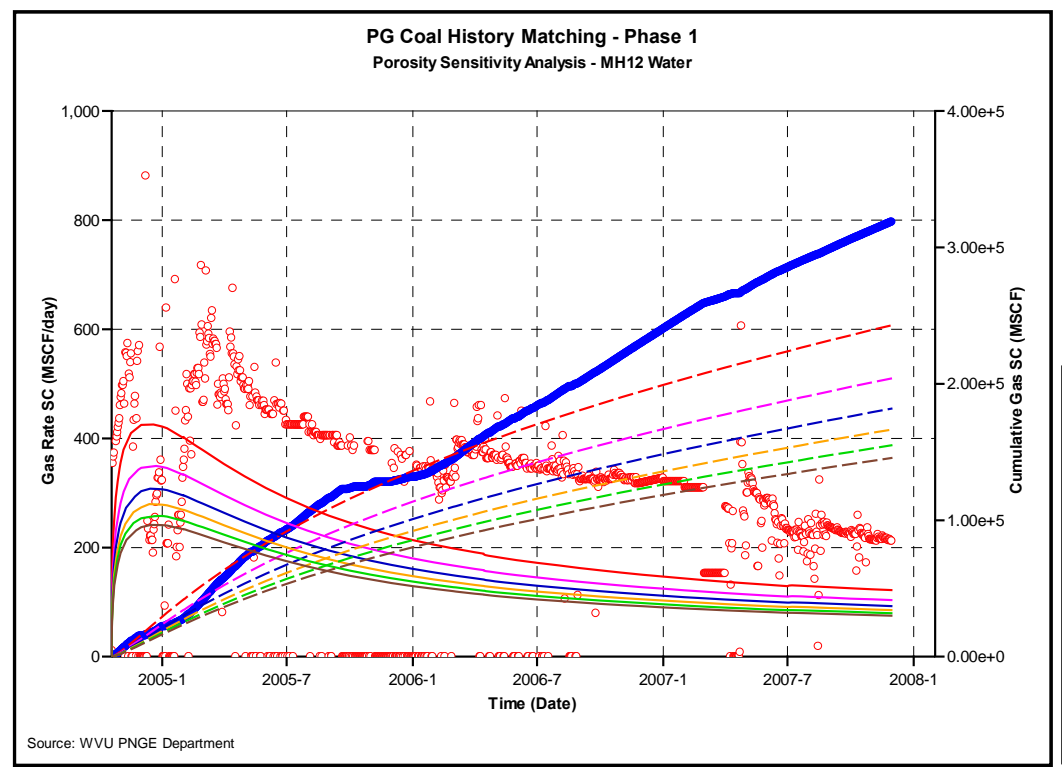

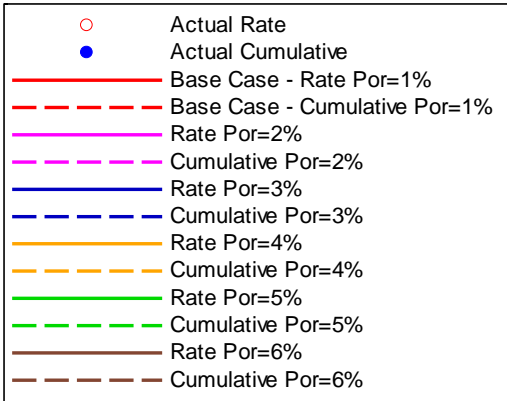

Figure 4-64: Gas production sensitivity for porosity in MH12- HMPH1-PG coal 


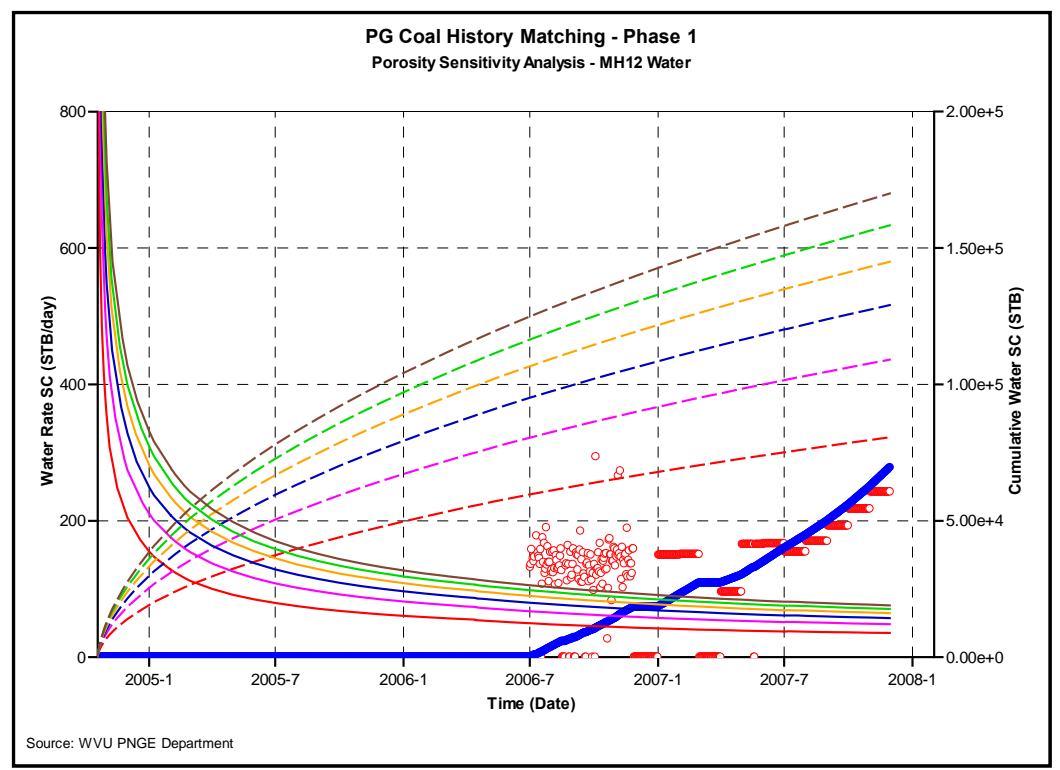

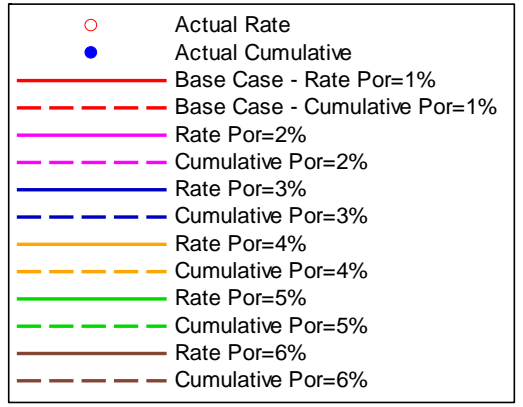

Figure 4-65: Water production sensitivity for permeability in MH12- HMPH1-PG coal

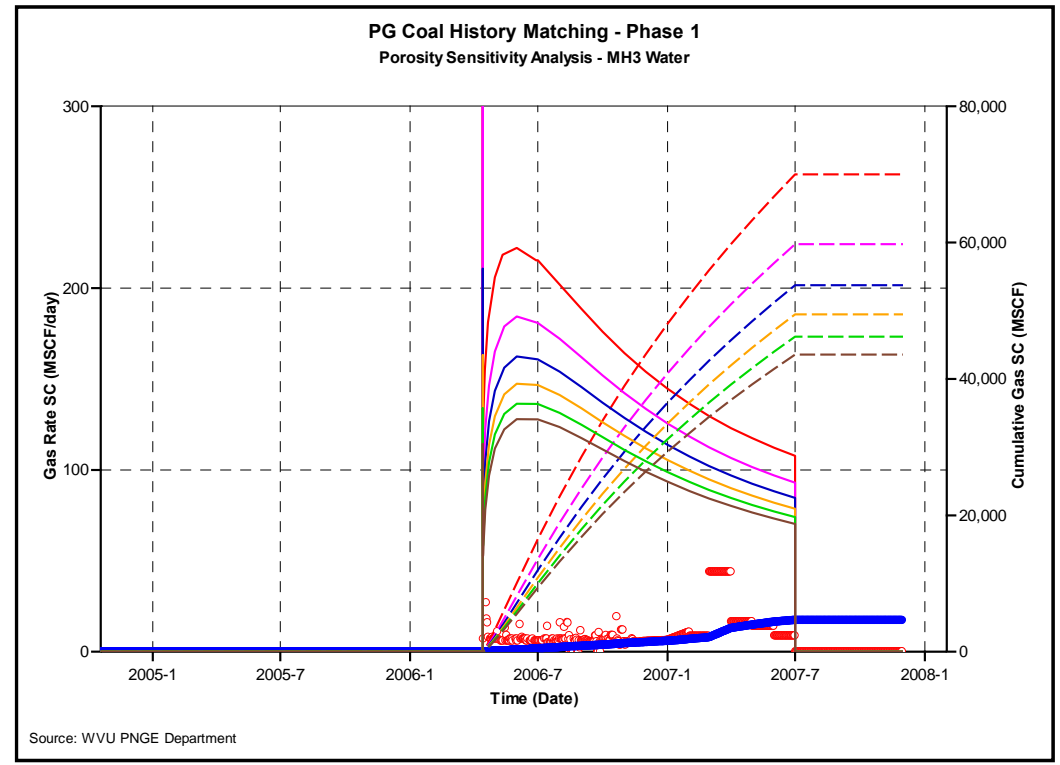

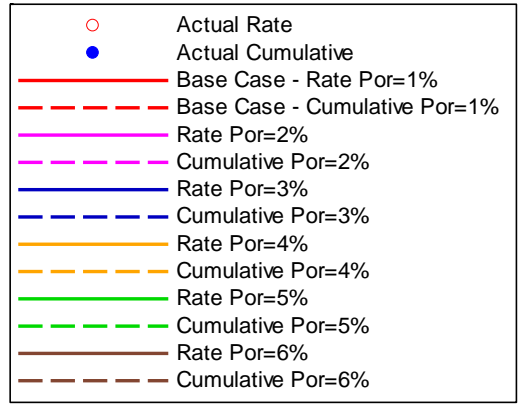

Figure 4-66: Water production sensitivity for porosity in MH3- HMPH1-PG coal 


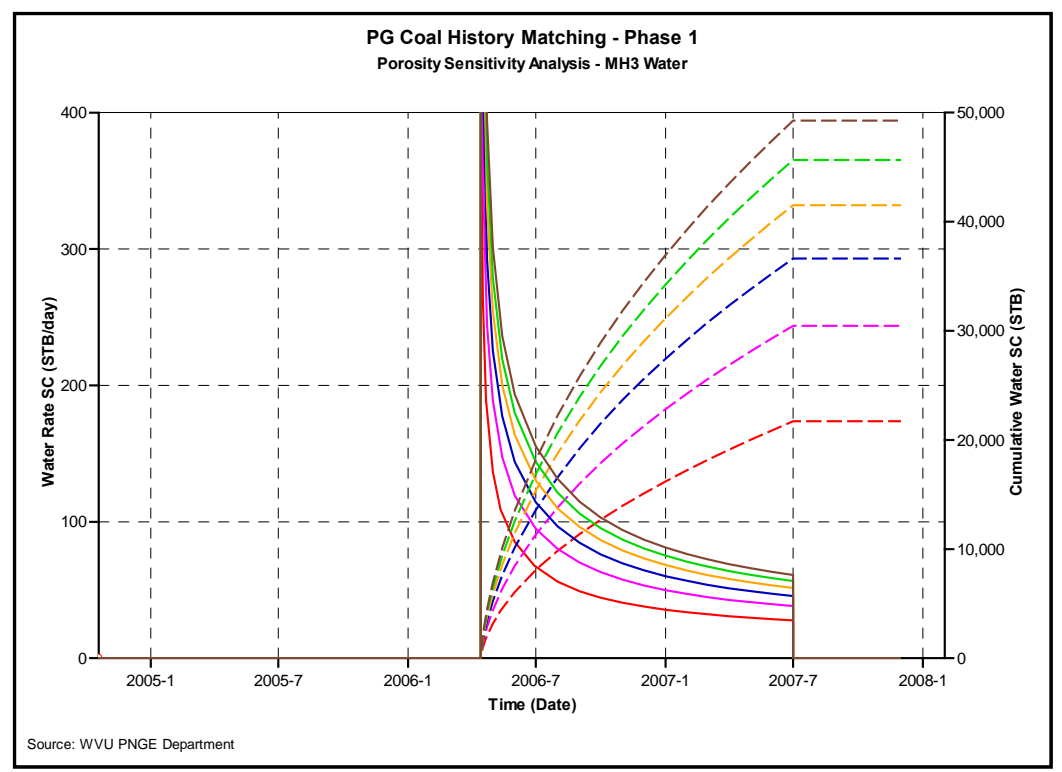

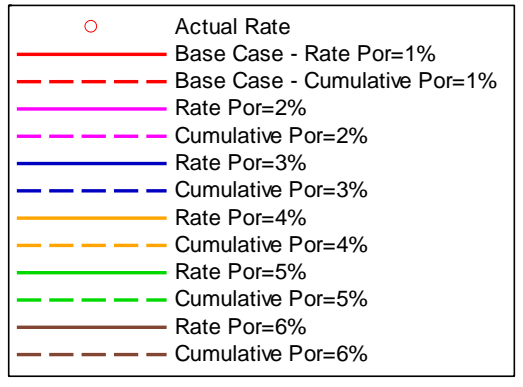

Figure 4-67: Water production sensitivity for porosity in MH3- HMPH1-PG coal 


\section{History Matching Phase II}

Sensitivity studies by changing permeability, porosity, gas content, desorption time, Langmuir parameters, well length, skin factor, and minimum bottom-hole pressure are performed.

As an example; sensitivity analysis of gas and water production in PG coal for the permeability case, strategy 1 is presented. Sensitivity analysis is performed by setting two homogeneous reservoir regions within the coal. Figure 4-68 shows how the regions are configured; the red area represents the region 1 where MH12 is located and also the area where the reservoir parameters, from previous match in History Matching Phase I, are kept the same. The blue area represents the region 2 where MH3 is located and the permeability values in this case are changed. Table 4-11 shows the values used in the region 2 for this study.

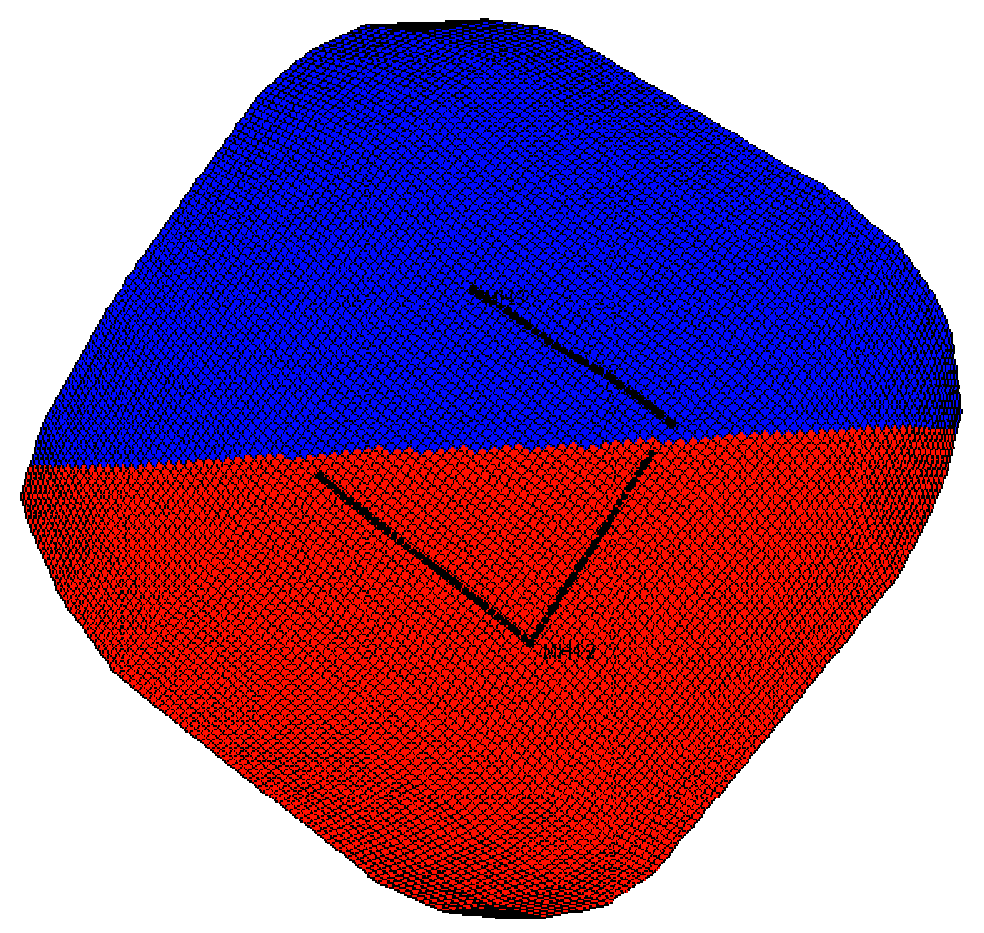

Figure 4-68: Region configuration HMPH2-PG coal 
Table 4-11: Permeability case sensitivity analysis for HMPH2-PG coal

\begin{tabular}{|c|c|}
\hline Case & $\mathrm{K}, \mathrm{md}$ \\
\hline 1 & 0.011 \\
\hline 2 & 0.031 \\
\hline 3 & 0.051 \\
\hline 4 & 0.071 \\
\hline 5 & 0.091 \\
\hline
\end{tabular}

Figures 4-69 shows a comparison between the actual gas production and the simulated one from MH12. In the Figure 4-69, the red round dots represent the actual gas rate production while the blue round dots the actual gas cumulative. Also continuous lines represent the simulated gas production for the different cases while dashed lines the simulated cumulative gas. The graph shows the match of the production profiles in MH12 for the different cases, and how they overlap each other meaning that the gas production in MH12 is not affected by the permeability changes made in the region 2 (around MH3).

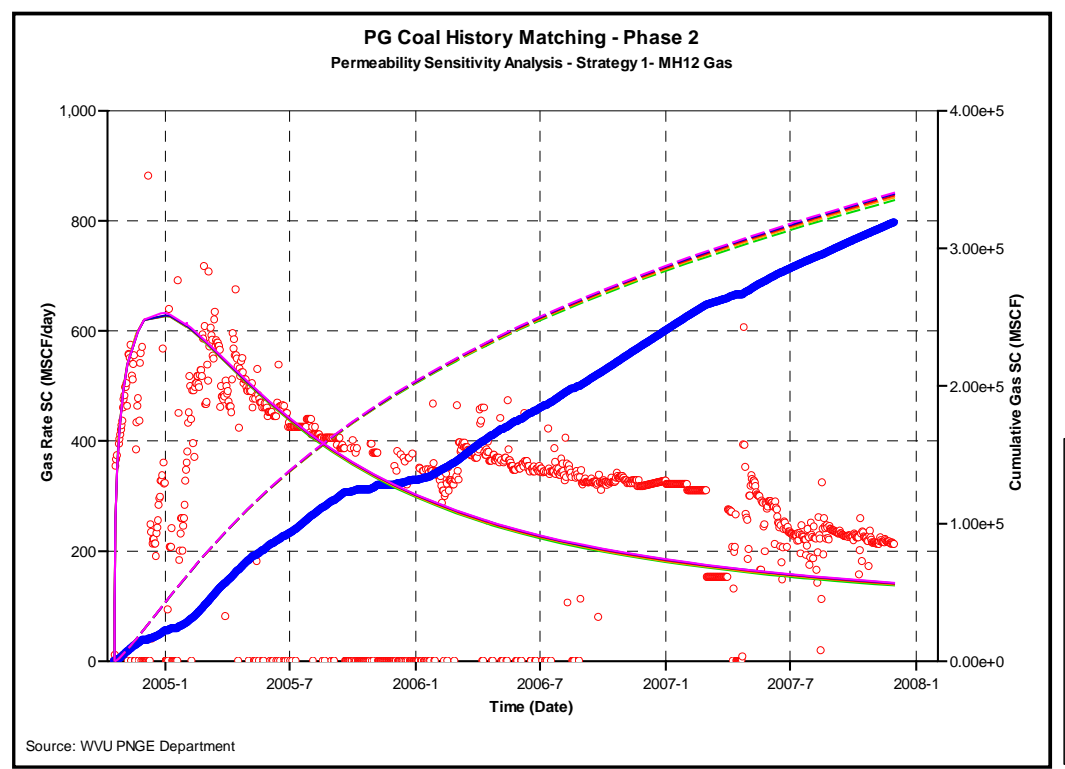

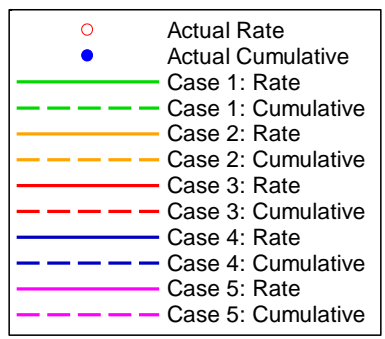

Figure 4-69: Gas production sensitivity for permeability in MH12 HMPH2-PG coal

Figures 4-70 shows a comparison between the actual water production and the simulated one from MH12. In the Figure 4-70, the red round dots represent the actual water rate production while the blue round dots the actual water cumulative. Also continuous lines represent the 
simulated water production for the different cases while dashed lines the simulated cumulative water. The graph shows the match of the production profiles in MH12 for the different cases, and how they overlap each other meaning that the water production in MH12 is not affected by the permeability changes made in the region 2 (around MH3).

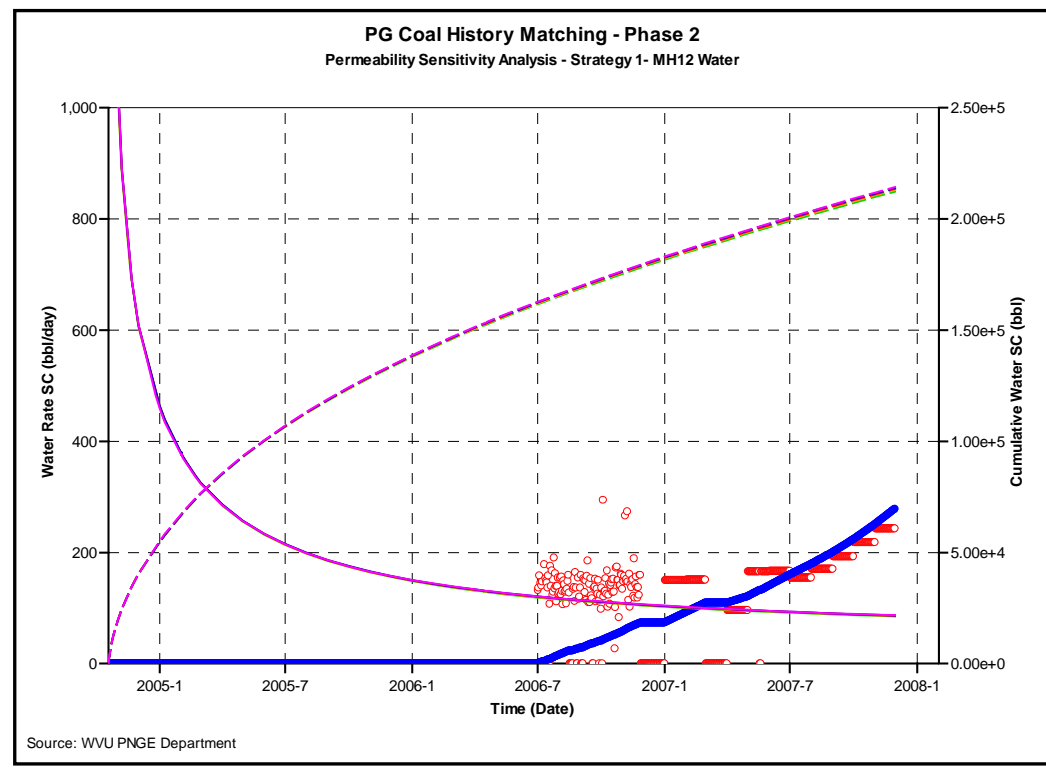

\begin{tabular}{|cc|}
\hline$\bullet$ & Actual Rate \\
Actual Cumulative \\
Case 1: Rate \\
\hline----- Case 1: Cumulative \\
\hline----- Case 2: Rate \\
-- Case 2: Cumulative \\
----- Case 3: Rate \\
\hline----- Case 4: Rumulative \\
-- Case 4: Cumulative \\
---- Case 5: Rate \\
\hline- Case 5: Cumulative \\
\hline
\end{tabular}

Figure 4-70: Water production sensitivity for permeability in MH12 HMPH2-PG coal

Figures 4-71 shows the simulated gas rate and cumulative production results from MH3 for the different permeability values set in the region 2 (around MH3). In the Figure 4-71, the red round dots represent the actual gas rate production while the blue round dots the actual gas cumulative. Also continuous lines represent the simulated gas production for the different cases while dashed lines the simulated cumulative gas. As it is shown below, a match in the gas rate production is achieved when the permeability value around MH3 is set to $0.011 \mathrm{md}$. 


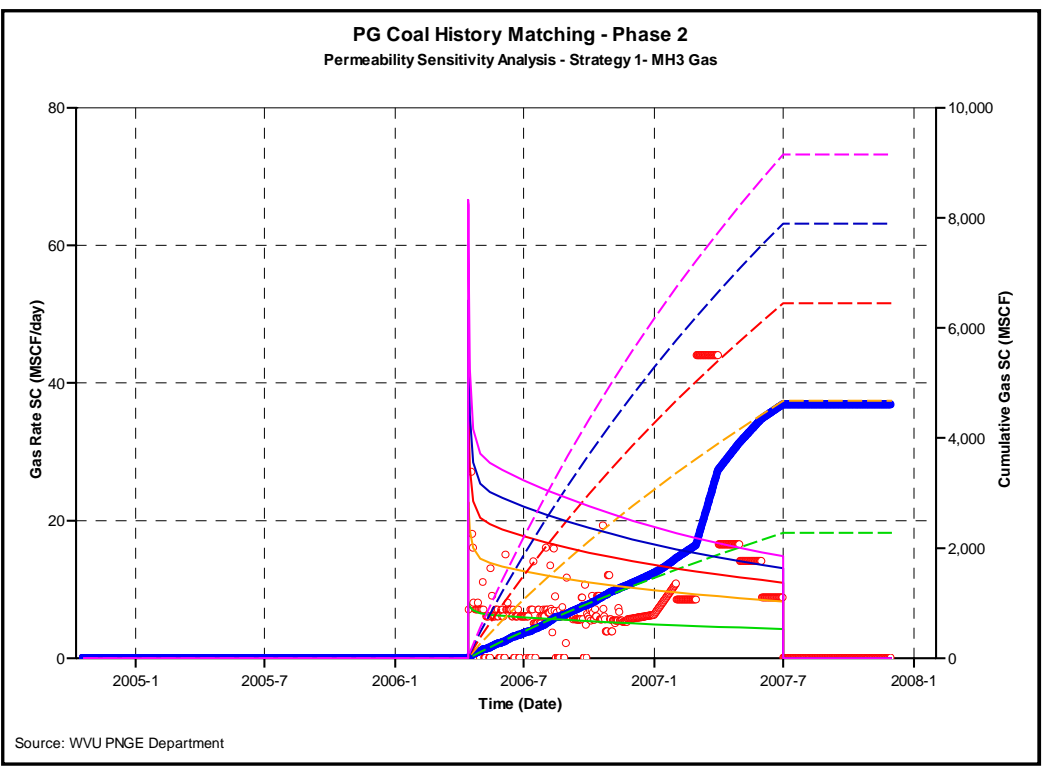

\begin{tabular}{|cc|}
\hline$\bullet$ & Actual Rate \\
Actual Cumulative \\
Case 1: Rate \\
\hline----- Case 1: Cumulative \\
- Case 2: Rate \\
---- Case 2: Cumulative \\
-- Case 3: Rate \\
\hline--- Case 3: Cumulative \\
--- Case 4: Rate \\
--- Case 4: Cumulative \\
\hline-- Case 5: Rate \\
\hline
\end{tabular}

Figure 4-71: Gas production sensitivity for permeability in MH3 HMPH2-PG coal

Figure 4-72 shows the gas rate match in MH3 when permeability is equal to $0.011 \mathrm{md}$. Notice that there is an increment in the gas production during the late time period which is assumed to be attributed to a jack pump installed in the system.

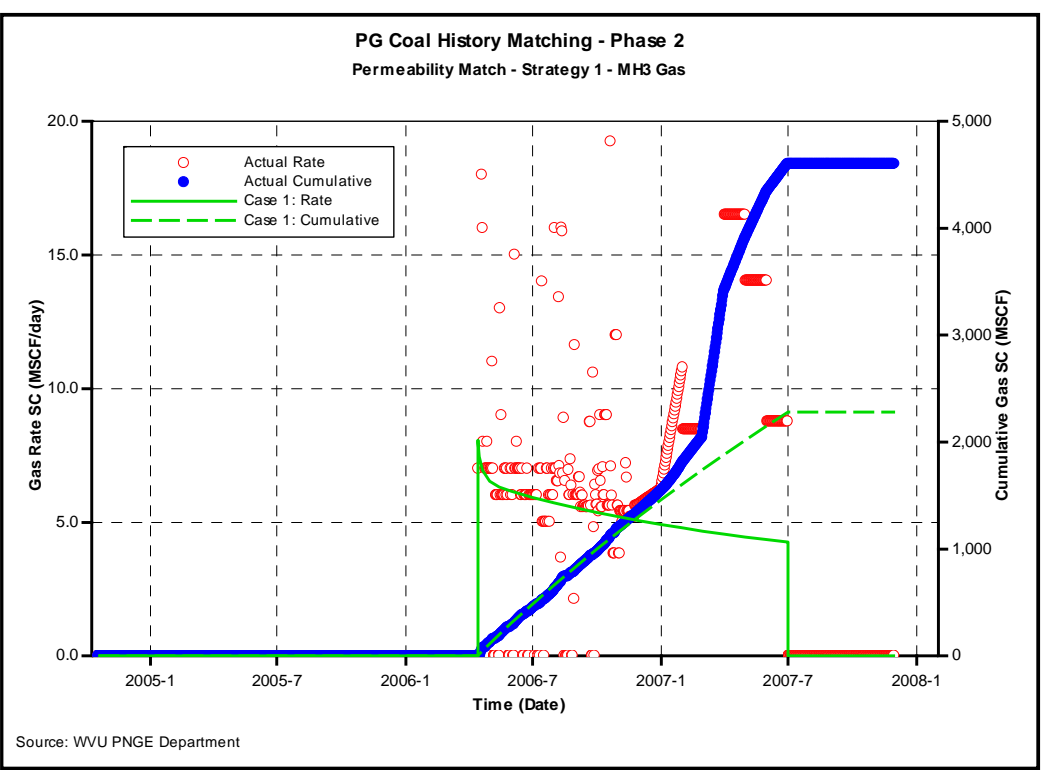

Figure 4-72: Gas production permeability case strategy 1 match in MH3 HMPH2-PG coal 
Figures 4-73 shows the simulated water rate and cumulative production results from MH3 for the different permeability values set in the region 2 (around MH3). Notice that MH3 is not producing any actual water. As it is shown below, water production is not matched for any of the cases.
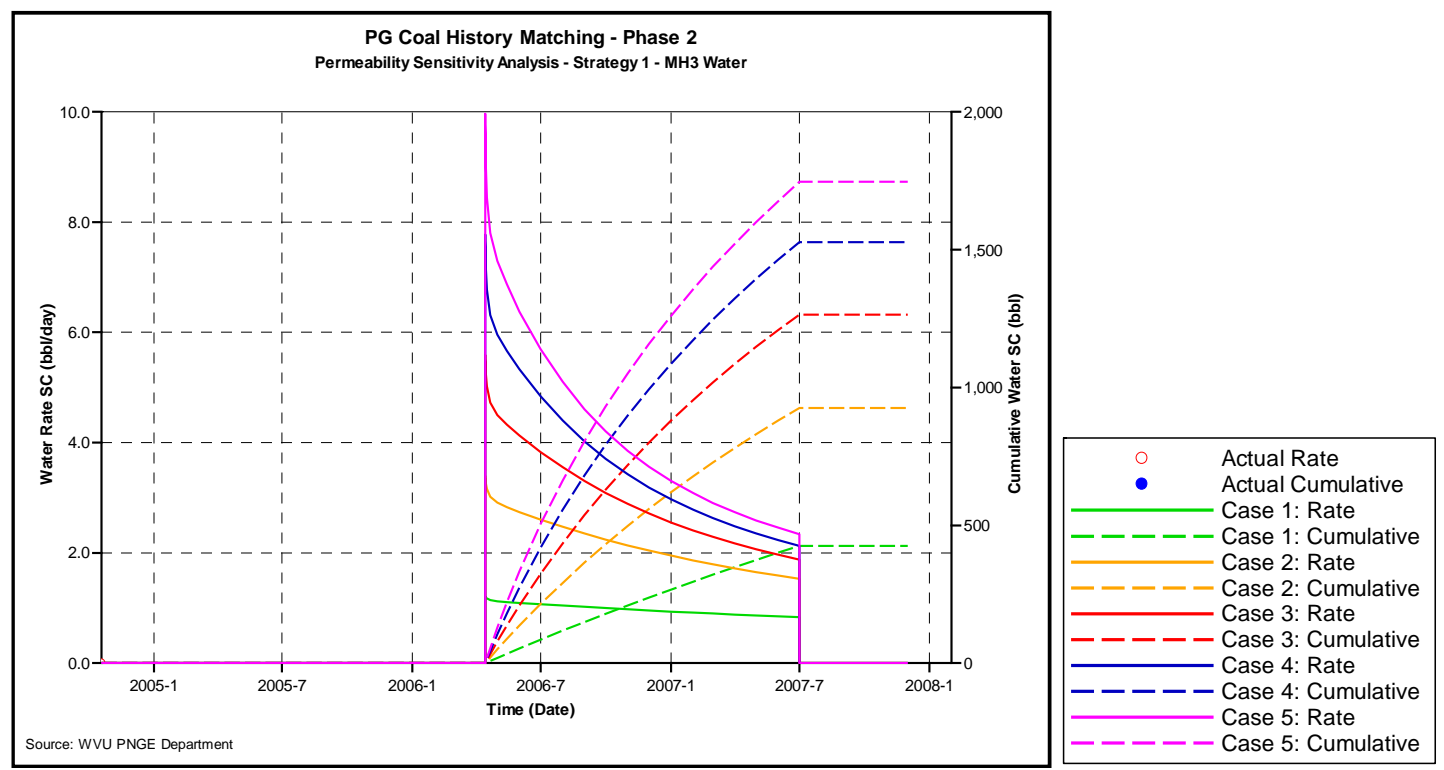

Figure 4-73: Water production sensitivity for permeability strategy 1 in MH3 HMPH2-PG coal

As another example for Permeability case, Strategy 2, sensitivity analysis is performed by setting two homogeneous reservoir regions within the coal. Figure 4-74 shows the relative permeability curve and Table 4-12 shows the permeability values used in the region 2 for this study. 


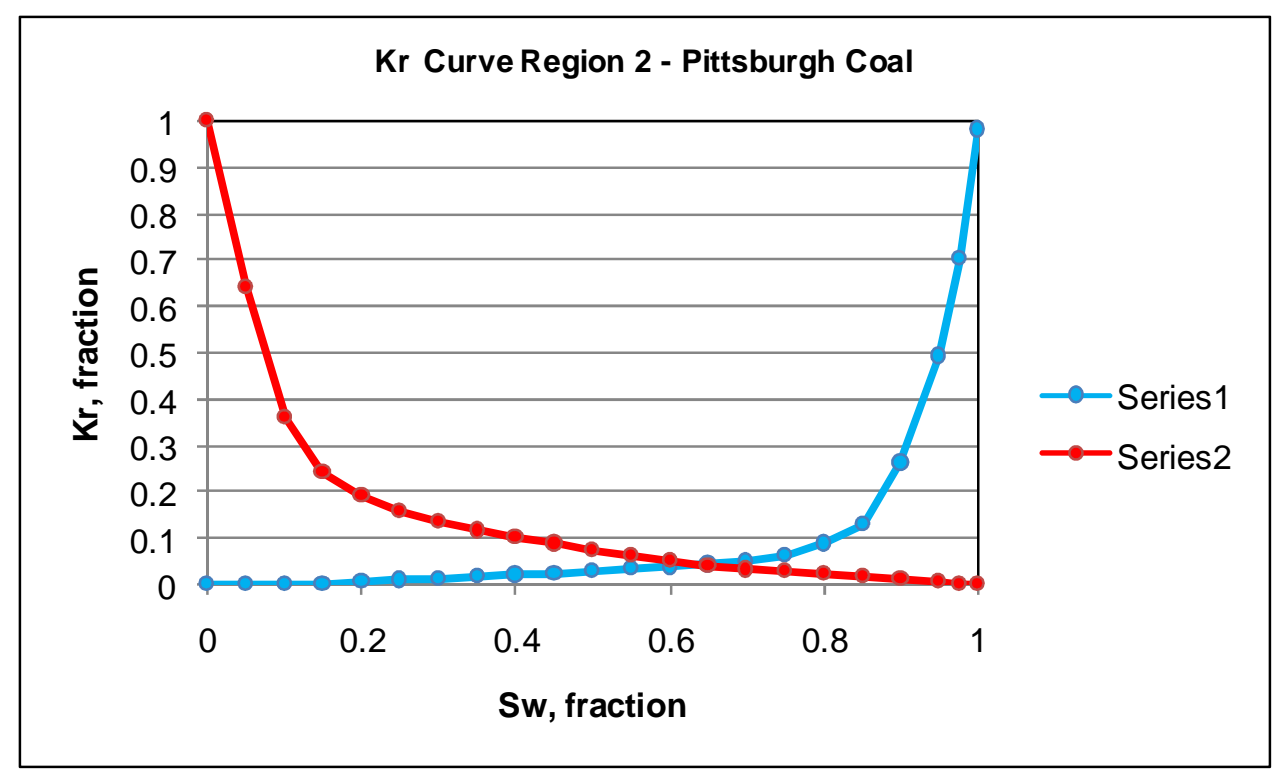

Figure 4-74: Relative permeability curve region 2 HMPH2-PG coal

Table 4-12: Relative permeability case sensitivity analysis for HMPH2-PG coal

\begin{tabular}{|c|c|}
\hline Case & $\mathrm{K}, \mathrm{md}$ \\
\hline 1 & 0.1 \\
\hline 2 & 0.3 \\
\hline 3 & 0.5 \\
\hline 4 & 0.7 \\
\hline 5 & 0.9 \\
\hline
\end{tabular}

Figures 4-75 and 4-76 show gas and water production in MH12 respectively, and how its production is not affected by changing the relative permeability curve in the region 2 (around MH3). 


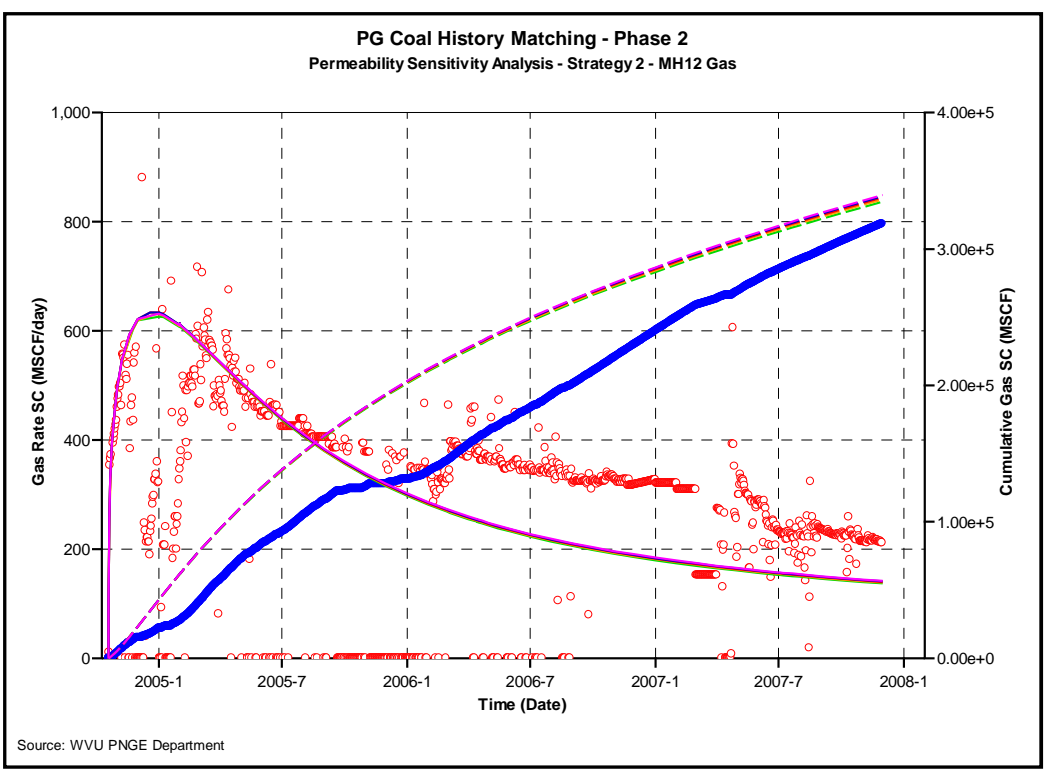

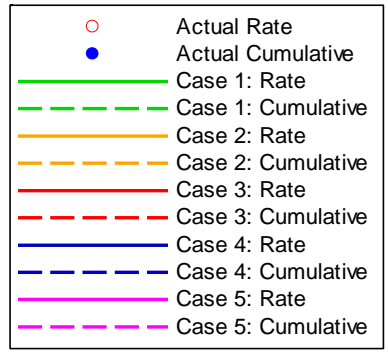

Figure 4-75: Gas production sensitivity for relative permeability in MH12 HMPH2-PG coal

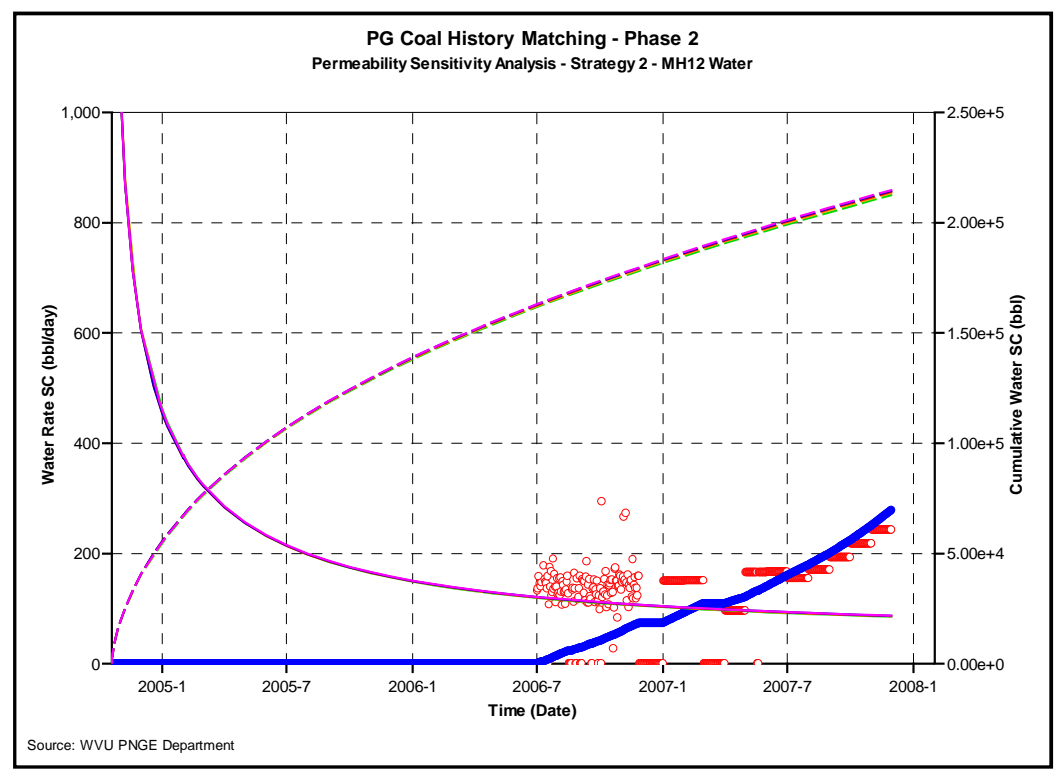

\begin{tabular}{|c|c|}
\hline • & $\begin{array}{l}\text { Actual Rate } \\
\text { Actual Cumulative }\end{array}$ \\
\hline$\overline{-----}$ & $\begin{array}{l}\text { - Case 1: Rate } \\
\text { - Case 1: Cumulative }\end{array}$ \\
\hline & - Case 2: Rate \\
\hline---- . & - Case 2: Cumulative \\
\hline---- & - Case 3: Cumulative \\
\hline- & $\begin{array}{l}\text { Case 4: Rate } \\
\text { Case 4: Cumulative }\end{array}$ \\
\hline & $\begin{array}{l}\text { Case 5: Rate } \\
\text { Case 5: Cum }\end{array}$ \\
\hline
\end{tabular}

Figure 4-76: Water production sensitivity for relative permeability in MH12 HMPH2-PG coal

Figures 4-77 shows the simulated gas rate and cumulative production results from MH3 for the different permeability values and a different relative permeability curve set in the region 2 (around MH3). As it is shown below, a match in the gas rate production is achieved when the permeability value around $\mathrm{MH} 3$ is set to $0.1 \mathrm{md}$. 


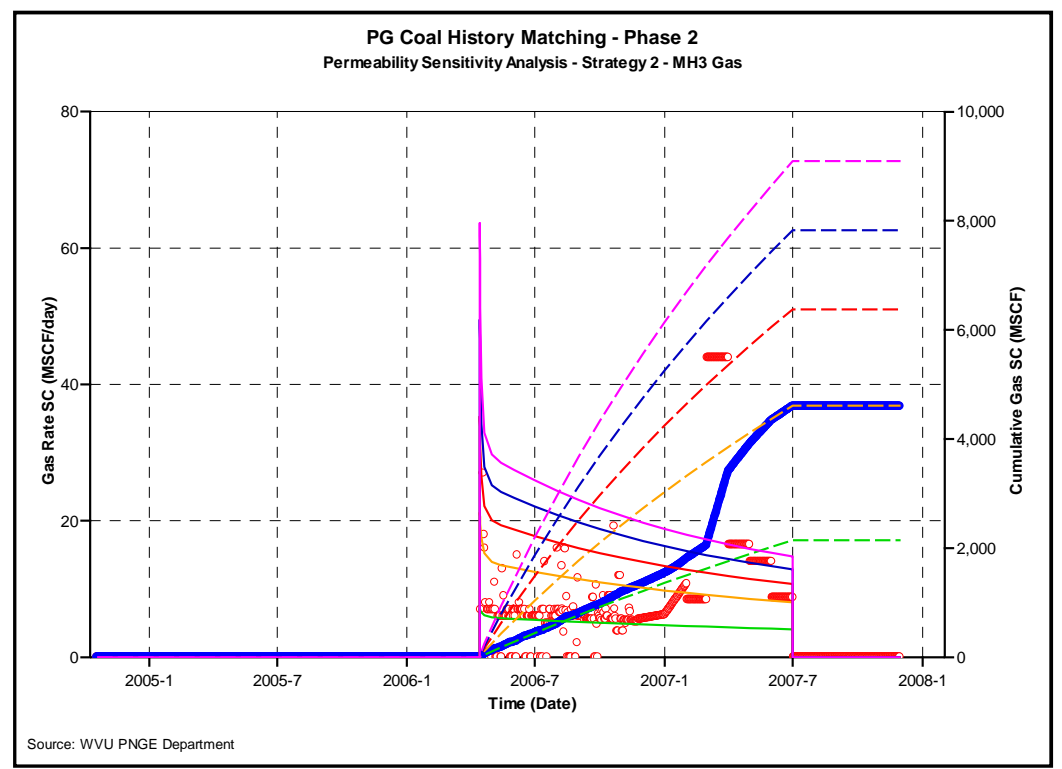

\begin{tabular}{|cc|}
\hline & Actual Rate \\
Actual Cumulative \\
Case 1: Rate \\
----- Case 1: Cumulative \\
\hline--- Case 2: Rate \\
-- Case 2: Cumulative \\
--- Case 3: Rate \\
--- Case 3: Cumulative \\
----- Case 4: Rate \\
--- Cumulative \\
---- Case 5: Rate \\
\hline
\end{tabular}

Figure 4-77: Gas production sensitivity for relative permeability in MH3 HMPH2-PG coal

Figure 4-78shows the gas rate match in MH3 when permeability is equal to $0.12 \mathrm{md}$. Notice that there is an increment in the gas production during the late time period which is assumed to be attributed to a jack pump installed in the system.

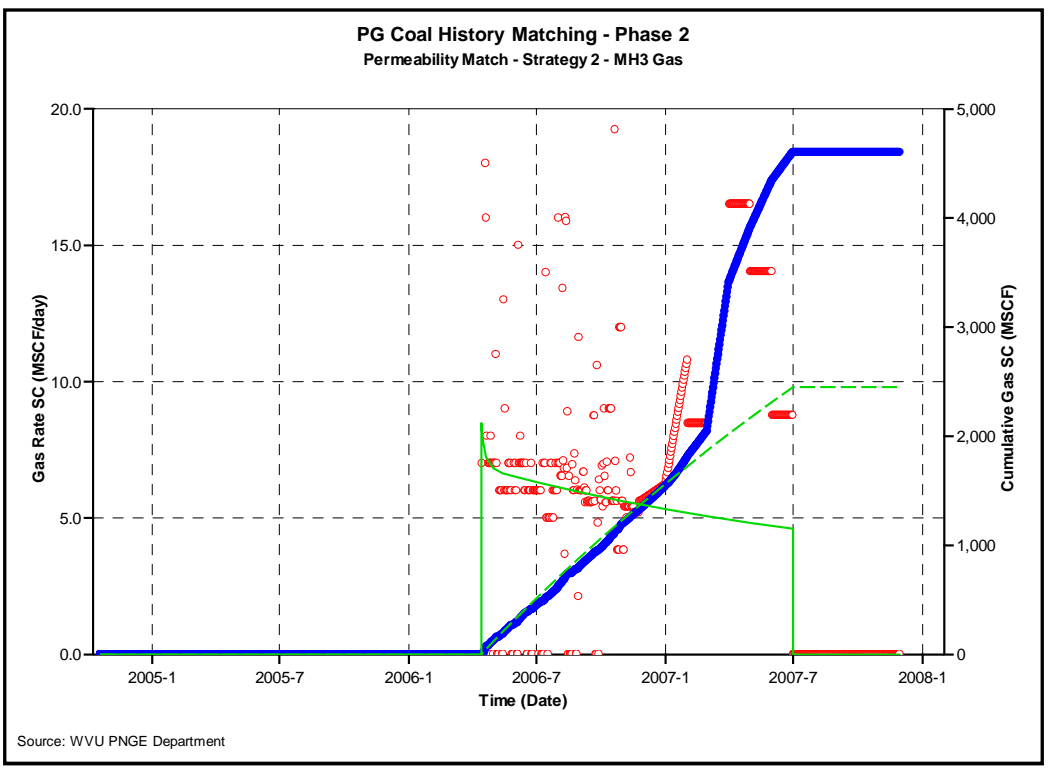

Figure 4-78: Gas production match for relative permeability in MH3 strategy 2 in HMPH2-PG coal 
Figures 4-79 shows the simulated water rate and cumulative production results from MH3 for the different permeability values and a different relative permeability curve set in the region 2 (around $\mathrm{MH} 3$ ). As it is shown below, water production is not matched for any of the cases and the sensitivity of gas production decreases as permeability values increases. Also water production is directly proportional to permeability values.
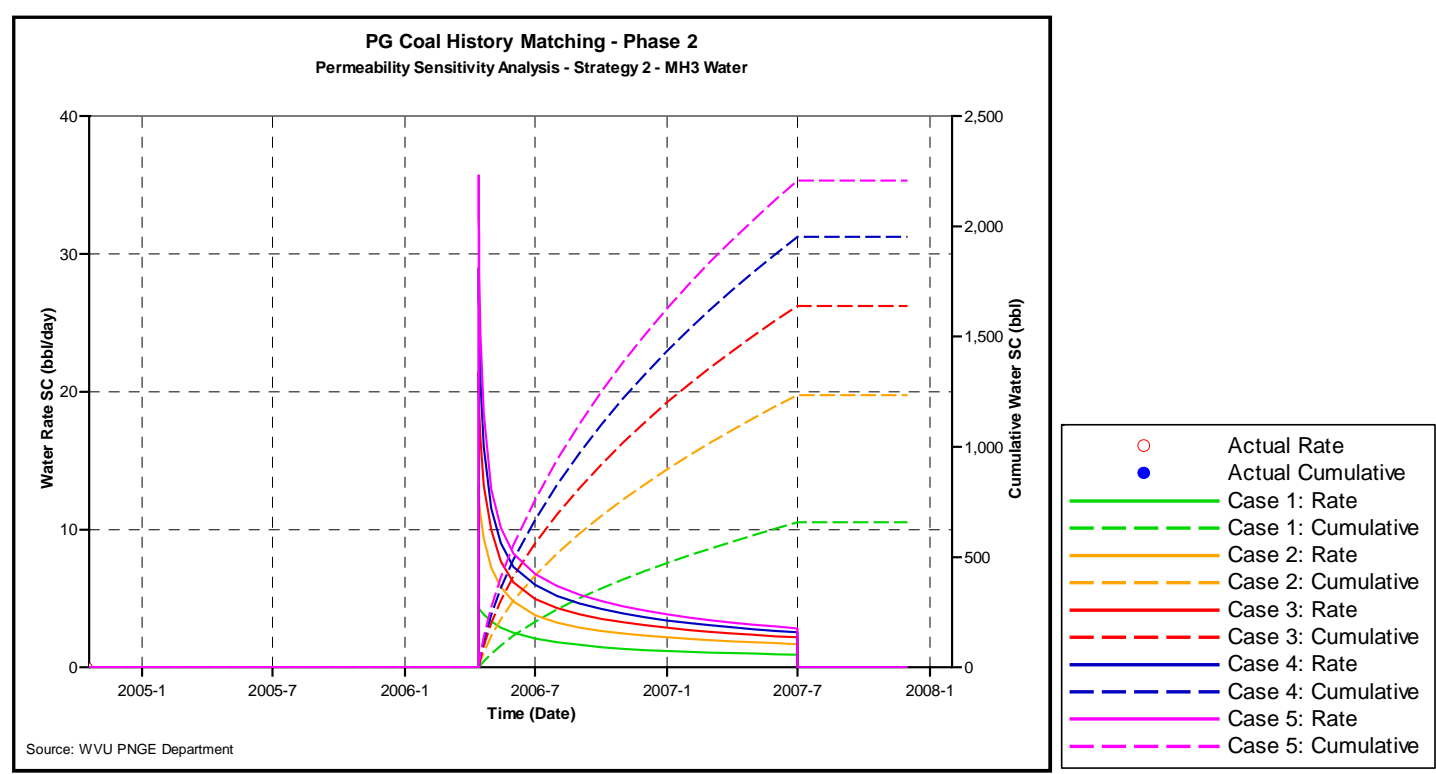

Figure 4-79: Water production for relative permeability in MH3 strategy 2 in HMPH2-PG coal

\section{Anisotropy Permeability Case:}

Based on the results of core analysis performed in a sample for PG coal, it seems to be a difference in the horizontal directional permeability for about 15 times from one direction to another. A study to evaluate the effects of anisotropy permeability in Pittsburgh coal is performed in order to account for uncertainties associated with the core analysis. Figure 4-80 shows the permeability orientation in the formation used for this study and based on the core analysis. 


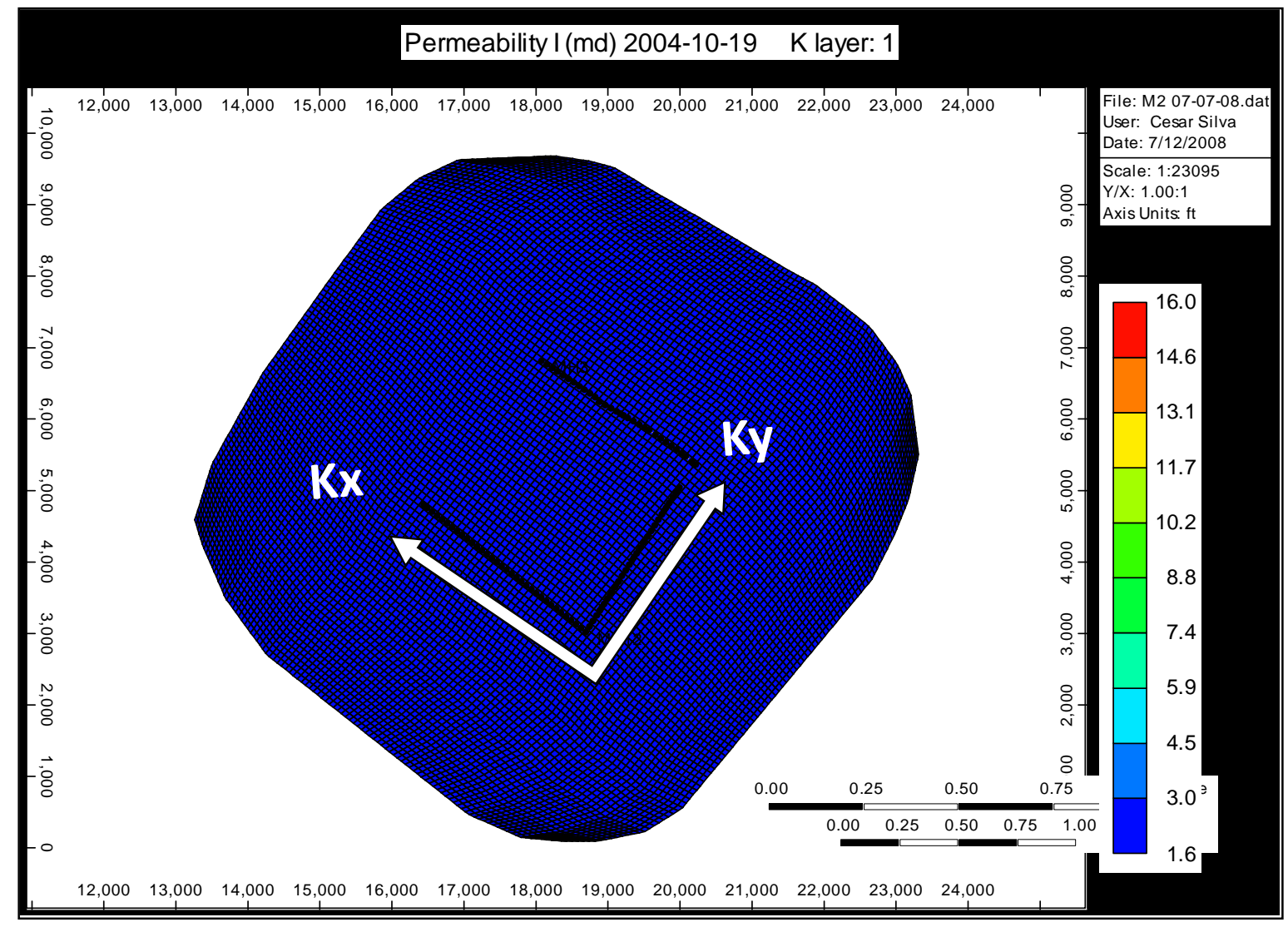

Figure 4-80: Permeability orientation in HMPH2-PG coal 
In order to perform the study, different permeability anisotropy ratios are used. Table 413 shows the different cases. Figure 4-81 shows the results for gas rate and cumulative production from MH12 for the different cases in which permeability in the " $\mathrm{X}$ " direction is set to $40 \mathrm{md}$ in order to get a match in MH12 for the Case $1(\mathrm{Kx}=15 \mathrm{Ky})$. Also Figure 4-82 shows the results for water production from $\mathrm{MH} 12$.

Table 4-13: Anisotropy Ratio case sensitivity analysis for HMPH2-PG coal

\begin{tabular}{|c|c|}
\hline Case & Anisotropy Ratio \\
\hline 1 & $\mathrm{Kx}=(15) \mathrm{Ky}$ \\
\hline 2 & $\mathrm{Kx}=(30) \mathrm{Ky}$ \\
\hline 3 & $\mathrm{Kx}=(45) \mathrm{Ky}$ \\
\hline 4 & $\mathrm{Kx}=(60) \mathrm{Ky}$ \\
\hline
\end{tabular}

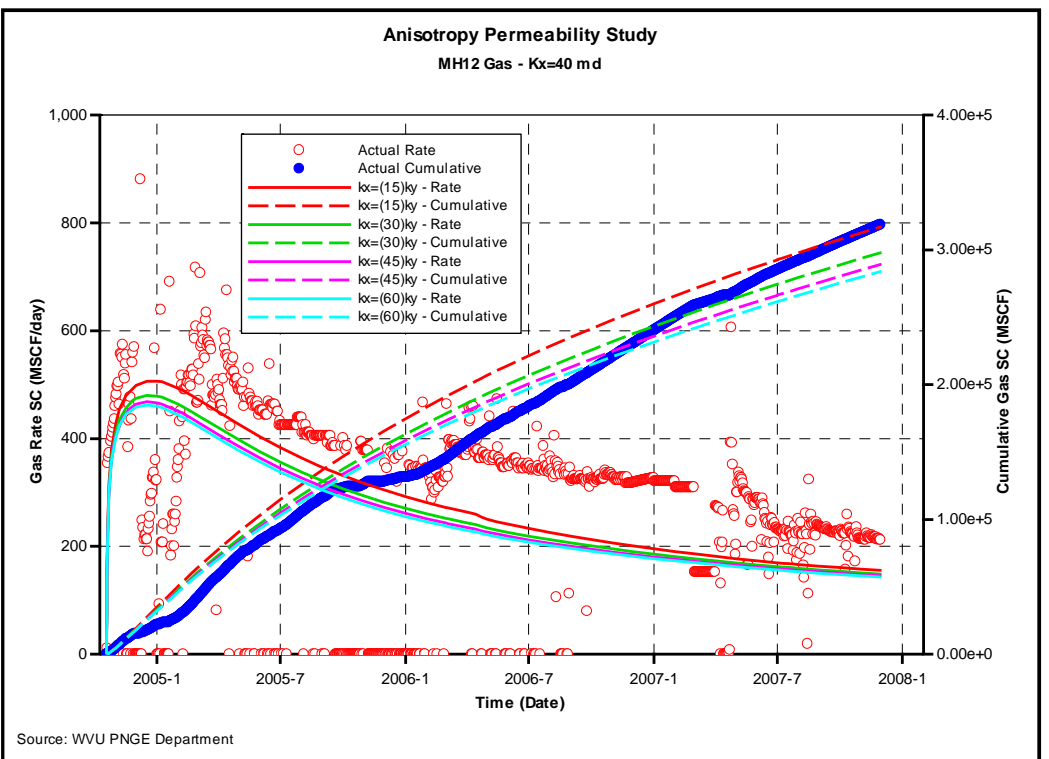

Figure 4-81: Gas production sensitivity for Anisotropy Ratio in MH12 HMPH2-PG coal 


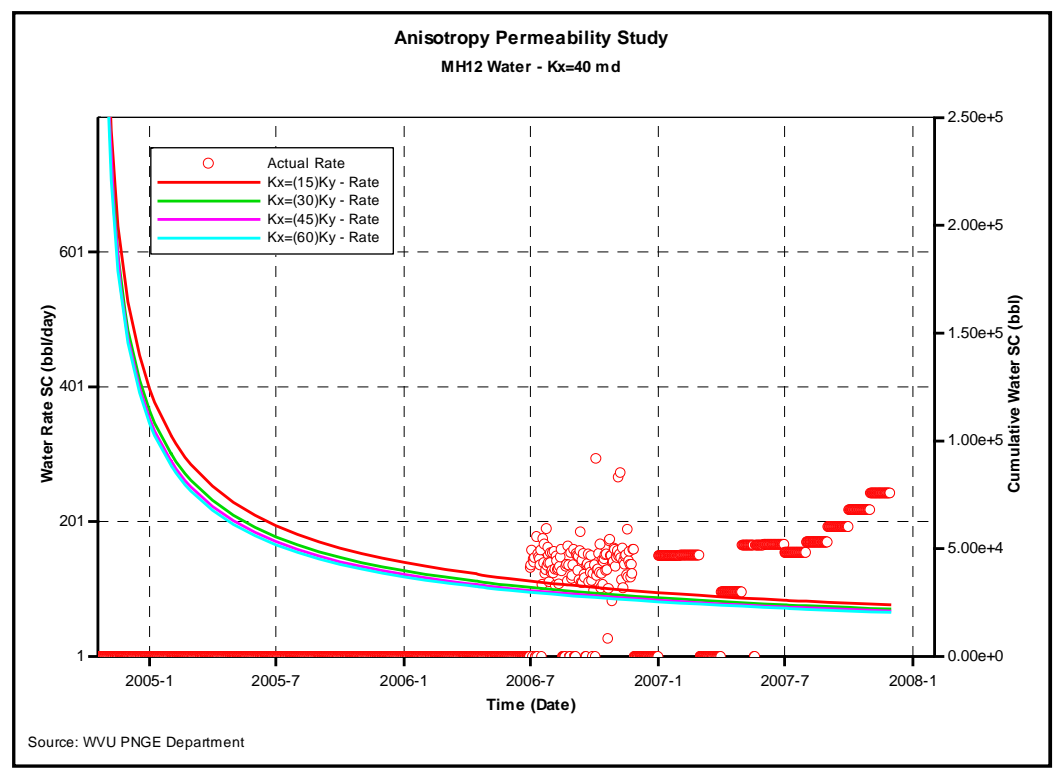

Figure 4-82: Water production sensitivity for Anisotropy Ratio in MH12 HMPH2-PG coal 
Figure 4-83 shows the results for gas rate and cumulative production from MH3 for the different cases in which permeability in the " $\mathrm{X}$ " direction is set to $40 \mathrm{md}$. As it shown in the Figure 4-83, by setting an anisotropy permeability ratio of $\mathrm{Kx}=15 \mathrm{Ky}$, the cumulative gas production is decreased by $50 \%$ respect to the isotropic case. Also Figure 4-84 shows that for the same case, cumulative water production is reduced by $43 \%$.

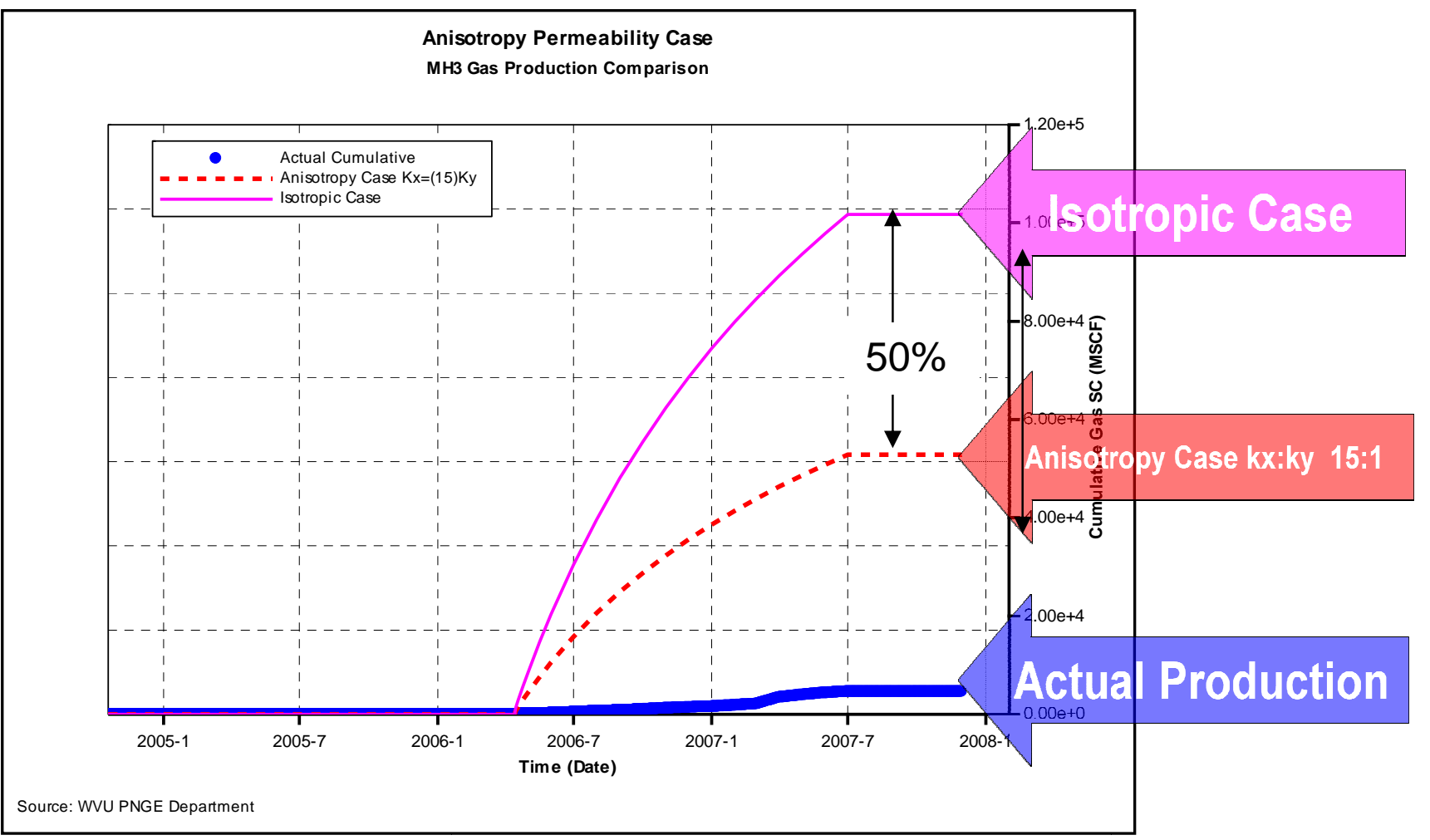

Figure 4-83: Gas production comparison due to Anisotropy permeability 


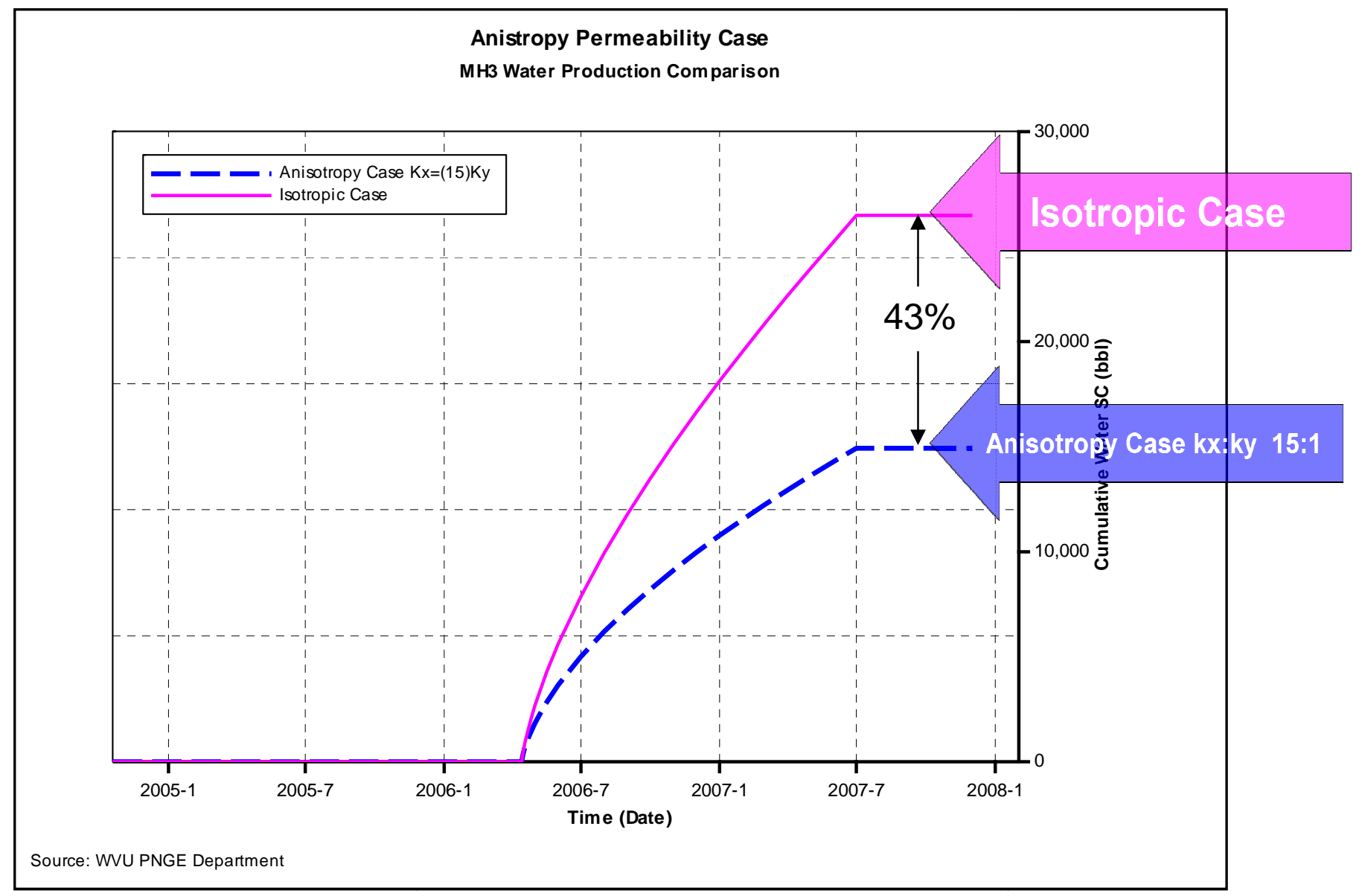

Figure 4-84: Water production due to Anisotropy Permeability

The following example shows the case of sensitivity analysis performed by reducing the length of well MH3 in PG coal. Table 4-14 shows the reduction of the well length in percentage, used for this study.

Table 4-14: Well length reduction case sensitivity analysis for HMPH2-PG coal

\begin{tabular}{|c|c|}
\hline Case & $\begin{array}{c}\text { Length Reduction, } \\
\%\end{array}$ \\
\hline 1 & 20 \\
\hline 2 & 40 \\
\hline 3 & 60 \\
\hline 4 & 80 \\
\hline 5 & 90 \\
\hline 6 & 96 \\
\hline
\end{tabular}


Figure4-85 shows gas rate and cumulative from MH12 for the different cases when the length of the well MH3 is reduced. The result shows that as the length of the well MH3 is reduced less interference between the two wells is encountered due to the fact that the contact of MH3 with the coal is reduced, so less gas is produced leaving resources behind to be produced by MH12.
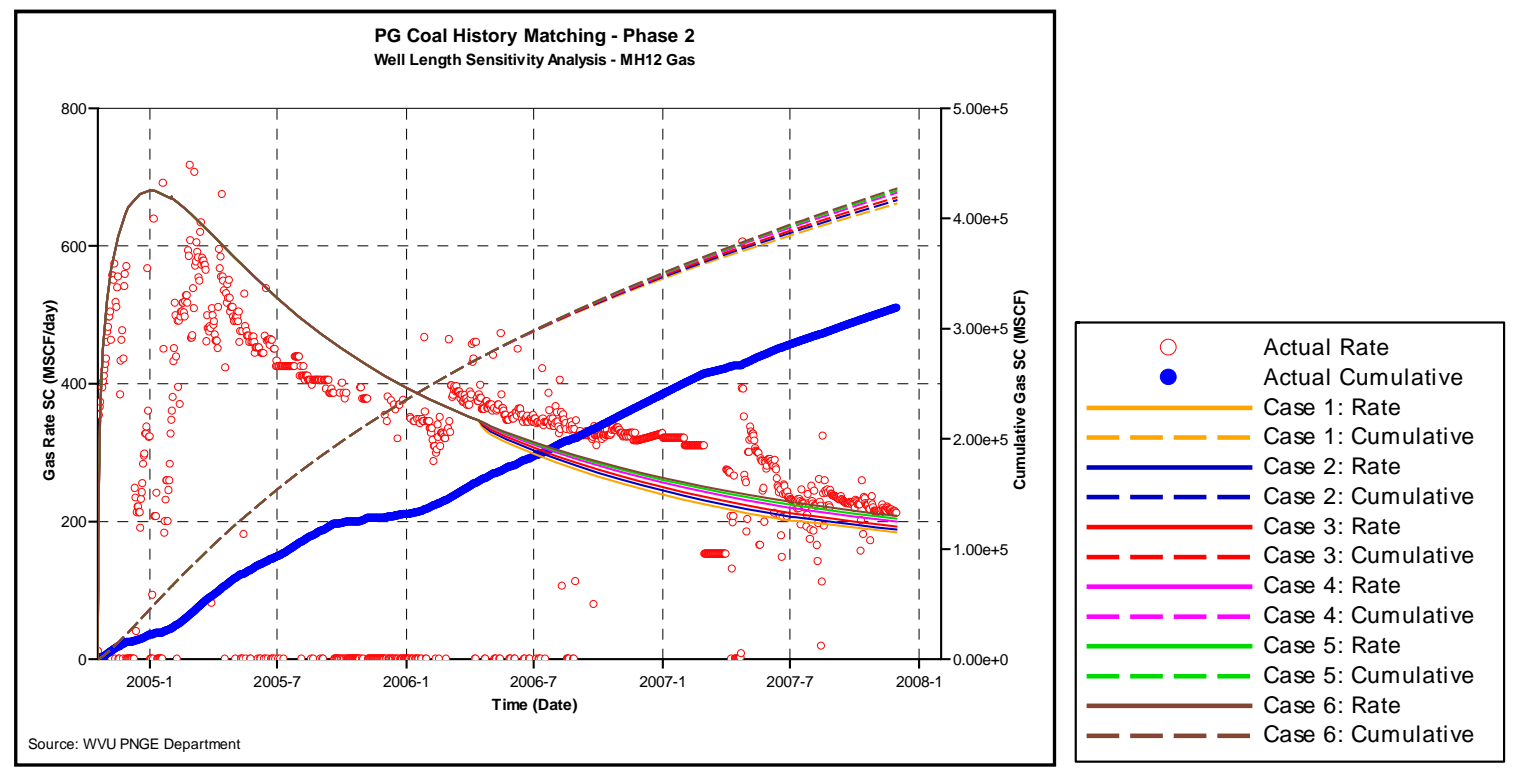

Figure 4-85: Gas production sensitivity for well length reduction in MH12 HMPH2-PG coal

Figure 4-86 shows water rate and cumulative from MH12 for the different cases when the length of the well MH3 is reduced. The result shows that as the length of the well MH3 is reduced less interference between the two wells is encountered due to the fact that the contact of MH3 with the coal is reduced, so less water is produced leaving resources behind to be produced by MH12. 

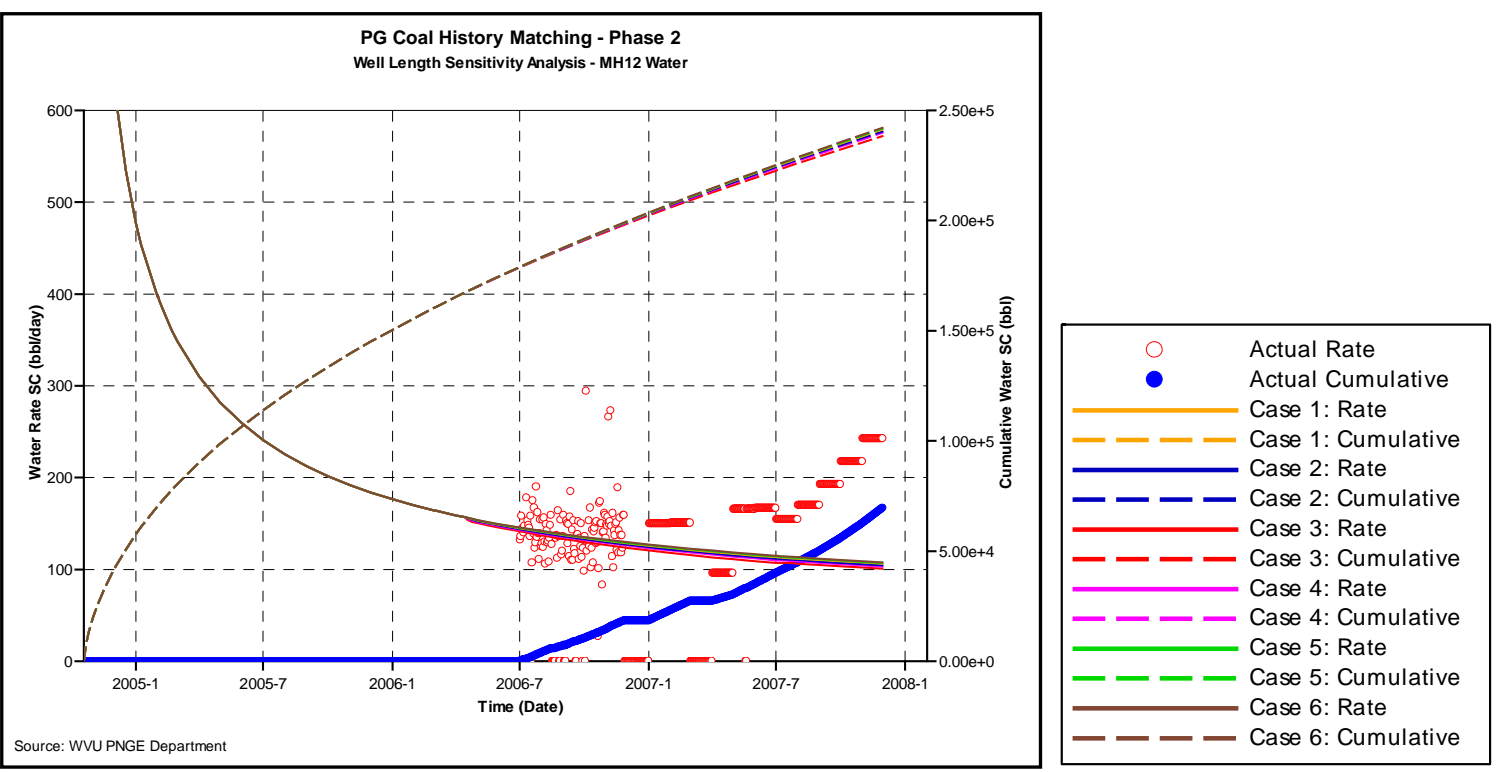

Figure 4-86: Water production sensitivity for well length reduction in MH12 HMPH2-PG coal

Figure 4-87 shows gas rate and cumulative from MH3 for the different cases when the length of the well MH3 is reduced. The result shows that the length of the well is directly proportional to the gas production. Based on the results not match is achieved for any of the cases even when the well is decreased by $96 \%$ of its total length.
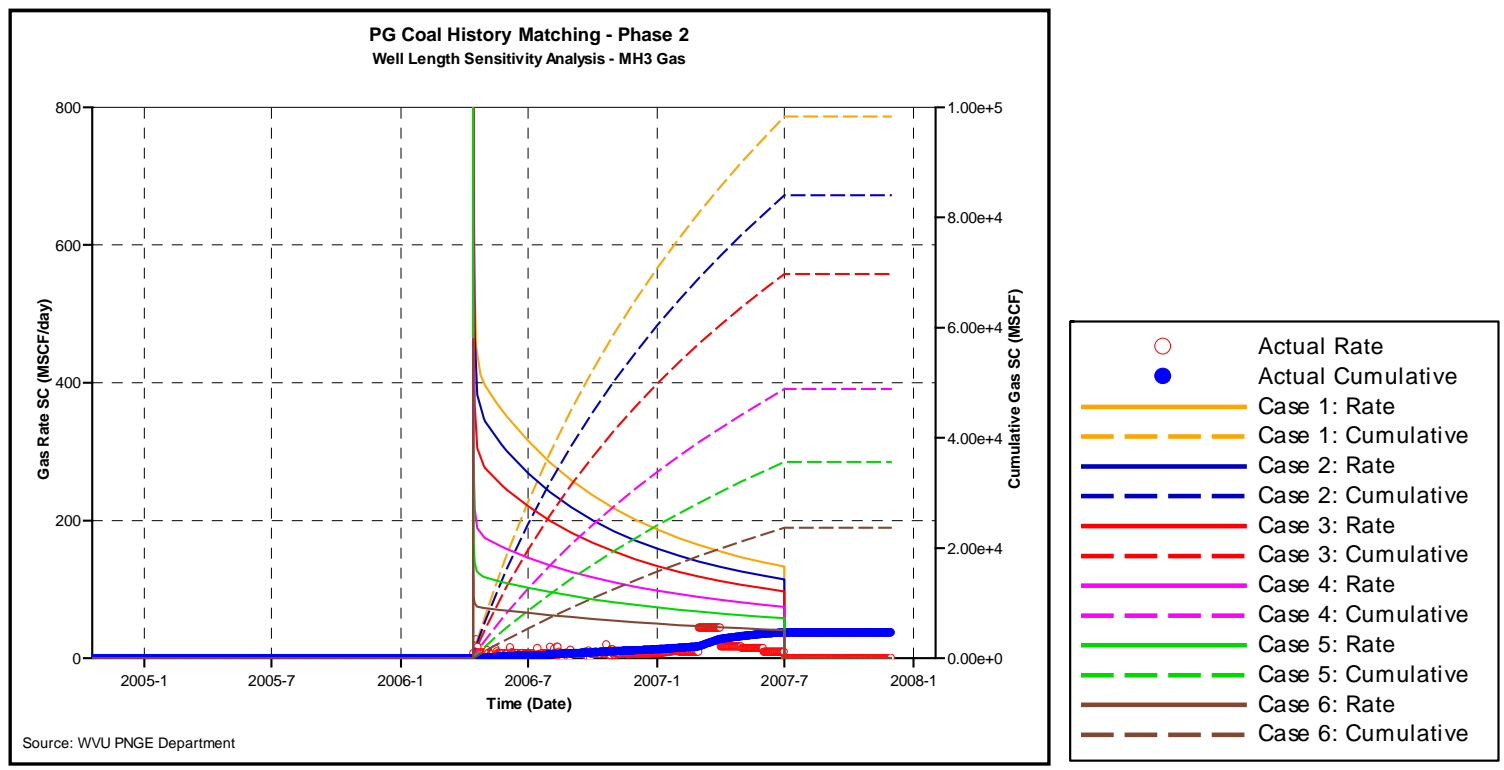

Figure 4-87: Gas production sensitivity for well length reduction in MH3 HMPH2-PG coal 
Figure 4-88 shows water rate and cumulative from $\mathrm{MH} 3$ for the different cases when the length of the well MH3 is reduced. The result shows that the length of the well is directly proportional to water production. Based on the results not match is achieved for any of the cases even when the well is decreased by $96 \%$ of its total length.
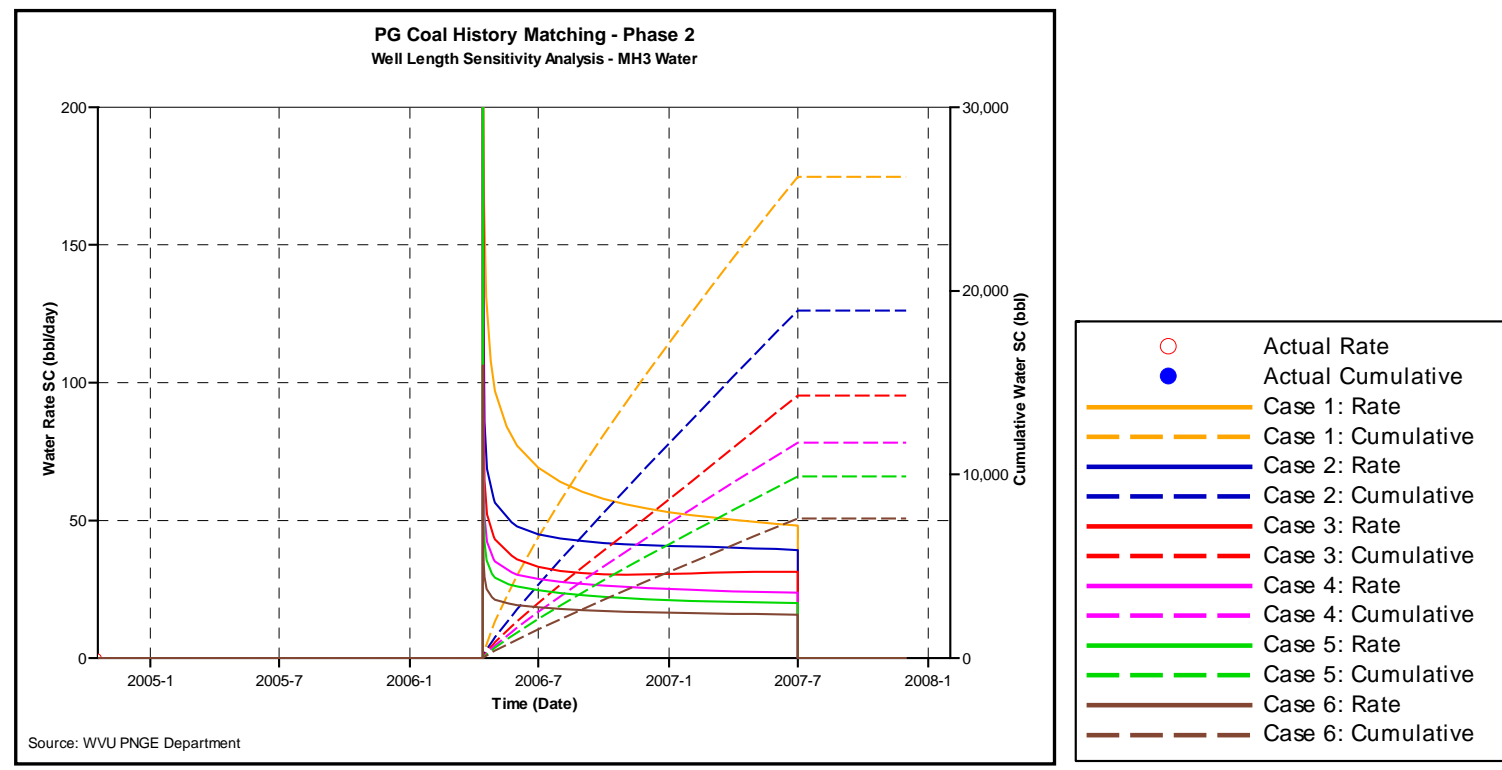

Figure 4-88: Water production sensitivity for well length reduction in MH3 HMPH2-PG coal 
As another example; sensitivity analysis of gas production in UF coal for the permeability values of shown in Table 4-15 is performed. Figures 4-89 to 4-93 show the sensitivity of production by changing permeability values.

Table 4-15: Permeability strategy 1 case sensitivity analysis for HMPH2-UF coal

\begin{tabular}{|c|c|}
\hline Case & $\mathrm{K}, \mathrm{md}$ \\
\hline 1 & 0.01 \\
\hline 2 & 0.1 \\
\hline 3 & 0.6 \\
\hline 4 & 1.1 \\
\hline 5 & 1.6 \\
\hline 6 & 2.1 \\
\hline
\end{tabular}

Figures 4-89 shows a comparison between the actual gas production and the simulated one from MH18. In the Figure 4-89, the red round dots represent the actual gas rate production while the blue round dots the actual gas cumulative. Also continuous lines represent the simulated gas production for the different cases while dashed lines the simulated cumulative gas. The graph shows the match of the production profiles in MH18 for the different cases. It can be seen from the graph that not significant changes in production are noticed by changing permeability values in region 2, that is, around MH5, MH20, and MH11.
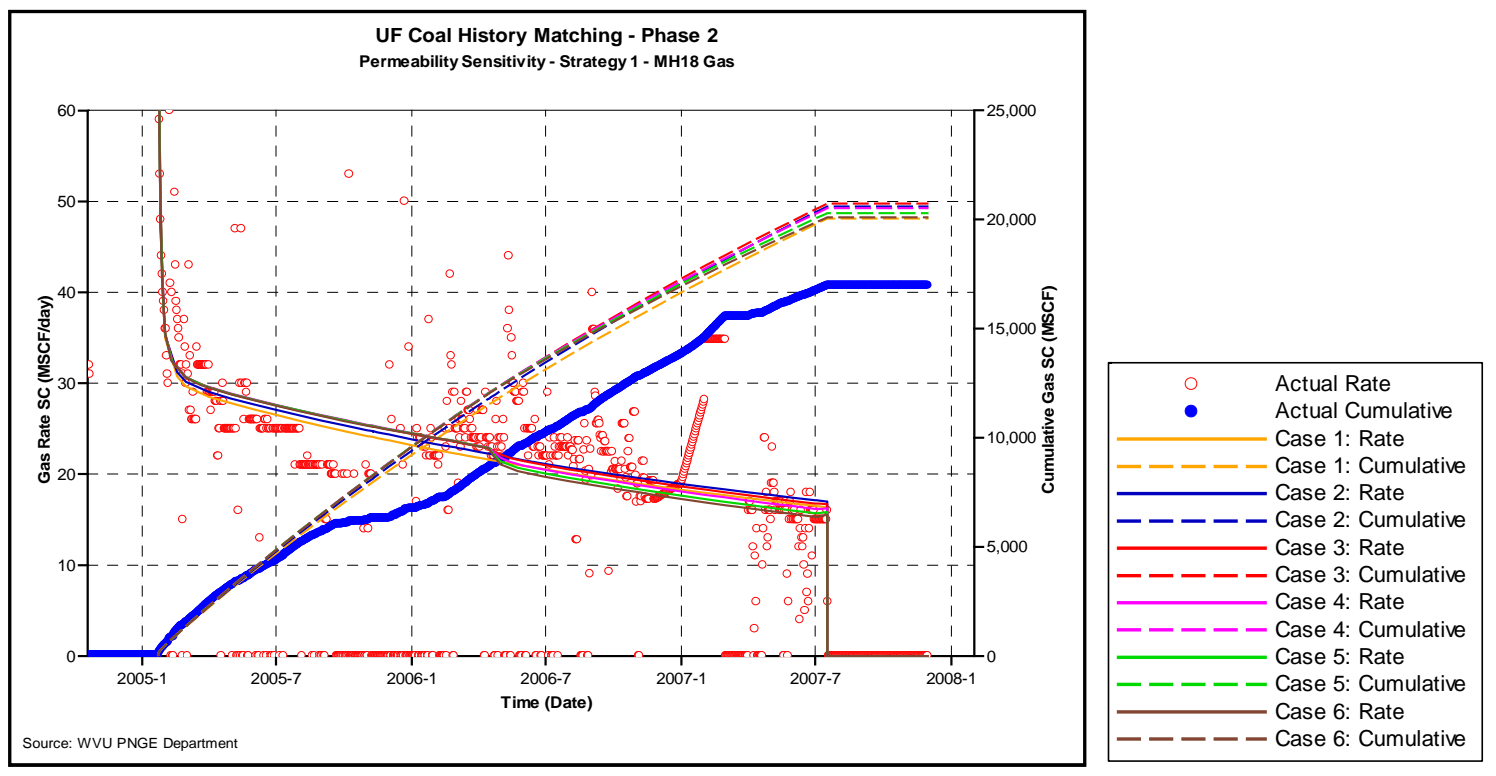

Figure 4-89: Gas production sensitivity for Permeability in MH18 HMPH2-UF coal 
Figure 4-90 shows a comparison between the actual gas production and the simulated one from MH5. In the Figure 4-90, the red round dots represent the actual gas rate production while the blue round dots the actual gas cumulative. Also continuous lines represent the simulated gas production for the different cases while dashed lines the simulated cumulative gas. In this well, MH5, it can be seen that changes in permeability in region 2 affect the production significantly. As it is notice in the graph, gas production is directly proportional to permeability values, and the sensitivity of gas production increases as permeability values decreases.
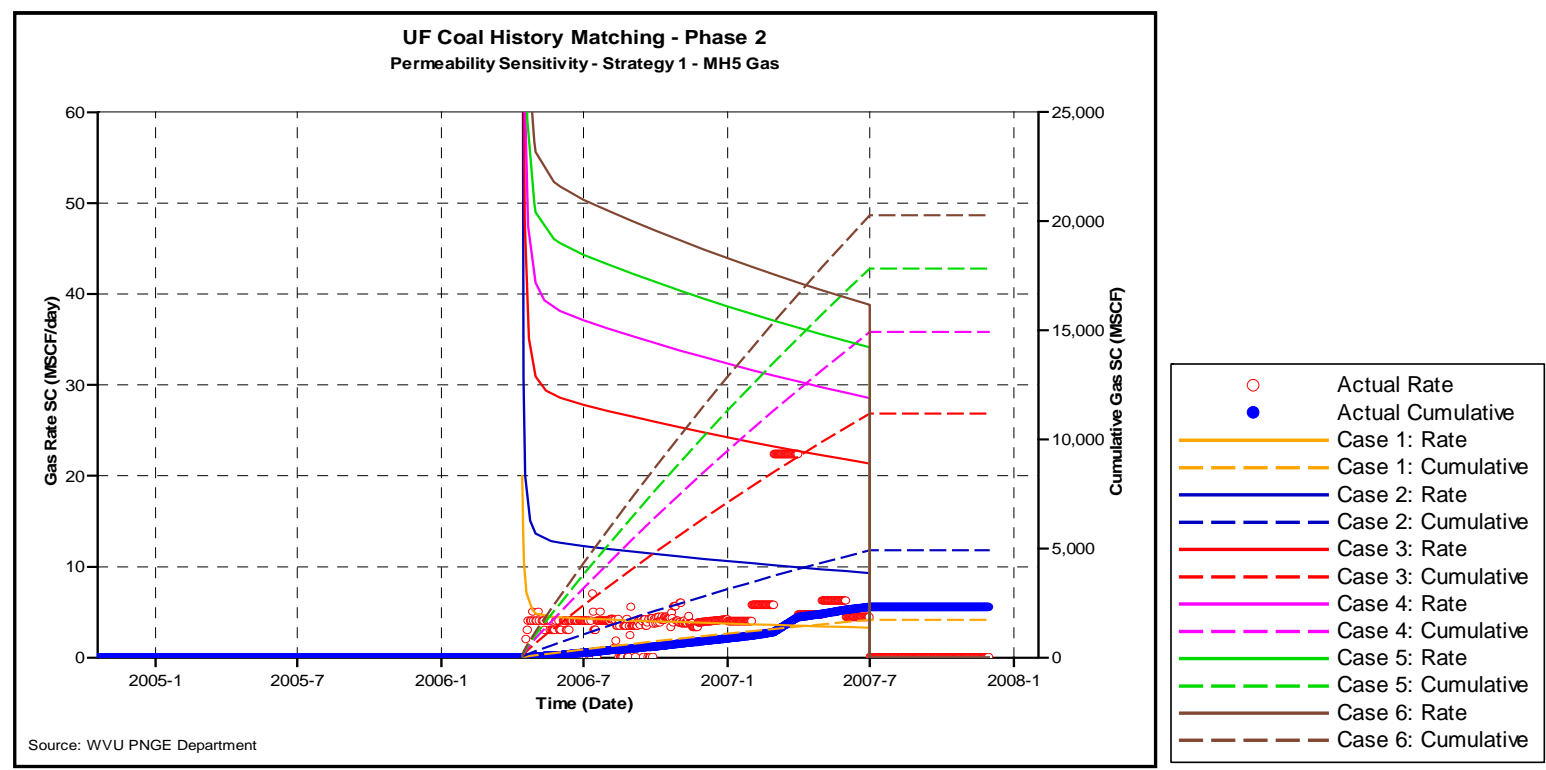

Figure 4-90: Gas production sensitivity for Permeability in MH5 HMPH2-UF coal

Figures 4-91 shows a comparison between the actual gas production and the simulated one from MH20. Changing Permeability in the region 2 where well MH20 is. As it is notice in the graph, gas production is directly proportional to permeability values, and the sensitivity of gas production increases as permeability values decreases. 


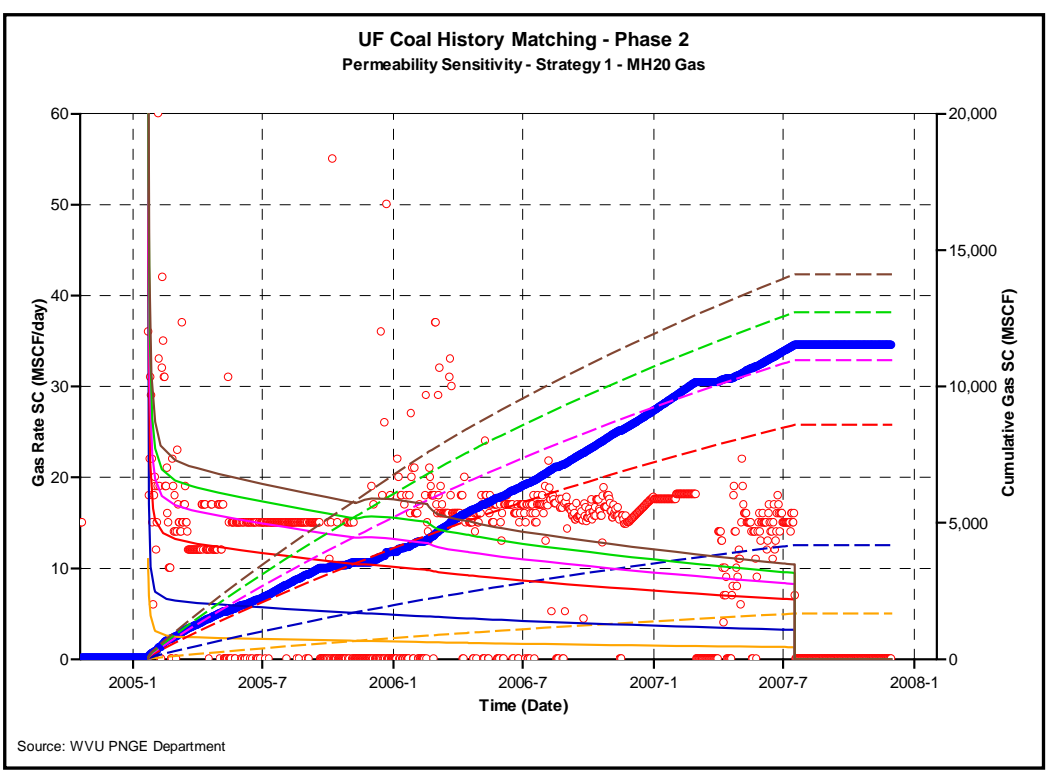

\begin{tabular}{|cc|}
\hline$\bullet$ & Actual Rate \\
Actual Cumulative \\
Case 1: Rate \\
----- Case 1: Cumulative \\
\hline-- Case 2: Rate \\
---- Case 2: Cumulative \\
\hline----- Case 3: Rate \\
-- Case 4: Rate \\
----- Case 4: Cumulative \\
------ Case 5: Rate \\
-- Case 6: Rate \\
----- Case 6: Cumulative \\
\hline
\end{tabular}

Figure 4-91: Gas production sensitivity for Permeability in MH20 HMPH2-UF coal

Figure 4-92 shows a comparison between the actual gas production and the simulated one from MH11. As it is notice in the graph, gas production is directly proportional to permeability values, and the sensitivity of gas production increases as permeability values decreases.

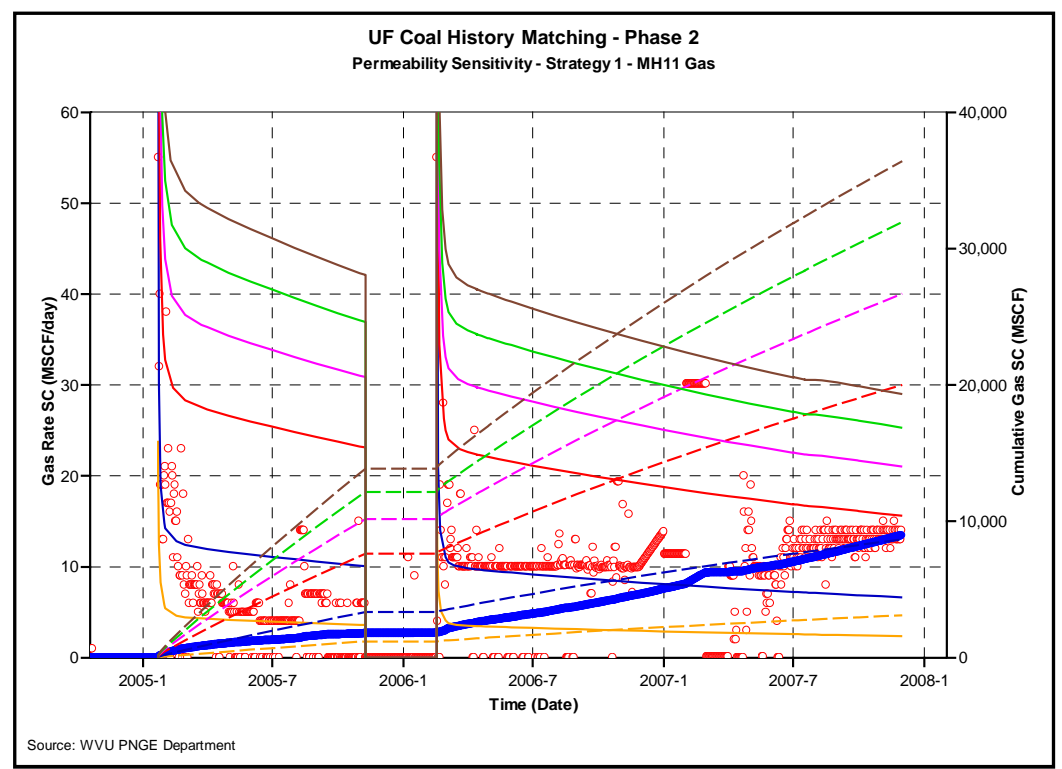

\begin{tabular}{|c|c|}
\hline$\bullet$ & $\begin{array}{l}\text { Actual Rate } \\
\text { Actual Cumulative }\end{array}$ \\
\hline----- & $\begin{array}{l}\text { - Case 1: Rate } \\
\text { - Case 1: Cumulative }\end{array}$ \\
\hline & - Case 2: Rate \\
\hline -ーーー- & $\begin{array}{l}\text { - Case 2: Cumulative } \\
\text { - Case 3: Rate }\end{array}$ \\
\hline -ーーーー & - Case 3: Cumulative \\
\hline----- & - Case 4: Cumulative \\
\hline----- & $\begin{array}{l}\text { Case 5: Rate } \\
\text { Case 5: Cumulative }\end{array}$ \\
\hline & \\
\hline & $-\mathrm{C}$ \\
\hline
\end{tabular}

Figure 4-92: Gas production sensitivity for Permeability in MH11 HMPH2-UF coal 
Figures 4-93 shows a comparison between the actual water production and the simulated one from MH11 for the case above. The graph shows that non-water is produced by any of the cases.

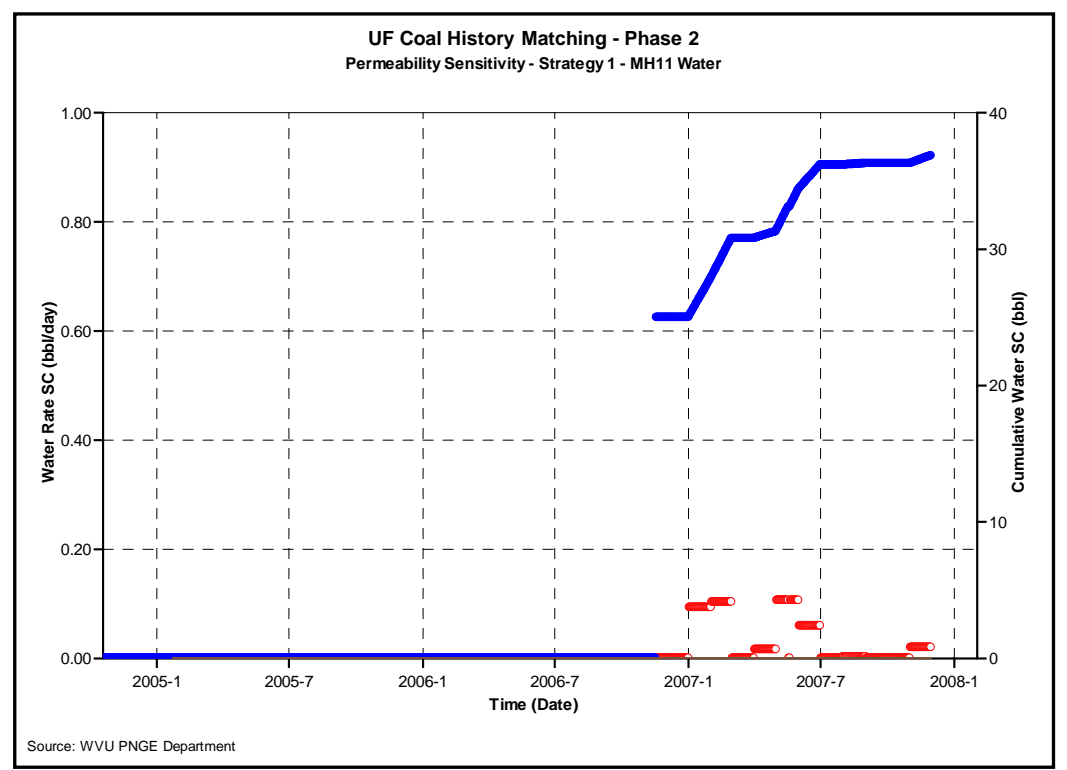

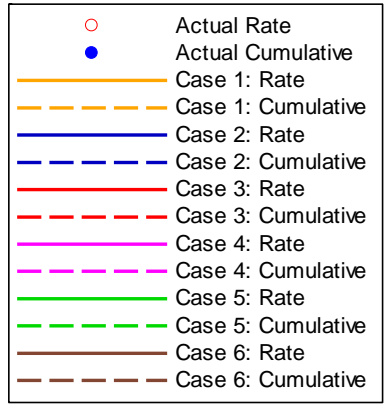

Figure 4-93: Water production sensitivity for Permeability in MH11 HMPH2-UF coal 
Figure 4-95 shows the simulated gas rate and cumulative production results from MH5 for the different permeability values and a different relative permeability curve set in the region 2. Such alterations on relative permeability curves are not affecting significantly to the production as compared to the case where relative permeability curve in both regions are the same.
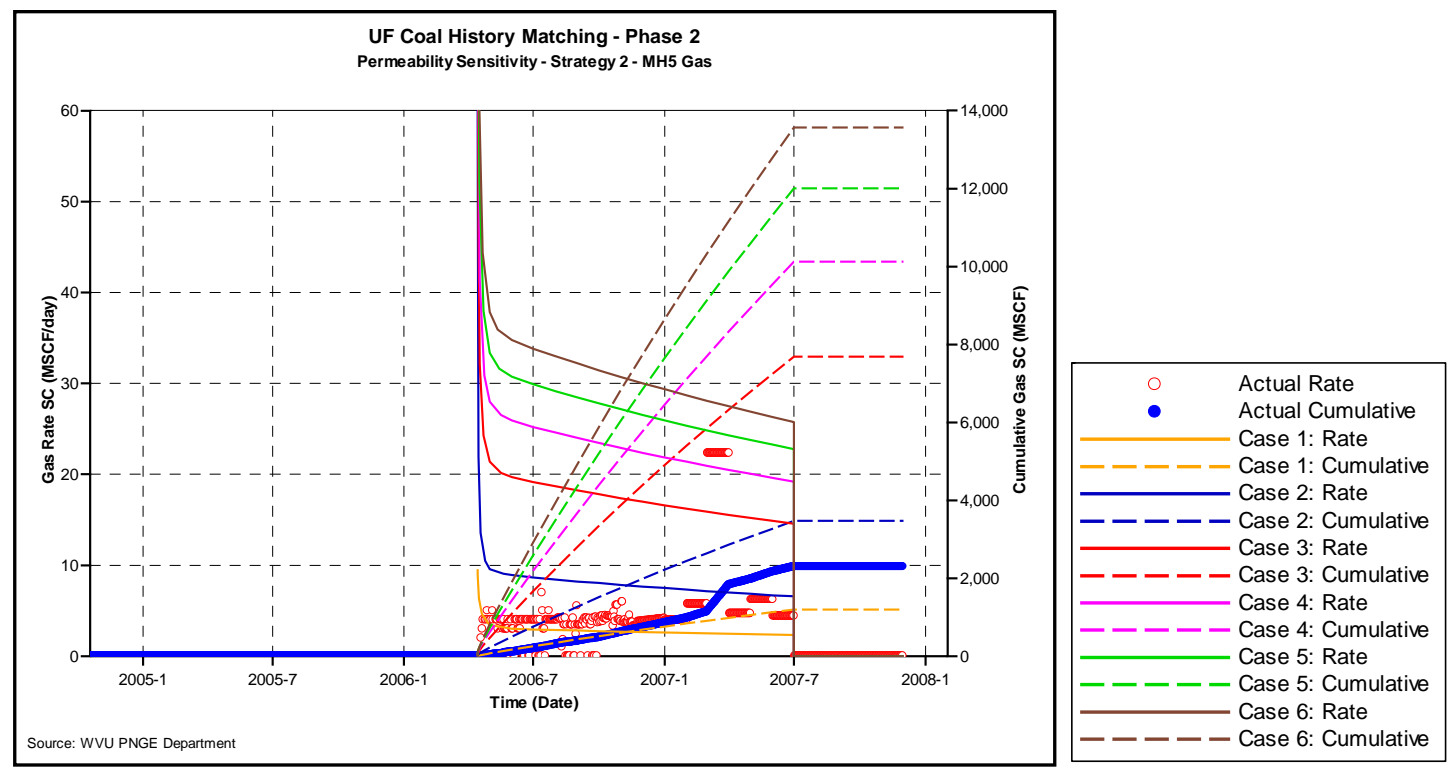

Figure 4-95: Gas production sensitivity for Permeability Strategy 2 in MH5 HMPH2-UF coal

Figure 4-96 shows the simulated gas rate and cumulative production results from $\mathrm{MH} 20$ for the different permeability values and a different relative permeability curve set in the region 2. Again the alterations on relative permeability curves are not affecting significantly to the production as compared to the case where relative permeability curve in both regions are the same. 

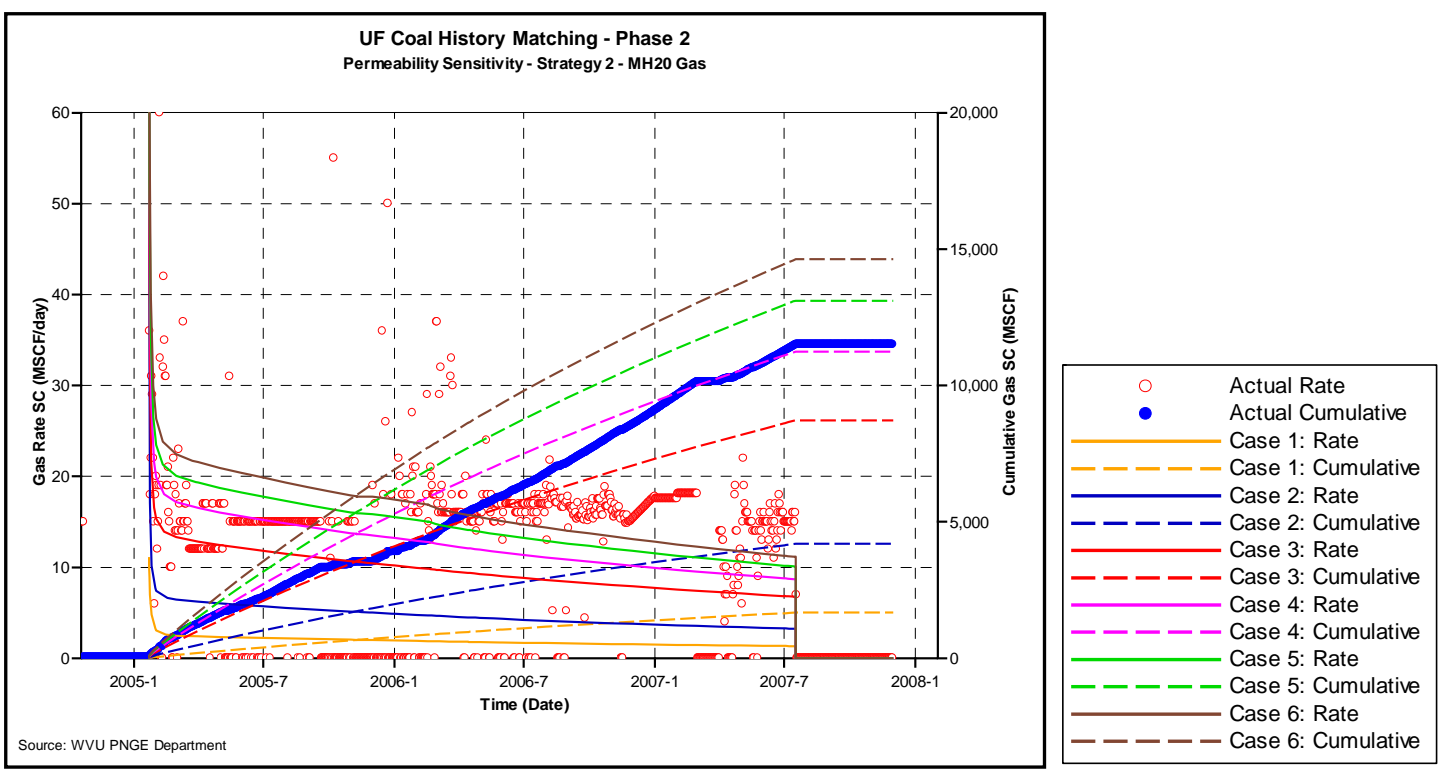

Figure 4-96: Gas production sensitivity for Permeability Strategy 2 in MH20 HMPH2-UF coal

Figure 4-97 shows the simulated gas rate and cumulative production results from MH11 for the different permeability values and a different relative permeability curve set in the region 2. Such alterations on relative permeability curves are not affecting significantly to the production as compared to the case where relative permeability curve in both regions are the same.
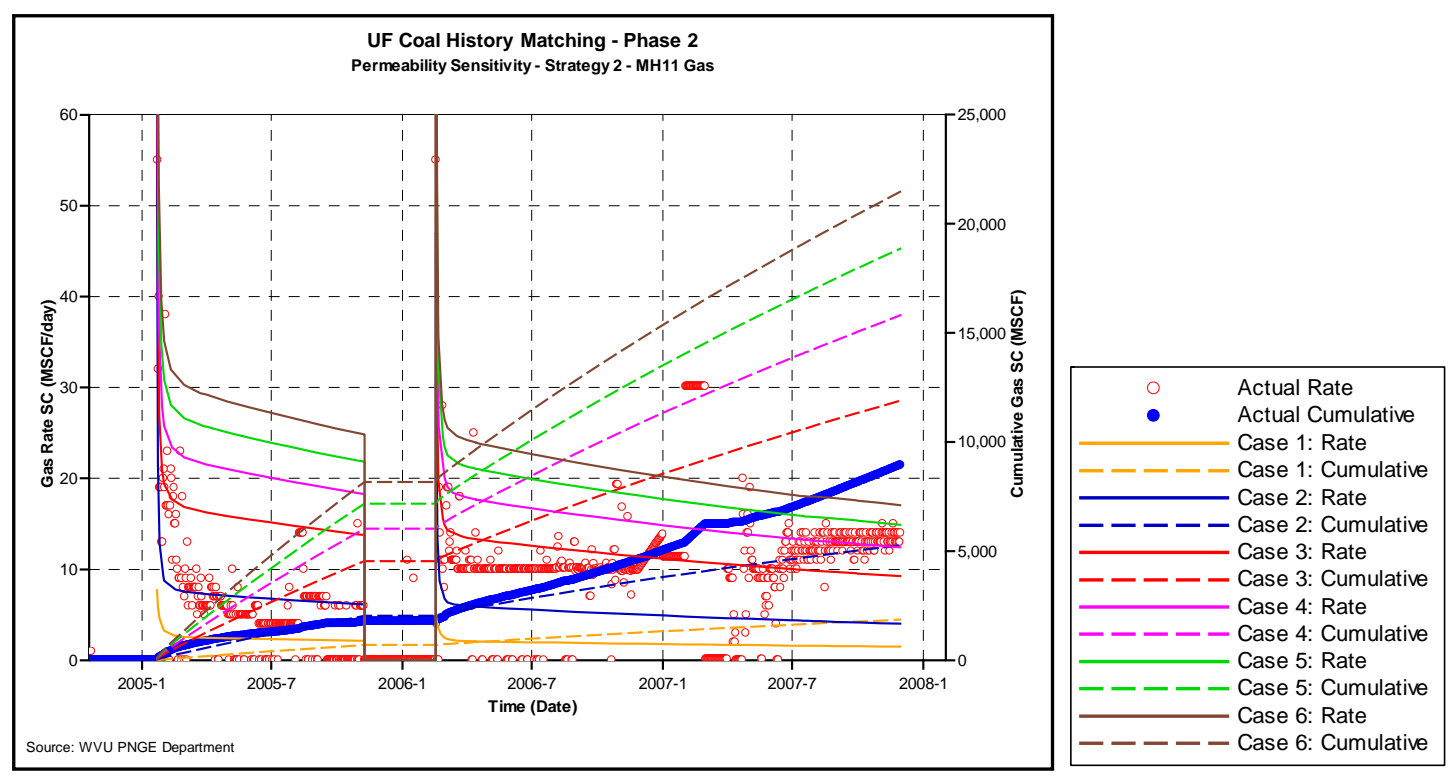

Figure 4-97: Gas production sensitivity for Permeability Strategy 2 in MH11 HMPH2-UF coal 
Figure 4-98 shows the simulated water rate and cumulative production results from MH11 for the different permeability values and a different relative permeability curve set in the region 2. Notice that no water production is simulated.
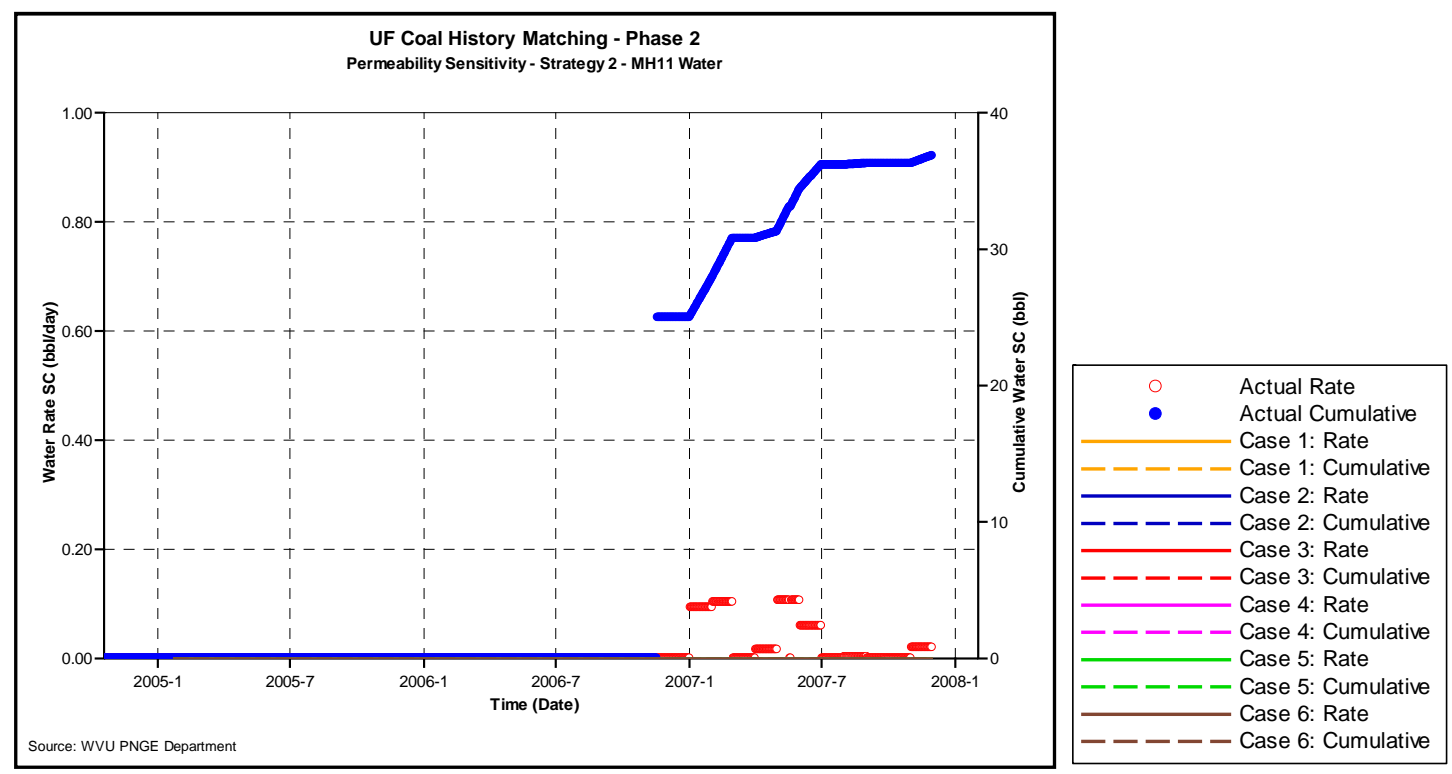

Figure 4-98: Water production sensitivity for Permeability Strategy 2 in MH11 HMPH2-UF coal

Wellbore Parameters:

Well Length:

Table 4-17: Well reduction case sensitivity analysis for HMPH2-UF coal

\begin{tabular}{|c|c|}
\hline Case & $\begin{array}{c}\text { Length } \\
\text { Reduction, \% }\end{array}$ \\
\hline 1 & 0 \\
\hline 2 & 22 \\
\hline 3 & 44 \\
\hline 4 & 66 \\
\hline 5 & 88 \\
\hline
\end{tabular}

Figure 4-99 shows gas rate and cumulative from MH18 for the different cases when the length of the other wells in region 2 are reduced. The result shows that as the length of the wells in region 2 are reduced, less interference among the wells are encountered due to the fact that the 
contact of the other wells in region 2 with the coal is reduced, so less gas is produced leaving resources behind to be produced by $\mathrm{MH} 18$.

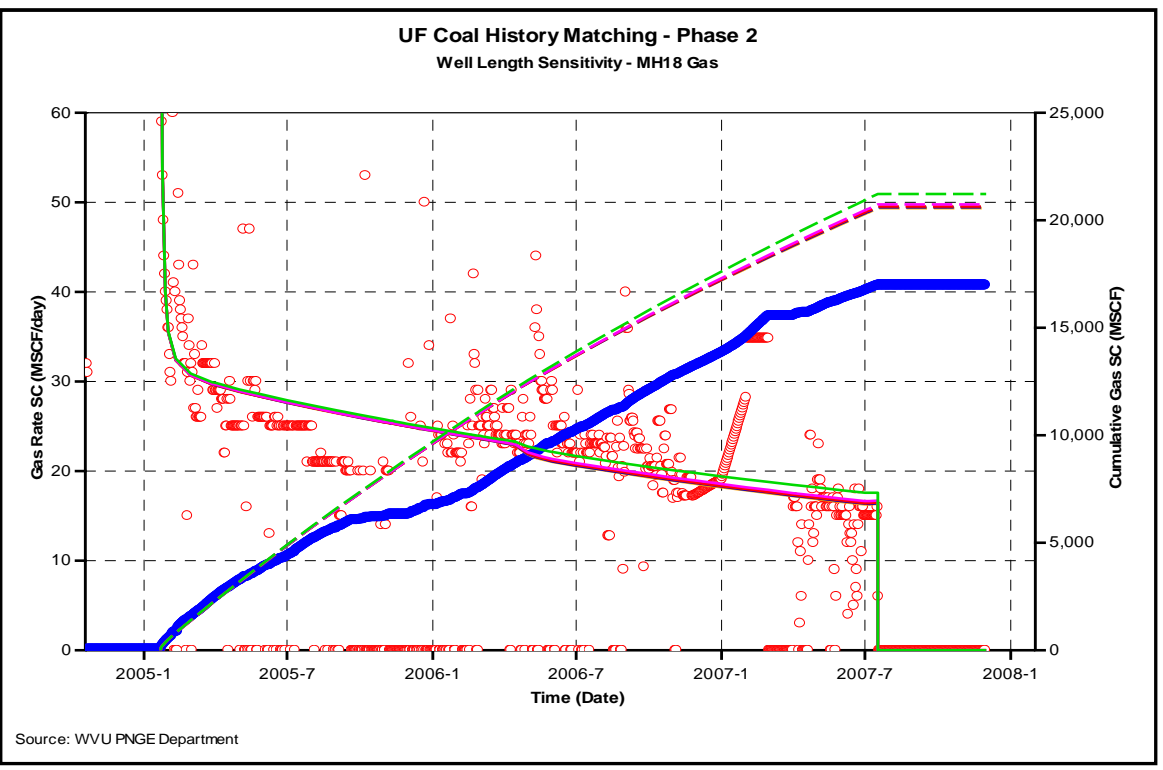

\begin{tabular}{cc|}
\hline- & Actual Rate \\
Actual Cumulative \\
Case 1: Rate \\
-- Case 1: Cumulative \\
-- Case 2: Rate \\
--- Case 2: Cumulative \\
-- Case 3: Rate \\
--- Case 3: Cumulative \\
-- Case 4: Rate \\
-- Case 4: Cumulative \\
-- Case 5: Rate \\
\hline- Case 5: Cumulative
\end{tabular}

Figure 4-99: Gas production sensitivity for Well length reduction in MH18 HMPH2-UF coal

Figure 4-100 shows less than 0.15 bbls of water production in MH18.

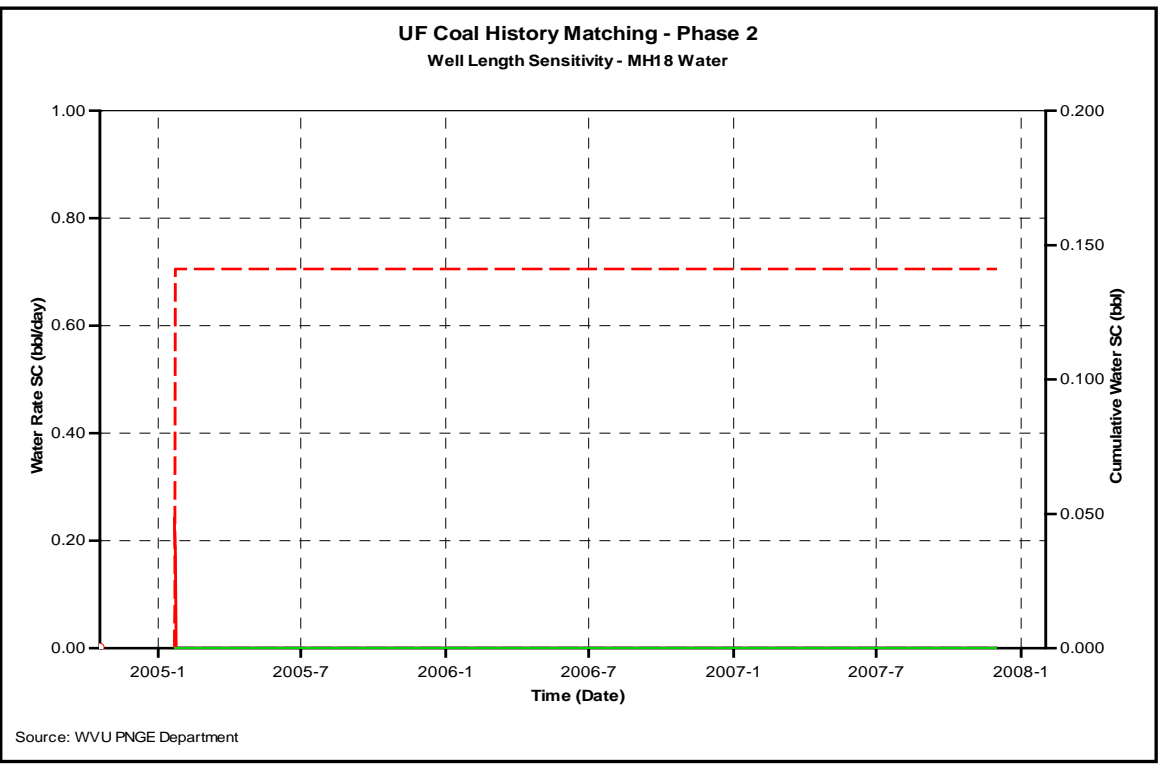

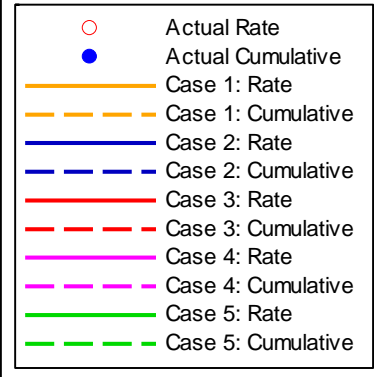

Figure 4-100: Water production sensitivity for Well length reduction in MH18 HMPH2-UF coal 
Figure 4-101 shows gas rate and cumulative from MH5 when all the well lengths in region 2, which includes $\mathrm{MH5}$, are reduced. The result shows that the well length is directly proportional to the gas production. Based on the results not match is achieved for any of the cases.
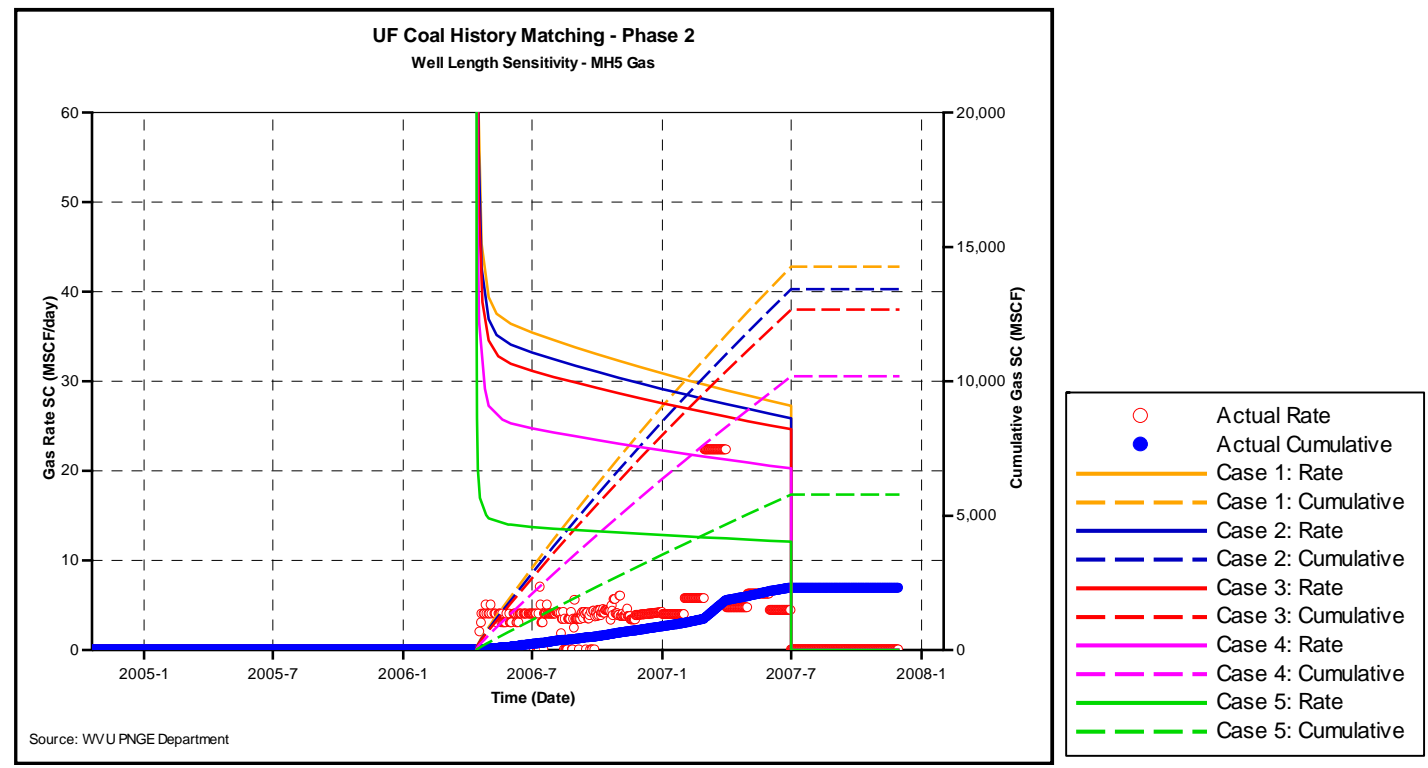

Figure 4-101: Gas production sensitivity for Well length reduction in MH5 HMPH2-UF coal

Figure 4-102 shows water production of well MH5 due to Well Length variation in other wells in region 2. A very small amount of water was produced for this well (less than 0.14 bbls).

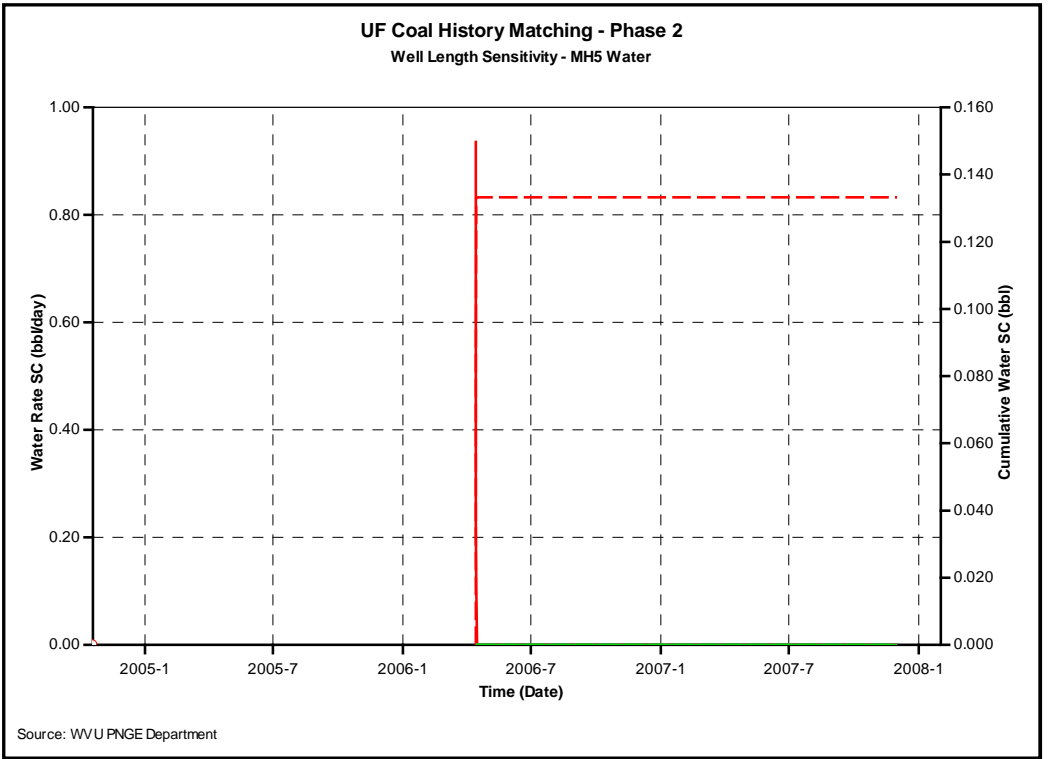

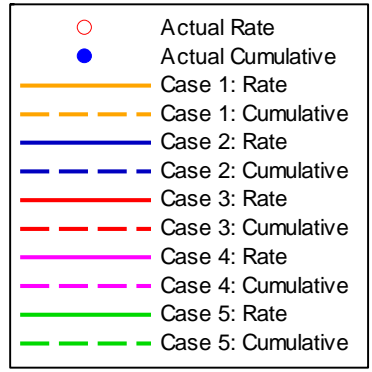

Figure 4-102: water production sensitivity for Well length reduction in MH5 HMPH2-UF coal 
Figure 4-103 shows gas rate and cumulative gas production from $\mathrm{MH} 20$ when the length of the wells in region 2, which includes $\mathrm{MH} 20$, are reduced. As the length of well MH20 is reduced production of gas decreases.

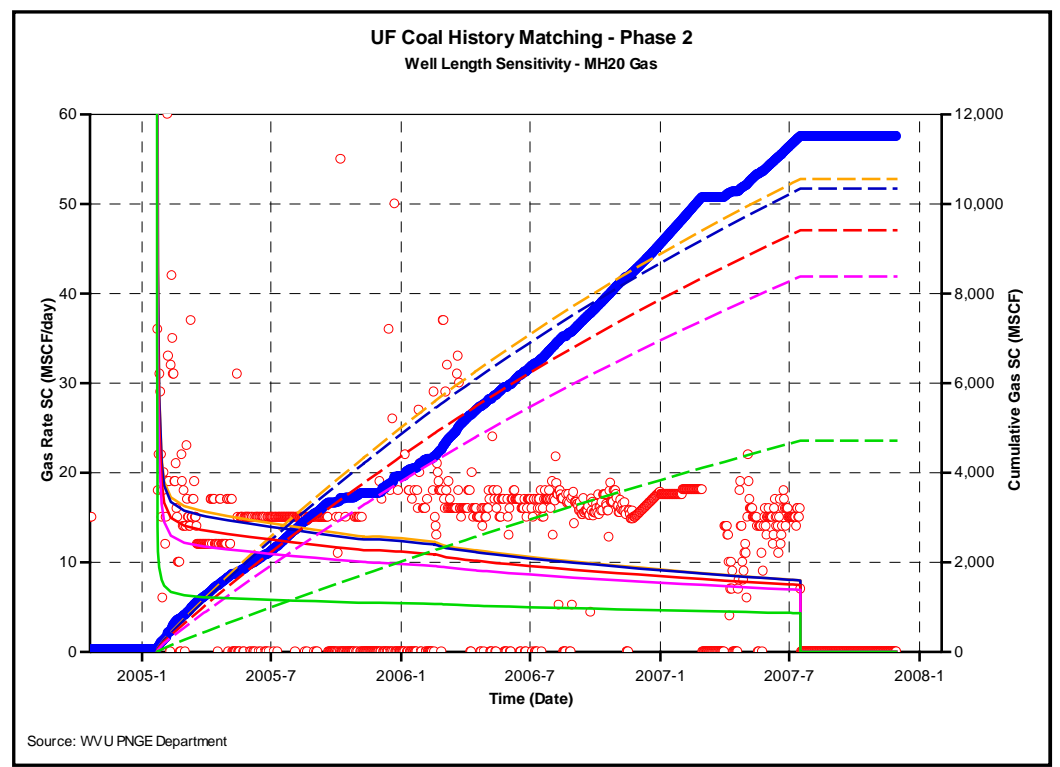

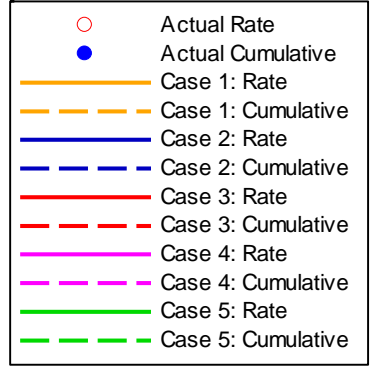

Figure 4-103: Gas production sensitivity for Well length reduction in MH20 HMPH2-UF coal

Figure 4-104 shows water production of well MH20 due to Well Length variation in other wells in region 2 . A very small amount of water was produced for this well.
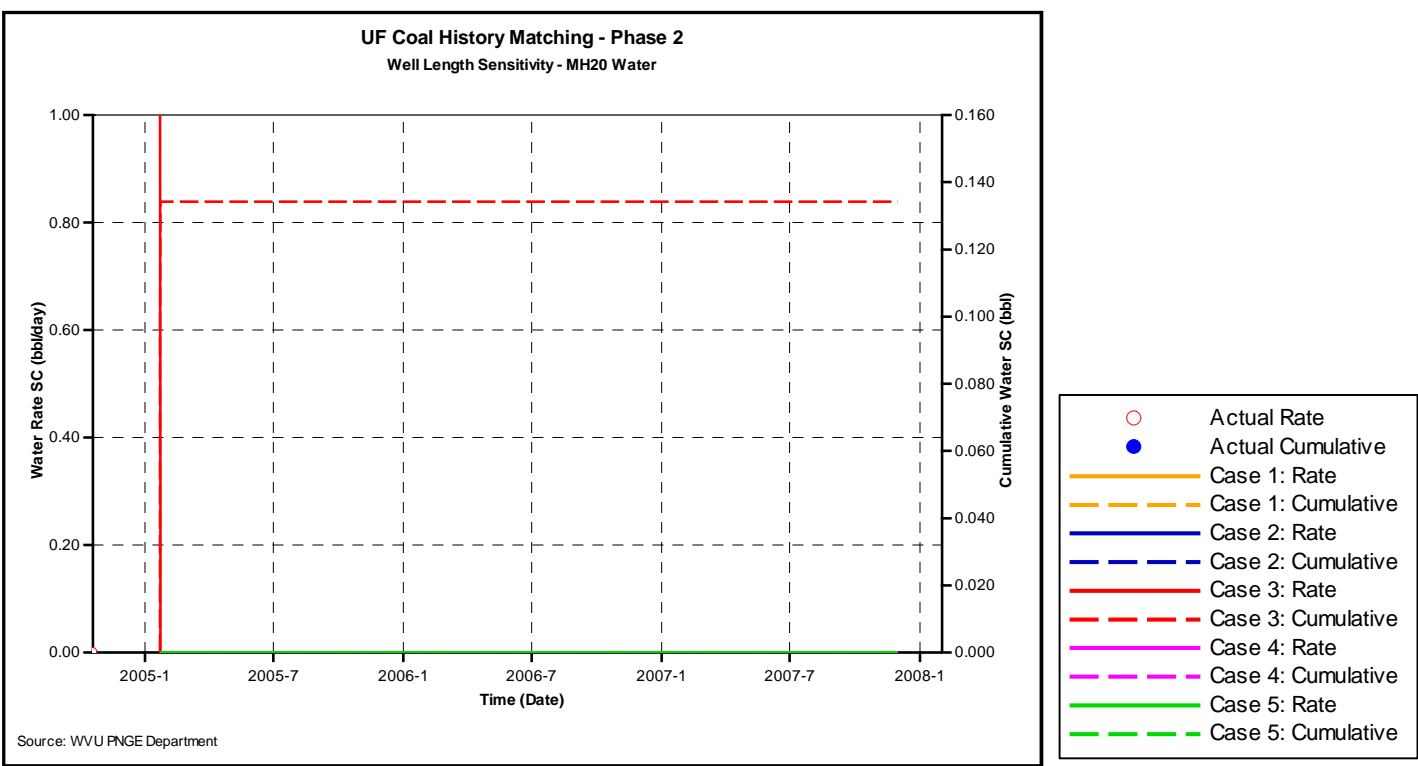

Figure 4-104: Water production sensitivity for Well length reduction in MH20 HMPH2-UF coal 
Figure 4-105 shows gas rate and cumulative gas production from MH11 when the length of the wells in region 2, which includes MH11, are reduced. As the length of well MH11 is reduced production of gas decreases. Despite the reduction in length of MH11 an acceptable match is achieved for the case when the length of the well has been reduced by $88 \%$
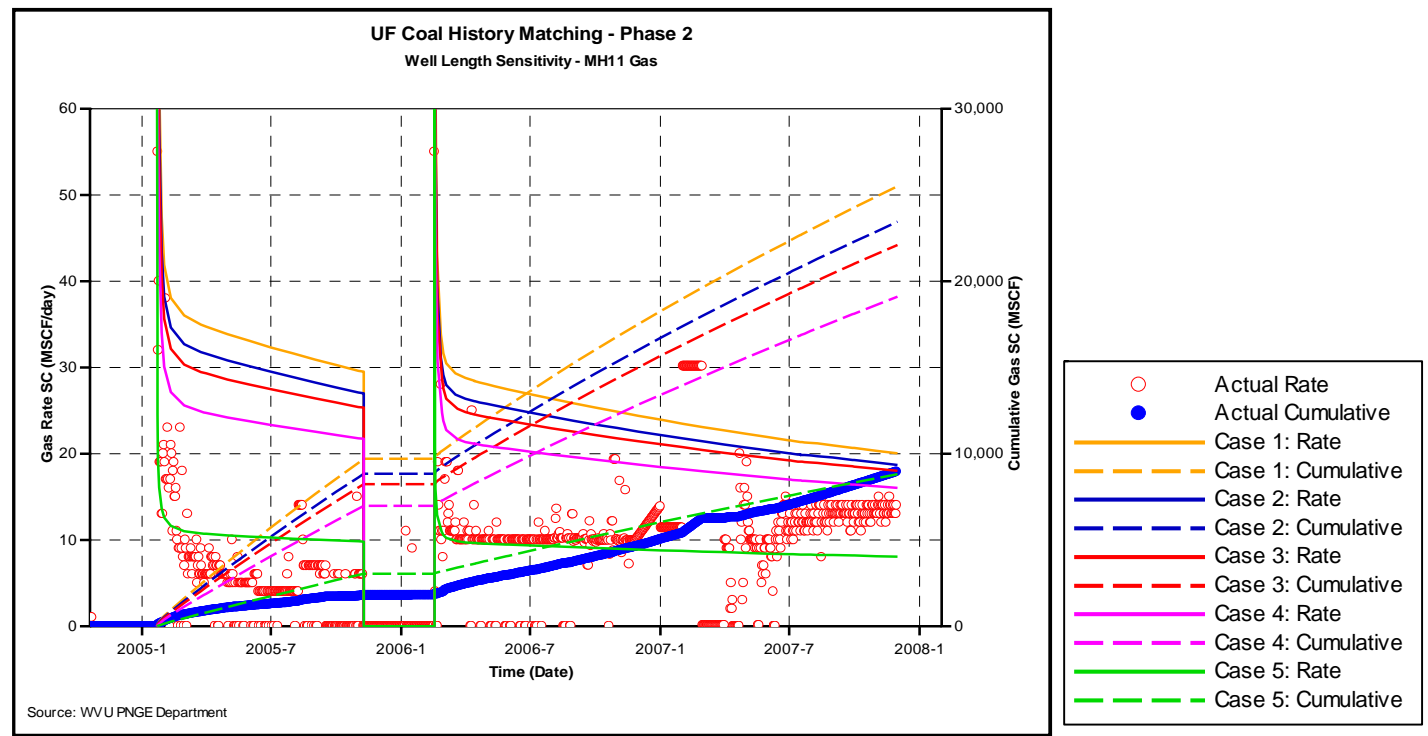

Figure 4-105: Gas production sensitivity for Well length reduction in MH11 HMPH2-UF coal

Figure 4-106 shows a comparison between the actual water production and the simulated one from well MH11 due to its Well Length variation. Cumulative water production for about 2 bbls is achieved by the model.

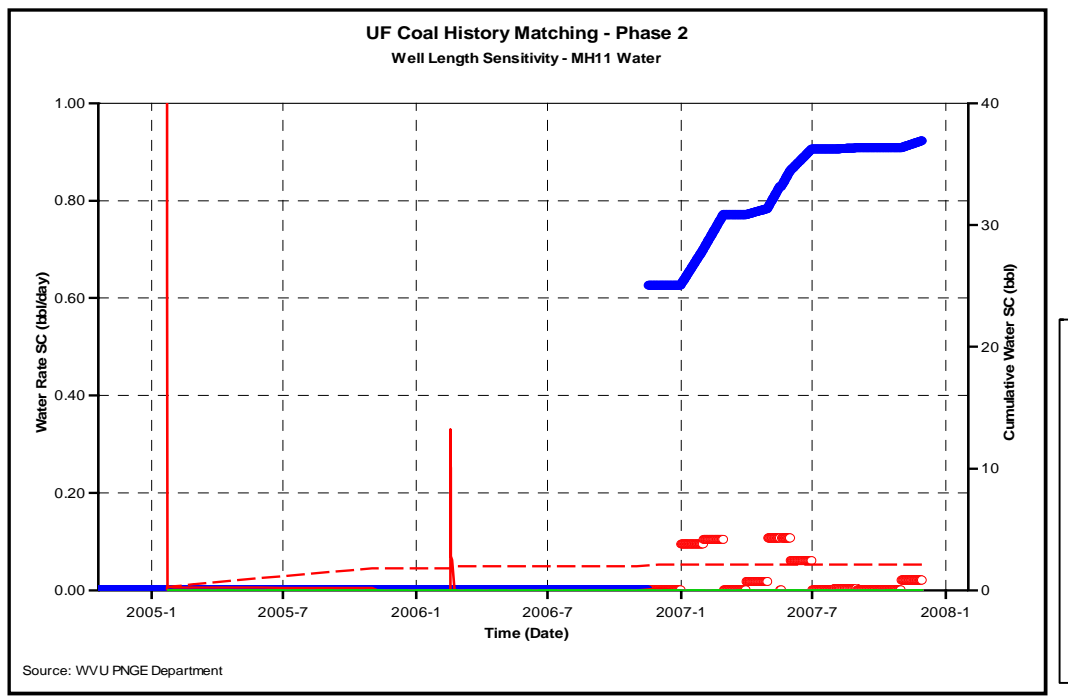

\begin{tabular}{|c|c|}
\hline$\bullet$ & $\begin{array}{l}\text { Actual Rate } \\
\text { Actual Cumulative }\end{array}$ \\
\hline---- & $\begin{array}{l}\text { - Case 1: Rate } \\
\text { - Case 1: Cumulative }\end{array}$ \\
\hline & - Case 2: Rate \\
\hline - - - & $\begin{array}{l}\text { - Case 2: Cumulative } \\
\text { - Case 3: Rate }\end{array}$ \\
\hline---- & - Case 3: Cumulative \\
\hline---- & $\begin{array}{l}\text { Case 4: } 4 \text { : Cumulative } \\
\text { - Case }\end{array}$ \\
\hline---- & $\begin{array}{l}\text { - Case 5: Rate } \\
\text { Case 5: Cumulative }\end{array}$ \\
\hline
\end{tabular}

Figure 4-106: Water production sensitivity for Well length reduction in MH11 HMPH2-UF coal 


\section{History Matching Phase III}

In this phase, one of the focuses is in measuring the impact of the parameters changes and its consequences in the gas production. In order to continue the history matching process, the same considerations, conditions and results from history Match Phase II were taken into account during this phase. This analysis has been performed for every parameter in both PG and UF coal.

As an example, Figure 4-107 shows a comparison among all the trend-lines generated from the steps explain in the methodology for History Match Phase III for the permeability case in the UF coal. In the Figure, there are 4 different trend lines, one for each well respectively as indicated by colored lines. The higher the slope of the line is, the higher the sensitivity of gas production. The blue line represents the sensitivity of well MH18, which belongs to region 1, where the value of the parameters did not change, whereas in other wells, which are in region 2, all the parameters were modified. This explains, for example, why the slope of MH18 is very low, meaning that the changes of the parameters in region 2 did not affect gas production in the well MH18 in region 1. Opposite to what is happening for example, in MH5 where production is highly sensitive to the changes of the parameters in its region, in this case permeability.

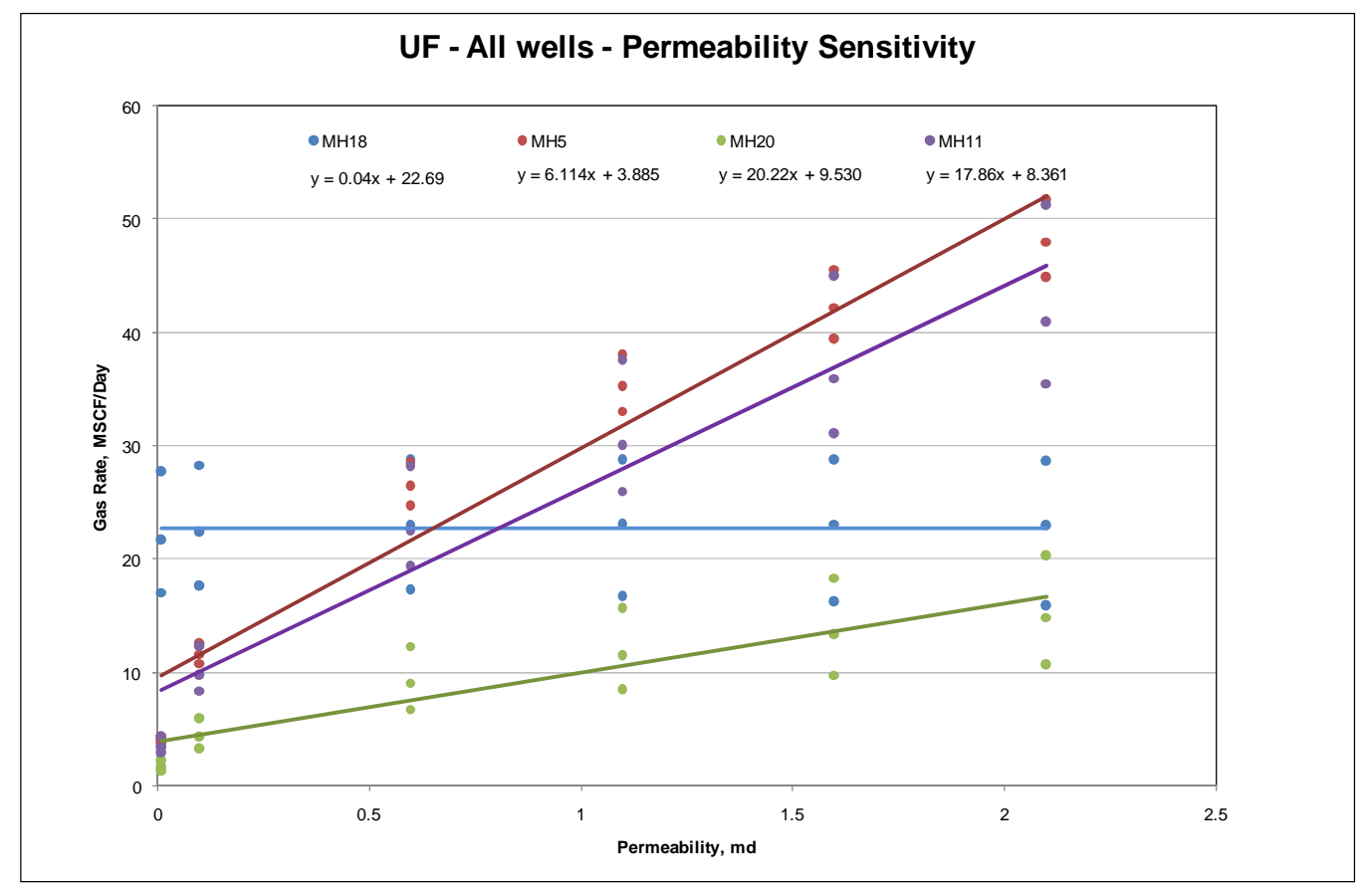

Figure 4-107: Comparison of Permeability Sensibility all Wells HMPH3-UF 
In table 4-18 all the slopes related to the trend lines are organized and ranked for better visualization.

Table 4-18: Absolute Slope and sensitivity ranking for Permeability case UF coal

\begin{tabular}{|c|c|c|c|}
\hline Well & $\begin{array}{c}\text { Absolute } \\
\text { Slope }\end{array}$ & $\begin{array}{c}\text { Normalized } \\
\text { Slope }\end{array}$ & Sensitivity \\
\hline $\mathrm{MH} 18$ & 0.04 & $0 \%$ & Low \\
\hline $\mathrm{MH} 5$ & 20.22 & $100 \%$ & High \\
\hline $\mathrm{MH} 20$ & 6.11 & $30 \%$ & Medium \\
\hline $\mathrm{MH} 11$ & 17.86 & $88 \%$ & High \\
\hline
\end{tabular}

Figure 4-108 shows how gas content changes in the region 2 is affecting the production in well MH18, in contrast with the results of the previous example, where MH18 was not affected. Since gas content changes is affecting all the wells production including MH18, then it means that gas is migrating from one region to another depending on the gas concentration, from high to low.

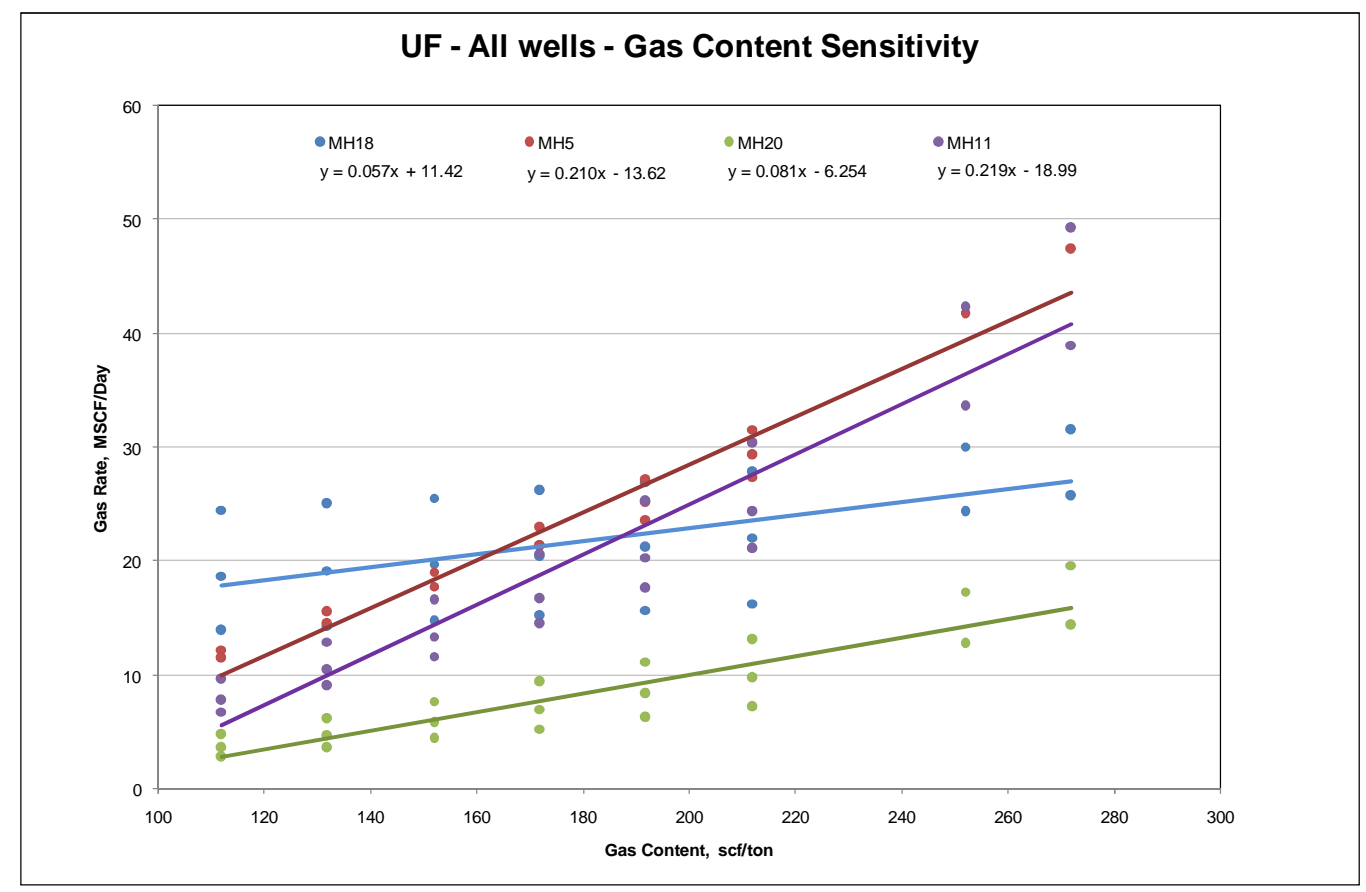

Figure 4-108: Comparison of Gas Content Sensitivity HMPH3-UF 
In table 4-19 all the slopes related to the trend lines are organized and ranked for better visualization.

Table 4-19: Absolute Slope and sensitivity ranking for Gas Content case UF coal

\begin{tabular}{|c|c|c|c|}
\hline Well & $\begin{array}{c}\text { Absolute } \\
\text { Slope }\end{array}$ & $\begin{array}{c}\text { Normalized } \\
\text { Slope }\end{array}$ & Sensitivity \\
\hline MH18 & 0.057 & $26 \%$ & Low \\
\hline MH5 & 0.210 & $96 \%$ & High \\
\hline MH20 & 0.081 & $37 \%$ & Medium \\
\hline MH11 & 0.219 & $100 \%$ & High \\
\hline
\end{tabular}

Based on the analysis above and the slopes of the trend lines for each well; a yardstick to measured the effects in the production of each parameter changes is selected. The yardstick consists in the magnitude of a particular parameter to achieve 5 MSCFD of gas. Then the parameters are ranked in High, Medium, and Low. Low changes in the parameter are ranked as High, high changes in the parameter are ranked as Low, and medium changes as Medium all those within a range of acceptable values. Table 4-20 shows the results for the analysis done in PG coal.

Table 4-20: Parameters ranking based on the yardstick of 5MSCFD for PG Wells

\begin{tabular}{|l|c|c|c|}
\hline \multirow{2}{*}{ Parameter } & \multicolumn{2}{|c|}{$\begin{array}{c}\text { Parameter Changes to } \\
\text { achieve 5 MSCFD at Well }\end{array}$} & $\begin{array}{c}\text { Parameters } \\
\text { Rank for } \\
\text { MH3 }\end{array}$ \\
\cline { 2 - 3 } & MH12 & MH3 & \\
\hline Permeability, md & 0.09 & 0.03 & High \\
\hline Porosity, \% & -3.19 & -0.65 & High \\
\hline Desorption Time, days & -125.00 & -71.43 & Low \\
\hline Gas Content, scf/ton & 4.80 & 2.20 & High \\
\hline Langmuir Pressure, psi & 16.61 & 12.82 & Medium \\
\hline Langmuir Volume, scf/ton & -20.66 & -18.66 & Medium \\
\hline Well Length reduction, \% & 54.95 & -2.16 & High \\
\hline Skin Factor & 40.65 & -1.12 & High \\
\hline Minimum Pwf & 46.30 & -1.77 & High \\
\hline Anisotropy Permeability, Kx:Ky & -7.50 & -1.81 & High \\
\hline
\end{tabular}


After all the parameters have been ranked based on the slope of their gas sensitivity, different matches are achieved for both coals by using a combination of the parameters based on the accessibility of the well (contact between the well and the formation). Below are the results for this study.

\section{Pittsburgh Coal:}

Case 1: All the well-bore is accessible.

- As compared to MH12, MH3 must be in a region with the following conditions and parameters:

\begin{tabular}{ll} 
Parameter & Parameter Ratio \\
\hline Permeability, md & $\mathrm{K}_{\mathrm{MH} 12}=1.8 \mathrm{~K}_{\mathrm{MH} 3}$ \\
Porosity, \% & $\phi_{\mathrm{MH} 12}=6 \phi_{\mathrm{MH} 3}$ \\
Gas Content, scf/ton & $\mathrm{Gc}_{\mathrm{MH} 12}=2.1 \mathrm{Gc}_{\mathrm{MH} 3}$ \\
Skin Factor & $\mathrm{S}_{\mathrm{MH} 12}+7=\mathrm{S}_{\mathrm{MH} 3}$ \\
Minimum Pwf, psi & $\mathrm{Pwf}_{\mathrm{MH} 12}=0.35 \mathrm{Pwf}_{\mathrm{MH} 3}$ \\
Water-Gas contact (WGC), ft & $\mathrm{WGC}_{\mathrm{MH} 12}=\mathrm{WGC}_{\mathrm{MH} 3}$ \\
Desorption Time, days & $\tau_{\mathrm{MH} 12}=0.33 \tau_{\mathrm{MH} 3}$ \\
Relative Permeability & $\mathrm{See} \mathrm{Figure} \mathrm{\#} \mathrm{and} \mathrm{\#}$ \\
Sw below WGC, \% & $\mathrm{Sw}_{\mathrm{MH} 12}=2 \mathrm{Sw} \mathrm{MH}_{3}$ \\
Anisotropy K, Kx:Ky & $\mathrm{Kx}_{\mathrm{K}} \mathrm{K}_{\mathrm{MH} 12}=\mathrm{Kx}: \mathrm{Ky}_{\mathrm{MH} 3}$
\end{tabular}

Table 4-21 shows the parameters used to achieve the match in case 1. Figures 4-115 to 4117 shows the matches for all the cases.

Table 4-21: Parameter values for HMPH3 Case 1 in PG coal

\begin{tabular}{|l|c|c|}
\hline \multicolumn{1}{|c|}{ Parameters } & $\begin{array}{c}\text { Region 1 } \\
\text { MH12 Area }\end{array}$ & $\begin{array}{c}\text { Region 2 } \\
\text { MH3 Area }\end{array}$ \\
\hline Permeability X, md & 45 & 25 \\
\hline Porosity, \% & 6 & 1 \\
\hline Gc. Scf/ton & 186 & 88 \\
\hline Skin Factor & 0 & 7 \\
\hline Minimum Pwf, psi & 28 & 80 \\
\hline WGC, ft & 730.5 & 730.5 \\
\hline Dt, days & 100 & 300 \\
\hline Kr & See Figures $4-109,110$ \\
\hline Sw, \% & 100 & 50 \\
\hline $\begin{array}{l}\text { Anisotropy K, } \\
\text { Kx:Ky }\end{array}$ & $20: 1$ & $20: 1$ \\
\hline
\end{tabular}




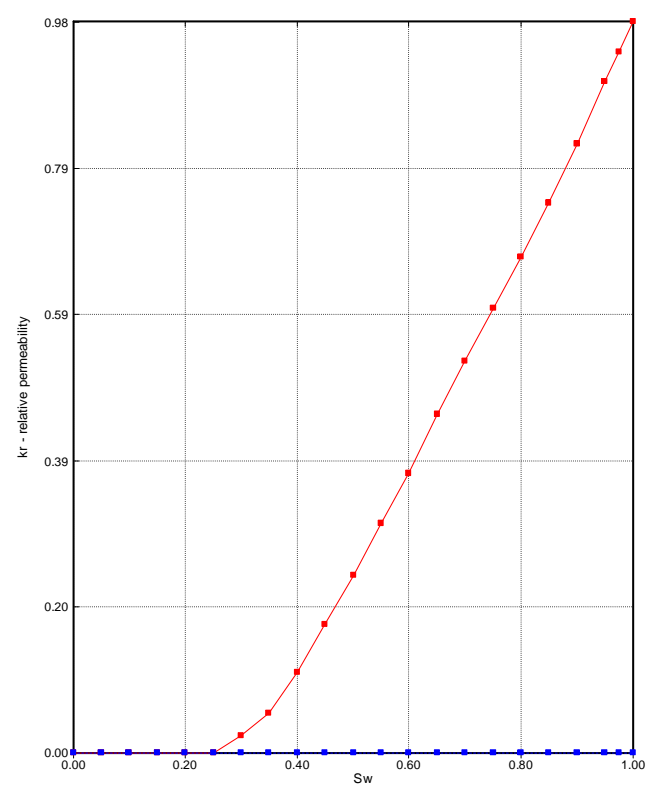

krws Sw

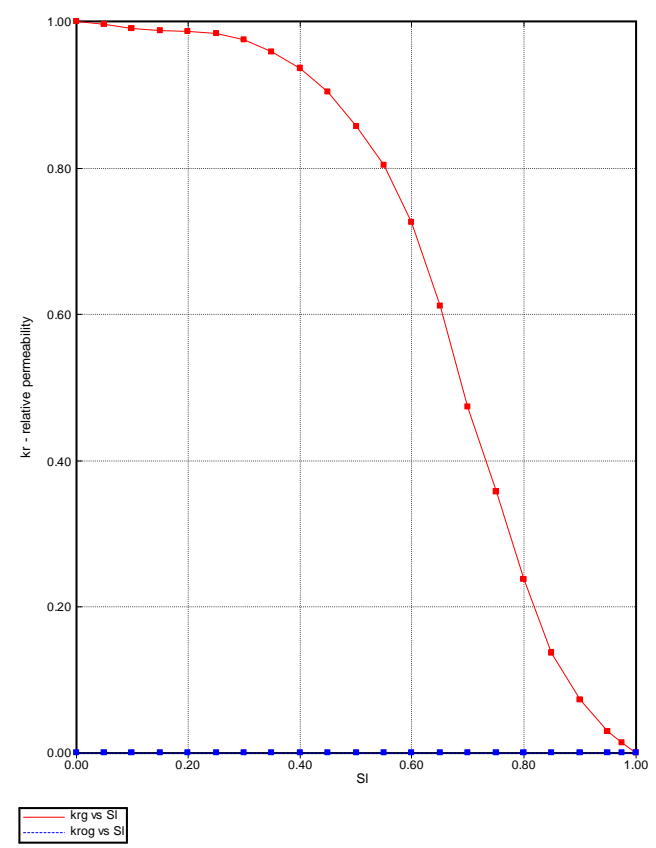

Figure 4-109: Relative Permeability curves for Region 1 in Case 1 HMPH3-PG

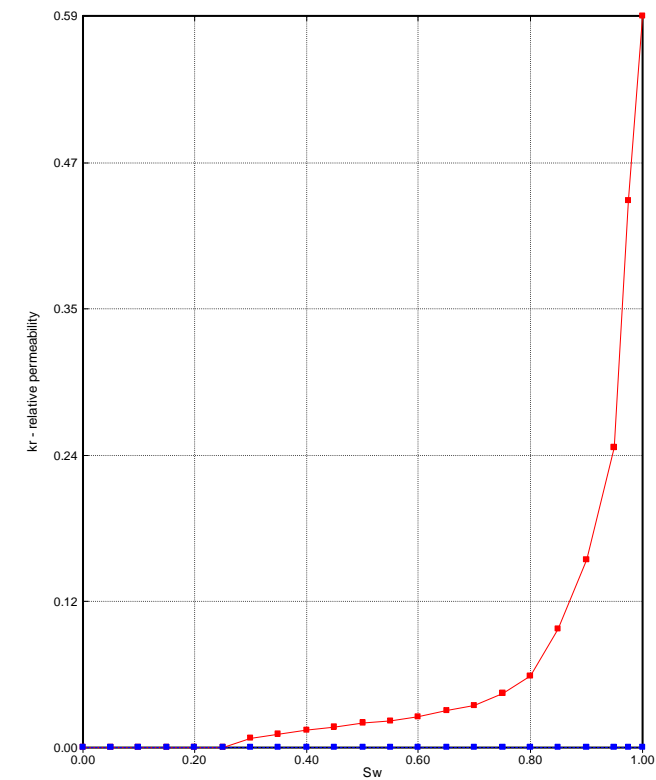

krw vs Sw

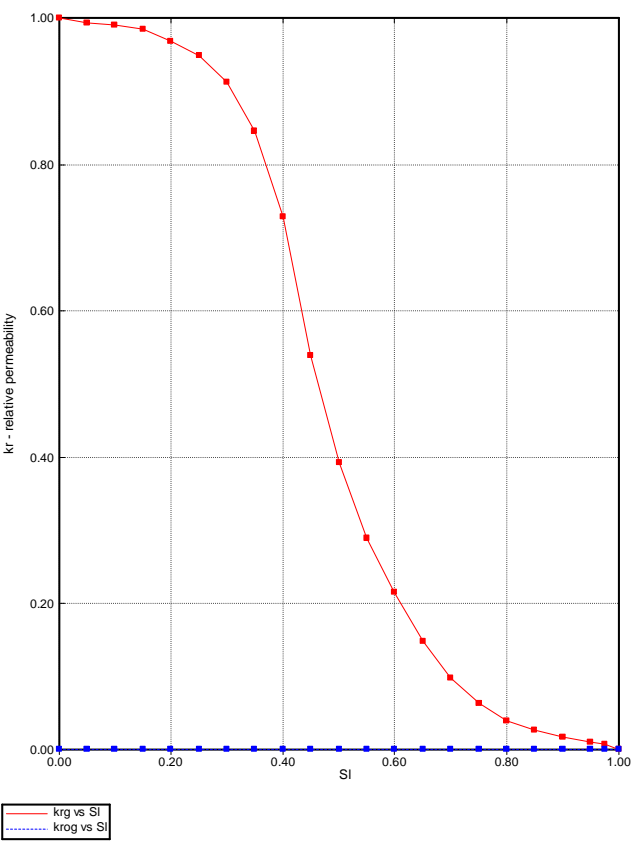

krg vs ST
krog vs SI

Figure 4-110: Relative Permeability curves for Region 2 in Case 1 HMPH3-PG 
Case 2: $49 \%$ of the well-bore is accessible.

- As compared to MH12, MH3 must be in a region with the following conditions and parameters:

\begin{tabular}{ll} 
Parameter & Parameter Ratio \\
\hline Permeability, md & $\mathrm{K}_{\mathrm{MH} 12}=1.8 \mathrm{~K}_{\mathrm{MH} 3}$ \\
Porosity, \% & $\phi_{\mathrm{MH} 12}=6 \phi_{\mathrm{MH} 3}$ \\
Gas Content, scf/ton & $\mathrm{Gc}_{\mathrm{MH} 12}=1.86 \mathrm{Gc}_{\mathrm{MH} 3}$ \\
Skin Factor & $\mathrm{S}_{\mathrm{MH} 12}+7=\mathrm{S}_{\mathrm{MH} 3}$ \\
Minimum Pwf, psi & $\mathrm{Pwf}_{\mathrm{MH} 12}=0.32 \mathrm{Pwf}_{\mathrm{MH} 3}$ \\
Water-Gas contact (WGC), ft & $\mathrm{WGC}_{\mathrm{MH} 12}=\mathrm{WGC}_{\mathrm{MH} 3}$ \\
Desorption Time, days & $\tau_{\mathrm{MH} 12}=0.33 \tau_{\mathrm{MH} 3}$ \\
Relative Permeability & $\mathrm{See} \mathrm{Figure} \mathrm{\#} \mathrm{and} \mathrm{\#}$ \\
Sw below WGC, \% & $\mathrm{Sw}_{\mathrm{MH} 12}=2 \mathrm{Sw} w_{\mathrm{MH} 3}$ \\
Anisotropy K, Kx:Ky & $\mathrm{Kx}: \mathrm{Ky}_{\mathrm{MH} 12}=\mathrm{Kx}_{\mathrm{K}} \mathrm{Ky}_{\mathrm{MH} 3}$
\end{tabular}

Table 4-22 shows the parameters used to achieve the match.

Table 4-22: Parameter values for HMPH3 Case 2 in PG coal

\begin{tabular}{|l|c|c|}
\hline \multicolumn{1}{|c|}{ Parameters } & $\begin{array}{c}\text { Region 1 } \\
\text { MH12 Area }\end{array}$ & $\begin{array}{c}\text { Region 2 } \\
\text { MH3 Area }\end{array}$ \\
\hline Permeability X, md & 45 & 25 \\
\hline Porosity, \% & 6 & 1 \\
\hline Gc. Scf/ton & 186 & 100 \\
\hline Skin Factor & 0 & 7 \\
\hline Minimum Pwf, psi & 28 & 88 \\
\hline WGC, ft & 730.5 & 730.5 \\
\hline Dt, days & 100 & 300 \\
\hline Kr & See Figures $4-111,112$ \\
\hline Sw, \% & 100 & 50 \\
\hline $\begin{array}{l}\text { Anisotropy K, } \\
\text { Kx:Ky }\end{array}$ & $20: 1$ & $20: 1$ \\
\hline
\end{tabular}



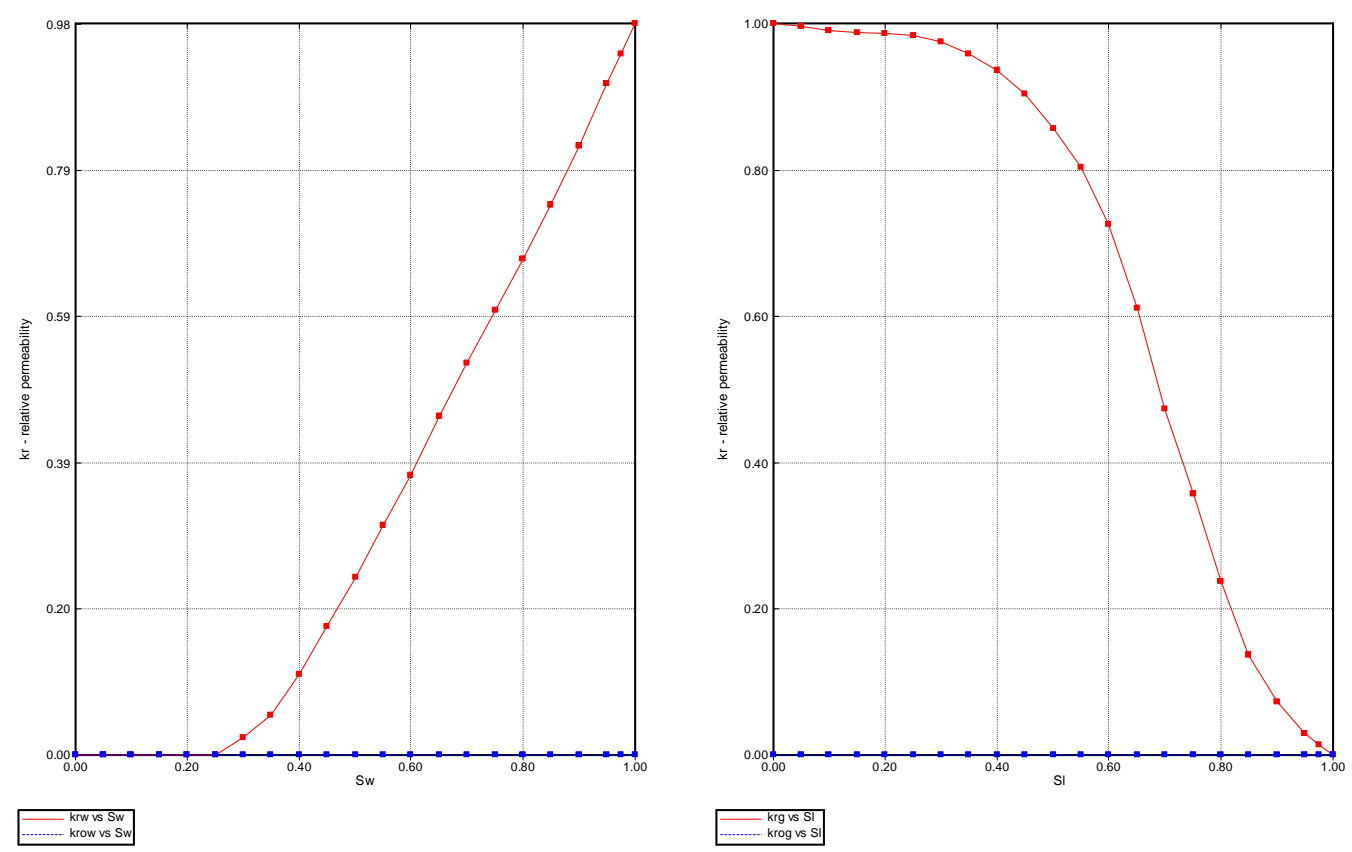

Figure 4-111: Relative Permeability curves for Region 1 in Case 2 HMPH3-PG
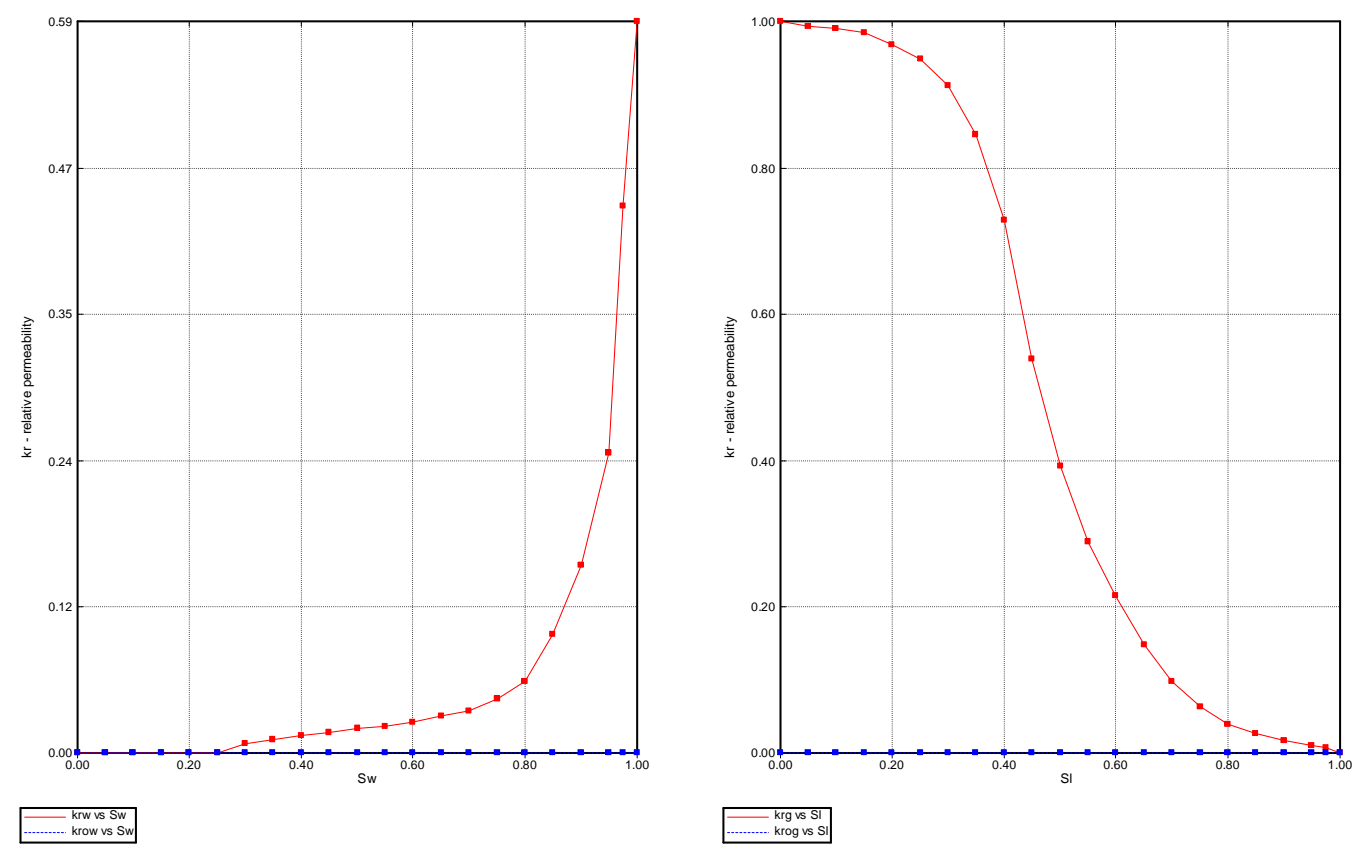

Figure 4-112: Relative Permeability curves for Region 2 in Case 2 HMPH3-PG 
Case 3: $23 \%$ of the well-bore is accessible.

- As compared to MH12, MH3 must be in a region with the following conditions and parameters:

\begin{tabular}{ll} 
Parameter & Parameter Ratio \\
\hline Permeability, md & $\mathrm{K}_{\mathrm{MH} 12}=1.8 \mathrm{~K}_{\mathrm{MH} 3}$ \\
Porosity, \% & $\phi_{\mathrm{MH} 12}=6 \phi_{\mathrm{MH} 3}$ \\
Gas Content, scf/ton & $\mathrm{Gc}_{\mathrm{MH} 12}=1.66 \mathrm{Gc}_{\mathrm{MH} 3}$ \\
Skin Factor & $\mathrm{S}_{\mathrm{MH} 12}+7=\mathrm{S}_{\mathrm{MH} 3}$ \\
Minimum Pwf, psi & $\mathrm{Pwf}_{\mathrm{MH} 12}=0.3 \mathrm{Pwf}_{\mathrm{MH} 3}$ \\
Water-Gas contact (WGC), ft & $\mathrm{WGC}_{\mathrm{MH} 12}=\mathrm{WGC}_{\mathrm{MH} 3}$ \\
Desorption Time, days & $\tau_{\mathrm{MH} 12}=0.33 \tau_{\mathrm{MH} 3}$ \\
Relative Permeability & $\mathrm{See} \mathrm{Figure} \mathrm{\#} \mathrm{and} \mathrm{\#}$ \\
Sw below WGC, $\%$ & $\mathrm{Sw}_{\mathrm{MH} 12}=2 \mathrm{Sw} \mathrm{MH}_{\mathrm{M} 3}$ \\
Anisotropy K, Kx:Ky & $\mathrm{Kx}_{\mathrm{K}} \mathrm{Ky}_{\mathrm{MH} 12}=\mathrm{Kx}: \mathrm{Ky}_{\mathrm{MH} 3}$
\end{tabular}

Table 4-23 shows the parameters used to achieve the match.

Table 4-23: Parameter values for HMPH3 Case 3 in PG coal

\begin{tabular}{|l|c|c|}
\hline \multicolumn{1}{|c|}{ Parameters } & $\begin{array}{c}\text { Region 1 } \\
\text { MH12 Area }\end{array}$ & $\begin{array}{c}\text { Region 2 } \\
\text { MH3 Area }\end{array}$ \\
\hline Permeability X, md & 45 & 25 \\
\hline Porosity, \% & 6 & 1 \\
\hline Gc. Scf/ton & 186 & 100 \\
\hline Skin Factor & 0 & 7 \\
\hline Minimum Pwf, psi & 28 & 91 \\
\hline WGC, ft & 730.5 & 730.5 \\
\hline Dt, days & 100 & 300 \\
\hline Kr & See Figures $4-113-114$ \\
\hline Sw, \% & 100 & 50 \\
\hline $\begin{array}{l}\text { Anisotropy K, } \\
\text { Kx:Ky }\end{array}$ & $20: 1$ & $20: 1$ \\
\hline
\end{tabular}



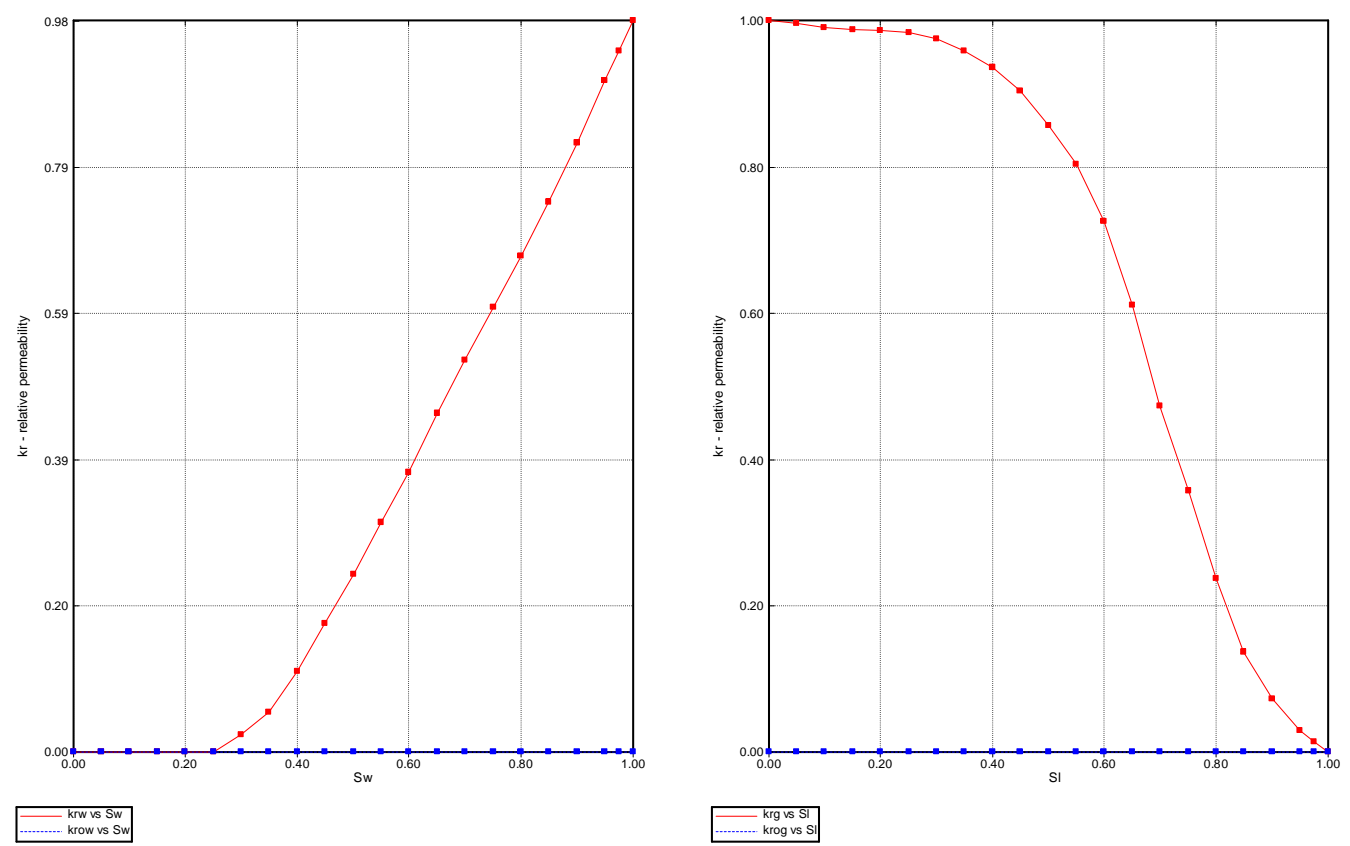

Figure 4-113: Relative Permeability curves for Region 1 in Case 3 HMPH3-PG
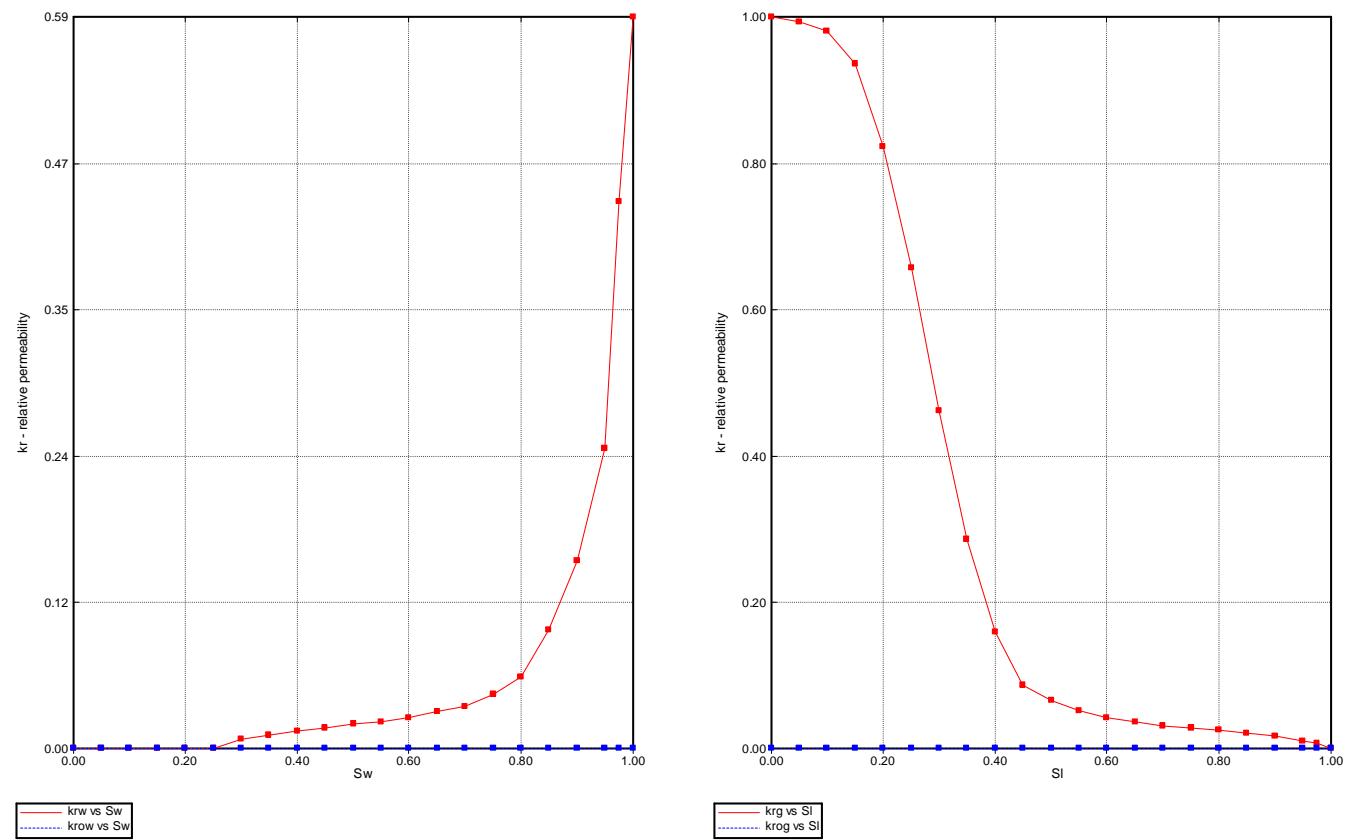

Figure 4-114: Relative Permeability curves for Region 2 in Case 3 HMPH3-PG 


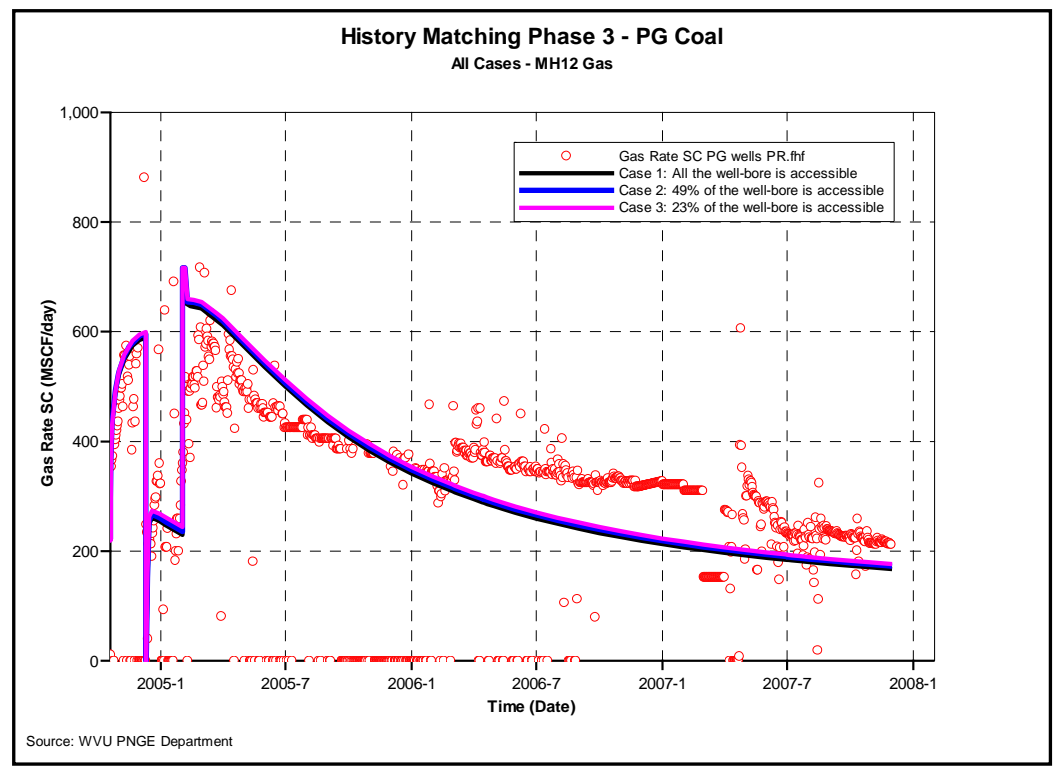

Figure 4-115: MH12 Gas Rate Production History Matching Results for all the cases HMPH3-PG

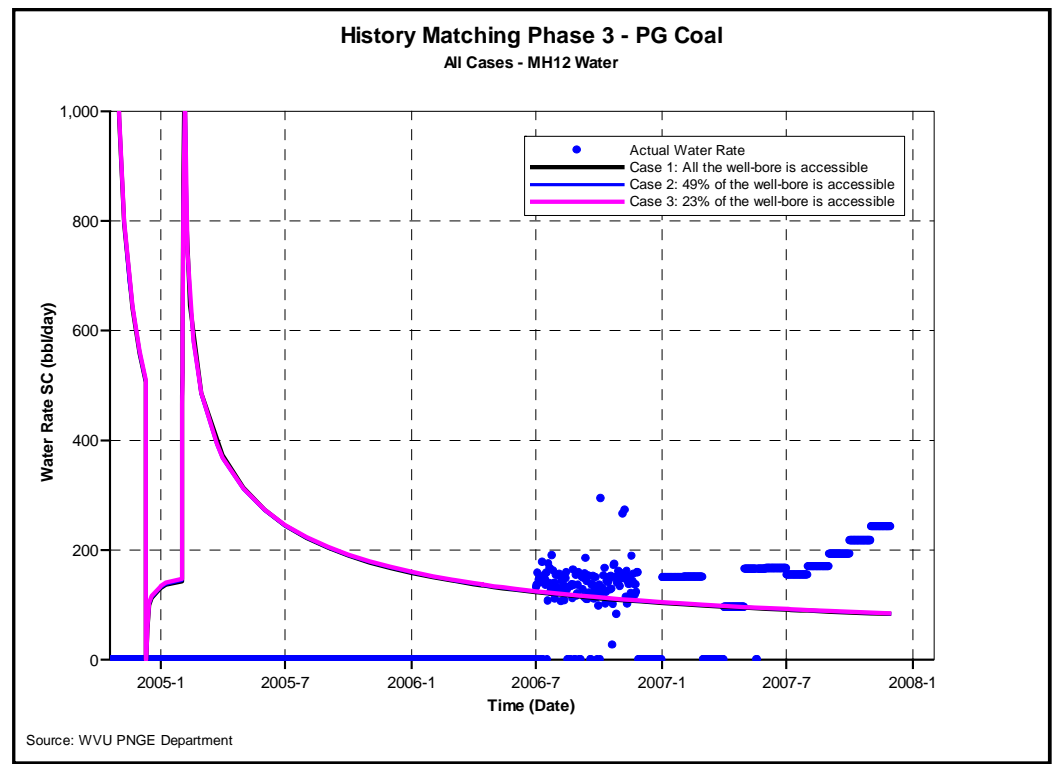

Figure 4-116: MH12 Water Rate Production History Matching Results for all the cases HMPH3-PG 


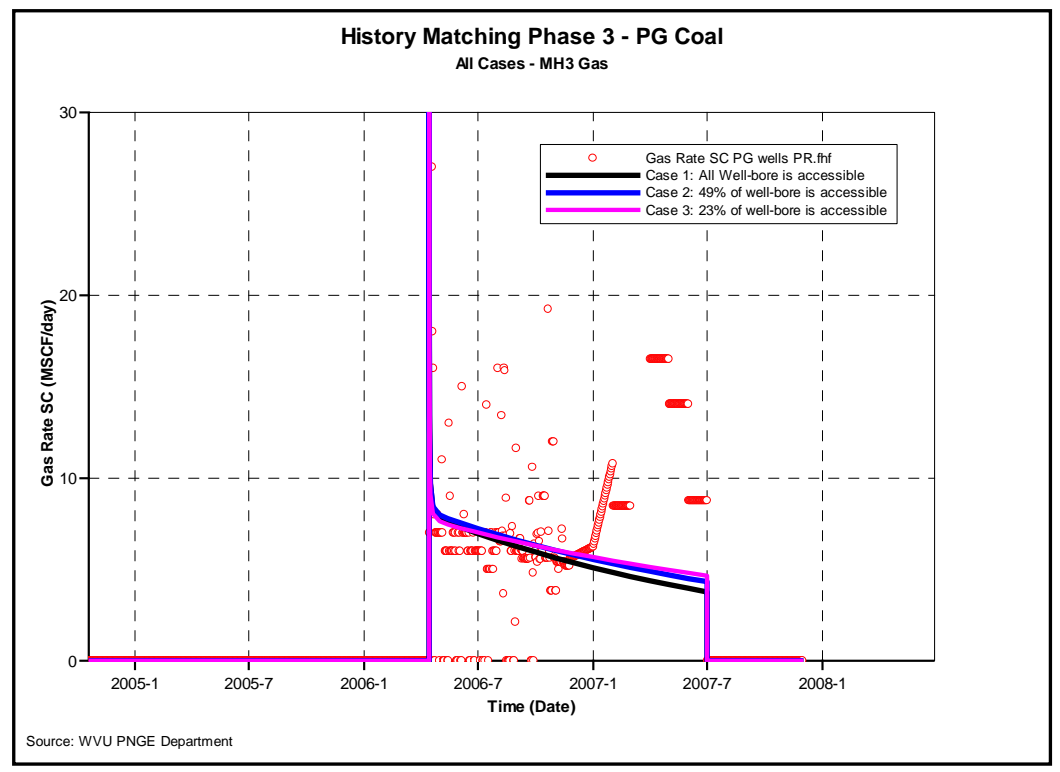

Figure 4-117: MH3 Gas Rate Production History Matching Results for all the cases HMPH3-PG

No water production is simulated in $\mathrm{MH} 3$, as compared to the actual production.

Based on the results, even by decreasing the length of well $\mathrm{MH} 3$ by $77 \%$, a very heterogeneous formation is needed in order to achieve a match in both wells. Even, when verifiable evidences for liquid loading to be happening in well MH3 do not exist, the fact of having a lot of water production from MH12 as compared to MH3 that has not produced any water during its life, suggest that it may be happening under the non-presence of other formation features such as faults. 
Upper Freeport Coal: Table 4-24 shows the results for the analysis done in PG coal. Notice that relative permeability curves, Figure 4-109, have kept the same for all the cases and regions. Figures 4-119 to 4-122 shows the matches for all the cases.

Table 4-24: Parameters ranking based on the yardstick of 5MSCFD for UF Wells

\begin{tabular}{|c|c|c|c|c|c|c|}
\hline \multirow[t]{2}{*}{ Parameter } & \multicolumn{4}{|c|}{$\begin{array}{l}\text { Parameter Changes to achieve } 5 \text { MSCFD at } \\
\text { Well }\end{array}$} & \multirow{2}{*}{$\begin{array}{c}\text { Average } \\
\text { Parameter } \\
\text { Changes }\end{array}$} & \multirow{2}{*}{$\begin{array}{c}\text { Average } \\
\text { Parameters Rank } \\
\text { for } \mathrm{MH} 5, \mathrm{MH} 11 \text {, } \\
\mathrm{MH} 20\end{array}$} \\
\hline & $\mathrm{MH} 18$ & $\mathrm{MH} 5$ & $\mathrm{MH} 20$ & $\mathrm{MH} 11$ & & \\
\hline Permeability, md & 125.0 & 0.8 & 0.2 & 0.3 & 0.4 & High \\
\hline Desorption Time, days & 5000.0 & -312.5 & -1250.0 & -500.0 & -687.5 & Low \\
\hline Gas Content, scf/ton & 87.7 & 23.8 & 61.7 & 22.8 & 36.1 & Medium \\
\hline Langmuir Pressure, psi & 277.8 & 56.8 & 166.7 & 58.8 & 94.1 & Low \\
\hline Langmuir Volume, scf/ton & -625.0 & -135.1 & -454.5 & -147.1 & -245.6 & Low \\
\hline Well Length reduction, \% & -92.6 & -23.0 & -68.5 & -22.1 & -37.9 & Medium \\
\hline Skin Factor & 312.5 & -9.3 & -29.8 & -9.2 & -16.1 & High \\
\hline Minimum Pwf & 1666.7 & -42.7 & -108.7 & -48.1 & -66.5 & Medium \\
\hline
\end{tabular}

Case 1: All the well-bore is accessible.

- In order to achieve history matching, the wells must be in regions with the conditions and parameters in Table 4-25:

Table 4-25: Parameter values for HMPH3 Case 1 in PG coal

\begin{tabular}{|l|c|c|c|c|}
\hline \multicolumn{1}{|c|}{ Parameters } & $\begin{array}{c}\text { Region 1 } \\
\text { MH18 } \\
\text { Area }\end{array}$ & $\begin{array}{c}\text { Region 2 } \\
\text { MH20 } \\
\text { Area }\end{array}$ & $\begin{array}{c}\text { Region 1 } \\
\text { MH5 } \\
\text { Area }\end{array}$ & $\begin{array}{c}\text { Region 2 } \\
\text { MH11 } \\
\text { Area }\end{array}$ \\
\hline Permeability_X, md & 1 & 1.5 & 0.025 & 0.09 \\
\hline Porosity, \% & \multicolumn{5}{|c|}{1} \\
\hline Gc. Scf/ton & \multicolumn{5}{|c|}{232} \\
\hline Skin Factor & 0 & 0 & 7 & $7 /-1$ \\
\hline Minimum Pwf, psi & \multicolumn{5}{|c|}{600} \\
\hline WGC, ft & \multicolumn{5}{|c|}{20} \\
\hline Dt, days & \multicolumn{5}{|c|}{$1: 17$} \\
\hline Sw, \% & \multicolumn{5}{|c|}{} \\
\hline Anisotropy K, Kx:Ky & \multicolumn{5}{|c|}{} \\
\hline
\end{tabular}



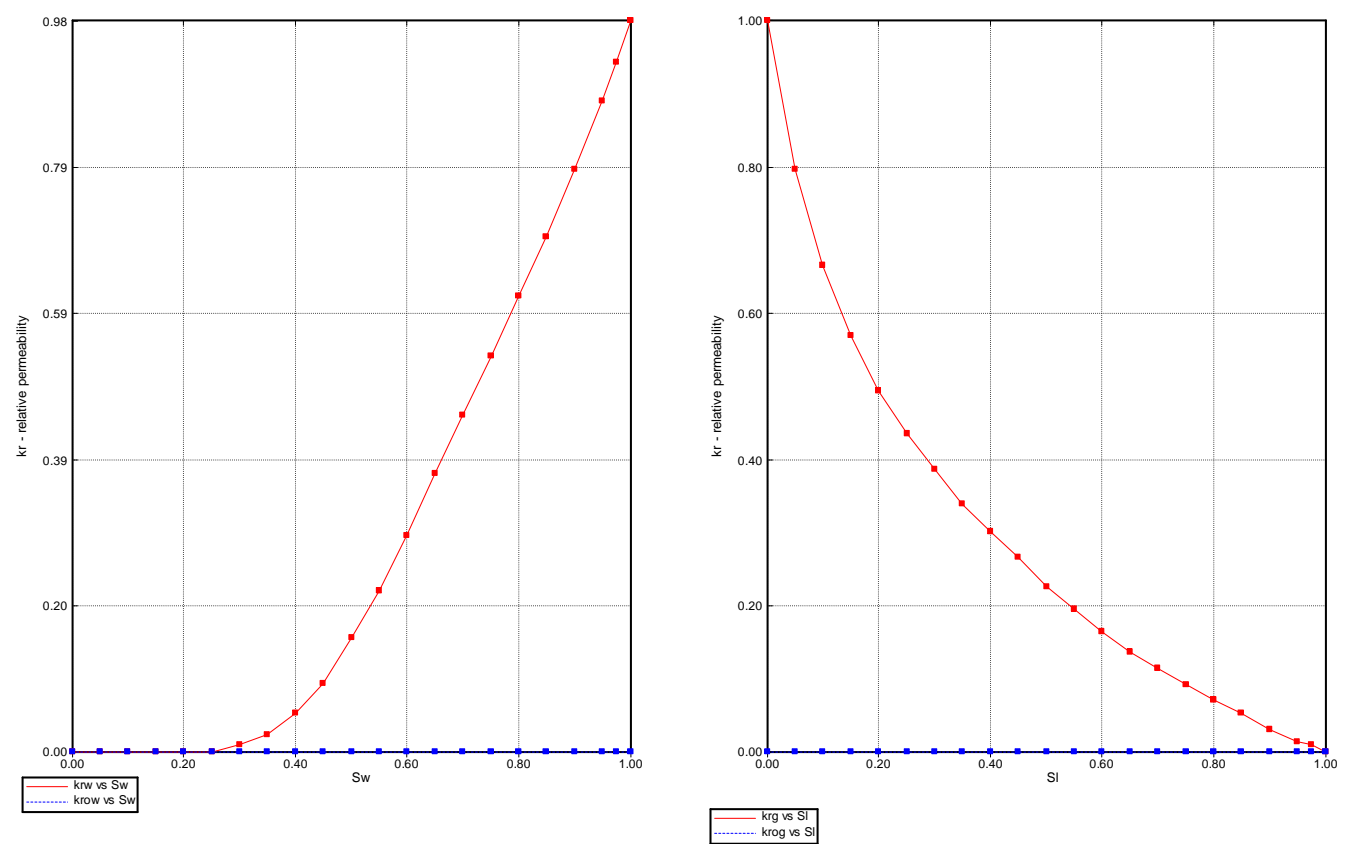

Figure 4-118: Relative Permeability curves for all the regions for all the cases HMPH3-UF

Case 2: $49 \%$ of the well-bore is accessible.

- In order to achieve history matching, the wells must be in regions with the conditions and parameters in Table 4-26.

Table 4-26: Parameter values for HMPH3 Case 3 in UF coal

\begin{tabular}{|c|c|c|c|c|}
\hline \multirow[b]{2}{*}{ Parameters } & & & \multicolumn{2}{|c|}{ Well length reduced } \\
\hline & $\begin{array}{c}\text { Region } 1 \\
\text { MH18 Area }\end{array}$ & $\begin{array}{c}\text { Region } 2 \\
\text { MH20 Area }\end{array}$ & $\begin{array}{l}\text { Region } 1 \\
\text { MH5 Area }\end{array}$ & $\begin{array}{c}\text { Region } 2 \\
\text { MH11 Area }\end{array}$ \\
\hline Well Length reduced, \% & & & 51 & 51 \\
\hline Permeability_X, md & 1 & 1.5 & 0.065 & 1 \\
\hline Porosity, $\%$ & \multicolumn{4}{|c|}{1} \\
\hline Gc. Scf/ton & \multicolumn{4}{|c|}{232} \\
\hline Skin Factor & \multicolumn{2}{|r|}{7} & \multicolumn{2}{|c|}{$7 /-1$} \\
\hline Minimum Pwf, psi & \multicolumn{2}{|r|}{28} & \multicolumn{2}{|c|}{40} \\
\hline WGC, $\mathrm{ft}$ & \multicolumn{4}{|c|}{1317} \\
\hline Dt, days & \multicolumn{4}{|c|}{600} \\
\hline $\mathrm{Sw}, \%$ & \multicolumn{4}{|c|}{20} \\
\hline Anisotropy $\mathrm{K}, \mathrm{Kx}: \mathrm{Ky}$ & \multicolumn{4}{|c|}{$1: 1$} \\
\hline
\end{tabular}


Case 3: $24 \%$ of the well-bore is accessible.

- In order to achieve history matching, the wells must be in regions with the conditions and parameters in Table 4-27.

Table 4-27: Parameter values for HMPH3 Case 3 in PG coal

\begin{tabular}{|l|c|c|c|c|}
\cline { 3 - 5 } \multicolumn{1}{c|}{} & \multicolumn{2}{c|}{ Well length reduced } \\
\hline Parameters & $\begin{array}{c}\text { Region 1 } \\
\text { MH18 Area }\end{array}$ & $\begin{array}{c}\text { Region 2 } \\
\text { MH20 Area }\end{array}$ & $\begin{array}{c}\text { Region 1 } \\
\text { MH5 Area }\end{array}$ & $\begin{array}{c}\text { Region 2 } \\
\text { MH11 Area }\end{array}$ \\
\hline Well Length reduced, \% & 0 & 0 & 77 & 75 \\
\hline Permeability_X, md & 1 & 1.5 & 0.2 & 1.5 \\
\hline Porosity, \% & \multicolumn{5}{c|}{1} \\
\hline Gc. Scf/ton & & 0 & 7 & 72 \\
\hline Skin Factor & 0 & 28 & 28 & 28 \\
\hline Minimum Pwf, psi & 28 & \multicolumn{5}{c|}{1317} \\
\hline WGC, ft & & 600 \\
\hline Dt, days & \multicolumn{5}{|c|}{20} \\
\hline Sw, \% & \multicolumn{5}{|c|}{$1: 1$} \\
\hline Anisotropy K, Kx:Ky & \multicolumn{5}{|c|}{} \\
\hline
\end{tabular}

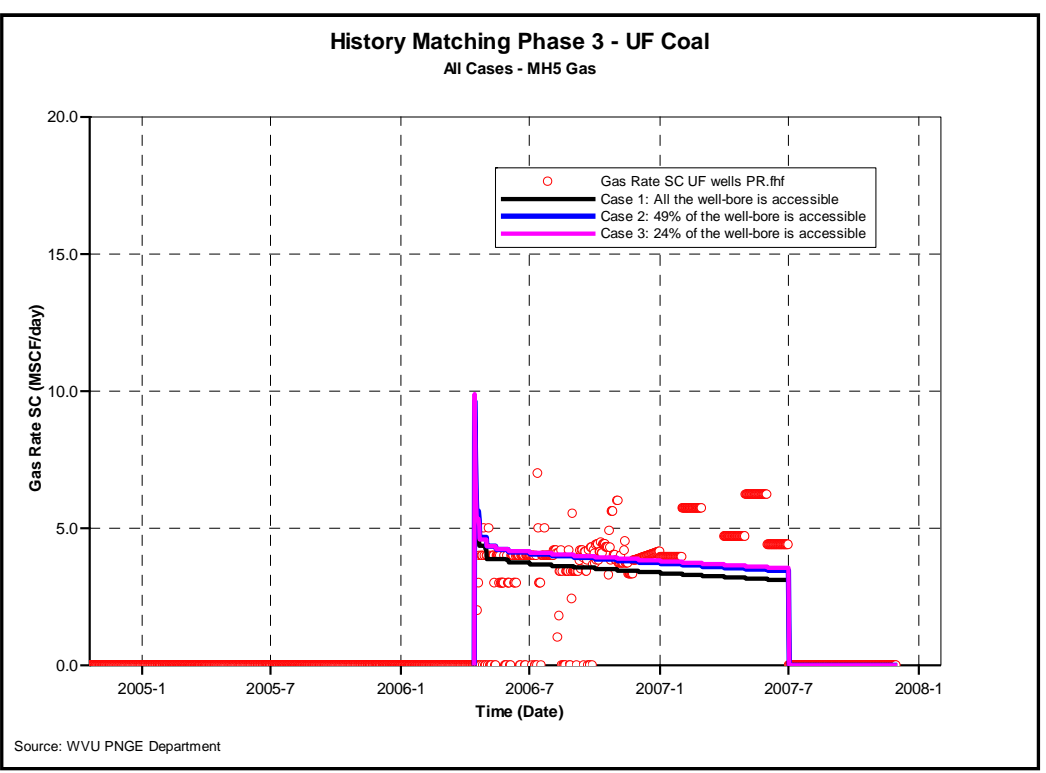

Figure 4-119: MH5 Gas Rate Production History Matching Results for all the cases HMPH3-UF 


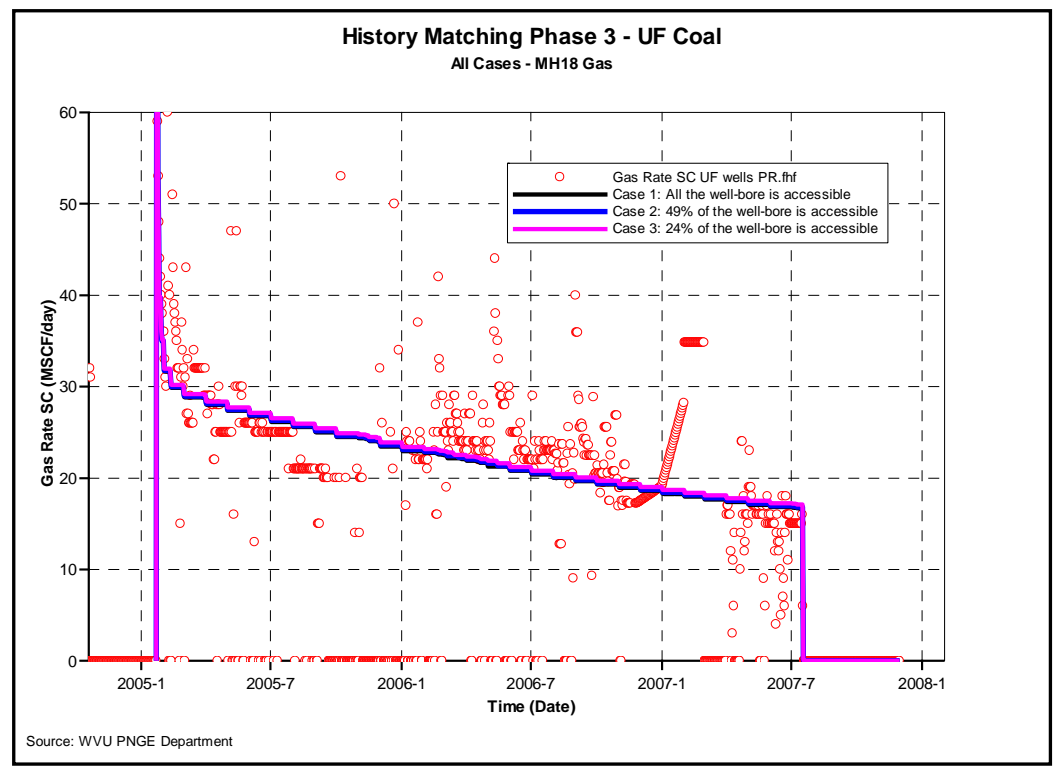

Figure 4-120: MH18 Water Rate Production History Matching Results for all the cases HMPH3-UF

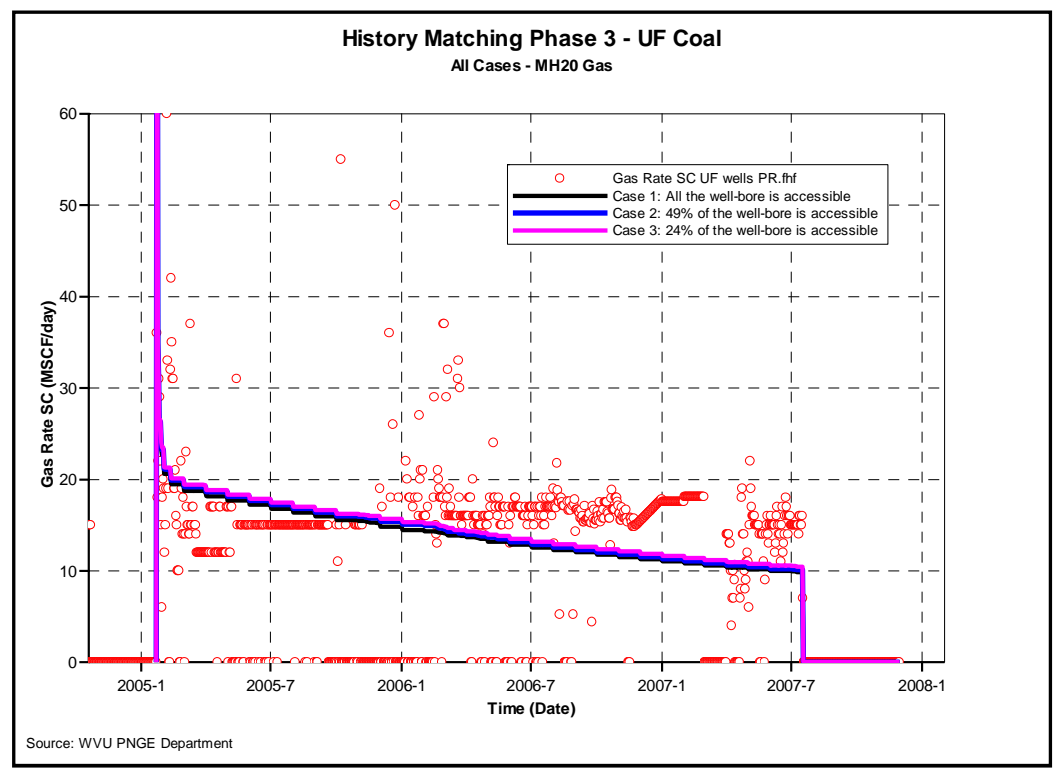

Figure 4-121: MH20 Gas Rate Production History Matching Results for all the cases HMPH3-UF 


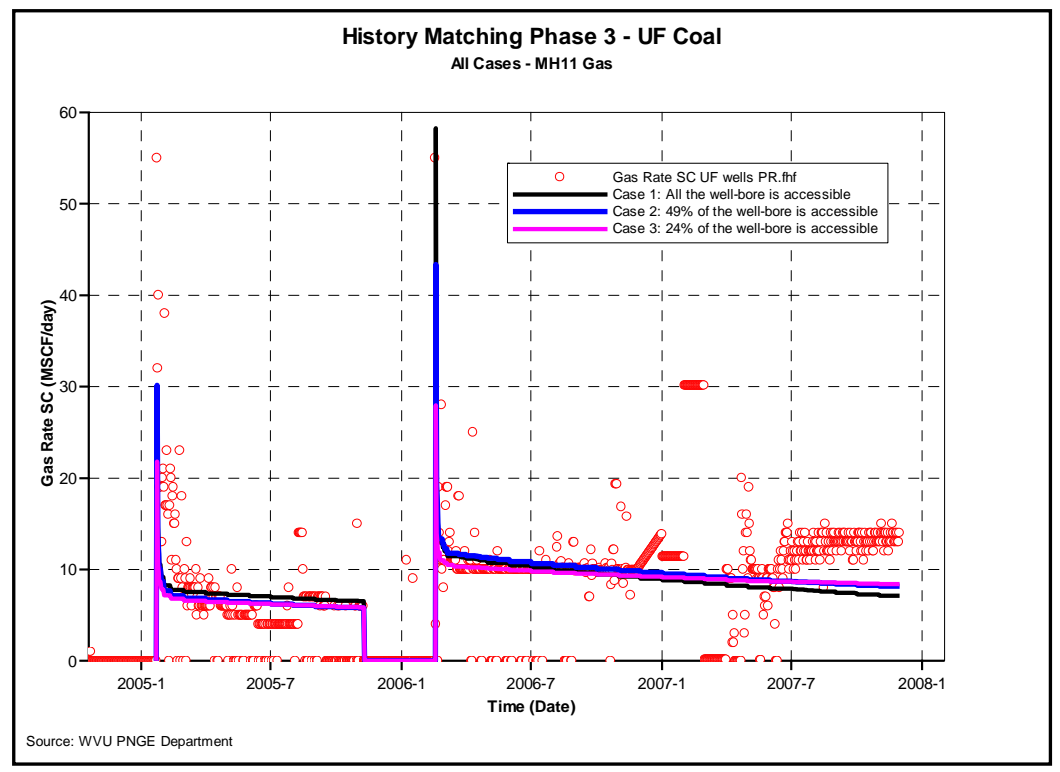

Figure 4-122: MH11 Gas Rate Production History Matching Results for all the cases HMPH3-UF

Based on the results, a permeability trend decreasing south-north is noticed. Most of the wells (MH5, MH11, and MH20) show gas linear flow throughout their production profiles. Matches during the linear flow are achieves for MH5 and MH11 for some of the cases, but non linear-flow matches are achieved in MH20 for any of the cases. 


\section{Chapter 5 Conclusions and Recommendations}

A Simulation model that is able to mimic the CBM production history of the wells for both, Pittsburgh and Upper Freeport coals has been developed.

\section{A. Pittsburgh CBM Formation:}

Different realizations of history matching have been generated for Pittsburgh coal in order to account for uncertainties associated to reservoir characteristics and operational issues.

For all the history matching cases in Pittsburgh coal, the reservoir presents high level of heterogeneity in the reservoir properties.

Considerable uncertainties are also associated with -well conditions and operations.

In Pittsburgh coal, large amounts of water is being produced from MH12 and no water is produced from MH3. Based on the result one of the following items may explain the observed behavior:

1. Well MH3 seems to be in a region with very low water saturation in contrast to the region where $\mathrm{MH} 12$ is, suggesting possible faults in the formation with different initial reservoir conditions and properties.

2. In the other hand, a more reliable theory about production problems in MH3 may be liquid loading effects in the wellbore.

3. Another possibility is the presence of an aquifer connected to the reservoir in the southern part of the pilot test where MH12 is.

Since there are no verifiable information to prove (or disprove) any of the abovementioned theories, it is recommended to conduct further studies including well tests in order to be conclusive.

Non-ideal drilling practices are certainly an issue that can be taken into consideration in order to evaluate the past behavior of the wells up to a degree; however, it is the author's opinion that non-ideal drilling practices may not explain the major problem in production inconsistency in Pittsburgh formation.

A lot of inconsistencies are observed between the available data and the results. These inconsistencies may be attributed to the fact that the majority of the data acquired from the wells that are located in the north-west part of the pilot test. 
Permeability Anisotropy seems to play an important role while history matching the observed production behavior in Pittsburgh coal. Parameters such as permeability, porosity, desorption time, and gas content Also played a significant role in achieving gas and water rate matches

\section{B. Upper Freeport CBM Formation}

Different realizations of history matching have been generated for Upper Freeport coal in order to account for uncertainties associated to reservoir characteristics and operational issues.

Even though, upper Freeport coal seems to less heterogeneous when compared to Pittsburgh coal, possibilities for reservoir features as faults needs to be considered for further studies.

It is recommended to conduct further studies in order to determine whether or not a shale formation right above Upper Freeport coal may be contributing to the production of the wells completed in this formation. 


\section{References}

1. Report. EIA Energy Information Administration US natural gas production 2006.

2. Report of the Potential Gas Committee (PGC), 12/31/2006

3. Article. Wikipedia. http://en.wikipedia.org/wiki/Coalbed_methane.

4. Lennon, Linda. Coalbed Methane. Integrating Research and Education. [Online] http://serc.carleton.edu/research_education/cretaceous/coalbed.html.

5. GRI. "A Guide to Coalbed Methane Reservoir Engineering". 1996.

6. Gray, I., "Reservoir Engineering in Coal Seams: Part I- The Physical Process of Gas Storage and Movement in Coal Seams," SPE Reservoir Engineering (February, 1987) pp. 28-34.

7. Smith, D.M. and F.L. Williams, "Diffusional Effects in the Recovery of Methane from Coalbeds," Society of Petroleum Engineers Journal (October, 1984) pp. 529-535

8. Crank, J. "The Mathematics of Diffusion", second edition, Oxford University Press (1975).

9. Article. http://www.chem.qmul.ac.uk/surfaces/scc/scat3.htm

10. Palmer, I. and Mansoori, I.: "How Permeability Depends on Stress and Pore Pressure in Coal beds: A New Model," paper SPE 52607 presented at the 1996 SPE Annual Technical Conference \& Exhibition, Denver, 6-9 October.

11. Oudinot, A., Schepers, K. and Reeves, S. "Gas Injection and Breakthrough Trends as Observed in ECBM Sequestration Pilot Projects and Field Demostrations" document 0714 presented at the 2007 International Coalbed Methane Symposium.

12. Article. Roxar. http://www.roxar.com/category.php?categoryID=1081.

13. Masemore, S., Piccot, S., Ringer, E., and Diamond, P. "Evaluation and Analysis of Gas Content and Coal Properties of Major Coal Bearing Regions of the United States" EPA. 600/SR96/065. June 1996. 